UNIVERSIDAD AUTÓNOMA METROPOLITANA - IZTAPALAPA DIVISIÓN DE CIENCIAS BÁSICAS E INGENIERÍA

\title{
APLICACIÓN DE LA TEORÍA DE GRÁFICAS AL ANÁLISIS DE LA CONECTIVIDAD FUNCIONAL CEREBRAL A PARTIR DEL EEG
}

\author{
Tesis que presenta \\ Javier Alducin Castillo \\ Para obtener el grado de \\ Maestro en Ciencias (Ingeniería Biomédica)
}

Asesor: $\quad$ M. en I. Óscar Yáñez Suárez

Jurado Calificador:

Presidente:

Dr. Tomás Aljama Corrales

Secretario:

M. en I. Óscar Yáñez Suárez

Vocal:

Dr. Héctor Brust Carmona

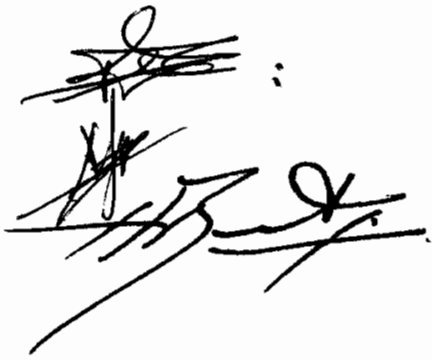

México, D.F. Marzo 2014 
UNIVERSIDAD AUTONOMA METRPOLITANA

\author{
Resumen \\ División de Ciencias Básicas e Ingeniería \\ Ingeniería Eléctrica \\ Maestro en Ciencias (Ingeniería Biomédica) \\ Javier Alducin Castillo
}

\title{
Aplicación de la teoría de gráficas al análisis de la conectividad funcional cerebral a partir del EEG
}

\begin{abstract}
En los últimos años ha habido un gran interés en la búsqueda de evidencias que describan la conectividad funcional entre diferentes regiones del cerebro. Consecuentemente hay un amplio interés en desarrollar diversas herramientas matemáticas y computacionales, que aporten características significantes para la aproximación de la estructura de las conexiones cerebrales. En este trabajo, se desarrolla una herramienta computacional para el estudio de la conectividad funcional del cerebro, a partir de registros de EEG, mediante medidas de la teoría de gráficas. Se estiman las distribuiciones de conectividad mediante cuatro medidas de sincronización y a partir de dichas distribuciones se calculan los parámetros de redes. La información obtenida se despliega en gráficas que muestran la dinámica a lo largo de toda la duración del registro de dos grupos de sujetos: control y pacientes de Evento Vascular Cerebral (EVC).

Los resultados obtenidos muestran dinámicas de los parámetros de redes que pueden diferenciarse del grupo control, lo que indica un posible uso en el campo clínico en el futuro.
\end{abstract}




\section{Índice general}

Resumen I

$\begin{array}{lll}\text { Lista de figuras } & \text { IV }\end{array}$

1. Introducción 1

2. Antecedentes 3

2.1. Electroencefalografía . . . . . . . . . . . . . . . . . . 3

2.2. Artefactos en EEG . . . . . . . . . . . . . . . . . 5

2.3. Métodos de Re-referenciación . . . . . . . . . . . . . . . . 9

2.4. Conectividad Funcional . . . . . . . . . . . . . . . . . . . . . . 12

2.5. Medidas de conectividad en el EEG . . . . . . . . . . . . . . . . . 14

2.5.1. Función de Coherencia . . . . . . . . . . . . . . . . . . . . . 14

2.5.2. Coherencia Wavelet . . . . . . . . . . . . . . . . . . . . . . . . . . 17

2.5.3. Teoría de la Información . . . . . . . . . . . . . . . . . . . 19

2.5.4. Otras medidas de conectividad . . . . . . . . . . . . 23

2.5.4.1. Función de correlación . . . . . . . . . . . . . . . . 23

2.5.4.2. Sincronización de fase . . . . . . . . . . . . . 24

2.5.4.3. Sincronización Generalizada . . . . . . . . . . . . . 24

2.5.4.4. Verosimilitud de Sincronización . . . . . . . . . . 25

2.6. Teoría de Gráficas . . . . . . . . . . . . . . . . . . 26

2.6.1. Gráficas binarias y pesadas . . . . . . . . . . . . . . . 2 29

2.6.2. Teoría de Gráficas y la conectividad cerebral . . . . . . . . . . . 30

2.6.3. Otras técnicas de evaluación de conectividad . . . . . . . . . 34

3. Propuesta de Trabajo $\quad 36$

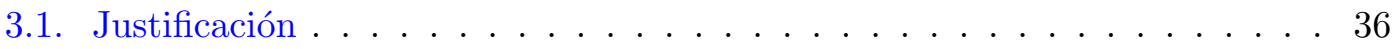

3.2. Propuesta . . . . . . . . . . . . . . . . . . . . 38

3.3. Objetivo Principal . . . . . . . . . . . . . . . . 38

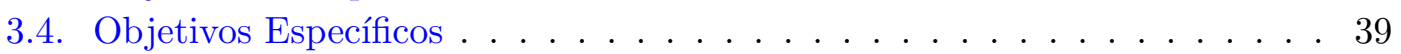

3.5. Descripción del trabajo . . . . . . . . . . . . . . . . . 39

4. Metodología $4 \mathbf{4 1}$

4.1. Registros Electroencefalográficos . . . . . . . . . . . . . . . 42

4.2. Procesamiento de señales . . . . . . . . . . . . . . . . . . . . . . . . . . . . . . . . . 42

4.2.1. Remoción de Artefactos . . . . . . . . . . . . . . . . . . . 43 
4.2.2. Re-referenciación . . . . . . . . . . . . . . . . . . . 44

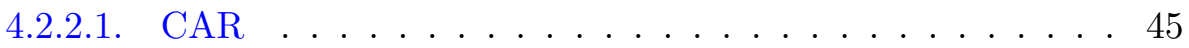

4.2.2.2. Promedio de A1 y A2 . . . . . . . . . . . 45

4.2.2.3. Arreglo bipolar . . . . . . . . . . . . . . . 46

4.2.3. Filtrado digital . . . . . . . . . . . . . . . . . . . . . . . . . . . . . . . . . 47

4.3. Medidas de conectividad . . . . . . . . . . . . . . . . . 47

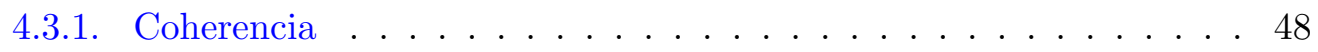

4.3.2. Coherencia Wavelet . . . . . . . . . . . . . . . 50

4.3.3. Entropía Cruzada . . . . . . . . . . . . . . . . 53

4.4. Visualización de gráficas de conectividad . . . . . . . . . . . . . . . 54

4.5. Parámetros de red . . . . . . . . . . . . . . . . . 56

4.5.1. Grado de nodo . . . . . . . . . . . . . . . . 59

4.5.2. Densidad . . . . . . . . . . . . . . . . 61

4.5.3. Coeficiente de agrupamiento característico . . . . . . . . . . . . 62

4.5.4. Distancia mínima característica y Eficiencia . . . . . . . . . . . . 64

4.5.5. Grado promedio . . . . . . . . . . . . . . 65

4.6. Visualización de los parámetros de redes complejas . . . . . . . . . . 68

$\begin{array}{lr}\text { 5. Resultados } & \mathbf{7 1}\end{array}$

5.1. Preprocesamiento . . . . . . . . . . . . . . . . . . 71

5.2. Pacientes de EVC . . . . . . . . . . . . . . . . . 71

5.3. Grupo Control . . . . . . . . . . . . . . . . . . . . . . . 84

5.4. Curvas poblacionales . . . . . . . . . . . . . . . . . 90

$\begin{array}{lr}\text { 6. Conclusiones } & 99\end{array}$

$\begin{array}{ll}\text { A. Teoría de Gráficas } & 103\end{array}$

B. Código 107

B.1. Registros Electroencefalográficos . . . . . . . . . . . . . . . . 107

B.2. Procesamiento de señales . . . . . . . . . . . . . . . . . . . . . 109

B.3. Medidas de conectividad . . . . . . . . . . . . . . . . . . . . . 113

B.4. Visualización de gráficas de conectividad . . . . . . . . . . . . . . . . 117

B.5. Parámetros de Red . . . . . . . . . . . . . . . . . . . . . . . . . 119

B.6. Visualización de los parámetros de red . . . . . . . . . . . . . . . . . . 121 


\section{Índice de figuras}

2.1. Sistema Internacional 10-20 del EEG . . . . . . . . . . . . . . . . . . . 4

2.2. Técnicas de adquisición de datos electrofisiológicos, comparación de resoluciones temporal y espacial. . . . . . . . . . . . . . . 6 6

2.3. Separación Ciega de Fuentes mediante ICA . . . . . . . . . . . . 8

2.4. Problema de uso de referencia común . . . . . . . . . . . . . . . . . . . 10

2.5. Ejemplos de gráficas . . . . . . . . . . . . . . . . . . 26

2.6. Conectividad cerebral y teoría de gráficas . . . . . . . . . . . . 30

4.1. Etapas del trabajo . . . . . . . . . . . . . . . . . . . . . . 41

4.2. Protocolo de adquisición de registros de EEG del INR . . . . . . . . . . . 43

4.3. Ejemplo de remoción de artefactos . . . . . . . . . . . . . . . . . . 44

4.4. Diagrama de distribución de electrodos: monopolar y bipolar . . . . . . . 46

4.5. Esquema de cuantificación de conectividad entre dos series de tiempo . . . 48

4.6. Esquema de cuantificación de entropía cruzada espectral . . . . . . . . . . 54

4.7. Esquema de cuantificación de entropía cruzada temporal . . . . . . . . . . 55

4.8. Ejemplos de gráficas de conectividad funcional no direccional . . . . . . . . 57

4.9. Ejemplos de gráficas de conectividad funcional direccionales . . . . . . . . 58

4.10. Diferentes gráficas de conectividad con diferentes valores de umbral . . . . 59

4.11. Procedimiento para obtener el grado de cada nodo . . . . . . . . . . . . . 60

4.12. Visualización de la matriz grado nodo. . . . . . . . . . . . . . . . . . . 61

4.13. Procedimiento para obtener la densidad . . . . . . . . . . . . . . 62

4.14. Visualización de la matriz densidad. . . . . . . . . . . . . . . . . . 63

4.15. Procedimiento para obtener el coeficiente de agrupamiento característico. 64

4.16. Visualización de la matriz coeficiente agrupamiento. . . . . . . . . . . . 65

4.17. Procedimiento para obtener el la distancia mínima característica y eficiencia de la matriz de conectividad. . . . . . . . . . . . . . 66

4.18. Visualización de la distancia mínima característica y eficiencia. . . . . . . 67

4.19. Procedimiento para obtener el grado promedio. . . . . . . . . . . . . . 68

4.20. Visualización del grado promedio. . . . . . . . . . . . . . . . . . 69

4.21. Diagrama del procedimiento de visualización de los parámetros de redes. . 70

5.1. Imágenes de $\mathrm{C}$, densidad, L, eficiencia y G y G promedio sin remoción de artefactos y con etapa de remocion de artefactos . . . . . . . . . . 72

5.2. Imágenes de $\mathrm{C}, \mathrm{L}$ y $\mathrm{G}$ usando el promedio de A1 y A2 como técnica de re-referencia . . . . . . . . . . . . . . . . . . 73

5.3. Imágenes representativas del primer comportamiento de los seis parámetros de redes en banda delta y theta, usando coherencia y CAR en pa-

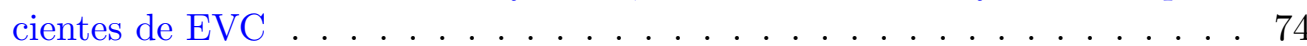


5.4. Imágenes representativas del primer comportamiento de los seis parámetros de redes en banda alfa, usando coherencia y CAR en pacientes de $\mathrm{EVC} \ldots \ldots \ldots \ldots \ldots \ldots \ldots \ldots$

5.5. Imágenes representativas del primer comportamiento de los seis parámetros de redes en banda delta y theta, usando coherencia y arreglo bipolar en pacientes de EVC. . . . . . . . . . . . . . . . . . 76

5.6. Imágenes representativas del primer comportamiento de los seis parámetros de redes en banda delta y theta, usando entropía cruzada temporal y CAR en pacientes de EVC . . . . . . . . . . . . . . . . . . . . . 77

5.7. Imágenes representativas del segundo comportamiento de los seis parámetros de redes en banda delta, usando coherencia y CAR en pacientes de $\mathrm{EVC} \ldots \ldots \ldots \ldots \ldots \ldots \ldots \ldots$

5.8. Imágenes representativas del segundo comportamiento de los seis parámetros de redes en banda theta, usando coherencia y CAR en pacientes de $\mathrm{EVC} \ldots \ldots \ldots \ldots \ldots \ldots \ldots \ldots \ldots \ldots \ldots \ldots \ldots \ldots$

5.9. Imágenes representativas del segundo comportamiento de los seis parámetros de redes en banda delta, usando entropía cruzada temporal y CAR en pacientes de EVC . . . . . . . . . . . . . . . . . . . . 80

5.10. Imágenes representativas del segundo comportamiento de los seis parámetros de redes en banda theta, usando entropía cruzada temporal y CAR en pacientes de EVC . . . . . . . . . . . . . . . . . . . 81

5.11. Imágenes representativas comportamiento de los seis parámetros de redes en banda theta, alfa y beta usando coherencia wavelet y CAR en pacientes de EVC . . . . . . . . . . . . . . . . . . . . 82

5.12. Imágenes representativas comportamiento de los seis parámetros de redes en banda delta, usando coherencia wavelet y CAR en pacientes de EVC . 83

5.13. Imágenes representativas comportamiento de los seis parámetros de redes en banda delta, usando coherencia wavelet y arreglo bipolar en pacientes de $\mathrm{EVC} \ldots \ldots \ldots \ldots \ldots$. . . . . . . . . . . . . . . 83

5.14. Imágenes representativas comportamiento de los seis parámetros de redes en las bandas theta, alfa y beta usando entropía cruzada espectral y arreglo bipolar en pacientes de EVC . . . . . . . . . . . . . . . 84

5.15. Imágenes representativas del comportamiento de los seis parámetros de redes en banda delta, usando entropía cruzada espectral y arreglo bipolar en pacientes de EVC . . . . . . . . . . . . . . . . . . . . . 84

5.16. Imágenes representativas del comportamiento de los seis parámetros de redes en banda delta, usando coherencia y CAR en 3 sujetos del grupo control . . . . . . . . . . . . . . . . . . . . 85

5.17. Imágenes representativas del comportamiento de los seis parámetros de redes en banda theta, usando coherencia y CAR en 4 sujetos del grupo control . . . . . . . . . . . . . . . . . . . 86

5.18. Imágenes representativas del comportamiento de los seis parámetros de redes en banda delta, usando coherencia y arreglo bipolar en 3 sujetos del grupo control . . . . . . . . . . . . . . . . . . 87

5.19. Imágenes representativas del comportamiento de los parámetros de redes de cinco sujetos control en banda delta, theta y alfa, usando entropía cruzada temporal y CAR . . . . . . . . . . . . . . . . . 88 
5.20. Imágenes representativas del comportamiento de los parámetros de redes de cuatro sujetos control en banda beta, usando entropía cruzada temporal y CAR . . . . . . . . . . . . . . . . . . . 88

5.21. Imágenes representativas del comportamiento de los parámetros de redes de cuatro sujetos control en bandas delta, theta y alfa usando entropía cruzada temporal y arreglo bipolar . . . . . . . . . . . . . . . 89

5.22. Imágenes representativas del comportamiento de los seis parámetros de redes en banda theta, usando coherencia wavelet y CAR en el grupo control 89

5.23. Imágenes representativas del comportamiento de los seis parámetros de redes en bandas theta, alfa y beta, usando entropía cruzada espectral y arreglo bipolar en el grupo control . . . . . . . . . . . . . . . . 9 90

5.24. Imágenes representativas del comportamiento de los seis parámetros de redes en banda delta, usando entropía cruzada espectral y arreglo bipolar en el grupo control . . . . . . . . . . . . . . . . . . . . . 990

5.25. Curvas promedio del grupo control y EVC en banda delta y theta usando coherencia y CAR. . . . . . . . . . . . . . . . . 92

5.26. Curvas promedio del grupo control y EVC en banda delta y theta usando coherencia y CAR. . . . . . . . . . . . . . 93

5.27. Curvas promedio del grupo control y EVC en banda delta y theta usando entropía cruzada temporal y CAR. . . . . . . . . . . . . . . . 94

5.28. Curvas promedio del grupo control y EVC en banda delta y theta usando entropía cruzada temporal y CAR . . . . . . . . . . . . . 95

5.29. Diagrama de cajas en banda delta y theta usando coherencia y CAR. . . . 96

5.30. Curvas promedio del grupo control y EVC en banda alfa y beta usando coherencia y CAR. . . . . . . . . . . . . . . 97

5.31. Curvas promedio del grupo control y EVC en banda delta y theta usando coherencia y CAR. . . . . . . . . . . . . . . . . . . 9 98

A.1. Puentes de Königsberg . . . . . . . . . . . . . . . . . . . . . . 103

A.2. Procedimiento de reconexión de la red regular, red de pequeño mundo y red aleatoria . . . . . . . . . . . . . . . 105 
Dedicado a mi familia, sin apoyo de ellos no podría ser lo que soy ahora.

A mis padres, que me inculcaron ideales y pragmatismo.

A mis hermanos, apoyo incondicional.

A mi esposa, una vida juntos y otra vida por seguir.

A mi hija, la razón más grande para seguir creyendo en mis ideales para que ella disfrute de este mundo sin igual.

A mi asesor, su apoyo, consejos y ánimos que guiaron este trabajo en todo momento.

\section{Agradezco}

A CONACyT, por su apoyo en mi formación académica. A la UAM, una universidad sin igual. Formar parte de dos unidades, Iztapalapa y Azcapotzalco, me hace confirmar lo extraordinaria que es mi alma máter. 


\section{Capítulo 1}

\section{Introducción}

En los últimos años ha habido un gran interés en la búsqueda de evidencias que describan la ausencia o incremento de la conectividad funcional entre diferentes regiones del cerebro [1]. Se ha entendido como conectividad funcional la interdependencia estadística entre la actividad cerebral registrada en series de tiempo [2-4], es decir, se busca la relación (a través de medidas de sincronización) temporal entre procesos neurofisiológicos espacialmente distribuidos [5].

Consecuentemente hay un amplio interés en desarrollar diversas herramientas matemáticas y computacionales, que aporten características significantes para la aproximación de la estructura de las conexiones cerebrales. Con el avance en poder de cómputo, equipos de adquisición de señales electrofisiológicas, la cantidad de datos que se pueden procesar es inimaginable, sin embargo, a pesar de esto es necesario desarrollar herramientas de análisis, con las cuales se pueda explorar y tratar de encontrar patrones o características electrofisiológicas propias de un fenómeno o tarea específica.

La teoría de gráficas o la teoría moderna de gráficas ha sido utilizada en años recientes para tratar de caracterizar la conectividad funcional cerebral en condiciones normales o patológicas en estudios de Magnetoencefalograma (MEG) e Imagen por Resonancia Magnética funcional (fMRI) principalmente, encontrado valiosas aportaciones [6-11]. Esta caracterización se busca a partir de medidas o parámetros propios de una red compleja (siendo el cerebro humano una red compleja por excelencia) para modelar o caracterizar patrones de conectividad cerebral.

En este trabajo, se desarrolla una herramienta computacional para el estudio de la conectividad funcional del cerebro, a partir de registros de EEG, mediante medidas de la teoría de gráficas. Se plantea el uso de tres medidas de sincronización entre canales de EEG, dos medidas no direccionales (Coherencia y Coherencia Wavelet) y una direccional 
(Entropía cruzada en dos variantes). Los parámetros de redes complejas que se incorporaron para el análisis de conectividad son: grado de nodo, grado promedio, coeficiente de agrupamiento, longitud de camino característica, densidad y eficiencia. Dicha herramienta también cuenta con funciones de visualización de la evolución de la conectividad con cada medida de sincronización y parámetro de la red compleja, es decir, puede observarse cómo se modifican las conexiones entre electrodos, como varían los parámetros de redes complejas en el tiempo, en presencia de algún evento o estímulo. 


\section{Capítulo 2}

\section{Antecedentes}

\subsection{Electroencefalografía}

El Electroencefalograma (EEG) es el registro de actividad eléctrica cerebral, obtenida por medio de electrodos colocados en diferentes sitios de la cabeza. Esta actividad eléctrica (potenciales eléctricos) se obtiene de manera monopolar (con electrodos de referencia) y bipolar (entre pares de electrodos activos) principalmente. El EEG puede ser obtenido en el cuero cabelludo (más utilizado) o intracraneal, este último requiere de una intervención quirúrgica.

La posición de colocación de los electrodos está regida por el Sistema Internacional 10-20 [12, 13] (figura 2.1), dicho sistema establece que el primer electrodo Fp se debe colocar a un $10 \%$ de la distancia existente entre Inion y Nasion (pasando por la parte central de la cabeza), el siguiente electrodo $\mathrm{Fz}$ a un $20 \%$ de la distancia, el siguiente $\mathrm{Cz}$ a un $20 \%$ hasta el último electrodo Oz colocado a un $10 \%$ de la distancia patrón. Los electrodos de ambos hemisferios se colocan con la misma regla, con una diferencia, los electrodos del hemisferio izquierdo se enumeran de manera impar y del lado derecho par, aumentando de centro hacia afuera. Por último las letras para llamar a cada electrodo, guardan relación con los lóbulos sobre los cuales se colocan, por ejemplo T de Temporal, C de Central, P de Parietal y Z los electrodos que se encuentran en la línea central de la cabeza.

El EEG cambia de acuerdo a la actividad eléctrica registrada, esto manifiesta cambios en el estado de consciencia, durante una tarea específica, por alguna patología o ausencia de las anteriores. Debido a ello a través de diversos estudios, en la literatura se han establecido frecuencias a las cuales diversas regiones del cerebro se activan o inhiben ante diferentes actividades o tareas específicas, resultando en un listado de bandas (intervalos de frecuencia) con funciones específicas: 
A

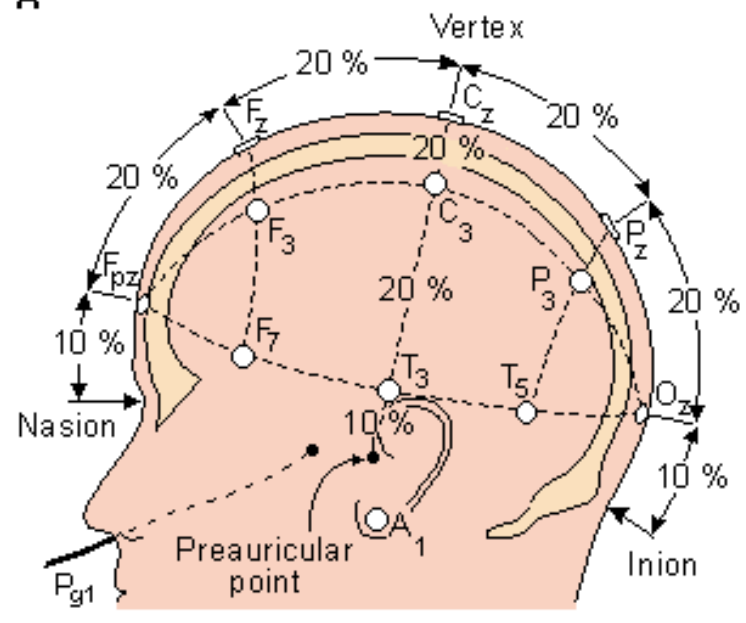

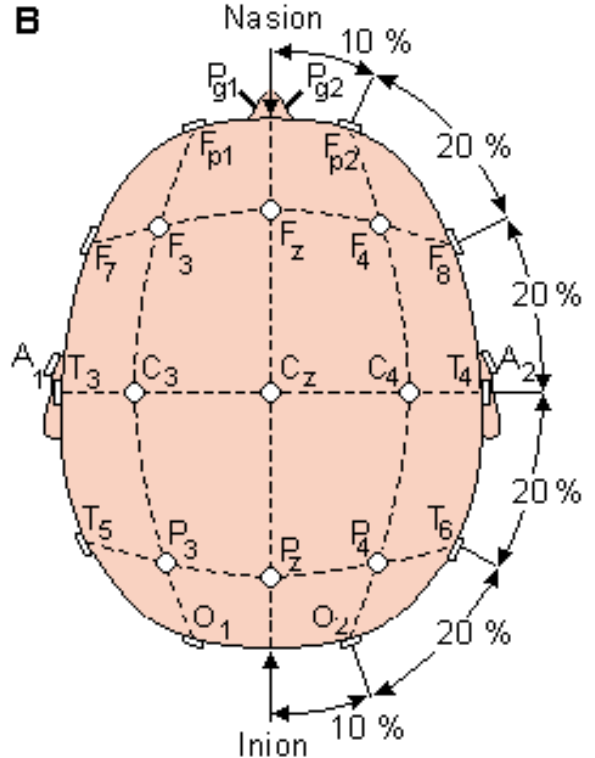

$\mathrm{C}$
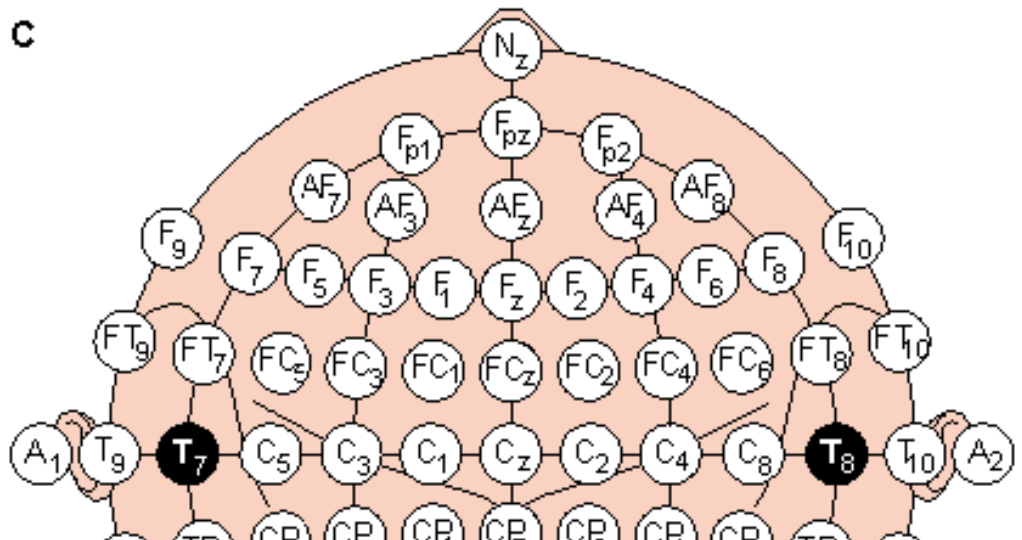

$\left(\mathrm{TP}_{9}\right)\left(\mathrm{TP}_{7}\right)\left(\mathrm{CP}_{5}\right)\left(\mathrm{CP}_{3}\right)\left(\mathrm{CP}_{1}\right)\left(\mathrm{CP}_{2}\right)\left(\mathrm{CP}_{2}\right)\left(\mathrm{CP}_{4}\right)\left(\mathrm{CP}_{6}\right)\left(\mathrm{TP}_{3}\right)\left(\mathrm{TP}_{9}\right)$
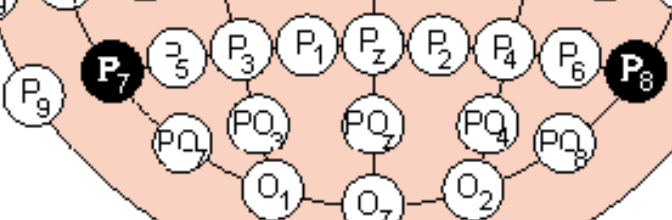

$(\mathrm{PQ})$

FiguRA 2.1: Sistema Internacional 10-20 expandido a 75 electrodos. Imagen tomada de http://www.bci2000.org/wiki/index.php/File:ElectrodePositions1020.PNG. 
- Banda Delta (0.5-4 Hz). Caracteriza el estado de sueño profundo en el adulto y en niños menores de 1 año.

- Banda Theta (4-8 Hz). Caracteriza el adormecimiento en niños y sueño en adultos, en estos últimos la presencia de alta actividad en esta banda puede ser indicio de alguna patología, además se asocia con la creatividad y meditación profunda [14].

- Banda Alfa (8-12 Hz). Se presenta en un estado de relajamiento o reposo y domina áreas posteriores en ambos hemisferios (es mayor en el hemisferio dominante de la persona).

- Banda Beta (12-30 Hz). Se presenta en estado de vigilia que se asocia con el pensamiento activo, atención en el mundo exterior y en la solución de problemas concretos dominando la parte frontal y central del cerebro.

Otras técnicas de adquisición de datos de la actividad cerebral son el Magnetoencefalograma (MEG) e Imagen por Resonancia Magnética funcional (IRMf). El MEG, a diferencia del EEG, mide el campo magnético generado por las corrientes eléctricas que fluyen en el tejido neuronal [15], tiene una resolución temporal y espacial similares al EEG. La fMRI mide el nivel de oxígeno en la sangre (señales BOLD) en las regiones cerebrales, su resolución temporal es menor que la del EEG/MEG pero la resolución espacial es mayor, en la figura 2.2 puede observarse la comparación entre resoluciones espaciales y temporales de las técnicas de adquisición.

Para que una característica o medida, a partir del EEG, pueda ser clínicamente útil debe ser muy estable en el sentido de que las mediciones de una característica en particular de un sujeto no presente fluctuaciones cuando se presenta un cambio sistemático [16], sin embargo, la estabilidad por sí misma no garantiza un claro uso clínico, dicha estabilidad puede no ser relevante para la condición o padecimiento de interés. En dichos casos se busca una variabilidad que pueden ser atribuida por cambios en la actividad desempeñada o padecimientos presentes.

Las señales de EEG son altamente no gaussianas, no estacionarias y de naturaleza no lineal, por lo tanto entender el comportamiento y la dinámica de la conectividad funcional cerebral ha llevado a desarrollar técnicas de análisis de conectividad de tipo lineal y no lineal, análisis en frecuencia, técnicas de eliminación de artefactos.

\subsection{Artefactos en EEG}

Al obtener registros de EEG, es inherente la inclusión de diversos artefactos (potenciales eléctricos) debido a movimientos oculares, movimientos musculares, por lo que una señal 


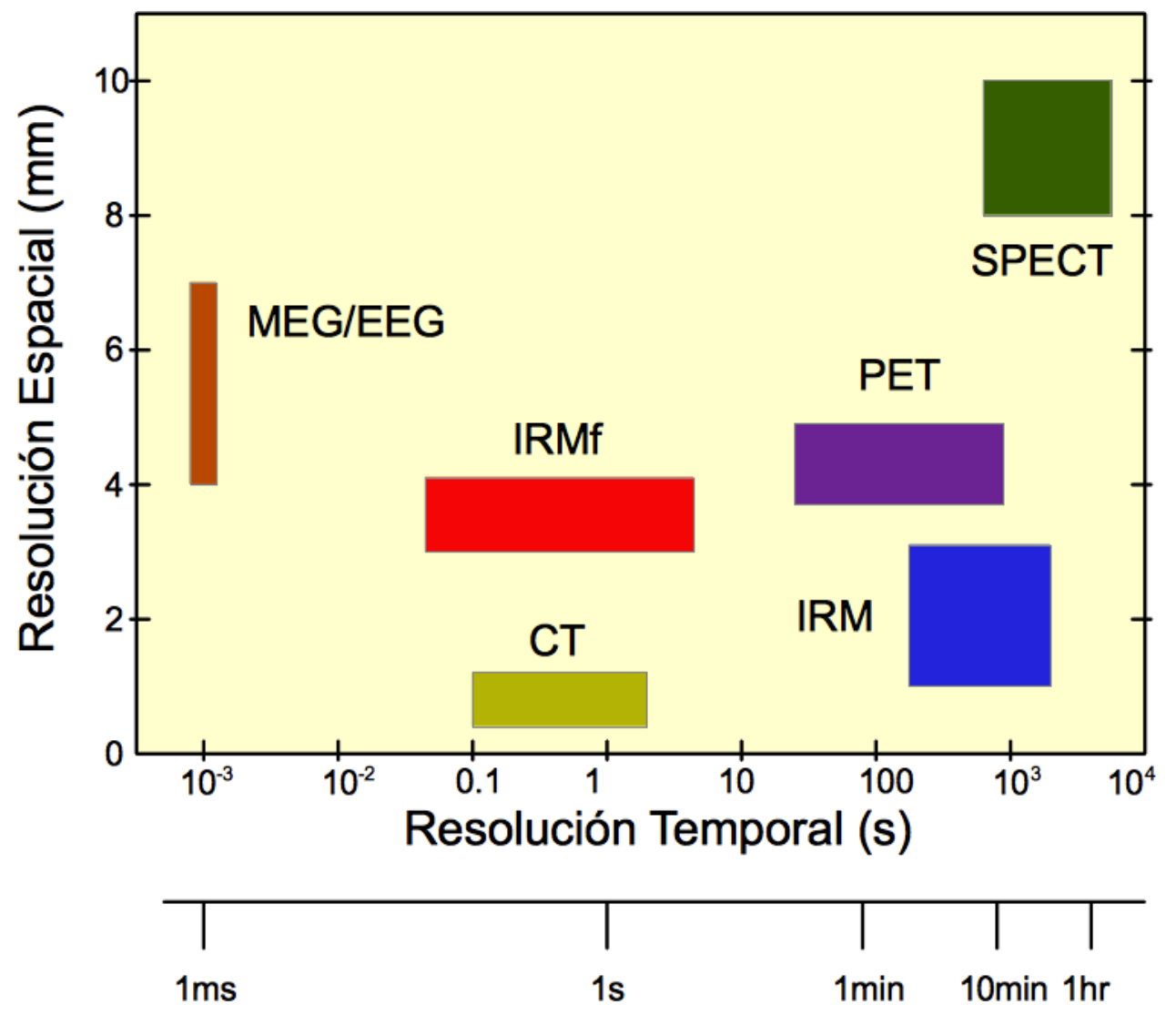

FigurA 2.2: Gráfica de comparación de diferentes técnicas de adquisición de datos electrofisiológicos, resolución temporal vs espacial.

obtenida de un electrodo no solo contiene la información de la actividad neuronal en la zona de colocación del electrodo (en forma de voltaje), sino también de la actividad neuronal de otras regiones del cerebro y otras partes del cuerpo, propagadas por campos electromagnéticos a través del tejido. Este fenómeno se conoce como Conducción por Volumen, el cual por sí mismo influye al cuantificar la conectividad entre dos electrodos, inflando el valor de conectividad y puede reducir la variabilidad de dicho valor. Diferentes técnicas y transformaciones se han desarrollado para tratar de reducir éste fenómeno, con el objetivo de obtener mayor veracidad en las cuantificaciones de conectividad. Se debe tener en cuenta que la contaminación de información no fluye en un solo sentido, es decir, los movimientos oculares, musculares y actividad eléctrica de otras regiones del cerebro también son contaminados con la actividad que se genera en el área de interés de un electrodo específico, por lo tanto al tratar de eliminar los efectos de la conducción por volumen, se estará eliminando parte de la información que originalmente se quiere aislar.

En la literatura hay una gran variedad de técnicas de eliminación del movimiento ocular, que afecta a los registros de EEG, basadas en métodos de regresión [17, 18], filtrado adaptable [18-20], separación ciega de fuentes [18, 21-24]. El método tradicional de regresión 
trata de estimar los coeficientes que describen el artefacto ocular a partir de un canal o varios canales que registren la actividad ocular (EOG), posteriormente se substrae el artefacto a cada canal del EEG. En este método se asume que la información proveniente del EOG es únicamente artefacto, sin embargo, debido al fenómeno de conducción por volumen el EOG efectivamente contamina el registro de EEG, pero también actividad eléctrica del cerebro (principalmente de la parte frontal) se propaga al EOG, es decir, mediante la regresión se elimina parte de información de actividad cerebral contenida en el EOG. En [17], realizan la corrección de registros de EEG mediante un método de análisis de regresión, en su modelo propuesto el registro de EEG se contamina por ruido aditivo, el cual se compone de un vector que contiene los valores de 3 electrodos, que registran la actividad ocular en forma de triángulo (alrededor de los ojos), y un vector de pesos de dicha influencia ocular. Mediante un análisis de regresión (encontrando el vector de pesos) eliminan el artefacto y la evaluación de resultados se realiza mediante dos expertos con inspección visual.

El método basado en Separación Ciega de Fuentes (BSS), utilizando Análisis de Componentes Independientes (ICA) [18, 21-24], permite asumir que las señales electrofisiológicas medidas $x=x_{1}(t), x_{2}(t), \ldots, x_{m}(t)$ son el resultado de la suma de $\mathbf{n}$ componentes estadísticamente independientes (fuentes):

$$
x_{i}(t)=a_{i 1} s_{1}(t)+a_{i 2} s_{2}(t)+\ldots+a_{i n} s_{n}(t)=\sum_{j=1}^{n} a_{i j} s_{j}(t)
$$

donde $x(t)$ es la señal electrofisiológica medida, $s_{i j}$ son los componentes independientes y los coeficientes $a_{i j}$ forman una matriz de pesos $\mathbf{A}$, que corresponde a la contribución de cada componente para formar la señal medida. Dado un modelo lineal, donde se desconoce la naturaleza de las fuentes o el proceso por el cual se mezclan dichas fuentes, la tarea consiste en recuperar una versión $\mathbf{u}$, de las fuentes originales, idéntica a $\mathbf{s}$, encontrando una matriz W (inversa de A) [21-23], que represente los componentes o fuentes del EEG. Posteriormente se analizan dichos componentes y se determina cuales contienen artefacto (esta selección suele ser por inspección), eliminándose para posteriormente combinar únicamente los componentes que contienen mayores proporciones de la señal de interés, para obtener un EEG corregido, el esquema del proceso de la Separación Ciega de Fuentes se puede observar en la figura 2.3.

Para que la descomposición de componentes mediante ICA tenga buenos resultados se tienen tres consideraciones básicas: 
(A)

\section{ICA decomposition}
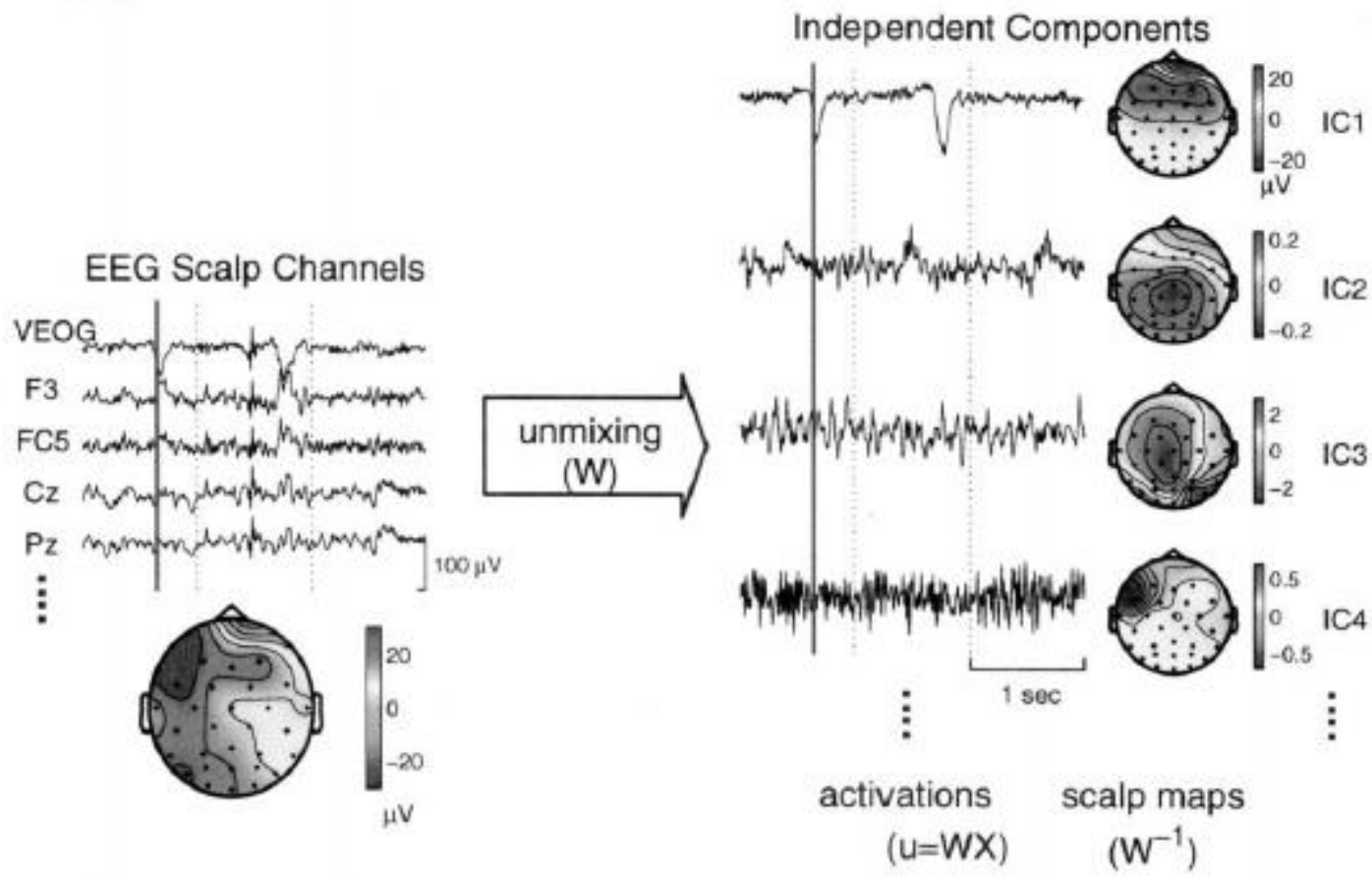

(B)

\section{Summed Projection of Selectrd Components}
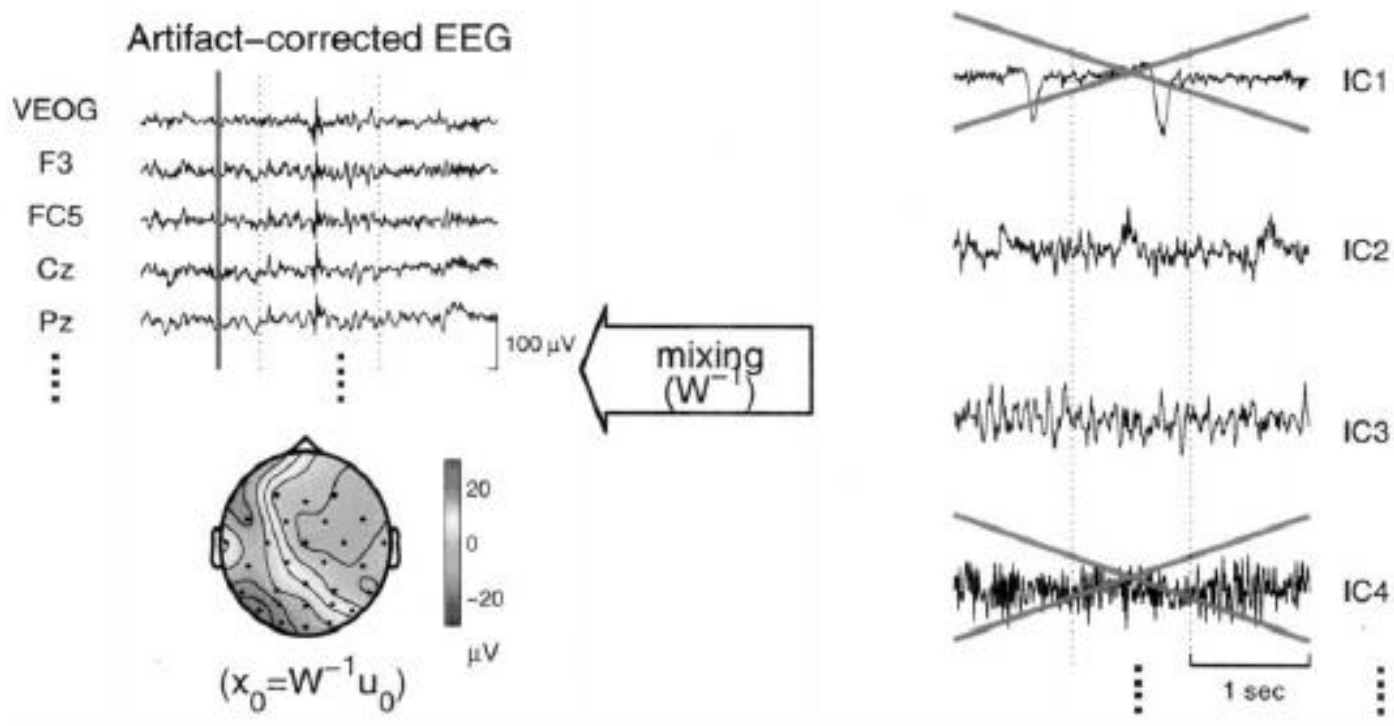

Figura 2.3: Esquema de eliminación de artefactos del EEG mediante ICA. A) Series de tiempo (registro de EEG) (izquierda), componentes obtenidos a través de ICA (derecha) con su distribución espacial. B) Eliminación de componentes ruidosos o con mayor proporción de artefactos (derecha), EEG corregido (izquierda). Imagen tomada de [22]. 
- Las fuentes son independientes, en el caso de registros de EEG las fuentes de contaminación (muscular, ocular, cardiaca, ruido blanco) se consideran estadísticamente independientes.

- El medio de combinación de señales sea lineal y los retardos de propagación sean insignificantes, se piensa que el fenómeno de conducción por volumen es lineal e instantáneo.

- El número de fuentes de señales independientes debe ser igual o menor que el número de sensores, está última consideración se evalúa aún, debido a que no se sabe el número exacto de señales independientes que contribuyen los potenciales medidos en un registro de EEG.

Otra consideración que se debe tener en cuenta, después de encontrar los componentes, es determinar qué componentes son ruidosos o contienen los artefactos a eliminar, ante ello la técnica más utilizada es la inspección visual por expertos, sin embargo, se ha observado que el espectro de potencia en algunos componentes de artefactos son diferentes y se ha tratado de generar técnicas para automatizar la eliminación de componentes ruidosos.

En la literatura existen algunos trabajos comparando diferentes enfoques de remoción de artefactos, siendo [18] uno de los más destacados, sus resultados indican que la eliminación de artefacto ocular mediante regresión y filtrado adaptable tienen niveles de similitud en su desempeño, ambos tienen errores al obtener las distribuciones topográficas en las regiones fronto-polar y fronto-lateral. Otro error se presenta en el espectro de potencia en bandas theta y beta. Mientras que el método de BSS presenta bajos errores en el espectro.

\subsection{Métodos de Re-referenciación}

Los potenciales obtenidos de un EEG son voltajes relativos a una referencia, idealmente los potenciales medidos por cada electrodo deberían representar solo la medida de la actividad eléctrica del lugar de colocación del electrodo, por lo tanto, si existe cualquier actividad eléctrica en el lugar de la referencia obviamente esto afecta las mediciones de los electrodos colocados, lo anterior se puede observar claramente en la figura 2.4. La forma más común de obtener registros de EEG es mediante una referencia común (EEG monopolar), un electrodo como referencia colocado en alguna parte de la cabeza sin actividad eléctrica aparente, otra forma es mediante un arreglo bipolar donde los electrodos tienen un arreglo diferencial entre sí, adicionalmente se han desarrollado técnicas de Re-referencia para tratar de minimizar efectos como la conducción por volumen entre 
los que destacan Common Average Reference (CAR) [25-29], Current Source Derivation (CSD) $[26,28,30,31]$ y un arreglo bipolar [32, 33].

¿Por qué es importante establecer la elección de la referencia en registros de EEG? Cada técnica puede producir una topografía de conectividad diferente, por ejemplo una referencia común colocada en ambos lóbulos de las orejas reduce la probabilidad de obtener actividad inflada artificial en los hemisferios, teniendo cuidado en mantener la impedancia por debajo de los $5 k \Omega$. En el caso de CAR el procedimiento es sencillo de obtener, la media de todos los electrodos en cada instante de tiempo es removida o restada a todos los electrodos en cada instante de tiempo. Al medir el diferencial de potencial se tiene $E_{n}-R$, es decir, el diferencial de potencial entre el voltaje obtenido de cualquier electrodo $E_{n}$ y el de la referencia $(R)$ y a partir de ahí se obtiene la referencia promediada. Este promedio es considerado como un estimado de la actividad de la referencia que está presente en todos los electrodos del registro, sin embargo, tiene una limitación ya que depende del número de electrodos y sus localizaciones; de acuerdo a la literatura, para obtener una mejor referencia es necesario tener gran cantidad de electrodos.

\section{Problema de Referencia}

\section{Referencia Ideal}

Señal adquirida

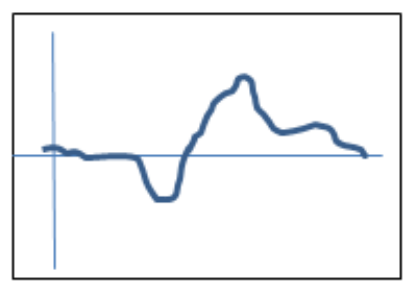

Referencia Real

Señal adquirida

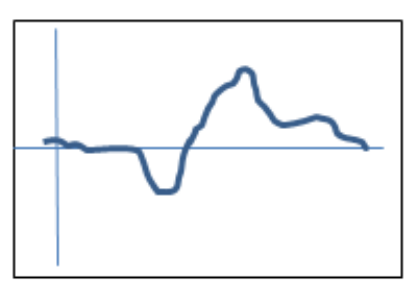

Referencia

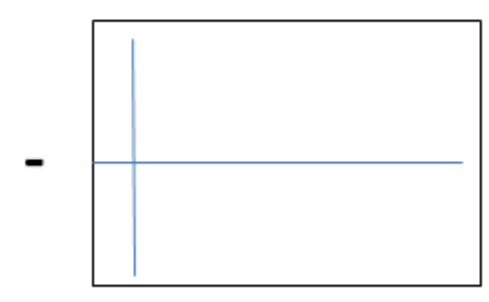

Referencia

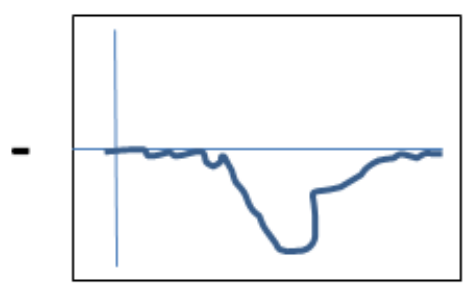

Resultado

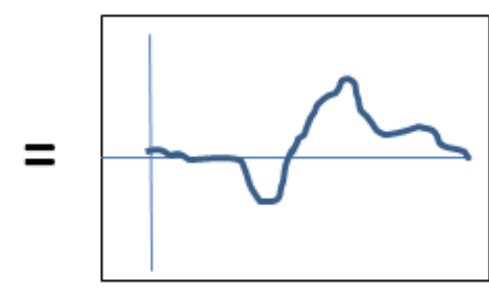

Resultado

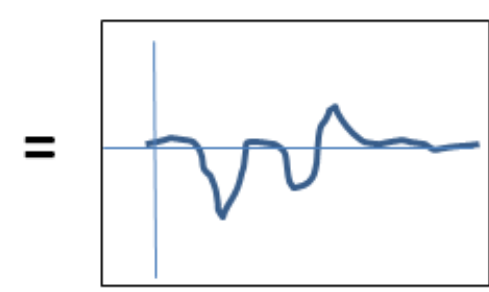

Figura 2.4: Problema de referencia en mediciones de EEG. Con referencia ideal, sin actividad eléctrica, la medición obtenida no es alterada, en el caso de que la referencia contenga actividad eléctrica, ésta afecta la medición obtenida. Imagen inspirada y modificada de [25]. 
Para re-referenciar a otro canal de EEG se realiza lo siguiente, por ejemplo para un canal $F 1$ referenciado al electrodo $A 1$ (lóbulo de la oreja izquierda), el diferencial de potencial se obtiene mediante $(F 1-A 1)$, si se desea re-referenciar a otro electrodo por ejemplo $A 2$ se obtiene mediante una simple resta $(F 1-A 1)-(A 2-A 1)=(F 1-A 2)$. Re-referenciar una señal a otro canal activo es útil para realizar una transformación bipolar, es decir, realizar la resta de las señales de dos electrodos activos sin afectaciones de la referencia común.

El Laplaciano o Densidad de Fuente Corriente (CSD), brinda una reducción de los efectos de la conducción por volumen a través de una transformación tetrapolar, mediante sustracciones entre electrodos adyacentes, es decir, una transformación de referencia independiente. Dicha transformación elimina los efectos de conducción, por los campos electromagnéticos, al doble de la distancia entre los electrodos. Para obtener el laplaciano o CSD con 4 canales adyacentes se realiza la resta del potencial de un electrodo central y la media pesada (un valor de peso entre 0 y 1 , dependiente de la distancia) de los 4 electrodos adyacentes al nodo central, por ejemplo $C z-\left[\frac{0.7(F c 1+F c 2+C p 1+C p 2}{4}\right]$. Si se cuenta con una gran cantidad de canales en el registro es posible realizar el laplaciano con ocho canales adyacentes, siguiendo el mismo principio $C z-\left[\frac{0.7(F c 1+F c 2+C p 1+C p 2}{4}+\right.$ $\left.\frac{0.5(F z+P z+C 3+C 4}{4}\right]$.

La cuantificación de la sincronización entre dos señales del cerebro debe realizarse con cuidado, ya que el uso de una referencia común puede representar valores inflados (comúnmente) o atenuados de conectividad. En el ámbito del análisis en frecuencia, si el espectro de potencia de la referencia es relativamente pequeño con respecto a los espectros de las dos señales a analizar, la medida de conectividad no será afectada, sin embargo, si el espectro de potencia es relativamente mayor que los dos espectros, la medida de conectividad no evaluará la interdependencia entre las dos señales de interés, sino la conectividad de la referencia consigo misma, aproximándose al valor máximo de sincronía; otro caso se presenta cuando el espectro es intermedio, es decir, no se sabe si inflará o atenuará el valor de conectividad entre los espectros de ambos canales.

Anteriormente se mencionaron apenas tres técnicas de re-referenciación, sin embargo, existen diversas técnicas las cuales se evalúan en diversos trabajos en la literatura. Por ejemplo en [26] realizan diferentes procedimientos de re-referenciación y los comparan para determinar los efectos de cada uno sobre la cuantificación de la coherencia entre canales de EEG, realizan la re-referenciación a través de:

- El lóbulo de la oreja izquierda $(A 1)$.

- Lóbulo de la oreja derecha $(A 2)$.

- $\operatorname{Nariz}(N)$. 
- Barbilla $(K)$.

- Media de los lóbulos de las orejas $\left(A=\frac{A 1+A 2}{2}\right)$.

- Promedio de los lóbulos de las orejas y nariz $\left(A N=\frac{A 1+A 2+N}{3}\right)$.

- Promedio de los lóbulos de las orejas, nariz y barbilla $\left(A N K=\frac{A 1+A 2+N+K}{4}\right)$.

- CAR con 19 canales.

- Laplaciano.

- Arreglo bipolar.

El cálculo de la coherencia se limitó entre los canales P3 y P4, los resultados que se obtienen muestran que el promedio de ambos lóbulos de las orejas $(A)$ brinda menores valores de coherencia en bandas superiores que la banda delta, las referencias promediadas (A,AN y ANK) pueden ofrecer resultados más fiables de coherencia que una referencia sencilla, a su vez al realizar el laplaciano genera valores bajos de coherencia ya que actúa como un filtro espacial pasa altas, sin embargo no concluyen con respecto a la mejor técnica de re-referenciación.

En [34] se hace la recomendación de evitar obtener la coherencia con una referencia común y realizar métodos de re-referenciación antes de un análisis de coherencia en registros de EEG, se hace énfasis que los resultados a partir de referencia común son dudosos y deben ser tomados cautelosamente sin aventurar conclusiones, por el contrario CSD permite un cálculo apropiado de la coherencia para evitar problemas de referencia común. Alhaddad en [27] realiza un estudio comparativo entre 21 diferentes técnicas de re-referenciación de registros de EEG orientado a un deletreador p300 con 3 conjuntos de datos con 32, 64 y 8 canales respectivamente. Concluye que los resultados mostrados por CAR son los mejores al utilzarla técnica de referencia. De estos trabajos se desprende que la elección de la referencia depende del estudio y el propósito del análisis, sin embargo, en [25-27] sugieren que para el análisis basado en correlación y función de coherencia debería de usarse CAR para evitar valores inflados artificialmente de correlación debido a la referencia común usada.

\subsection{Conectividad Funcional}

En los últimos años ha habido un gran interés en la búsqueda de evidencias que describan la ausencia o incremento de la conectividad funcional, entre diferentes regiones del cerebro [1]. Se ha entendido como conectividad funcional la interdependencia estadística entre la actividad cerebral registrada en series de tiempo [2-4], es 
decir, se busca la relación (a través de medidas de conectividad) temporal entre procesos neurofisiológicos espacialmente distribuidos [5]. El interés primordial para caracterizar la conectividad funcional del cerebro, en condiciones normales o patológicas, es que la mayoría de las funciones del cerebro están basadas en interacciones entre grupos de neuronas localizadas en diferentes áreas del cerebro, es decir, la actividad eléctrica modifica los patrones de conectividad ante la presencia o ausencia de tareas o padecimientos mentales. A lo largo del tiempo se han desarrollado teorías acerca de los desórdenes que afectan la actividad mental. En la década de los 60's se pensaba que la desconexión sugiría un déficit de las funciones derivadas de lesiones en la materia blanca [35]. Sin embargo, una alta conectividad también puede ser indicio de desordenes mentales [1].

Un elevado nivel de conectividad entre la actividad cerebral generada en diferentes regiones, posiblemente indica una relación funcional en dichas áreas, por lo tanto se pueden estimar distribuciones topográficas de las conexiones (cerebrales) durante una tarea o padecimiento específico. Dado que las señales cerebrales son altamente complejas, además que dependen de la edad del sujeto y su estado mental, al presentarse cambios en la conectividad funcional se generan diferentes redes de conectividad que aparecen en respuesta a tareas cognitivas específicas, relacionando áreas especializadas en la integración de la información. Sin embargo, surgen dificultades para la identificación de dichas redes [4]:

- Elección del método de adquisición de datos electrofisiológicos. Las diversas características de los métodos de adquisición de datos no brindan una medida directa de la conectividad entre distintas regiones cerebrales, dado que a partir de potenciales eléctricos (EEG), campos electromagnéticos (MEG) y señales BOLD (fMRI) se estima dicha conectividad, esta estimación puede ser influenciada por diversos fenómenos propios de la técnica de adquisición.

- La carencia de conocimiento acerca del vínculo entre las observaciones y los mecanismos neuronales involucrados durante interacciones de coordinación entre distintas áreas. En diversas patologías y tareas cognitivas, no se tiene una idea clara de la relación entre áreas del cerebro, sólo se tienen hipótesis de cómo interactúan, es por ello que en la literatura hay una gran cantidad de trabajos dedicados a encontrar dichas relaciones funcionales.

- Diversidad de métodos para estimar la conectividad funcional, todos basados en diferentes hipótesis sobre el modelo de conexión entre las señales analizadas, por ejemplo las medidas de conectividad lineales no pueden encontrar relaciones de características no lineales de las señales. 
Antes estas dificultades es importante plantear cúal método de adquisición, qué medidas de conectividad y por último la patología o actividad que se utilizarán para tratar de estudiar dicha conectividad funcional.

\subsection{Medidas de conectividad en el EEG}

Existe una gran cantidad de técnicas para evaluar la interdependencia estadística entre series de tiempo, las cuales pueden dividirse principalmente de dos maneras: dependientes de la linealidad (lineal y no lineal) y de acuerdo a la direccionalidad (no-direccionales y direccionales). Las técnicas lineales capturan sólo las propiedades lineales de la interacción entre señales analizadas. La direccionalidad de la medida de conectividad se refiere a establecer la dirección del flujo de información entre dos áreas del cerebro, es decir, sirven para determinar qué área afecta o influye a otra área del cerebro. Las medidas no direccionales, solo establecen la interdependencia entre dos áreas del cerebro sin importar dicho flujo de información. Las principales medidas lineales y a su vez no direccionales son los coeficientes de correlación y la función de coherencia. Ambas fueron las primeras en ser utilizadas para medir la conectividad entre diferentes áreas o electrodos en registros de EEG.

\subsubsection{Función de Coherencia}

La función de coherencia mide la correlación espectral de las señales (ecuación 2.2), a diferencia de los coeficientes de correlación, esta medida cuantifica la relación lineal entre las series de tiempo en una banda de frecuencia específica, es decir, cuantifica la semejanza entre las señales de acuerdo a sus espectros de potencia:

$$
\gamma_{X Y}^{2}(w)=\frac{\left|S_{X Y}(w)\right|^{2}}{S_{X X}(w) S_{Y Y}(w)} \leq 1
$$

El algoritmo más usado para el cálculo de la función de coherencia es mediante el método de Welch [36], donde se estima el espectro de potencia de una serie de tiempo estacionaria de segundo orden, mediante la división en segmentos traslapados de la misma longitud, calculando el periodograma a partir del promedio de todos los periodogramas. Este método se extiende de la misma forma para calcular el espectro de potencia cruzado, necesario para calcular la función de coherencia mediante la ecuación 2.2.

La medida de coherencia tiene un rango de valores entre [0-1], siendo un valor de 1 cuando los espectros de potencia de las señales tienen una relación lineal máxima y un 
valor de 0 corresponde a una total diferencia de los espectros. Puesto que los patrones de conectividad y función neuronal pueden ser específicos a una banda de frecuencia, una particular ventaja de la coherencia en registros de EEG, es la habilidad de evaluar relaciones topográficas de acuerdo a una banda de frecuencia específica [37].

A pesar de ser una medida muy utilizada en la literatura, conlleva a aceptar supuestos sobre las señales analizadas, es decir, se asumen que las señales son estacionarias (aún cuando se consideren estacionarias en segmentos pequeños) y que la interdependencia estadística entre dichas señales es únicamente lineal. Otra limitante recae en que la medida de coherencia por sí sola, no puede obtener información acerca de la estructura temporal de la coherencia, la cual es necesaria para el estudio de la dinámica del cerebro.

En el contexto de la conectividad funcional, la coherencia es una medida no-direccional, es decir, se puede estimar la relación entre los espectros de la señales pero no se puede establecer un flujo o dirección de la información, en este caso, la dirección de la conectividad, para determinar qué área afecta o influye a otra área del cerebro. Un aspecto a considerar es que la coherencia entre canales de EEG tiende a disminuir conforme los electrodos se encuentran separados con mayor distancia [38]. Además los valores de coherencia pueden ser afectados por el uso de un electrodo como referencia común.

La mayoría de las bioseñales son no-estacionarias, por lo tanto el método basado en Fourier resulta ser poco adecuado, ya que los segmentos pesados por la función ventana pueden corresponder a múltiples subprocesos con diferentes propiedades espectrales, y el promedio, para obtener la estimación espectral, podría no tomar en cuenta dichas propiedades, resultando en valores alterados de conectividad, sin embargo, diferencias o pequeñas perturbaciones son inevitables y no invalida la información obtenida de los cambios en conectividad funcional, para un fin médico o clínico [39].

Diferentes padecimientos o condiciones cerebrales han sido estudiados a través de la medida de coherencia para tratar de conocer, entender y observar las diferencias de la conectividad en áreas del cerebro que se presentan en cada condición especifica. Enfermedades como Alzheimer [40, 41], indican que los pacientes sufren una pérdida o reducción de la coherencia entre canales de EEG. Se pueden encontrar indicios de las afectaciones de conectividad en padecimientos degenerativos del cerebro, como la esquizofrenia $[42,43]$, en procesos de imitación de la conducta por medio de movimientos a través de las neuronas espejo [44], en afectaciones por apnea central obstructiva [45-47], en investigaciones acerca del desarrollo del cerebro humano [38], ante estímulos musicales [48], desarrollo de desórdenes en niños y adolescentes [49]. Por lo tanto se ha estudiado ampliamente como afectan fenómenos y artefactos a la medición de la coherencia en EEG [32, 39, 50], al análisis de la información estadística que otorga [39, 51], en la descripción de la topografía y estructura en frecuencia del cerebro [37]. 
El análisis de la estadística de la coherencia en el EEG se estudia en [39, 51], en [52] utilizan la coherencia como una forma de evaluación digital de un sistema en frecuencia. Los efectos del uso de un electrodo como referencia común, la conducción por volumen y distintas transformaciones de referencias en el cálculo de la coherencia entre canales de EEG se estudia en [39].

En $[40,41]$ modelan la integridad de la conectividad neuronal, en pacientes de Alzheimer en su etapa temprana. En pacientes esquizofrénicos la hipótesis principal expone que dichos pacientes sufren del síndrome de desconexión, ya que fallas o limitación de la conectividad funcional evita la red necesaria, entre regiones cerebrales, para realizar tareas de memoria. En [42] estudian a 10 personas esquizofrénicas y 10 personas del grupo control, mediante medidas de conectividad como coeficiente de correlación, coherencia (método de Welch [36]) y complejidad Omega. Los resultados arrojan una diferencia en la actividad de los canales fronto-temporales entre grupo control y grupo paciente, lo que sugiere una carencia de conectividad en el grupo paciente. Lo autores concluyen que los pacientes esquizofrénicos fallan para modificar la red neuronal de las regiones temporales, para poder tener la capacidad de realizar tareas de memoria. En [43] toman en cuenta el nivel de estudios de los sujetos control dado que en sujetos con mejor educación se presenta una conectividad funcional menos óptima, como resultado de una alta eficiencia.

Los procesos de imitación de la conducta en el cerebro humano se estudian en [44], encontrando que existe actividad asociada, en la banda alfa (región fronto-parietal) y delta (región occipital y central), de neuronas durante la ejecución, observación e imaginación de acciones motoras. Durante las sesiones de registro de EEG, los sujetos observaron películas con movimientos rápidos repetitivos de movimiento de dedos (clicks de ratón) y objetos en movimiento (haciendo los mismos movimiento pero con una barra de metal, en lugar de un dedo).

En [45] realizan una comparación entre la coherencia e Información Mutua, para obtener características que ayuden a un clasificador a discriminar dos padecimientos del sueño: apnea central del sueño y la apnea obstructiva. En [47], calculan los espectros de potencia de los registros obtenidos de EEG. Sus resultados muestran una alta coherencia (>0.8) en la frecuencia $0.012 \mathrm{~Hz}$ similar al ciclo ventilatorio durante las primeras fases de sueño.

Otros trabajos se han centrado en encontrar evidencia de la conectividad en la actividad cognitiva en infantes y adolescentes, con el fin de tratar de entender la aparición y desarrollo de desórdenes asociados a la deficiencia de funciones cognitivas. En [49], estudian a niños y adolescentes sanos (entre 6 y 18 años), mediante registros de EEG, en estado de reposo, centrándose en la banda alfa. Los resultados muestran que la conectividad se incrementa con la edad, mostrando cambios globales de coherencia notables en la 
banda alfa, otro punto importante es que las jóvenes presentan un desarrollo temprano de cambios a diferencia de los hombres. En [38] exploran el desarrollo humano (de la infancia a la adolescencia) en banda beta $13-25 \mathrm{~Hz}$, mediante registros de 458 niños de entre dos meses a 16 años de edad. Los resultados obtenidos muestran cambios notables en ambas medidas de 6 meses a 4 años y una tendencia lineal significativa a una mayor coherencia en corta distancia entre electrodos y retardos más grandes en electrodos a una mayor distancia.

Un estudió se realizó mientras sujetos escuchaban melodía clásica, para tratar de encontrara evidencia de activación de regiones cerebrales involucradas con aspectos emocionales [48]. Los resultados mostraron que los músicos (experimentados en música clásica) responden a los tonos musicales, la zona de activación se muestra alrededor de los electrodos T3 (centro auditivo), Fp2 (hemisferio frontal derecho relacionado a emociones).

En [37] se aborda la topografía y estructura, en estado de reposo, en bandas de frecuencia con la coherencia, mediante tres modelos de topografía. Sus resultados muestran que la actividad en la banda theta tiene diferentes fuentes temporales con una diferenciación anterior/posterior. En la banda alfa se tiene una orientación posterior y la banda beta muestra una estructura global definida.

\subsubsection{Coherencia Wavelet}

Una alternativa para cuantificar la sincronía con mejor resolución temporal y espectral, combina el uso de la transformada wavelet con la coherencia espectral. La coherencia wavelet espectral es definida como la magnitud del espectro cruzado wavelet normalizado e indica el grado de coherencia y la fase wavelet puede proporcionar la dirección de flujo de información entre canales en regiones corticales diferentes.

La transformada wavelet combina una resolución temporal alta y una resolución en frecuencia buena, por lo tanto es capaz de detectar eventos transitorios, lo que da como resultado un análisis adaptado a las frecuencias de interés. Una propiedad relevante de la transformada continua es que resulta invariante respecto de las traslaciones o escalamientos de la señal, es decir, estructuras similares serán detectadas de la misma forma, independientemente de su localización temporal y frecuencial. La transformación wavelet continua (CWT) se define, de la siguiente manera:

$$
W_{x}(t, s)=\int_{-\infty}^{+\infty} x(\tau) \psi_{(s, t)}^{*} d \tau
$$


La funcion wavelet $\psi_{(s, t)}(\tau)$ es una versión escalada y trasladada de una wavelet madre $\psi(\tau)$ :

$$
\psi_{(s, t)}(\tau)=\frac{1}{\sqrt{s}} \psi\left(\frac{\tau-t}{s}\right)
$$

donde $s$ es el parámetro escala, el cual permite el alargamiento o compresión de la wavelet madre,cuanto más pequeño es el factor escala, mayor es la compresión de la wavelet y puede reflejar cambios rápidos de las características de la señal, es decir, con escalas pequeñas se analizan frecuencias altas (compresión) y con escalas altas se analiza frecuencias de menor rango (alargamiento). El parámetro $t$ corresponde al desplazamiento de la wavelet, es decir, retraso o adelanto en el tiempo para el análisis en el domino del tiempo. El factor $\frac{1}{\sqrt{s}}$ tiene la función de normalizar la wavelet, es decir, que la transformada wavelet tenga la misma energía en cada escala. La representación tiempo-escala resultante puede ser transformada a tiempo- frecuencia mediante la relación inversa de escala y frecuencia de dicha transformada (la inversa de la escala $s$ es una aproximación y no el valor preciso en frecuencia). Con la transformada wavelet continua, es posible obtener una medida de conectividad a partir de una serie de tiempo y su respectiva transformación mediante la coherencia wavelet, siguiendo la misma idea que la función de coherencia:

$$
\begin{gathered}
W_{x y}(t, s)=W_{x}(t, s) W_{y}^{*}(t, s) \\
\gamma_{w}^{2}(t, s)=\frac{\left|W_{x y}(t, s)\right|^{2}}{W_{x}(t, s) W_{y}(t, s)} \leq 1
\end{gathered}
$$

A partir de la CWT de cada serie de tiempo se obtienen sus espectros-wavelet (ecuación 2.3), el espectro cruzado-wavelet (ecuación 2.5) y posteriormente la coherencia wavelet (ecuación 2.6). La coherencia wavelet retiene la ventaja de la alta resolución temporal del EEG pero añadiendo información en el dominio de la frecuencia.

Diversos trabajos se han enfocado en comparar el estudio de la conectividad cerebral mediante la coherencia y coherencia wavelet. En [53, 54], obtienen que la coherencia wavelet es más resistente a ruido gaussiano que la coherencia, ésta última obtiene valores mayores de conectividad en la banda alfa [53]. Con datos experimentales de 26 sujetos adultos, en [54] estudian cómo diferentes regiones del cerebro presentan conectividad entre ellas luego de aprender la asociación entre un estímulo visual y modalidades sensoriales, comparando ambas medidas de conectividad, obtienen que en banda delta la coherencia wavelet detecta características, que no ocurren en el grupo control. 
En [55-57] se trata de identificar diferencias entre frases en chino e inglés, los sujetos debían presionar un botón si el estímulo visual (frase) era verdadera o falsa, los registros de EEG fueron adquiridos con 128 electrodos. Los resultados muestran que en la banda de frecuencia 18-25 Hz existen diferencias entre la identificación del idioma ingles (conectividad entre lóbulo parietal, occipital derecho con el lóbulo frontal) y el chino (conectividad entre lóbulo temporal y parietal).

En [58] se estudia la conectividad cerebral mientras una persona trata de reconocer rostros familiares y no familiares, 10 sujetos fueron analizados mediante el análisis de coherencia wavelet con la función wavelet Harmonic, debido a que la resolución en frecuencia de la función Morlet disminuye en bandas de alta frecuencia. Sus resultados muestran una diferencia de conectividad, entre la región temporal y otras regiones del cerebro, en banda alfa, durante el proceso de reconocimiento.

En [59] se utiliza la coherencia de fase wavelet e Índice de Modulación para estudiar las interacciones en la frecuencia de un cerebro epiléptico, por medio de EEG intracraneal, la conectividad entre electrodos fue medida con la coherencia wavelet y las interacciones intraeléctrodo fueron medidas con Índice de modulación. La coherencia wavelet fue calculada por pares de electrodos en 5 bandas de frecuencia: 1-4 Hz, 4-8 Hz, 8-13 Hz, 13-30 Hz y 30-100 Hz. Los resultados muestran una alta coherencia en la banda 1-4 Hz y en contraste en la banda 13-30 $\mathrm{Hz}$ los valores fueron los mínimos registrados.

La incapacidad para detectar cambios sustanciales en el campo visual, se estudia en [60], intercalando imágenes en el experimento, observan que existen diferencias de conectividad entre en electrodos frontales cuando se presenta un cambio registrado en el campo visual por el sujeto y cuando no se percata el sujeto de dicho cambio.

En [61] se analizan, por medio de la coherencia wavelet en EEG, 15 pacientes con Transtorno del Espectro Autista (ASD) y 15 sujetos control, entre las frecuencias 5 a $40 \mathrm{~Hz}$, durante tareas de detección de caras y sillas (30 imágenes de caras y 30 de sillas), con el objetivo de encontrar evidencia de la reducción de coherencia interhemisférica en pacientes de ASD, en comparación del grupo control. Los resultados mostrados, indican una disminución significativa de valores de coherencia del grupo ASD, interhemisférica, a diferencia del grupo control pero no encuentran diferencias significantes en su análisis de espectro de potencia, durante tareas de visualización.

\subsubsection{Teoría de la Información}

La entropía (ecuación 2.7) cuantifica la información promedio contenida en una variable aleatoria $X$, y depende directamente de la distribución de probabilidad $p(x)$ e indica 
como es de predictible el resultado del proceso sujeto a incertidumbre.

$$
H(K)=-\sum_{x} p\left(x_{i}\right) \log \left(p\left(x_{i}\right)\right)
$$

La entropía siempre tendrá una valor positivo, ya que $0<p(x)<1$ y por lo tanto el logaritmo de $p(x)$ es negativo. Si la entropía resultante tiene un valor de cero, se tiene un proceso determinístico y no hay incertidumbre sobre los valores tomados por dicho proceso, es decir, se sabe con certeza la salida del proceso. En el caso contrario, la incertidumbre del proceso resulta ser alta y por tanto conlleva a una entropía mayor. Si se piensa en términos de información, la incertidumbre e información están altamente ligadas, cuanto mayor sea la irregularidad (incertidumbre) de un proceso, mayor información proporciona, por el contrario cuanto menor sea la irregularidad (proceso determinístico) la cantidad de información decrece. Esta medida de incertidumbre puede aplicarse a estudios de EEG, donde es un descriptor estadístico de la variabilidad entre señales de EEG, además parece ser razonable, debido a que la corteza cerebral tiene como objetivo principal el procesamiento de información, utilizar una medida de cuantificación de información [62].

Cuando el cerebro está en un estado de alerta, se supone en desorden (entropía alta), pero cuando el paciente pierde la conciencia, por resultado de una anestesia por ejemplo o desmayo, la cantidad de desorden decrece (entropía mínima), por lo tanto se puede asociar la complejidad de las señales cerebrales con el nivel de actividad cerebral. Una variante de la entropía, en el estudio de señales de EEG, se conoce como Entropía Espectral (SEN) [63], es decir, se aplica la entropía a la densidad espectral de potencia de la señal de EEG y mide la irregularidad o complejidad de dicha señal, a partir de las amplitudes espectrales (normalizadas), interpretándolas como probabilidades para el cálculo de la entropía:

$$
S=\frac{\sum p_{k} \log \left(p_{k}\right)}{\log (N)}
$$

donde $\left.p_{(} k\right)$ son las amplitudes en $k$ frecuencias y $N$ el número de frecuencias.

Un importante problema en estadística es definir una medida de diferencia entre dos funciones de densidad; para ello se define la entropía de Kullback-Leibler, también llamada entropía relativa o entropía cruzada, la cual establece una medida de similitud entre dos distribuciones [64]: 


$$
K(p, q)=\sum_{x} p(x) \log \left(\frac{p(x)}{q(x)}\right)
$$

$K(p, q)$ indica que tan parecidas son o no las distribuciones $p$ y $q$, es decir, $K(p, q)=0$ sí y solo sí $p(x)=q(x)$, pero no es simétrica ya que $K(p, q) \neq K(q, p)$. Una forma de utilizar esta entropía cruzada, es elegir una función de densidad de referencia y así estimar cuánto cambia la función de densidad a analizar del patrón correspondiente. Lo anterior puede generalizarse para poder utilizarse en registros de EEG, en lugar de elegir una función de densidad patrón, se puede utilizar las funciones de densidad, calculadas a partir de la serie de tiempo de cada electrodo del EEG y comparar entre si los pares de funciones para conocer el grado de diferencia, entre las funciones de densidad de las series de tiempo.

En años recientes se han desarrollado técnicas derivadas de la entropía y entropía cruzada. La entropía Aproximada (ApEn) [65], por ejemplo, propuesta por Pincus a principios de los 90's como una modificación para ser aplicada a procesos estocásticos, la cual cuantifica la predicción de valores de amplitud sucesivas de una serie de tiempo, basado en el conocimiento de valores de amplitud de valores previos. En cuanto a señales de EEG, puede cuantificar la predictibilidad de las amplitudes de los potenciales de EEG, basándose en las amplitudes anteriores con cierto error. Si se tiene una señal regular la predicción de las amplitudes futuras en base a las pasadas será mayor, dando un valor de ApEn baja y en caso contrario para una señal irregular las predicciones serán dadas en menor cantidad provocando un valor alto de ApEn. Una generalización de ApEn es la Entropía cruzada aproximada (X-ApEn) [66] la cual fue desarrollada bajo la idea de una medida de entropía cruzada para describir la conectividad o acoplamiento entre pares de señales en el tiempo, a partir de la característica de predictibilidad de una serie de tiempo. La Entropía Cruzada Muestral (X-SampEn) ha sido utilizada como medida de conectividad de patrones bivariados para caracterizar su interdependencia estadística entre señales cerebrales [67].

Otra medida para medir la interdependencia estadística de dos variables aleatorias $X$ y $Y$, utilizando las distribuciones de probabilidad se conoce como Información Mutua. Esta información mutua se define como la distancia de Kullback-Leibler de la probabilidad conjunta y las probabilidades de las variables aleatorias:

$$
I(X ; Y)=K(p(x, y), p(x) p(y))=\sum_{x} \sum_{y} p(x, y) \log \left(\frac{p(x, y)}{p(x) q(x)}\right)
$$

Esta medida es simétrica, es decir, $I(X ; Y)=I(Y ; X)$ y a su vez la información mutua de la variable $X$ consigo misma genera la entropía de $X, I(X ; X)=H(X)$. Cuando 
$X$ y $Y$ son la entrada y salida respectivamente, de un canal estocástico entonces la información mutua es la medida de transmisión de información en el canal estocástico. En el sentido de interdependencia estadística, se interpreta que la información mutua es una medida de la cantidad de información que $Y$ transmite de $X$ y se puede estimar la correlación estadística entre ambas variables aleatorias [64].

En [68] se estudian las relaciones mutuas, a través de características no lineales, entre áreas corticales en pacientes epilépticos, utilizando la Entropía Cruzada Condicional Corregida (CCCE) y la Entropía Condicional (CE). La Entropía Cruzada Aproximada (X-ApEn) y Entropía Cruzada Muestral (X-SampEn) han sido utilizadas como medidas de conectividad entre dos patrones para caracterizar su interdependencia estadística, por ejemplo en [67] se comparan las dos medidas anteriores con una Entropía Cruzada Difusa (X- FuzzEn), su estudio da muestras que la X-FuzzEn brinda una medida de conectividad conveniente ante señales contaminadas pata estudiar la dinámica cerebral.

En la literatura se ha investigado la influencia de aplicación de anestésicos en la conectividad funcional del cerebro mediante la entropía, ya que los analgésicos desacoplan áreas del cerebro en la banda de frecuencia gamma (percepción consciente). Una hipótesis de los efectos en conectividad supone un impedimento para la transmisión de la información de manera adecuada en las áreas corticales, sin embargo, no se sabe el efecto sobre redes locales, las cuales pueden ser resistentes a cambios globales, dando motivos para un incremento de sincronía y procesamiento de información a zonas muy específicas del cerebro. En [66] se estudia cómo afecta la conectividad en redes locales corticales en ratas la aplicación de anestesia, por medio de la XApEn, mediante un arreglo de electrodos comparando los patrones de actividad en estado de vigilia con aquellas ratas que se les suministro anestesia. Los resultados arrojan una disminución de la interdependencia del funcionamiento neuronal cortical local. En [62] comparan el rendimiento de diferentes estimadores de entropía aplicados a señales de EEG, durante rutinas de aplicación por anestesia general. Se trata de contestar una pregunta primordial cómo y cuáles patrones de conectividad pueden ser detectados por los diferentes estimadores: entropía espectral, entropía espectral generalizada.

También se ha estudiado los efectos sobre la conectividad durante la ingesta de Alprazo$\operatorname{lam}^{1}$ [69], en la conectividad funcional del cerebro durante estado de vigilia o desvelo, por medio de medidas lineales y no lineales. El análisis no lineal consistió de medir la conectividad de canales de EEG mediante Entropía Condicional (CE), Entropía Condicional Corregida (CCE), Entropía Cruzada Condicional Corregida (XCCCE) y la medida de

\footnotetext{
${ }^{1}$ Fármaco útil para el tratamiento de diferentes cuadros asociados con síntomas de ansiedad, trastorno de pánico y ansiedad asociada a depresión. Tomado de http://www.facmed.unam.mx/bmnd/gi_2k8/prods/PRODS/Alprazolam.html .
} 
coherencia como medida lineal. Los autores reportan cambios de pérdida de conexiones entre regiones corticales para medidas lineales y un incremento en el análisis no lineal.

En [70] se utiliza la entropía y entropía espectral para la detección de eventos de ritmo alfa y eventos epilépticos en señales de EEG. Los autores plantean, a partir de sus resultados, que los valores de entropía crecieron acorde al aumento de la amplitud de señal en todos los casos analizados. Para la entropía espectral se observó una disminución de acuerdo a la disminución del desorden de las señales. Debido a que existen numerosas medidas de entropía, en [65] realizan un estudio de comparación entre variedades de entropía con el objetivo de encontrar algunos patrones que ayuden a elegir, de manera adecuada, que medida se debe utilizar para extraer información de señales biológica en especial en casos de epilepsia.

En [63] comparan dos medidas de cuantificación de diferencias entre dos distribuciones a partir de señales de EEG, la entropía cruzada o relativa y la entropía cruzada renormalizada, de pacientes de epilepsia. Los resultados muestran que ambas entropías tiene resultados muy similares, siendo relativamente mejor la entropía cruzada (aplicada al espectro de potencia y su respectiva distribución de probabilidad) para detectar patrones anormales de las crisis epilépticas. Por último sugieren el uso de la entropía cruzada aplicada a una representación tiempo-frecuencia como wavelets.

\subsubsection{Otras medidas de conectividad}

\subsubsection{Función de correlación}

La primera medida usada para medir la interdependencia entre dos series de tiempo aplicada al EEG es la función de correlación cruzada, utilizando los coeficientes de correlación de las amplitudes:

$$
C_{x y}(\tau)=\frac{1}{N-\tau} \sum_{k=1}^{N-\tau} x(k+\tau) y(k)
$$

donde $\mathrm{N}$ es el número de muestras de las series de tiempo $x(t)$ y $y(t), \tau$ es el tiempo de retardo en la observación de ambas señales. Esta medida de conectividad tiene numerosos cuestionamientos: la magnitud de la correlación depende de la elección del tiempo de retardo $\tau$, no toma en cuenta que la correlación entre series de tiempo puede depender de bandas de frecuencias, se asumen que las series de tiempo son estacionarias [71, 72] y solo captura correlaciones de naturaleza lineal. 
Se han desarrollado otras medidas de conectividad pero bajo un enfoque de interdependencia estadística no lineal como entropía, entropía cruzada, conectividad likelihood, información mutua, conectividad generalizada son algunos ejemplos. Para tratar la limitante de direccionalidad de la función de coherencia se han desarrollado medidas de conectividad direccionales, derivadas de la teoría de la información como entropía cruzada, o modelos paramétricos como coherencia parcial dirigida (PDC). En la literatura existen diversos estudios de comparación entre diversas medidas de conectividad: (direccionales y no direccionales) evaluando la capacidad de diferenciar las conexiones causales directas de las conexiones no causales y los efectos de la relación señal-ruido (SNR) [73]. En [74] realizan una comparación de medidas direccionales con diferentes enfoques teóricos basados en la teoría de la teoría de la información, modelos paramétricos y diferencia de fase.

\subsubsection{Sincronización de fase}

La idea principal acerca de la conectividad de fase entre dos procesos oscilatorios, es que la diferencia de fase (entre dos series de tiempo) es limitada o acotada:

$$
\left|\Theta_{n, m}\right|=\left|n_{\Theta_{1}}-n_{\Theta_{2}}\right|<\text { const }
$$

Donde $\Theta_{1}$ y $\Theta_{2}$ son las fases de cada serie de tiempo y $\Theta$ es la diferencia de fase, la conectividad de fase $n$ a $m$ se describe en la ecuación 2.12. Para obtener dicha conectividad, son necesarias dos etapas: primero obtener los valores de fase (en cada instante) en la serie de tiempo, representando la serie de tiempo como una señal compleja, es decir, con valores de amplitud y fase en cada instante de tiempo, a partir de estas representaciones dos señales, se obtiene una distribución de diferencias de fases. Segundo, cuantificar la conectividad de fase, lo cual puede realizarse mediante la entropía (Teoría de la información) por ejemplo. Esta técnica tiene varias ventajas sobre las medidas lineales: no requiere de asumir estacionariedad de los datos, no depende de las amplitudes de la señal ni del espectro de potencia [46].

\subsubsection{Sincronización Generalizada}

El objetivo principal es investigar la interacción entre dos sistemas dinámicos no lineales sin conocimiento acerca de las ecuaciones que los gobiernan. Se generan a partir de dos pasos principales: no se consideran las series de tiempo tal cual, sino se reconstruye la trayectoria estado-espacio de cada serie de tiempo usando un método embebido de 
retardo [4]. Para cada tiempo discreto $n$ un vector de retardo correspondiente a un punto en el estado-espacio reconstruido de $x$ está dado por:

$$
X_{n}=\left(x_{n}, x_{n+\tau}, \ldots, x_{n+(m+1) \tau}\right) ; m=1, \ldots, N
$$

donde $m$ es la dimensión embebida y $\tau$ denota el retardo en el tiempo. De la misma forma se reconstruye la trayectoria estado-espacio del sistema, midiendo el grado de conectividad y usando una medida basada en distancia. En términos generales, el concepto implica que el estado del sistema dinámico $Y$, es función del estado del sistema dinámico $X$, esto es $Y=F(X)$ [75]. Donde $X$ es el control, $Y$ es la respuesta del sistema. Las ventajas de este enfoque es que no se requiere señales en banda limitada, sin embargo, la manera de construir el estado-espacio es compleja y requiere una gran cantidad de parámetros.

\subsubsection{Verosimilitud de Sincronización}

La Verosimilitud de Sincronización, propuesta por Stam y Van Dijk [76], trata de determinar la fuerza y la dirección de la Sincronización Generalizada, describe que tan fuerte es el vínculo entre un canal y los demás canales de EEG a un tiempo dado. La verosimilitud de conectividad es la máxima entre dos series de tiempo a partir de vectores reconstruidos, de dichas series, cerrados entre $Y_{j}$ a $Y_{i}$ dado que $X_{j}$ es cerrado a $Y_{i}$, donde el termino cerrado se refiere a como un intervector de distancia corta a una distancia de corte $[76]$.

$$
S L_{i}=\frac{1}{N_{p_{r e f}}} \sum_{j=i-w_{2}|j-i|>w_{1}}^{j=i+w_{2}} \Theta\left(r_{x, i}-\left|X_{i}-X_{j}\right|\right) \Theta\left(r_{x, i}-\left|Y_{i}-Y_{j}\right|\right)
$$

Esta medida toma valores entre $p_{\text {ref }}$ y 1 , el primer valor corresponde al valor de la conectividad de verosimilitud del canal $k$ al tiempo $i S_{k, i}=p_{\text {ref }}$ en el caso que todas las series de tiempos correspondientes al EEG no estén correlacionadas y $S_{k, i}=1$ corresponde cuando todas las series de tiempo están correlacionadas al tiempo $i$. La Verosimilitud de Sincronización asume una relación arreglada de fases entre las series de tiempo. En algunos padecimientos como Parkinson, el comportamiento transitorio de la fase entre las diferentes partes del sistema motor puede ser interrumpida por deslizamientos de fase, haciendo la suposición de periodos prolongados de sincronía de fase inadecuada. 


\subsection{Teoría de Gráficas}

Una gráfica es una representación de una red de objetos, a partir de nodos (vértices) que se vinculan entre sí mediante conexiones (aristas), dicha conexión puede ser de tipo binaria (conectado o no conectado) o pesada, de acuerdo a un valor de intensidad del vínculo. También se puede clasificar de acuerdo al flujo de la conexión, es decir, si el enlace de comunicación entre dos nodos tiene una dirección de flujo de información se dice que la gráfica es direccional, de lo contrario cuando no se puede establecer una dirección del vínculo se conocen como no direccional. En la figura 2.5 se presentan las cuatro combinaciones posibles de gráficas de acuerdo a las dos clasificaciones mencionadas.

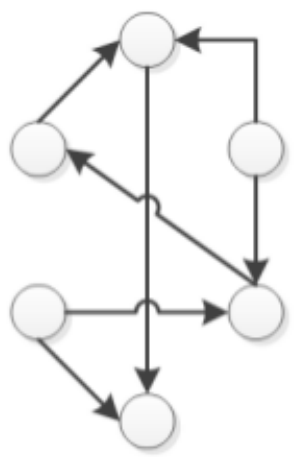

A

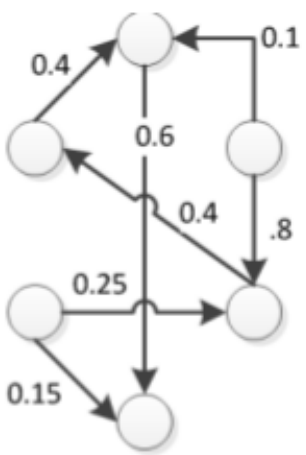

B

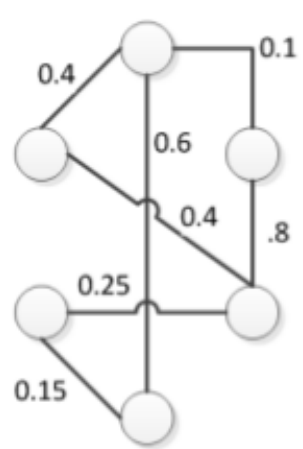

$\mathrm{C}$

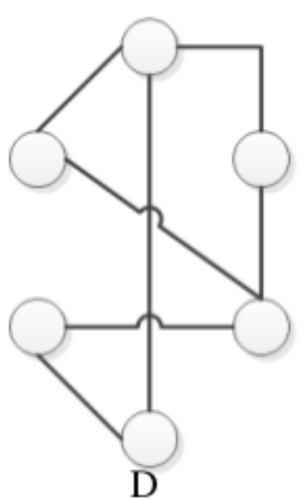

Figura 2.5: Ejemplos de gráficas. A) Gráfica dirigida binaria. B) Gráfica dirigida y pesada. C) Gráfica no dirigida pesada. D) Gráfica no dirigida binaria.

Para representar matemáticamente la conectividad dentro de una gráfica, se utiliza una matriz que contenga el patrón de conexiones: 1's o 0's en el caso de gráficas binarias, para gráficas pesadas el valor de conectividad, dicha matriz se conoce como matriz de asociación. A partir de esta matriz se basa el análisis de la teoría moderna de gráficas, para obtener diversas medidas que caractericen el comportamiento de la red.

La primera medida que se expone es el grado de un nodo $d(v)$, el cual se refiere al número de aristas o conexiones que tiene el nodo $v$ con los nodos restantes (ecuación 2.15). En una gráfica pesada, la fuerza del nodo no es más que la suma de todos los pesos de las conexiones que tiene un nodo con los demás que conforman la red (ecuación 2.16).

$$
\begin{aligned}
& d(v)=\sum_{j} a_{v j} \\
& d(v)=\sum_{j} w_{v j}
\end{aligned}
$$


donde $a_{v j}$ (ecuación 2.15) define todos los enlaces que interactúan con el nodo $v$, en la ecuación $2.16 w_{v j}$ define el valor de los pesos de las conexiones que interactúan con el nodo $v$. Para una gráfica pesada direccional se puede introducir el término fuerza de entrada y fuerza de salida, y se obtiene a partir de la suma algebraica de los pesos de las conexiones de entrada y salida respectivamente.

El grado promedio de una gráfica no pesada se obtiene mediante el promedio de todos los grados de los nodos de la gráfica (ecuación 2.17).

$$
d(G)=\frac{1}{|V|} \sum_{v \in V} d(v)
$$

El grado promedio de una gráfica pesada es el promedio de todos los pesos de los nodos, sin embargo, solo proporciona información acerca de la distribución de la intensidad de conexión al interior de la red. Para aumentar la información relevante relacionada con el grado promedio se puede utilizar una variación, dado un valor de intensidad (peso de conexión) se obtiene el número de nodos de la gráfica que tienen el mismo valor de conexión. Dicho de otro modo, se puede obtener la probabilidad de que un nodo elegido tenga un valor de conexión específico. Como resultado de esta medida se puede obtener un histograma de pesos de nodo, el cual representa el grado de distribución de la gráfica que permite entender la localización de la fuerza del sistema, además nos permite conocer si sigue una distribución conocida. Si la red es de tipo dirigida, se puede dividir la fuerza de distribución de acuerdo a su contribución de entrada o salida.

La densidad de la red se define como el número de conexiones de la red entre el máximo número de conexiones posibles (ecuación 2.18), por lo tanto su rango va de 0 a 1 , si una red es escasamente conectada el valor de la densidad es cercano a 0 en caso contrario el valor de la densidad será 1 . Para una gráfica pesada, se utiliza la densidad-pesada (ecuación 2.19), que evalúa la intensidad de las conexiones que componen la red brindando información acerca del nivel de conectividad global.

$$
\begin{gathered}
k(G)=\frac{1}{N(N-1)} \sum_{i \neq j} a_{i j} \\
k_{w}(G)=\sum_{i \neq j} w_{i j}
\end{gathered}
$$

El coeficiente de agrupamiento $C_{j}$ del j-ésimo nodo es la probabilidad de que sus nodos vecinos también estén conectados entre sí, es decir, evalúa el grado de interconectividad entre un grupo de nodos vecinos alrededor de un nodo central, de tal manera que se 
toma en cuenta el número de conexiones entre sus vecinos y el máximo número posible de conexiones entre los vecinos (ecuación 2.20). Este coeficiente se considera una medida local de interconexión de una red, se relaciona con la resistencia y adaptación a fallas en la red: la pérdida de nodos en los bordes afecta de menor manera el funcionamiento de la red que si todos los vecinos están conectados entre sí;

$$
c_{i}=\frac{\sum_{j, m} a_{i j} a_{j m} a_{m i}}{d_{i}\left(d_{i}-1\right)}
$$

donde $d_{i}$ es el grado del i-ésimo nodo. El promedio de todos los coeficientes de los nodos se obtiene mediante la ecuación 2.21 y se conoce como Coeficiente de Agrupamiento Característico (C).

$$
C(G)=\frac{1}{N} \sum_{i=1}^{N} c_{i}
$$

Un camino o vía (path) dentro de una gráfica se refiere a una secuencia de nodos conectados y su longitud es el número de aristas que conforman dicho camino. La longitud o distancia mínima, está definida por el menor número de nodos que deben estar conectados entre sí para que dos nodos se comuniquen. En el concepto de redes de pequeñomundo, no importando que existan gran cantidad de nodos, siempre existirá un camino corto entre cualquier par de nodos, así el promedio de las longitudes de todos los pares posibles de la red se conoce como la Distancia Mínima Característica (L) (ecuación 2.22) y es un indicador de la conectividad global de una red.

$$
L=\frac{1}{N(N-1)} \sum_{i \neq j} \bar{d}_{i j}
$$

Los nodos con la menor $L$ son considerados concentradores dentro de la red. También la medida $L$ indica qué tan bien está conectada la red, una red con baja $L$ es característica de distancias menores entre cualesquiera dos nodos, por el contrario una $L$ mayor indica que la información sufre retardos para llegar a su objetivo, teniendo un impacto sobre la distribución de la información. Un problema del cálculo de $L$ se presenta si hay elementos desconectados, pues $L$ diverge. Ante esto se desarrolló una medida conocida como eficiencia, la cual es un indicador de la capacidad de tráfico de la red, evita dicho problema de divergencia haciendo que la contribución de nodos no conectados sea cero. Esta medida al estar relacionada con $L$ nos indica que tan eficiente es la red en la transmisión de la información, es decir, una red altamente conectada con $L$ baja puede no ser eficiente al momento de transferir la información ya que necesita pasar por una 
gran cantidad de nodos antes de llegar a su destino, por el contrario una red con una $L$ mayor pero no altamente conectada conserva conexiones de baja distancia a pesar que dos nodos se encuentren lejanos, es posible que dicha red sea eficiente para transmitir la información.

Otras medidas han sido recientemente desarrolladas, a partir de comparar la red de interés con una red de referencia, que se crea a partir de un ensamble de redes aleatorias, con el mismo número de nodos, aristas y grado para cada nodo. Por ejemplo en el caso del coeficiente de agrupamiento, se obtiene para la gráfica de estudio y para el ensamble de redes aleatorias (con las mismas propiedades ya mencionadas) y al dividir el primer coeficiente con el coeficiente de ensamble se obtiene una versión normalizada $\gamma$ de dicha medida. De igual manera se realiza para $L$ obteniendo la medida $\lambda$, dichas medidas fueron introducidas en [77] como indicadores de comparación, éstos resaltan la observación de small-word-ness (pérdida de las características de redes de pequeño-mundo).

\subsubsection{Gráficas binarias y pesadas}

Las medidas básicas que se usan principalmente para caracterizar gráficas binarias son el grado de nodo, el grado promedio y densidad, por parte de las redes de pequeño mundo las medidas básicas son el coeficiente de agrupamiento característico, la distancia mínima característica y la eficiencia (ésta última derivada de la distancia mínima), sin embargo su aplicación para gráficas pesadas tiene que pasar por dos alternativas:

- Convertir una gráfica pesada en una binaria a partir de aplicar un umbral de conectividad, es decir, valores de conectividad por debajo de un valor de umbral se rompen y aquellas con un valor igual o superior se conservan, obteniendo una gráfica binaria. Realizar una umbralización (en la matriz de asociación) para generar un gráfica no pesada, obviamente el valor de umbral toma un papel importante, ya que de él dependerá la estructura y parámetros de la red resultante, sin embargo, no existe criterio alguno para elegir un umbral óptimo [4]. En la literatura, los autores utilizan valores de umbral en un rango de [0.6-0.8], sin especificar la razón de dicha elección, dando la impresión que es el intervalo donde sus resultados brindan información necesaria para respaldar su trabajo.

- Utilizar las versiones de dichas medidas para gráficas pesadas específicamente. Las medidas descritas en esta sección (2.6), se presentaron para gráficas no pesadas y pesadas, sin embargo, existen versiones pesadas del coeficiente de agrupamiento, la longitud característica y a su vez eficiencia local y global, mediante la inversión de la longitud característica pesada. 


\subsubsection{Teoría de Gráficas y la conectividad cerebral}

Con el desarrollo de las redes pequeño-mundo y de libres de escala, surgió un interés por estudiar la conectividad funcional del cerebro mediante el enfoque de análisis de redes complejas. ¿Es posible construir un modelo matemático simple basado en los datos de EEG que refleje el ambiente o patrón de un cerebro epiléptico? [78] ¿Qué patrones se pueden encontrar por medio de medidas de teorías de gráficas moderna, que reflejen la actividad cerebral? ¿Es posible estudiar el desarrollo y presencia de patologías con medidas de gráficas? La teoría de gráficas moderna ofrece una amplia selección de medidas para examinar y cuantificar las relaciones entre las activaciones de diferentes regiones del cerebro además puede utilizarse, en el estudio de la conectividad funcional, con varias técnicas de obtención de datos neurofisiológicos: EEG, MEG y fMRI, sin embargo, en la literatura se han establecido pasos específicos (sin importar la técnica de adquisición de datos) para realizar el análisis de grafos (figura 2.6).

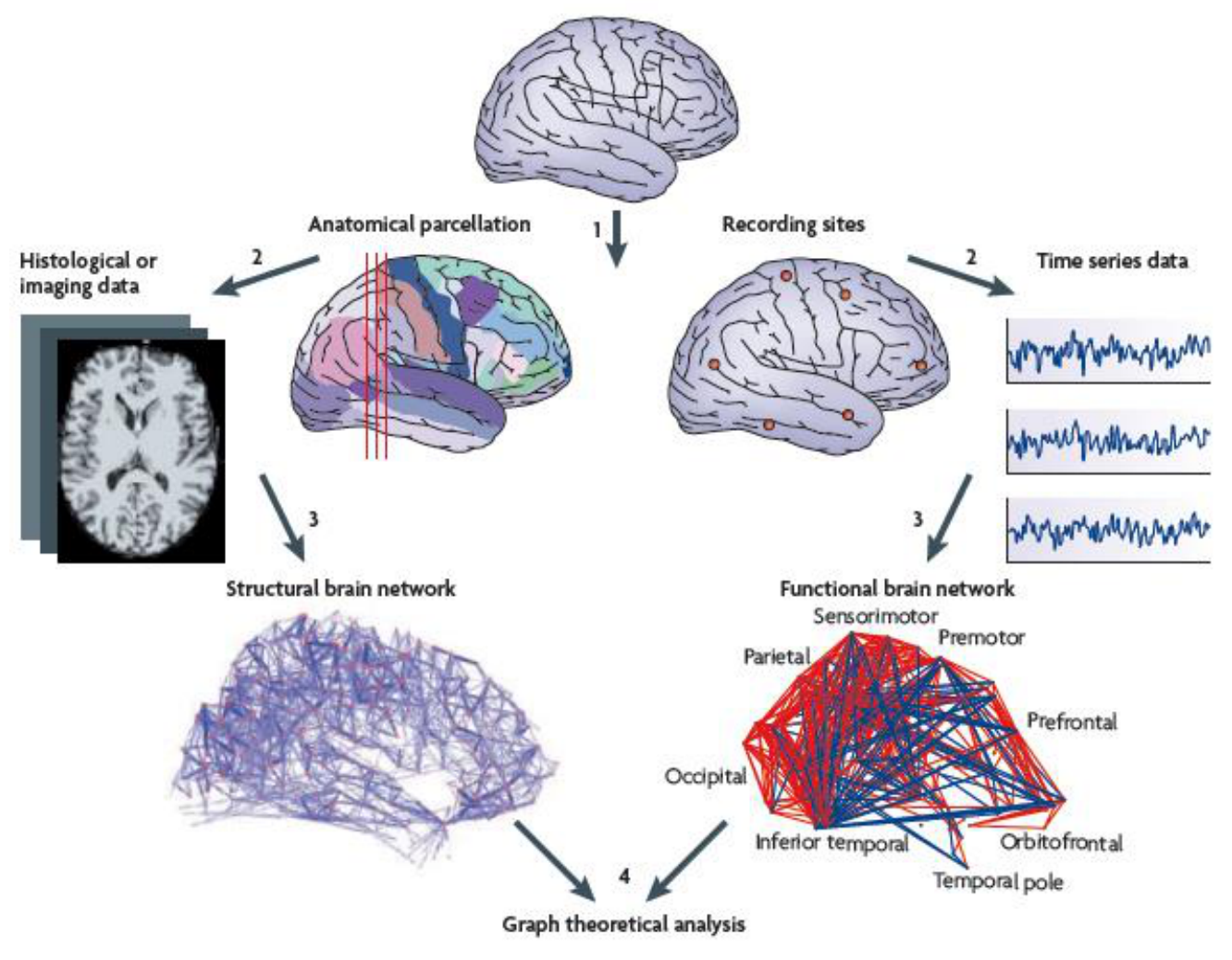

FigurA 2.6: Etapas para el estudio de la conectividad funcional del cerebro, utilizando la teoría moderna de gráficas. Imagen tomada de [79].

Como primer paso se requiere obtener el conjunto de datos a partir de la técnica de adquisición específica; en este trabajo se centra en el EEG, por lo tanto se requiere grabar un EEG con cierto número de canales, por medio de electrodos distribuidos de acuerdo al sistema 10-20. Dichos electrodos corresponderán a los nodos de la gráfica a 
modelar. Ya obtenidas las series de tiempo del registro de EEG, se procede a realizar el procesamiento de señales digitales apropiado (eliminación de artefactos, filtrado en banda, p.e) con el fin de calcular la medida de conectividad entre dichos electrodos. Con ello surge una pregunta ¿Qué medida es indicada? En la sección 2.5, se presentaron diversas técnicas de cuantificación de la conectividad, pero no existe una medida indicada como la mejor para captar la conectividad entre regiones del cerebro. Es entonces decisión propia qué medida utilizar, teniendo en cuenta las propiedades de cada técnica. Las mediciones de conectividad son obtenidas, mediante parejas, de todos los electrodos del registro de EEG a analizar. A continuación se porta la información de conectividad obtenida, a una matriz de asociación la cual será la base para obtener la gráfica de conectividad. En un registro se pueden obtener cierto número de matrices de asociación, es decir, si el registro se parte en segmentos de tiempo, se obtendrá un matriz por cada segmento, esto es de suma importancia ya que por cada matriz de asociación se obtiene una red con parámetros diferentes a las demás, estudiar dichas modificaciones o diferencias en estructuras es importante para poder describir el comportamiento del sujeto en toda la duración del EEG.

Diferentes técnicas de adquisición de señales electrofisiológicas han sido utilizadas para estudiar la conectividad funcional cerebral a través de la teoría de gráficas moderna, estos estudios se han enfocado en condiciones normales o en presencia de alguna patología, obteniendo que no solo en estudios de EEG se han encontrado características de las redes de pequeño-mundo, sino también en estudios de fMRI, MEG. Diversas patologías y condiciones cerebrales han sido estudiadas a través de la conectividad funcional y parámetros de la teoría moderna de gráficas: condiciones normales durante movimientos de pies [80, 81], Alzheimer [8, 82, 83], lesiones cerebrales [9, 84], lesiones de medula espinal [85], Transtorno del Espectro Autista (ASD) [86], Parkinson [87], Epilepsia [78, 88, 89], Esquizofrenia [90, 91], durante sueño [92], desarrollo del cerebro [93] y alcoholismo [94].

En condiciones normales, en [80] se estiman redes de conectividad cerebral mediante coherencia parcial dirigida en EEG, en sujetos sanos que realizan una tarea específica, una flexión dorsal del pie derecho. Sus resultados se centraron en la banda alfa, la cual refleja información acerca de este movimiento en las extremidades, a partir del grado de distribución, que las zonas corticales tienen una participación mayor para ejecutar dicha tarea. Se tienen un gran número de conexiones salientes de áreas corticales a las áreas motoras. También en [81] se muestran cambios estructurales en la banda beta, las áreas motoras de la corteza se comportan como concentradores, presentando una gran cantidad de conexiones salientes a otras regiones del cerebro. Adicionalmente los patrones de conectividad revelan una alta eficiencia durante la preparación del movimiento del pie, esto se asocia a las redes pequeño-mundo ya que efectivamente se cuenta con un 
coeficiente alto de agrupamiento y un promedio de distancia corta que conecta a las áreas corticales.

En $[8,82]$ se estudia a pacientes de Alzheimer utilizando señales de MEG para evaluar la conectividad, en estado de reposo. Mediante 151 canales estudiaron a 18 pacientes de Alzheimer y 18 sujetos sanos. Usaron dos medidas de conectividad: verosimilitud de sincronización y coherencia. En la banda alfa y beta los pacientes perdieron interacciones de larga distancia, principalmente perdieron conexiones fronto-temporal/parietal del lado izquierdo, además dichos pacientes incrementaron su conectividad, en la banda theta en la región centro-parietal, en banda beta y gamma en la región occipito-parietal. Por último, la conectividad funcional de los pacientes se caracterizó por cambios específicos de larga y corta distancia en bandas theta, alpha, beta y gamma.

Estudios basados en el impacto de lesiones cerebrales sobre los patrones de conectividad funcional han sido desarrollados para tratar de descifrar como el cerebro humano puede reorganizarse de tal manera que áreas, donde la conectividad ha sido perdida o disminuida por efecto de lesiones, no influyan en la pérdida de información y se pueda restituir la capacidad cerebral ante deficiencias del habla y la reducción de memoria. En [84], mediante estudios de MEG en estado de reposo, de dos grupos de personas: un grupo de personas sanas y un grupo de personas con lesiones cerebrales, calcularon parámetros de teoría de gráficas utilizando como medida de sincronización la coherencia wavelet, en bandas de frecuencias diferenciadas. En el caso de las personas con lesiones, se realizó un seguimiento en dos etapas: después de ocurrida la lesión y después de la rehabilitación. Se registró una pérdida de conectividad en la banda delta y theta y un incremento en la banda alfa y beta. Lo anterior tiene una correlación entre la reorganización y la recuperación cognitiva.

Otro hallazgo importante utilizando fMRI, se muestra en [9] en personas con lesiones cerebrales, dichos pacientes (23 adultos) y un grupo control (26 personas sanas) fueron instruidos para cambiar entre modos de coordinación (espacial y temporal) haciendo movimientos circulares con palancas durante la adquisición de fMRI. Sus resultados mostraron que el rendimiento de conmutación de los pacientes con lesiones es significativamente menor en comparación que el grupo control. Otro resultado es que comprueban que ambas redes cerebrales presentan características de pequeño-mundo, sin embargo, los pacientes mostraron un grado mayor de conectividad, lo anterior sugiere la interacción de sistemas adaptativos como sistemas de compensación ante lesiones.

En [86] se estudia la conectividad funcional en pacientes de ASD, centrándose en el método de verosimilitud de Sincronización en la banda delta. Los patrones de conectividad de pacientes con ASD y del grupo control eran distintos bajo parámetros de la teoría de gráficas, los sujetos con ASD carecían de conexiones de largo alcance con déficit 
en conexiones fronto-occipital, además de un aumento de conexiones de corto alcance en los electrodos lateral-frontal, tienen menor coeficiente agrupamiento y una longitud de camino mayor, lo que los aleja de las características de una red de pequeño-mundo, teniendo una mayor modularidad.

En [87] proponen la segmentación de EEG basado en la dinámica temporal de la función de densidad del espectro cruzado de los componentes independientes, utilizando el método de información mutua para calcular la dependencia estadística entre dos canales de EEG, además de calcular el coeficiente de agrupamiento $(\mathrm{C})$ y la longitud de ruta más corta (L). Como resultado en pacientes de Parkinson, sugieren que dichos sujetos son incapaces de sincronizar diferentes áreas del cerebro mientras realizan tareas simultáneas a comparación de tareas individuales, pero intentan relacionar grupos dispares para mantener el rendimiento.

En casos de epilepsia parcial, los lóbulos temporal y frontal pueden estar involucrados en la aparición de convulsiones [95]. El trabajo presentado por Wu y Li [88], se basa en torno a una pregunta ¿las propiedades de una red de pequeño-mundo se mantienen durante un episodio epiléptico? Mediante un análisis biespectral calcularon la interdependencia de dos registros de EEG, acoplamiento de fase, mediante una umbralización y con solo 6 canales de EEG en 5 bandas de frecuencia, obtuvieron una gráfica con 30 nodos y un grado de nodo de 4 a 7 . Los resultados mostraron que el coeficiente de agrupamiento es alto, como en las redes regulares, pero con una longitud de camino mucho menor, es decir, si el grado de los nodos esta entre 4-5 y 6-7 las propiedades de pequeño mundo aparecen en una crisis epiléptica. En [78] estudian el ambiente de un cerebro epiléptico por medio de tres modelos de gráficas, a través de los cambios dinámicos de parámetros de redes complejas, de un grupo de cuatro pacientes con epilepsia del lóbulo frontal (médicamente intratables) tomaron registros de EEG intracraneal entre 3 y doce días seguidos, la medida de conectividad utilizada fue exponentes de Lyapunov. La gráfica está conectada en su totalidad durante el estado interictal (ataque) y se desconecta inmediatamente después del ataque (durante el estado postictal), por último, el nodo con el máximo grado de conectividad corresponde al foco epileptogénico [78].

En [90] se estudia los cambios estructurales de la conectividad funcional del cerebro de pacientes con esquizofrenia comparando con sujetos sanos, con registros de EEG y función de coherencia, estiman las redes funcionales las cuales analizan con la teoría de gráficas. Los resultados que muestran, utilizando la densidad de red como parámetro de comparación, revelan que la estructura de los pacientes de esquizofrenia sufre alteraciones durante tareas de memoria, aumentó el número de conexiones (en estado de reposo) con respecto al grupo control en la banda alfa1 (11-13 Hz). También encontraron un mecanismo de compensación en los pacientes de esquizofrenia durante tareas de memoria 
donde el grado de nodo mostró una asimetría frontal con una activación del lóbulo frontal (alto número de conexiones) en la banda de frecuencia alpha2.

En [91] dos situaciones son consideradas, 1) situación control en reposo y 2) situación de activación durante tareas de memoria. El objetivo del trabajo es encontrar evidencia que soporte dicho aseveración mediante el análisis de la conectividad funcional, en redes complejas, usando medidas y visualización derivado de la teoría de gráficas. El experimento se conformó de registros de EEG de 20 pacientes de esquizofrenia y 20 sujetos sanos (grupo control), tomados en un cuarto con sonido y luz atenuados y sentados en una silla reclinable. Para obtener las medidas de redes complejas, coeficiente de agrupamiento, distancia mínima característica y grado promedio, promediaron dichos parámetros en un umbral entre 0.75 y 0.85 con pasos de 0.005 , este promedio da como resultado una diferencia en banda gamma de conectividad, en regiones frontales, fronto-central y temporal, es decir, en pacientes de esquizofrenia (comparados con el grupo control) disminuyen las conexiones entre electrodos de dichas regiones.

En [92] se estudia la aparición de agrupamientos funcionales que se relacionan con la actividad espontánea del cerebro durante el sueño. Para caracterizar la conectividad funcional utilizan dos métodos: la verosimilitud de sincronización y la Interdependencia No-lineal, adicionando el análisis de redes complejas, sugieren un aislamiento entre zonas corticales anterior y posterior en la fase Rem.

Otro caso de aplicación de las redes complejas es en el estudio del desarrollo del cerebro, a partir de diversos estudios se han reportado cambios en el volumen cerebral y en áreas específicas ante el crecimiento de las personas. En [93] se analiza la conectividad funcional para caracterizar la organización de las redes de niños y jóvenes adultos mediante fMRI, comparan varias parámetros de las redes complejas como distancia mínima, coeficiente de agrupamiento y conectividad regional. El cerebro de los niños y jóvenes adultos tienen similitudes a nivel global con las redes de pequeño-mundo pero difieren significativamente en la organización jerárquica y conectividad interregional.

\subsubsection{Otras técnicas de evaluación de conectividad}

La alteración de la conectividad funcional del cerebro se empezó a estudiar bajo fMRI, sin embargo, adolece de una relativa pobre resolución temporal. El uso de fMRI, en estado de reposo muestra redes de conectividad predeterminadas, es decir, regiones que tienen patrones temporales comunes de actividad hemodinámica y cuya estructura se modifica ante diferentes situaciones o tareas. Dichas redes de conectividad son estudiadas a través de la correlación, de la actividad hemodinámica, entre diferentes regiones del cerebro. Patrones análogos se estudian en registros de EEG en correlación de amplitudes, voltaje, 
medido en diferentes localizaciones del cuero cabelludo, a frecuencias específicas. Con el objetivo de investigar y entender como es la distribución de las regiones del cerebro que están conectadas para el intercambio de información, se estudia la relación que guardan un par de canales de EEG (analizando todos los posibles pares de canales de EEG).

A pesar de que se han desarrollado numerosas técnicas para cuantificar la conectividad entre canales de EEG, cada una de ellas tiene ventajas y desventajas, sin embargo se coincide en la literatura acerca de los efectos del nodo de referencia común, conducción por volumen y transformaciones de referencias sobre la cuantificación de la coherencia en bandas. 


\section{Capítulo 3}

\section{Propuesta de Trabajo}

\subsection{Justificación}

\section{¿Por qué usar la teoría de gráficas para el estudio de la conectividad fun- cional cerebral?}

Tratar de entender un sistema complejo requiere estudiar su estructura, ambiente y evolución, por lo tanto no sólo se requiere conocer los elementos primarios, sino también cómo esos elementos interactúan entre sí, bajo qué condiciones se dan dichas interacciones originando patrones dinámicos de conectividad. Establecer esos patrones de conectividad se puede realizar mediante la interacción de dos simples componentes: nodos y enlaces. Con esta abstracción se pueden generar redes complejas de conectividad y a su vez estudiar su comportamiento en función de los cambios de la dinámica cerebral ante alguna tarea especifica o padecimiento.

Para analizar la conectividad funcional cerebral por medio de parámetros de las redes complejas se requiere de una herramienta computacional, que facilite la obtención de resultados y su posterior discusión para usos clínicos. No se ha encontrado alguna herramienta que ayude a analizar la conectividad funcional cerebral con el paradigma de la teoría de gráficas, por lo tanto este trabajo se concibió bajo esa aportación principal.

\section{¿Paŕametros de gráficas binarias o de gráficas pesadas?}

Como se mencionó en la sección 2.6.1 existen una gran cantidad de parámetros de redes complejas, con versiones para gráficas binarias y pesadas, por lo tanto la elección de los parámetros es importante ya que dan información acerca del comportamiento dinámico del cerebro. Usar parámetros de gráficas binarias en gráficas pesadas supone un proceso de umbralización, pero usar un único valor de umbral puede influir los resultados, 
ya que diferentes patrones de conectividad se generan a diferentes valores de umbral, además en la literatura no existe un método de elección de umbral óptimo. Ante esta situación, utilizaremos parámetros de redes binarias en redes pesadas pero a diferencia de la literatura, no utilizaremos un sólo valor de umbral, es decir, como segunda aportación proponemos realizar un barrido de $m$ umbrales y obtener para cada valor de umbral la gráfica binaria correspondiente, a su vez para cada gráfica calcular las medidas de gráficas. Lo anterior con el objetivo de observar el comportamiento dinámico de los parámetros de redes complejas, a partir de diferentes valores de umbral de conectividad. Esto da la posibilidad de observar bajo qué valores de conectividad se cumplen las condiciones del modelo de una red de mundo-pequeño.

\section{¿Por qué el modelo de mundo-pequeño?}

Esta red ha sido asociada al comportamiento de la conectividad funcional cerebral en diversos trabajos a nivel cortical, la modificación del coeficiente de agrupamiento y distancia mínima característica da indicios de afectaciones o patologías en el cerebro, sin embargo, es importante aclarar lo anterior depende del valor de conectividad utilizado. Como tercera aportación este trabajo no solo considera al coeficiente de agrupamiento y distancia mínima característica, como parámetros a obtener, sino se complementan con el grado de nodo, grado promedio, eficiencia y densidad.

\section{¿Qué medidas de conectividad usar?}

Como se vió en la sección 2.5 se han desarrollado una gran cantidad de medidas de conectividad entre dos señales, de acuerdo a las características lineales o no lineales que pueda capturar así como su dirección en el flujo de la conectividad. Ante ello se propone usar medidas lineales y no lineales y a su vez direccionales y no direccionales. Se propone utilizar las siguientes medidas:

- Coherencia. Medida ampliamente utilizada, la cual permite establecer la conectividad en función de los espectros de potencia sin dirección de la relación entre dos señales.

- Coherencia wavelet. Alternativa a la coherencia que logra la cuantificación de la conectividad no solo en la frecuencia, sino también en el tiempo. No establece dirección de la relación.

- Entropía cruzada. Medida de la teoría de la información, no lineal y direccional que permite establecer una dirección del vinculo entre los nodos. 
Debido a que la herramienta planeada será para hacer estudios exploratorios, no hay una prueba clínica clara para evaluar los resultados que se obtendrán. Sin embargo, se buscará examinar la información a través de registros (obtenidos con anterioridad) de sujetos con padecimiento de Evento Vascular Cerebral (EVC), lo cual nos dará la oportunidad de establecer o no su utilidad práctica. Por lo tanto a partir de este trabajo, se espera:

- Encontrar evidencia de lo reportado en la literatura: que el modelo de red de pequeño-mundo caracteriza la conectividad funcional del cerebro, es decir, durante tareas específicas de actividad cerebral se conserven propiedades de coeficiente de agrupamiento alto y una longitud característica pequeña, como resultado de lo anterior los parámetros de eficiencia y densidad darían pauta a una interpretación de una distribución de información adecuada.

- Ante padecimientos cerebrales, es posible que las características de redes se alteren, es decir puedan reflejar una deficiencia en la conectividad entre regiones del cerebro o establezca una actividad excesiva al no tener las condiciones de transmisión y procesamiento de información adecuadas.

\subsection{Propuesta}

En este trabajo se desarrolla una herramienta computacional que realice los cálculos necesarios para el estudio de la conectividad funcional del cerebro, a partir de registros de EEG, mediante medidas de la teoría de gráficas. Se busca explorar el estudio de la conectividad con el enfoque de redes complejas, si bien la revisión de literatura dio una serie de trabajos buscando información, biomarcadores o patrones y estructuras de conectividad durante tareas específicos o padecimientos, no se ha encontrado una herramienta que explícitamente abarque ambos análisis y pueda brindar un análisis complementario para encontrar un significado clínico útil.

\subsection{Objetivo Principal}

Desarrollar una herramienta computacional que permita explorar la conectividad funcional del cerebro mediante medidas de la teoría de gráficas, en redes derivadas del análisis de conectividad funcional del EEG. 


\subsection{Objetivos Específicos}

Para realizar la herramienta computacional propuesta se proponen cumplir los siguientes objetivos específicos:

- Acceso a registros de EEG obteniendo información acerca de la adquisición de las señales de EEG.

- Procesar las señales con el fin de eliminar artefactos de EEG para evitar obtener valores inflados de conectividad entre canales de EEG.

- Obtener la conectividad entre canales de EEG para tres medidas de interdependencia: coherencia, coherencia wavelet y entropía cruzada.

- Visualizar los cambios de conectividad cerebral en el tiempo, a través de imágenes y vídeo.

- Cuantificar parámetros de caracterización de redes complejas: grado de nodo, grado promedio, densidad, eficiencia, coeficiente de agrupamiento y longitud característica.

- Visualizar de la dinámica de los parámetros de redes complejas en función del tiempo y de la intensidad de la conectividad entre canales de EEG.

\subsection{Descripción del trabajo}

La herramienta computacional se desarrolló en Octave. A continuación se mencionan las características de la herramienta computacional propuesta:

- Acepta cualquier número de electrodos configurados bajo el Sistema Internacional 10-20, es decir, la herramienta es capaz de adaptarse al número de electrodos de cada registro de EEG. Puede incluso reconocer más de 70 canales de EEG bajo la configuración extendida del sistema 10-20.

- Cada función desarrollada contiene la descripción detallada de su objetivo principal, su funcionamiento, parámetros de entrada y salida así como consejos para la modificación por el usuario para su personalización.

- Contiene funciones para la remoción de artefactos mediante ICA, además de incluir técnicas de transformación de referencia: CAR, Bipolar y promedio de A1 y A2. 
- Da diversas opciones de visualización conforme a la información generada por la herramienta:

- Imágenes y video (a partir de las imágenes) obtenidas para observar la dinámica de la conectividad entre electrodos, para la medida de conectividad elegida, de todo el tiempo duración del registro o un segmento especifico. Esta visualización se divide en representaciones:

- Se utilizan líneas para establecer la conectividad en base al valor de la interdependencia de los canales [0-1], está pensada para utilizarse con medidas no direccionales, por lo tanto no se establece la dirección o flujo de la sincronización.

- Dentro de cada electrodo se muestran todos los electrodos del registro estableciendo la relación de conectividad, así puede observarse el flujo de información que se obtiene de un nodo para con los demás. Esta representación se utiliza para medidas direccionales de conectividad.

- Imágenes del comportamiento dinámico para cada medida de redes complejas utilizadas. Se puede observar la totalidad del tiempo analizado o un segmento de total interés.

- Para obtener las matrices de adyacencia utilizadas para obtener las medidas de gráficas, no se utiliza un valor de umbral específico, en lugar de ello se realiza un barrido con $m$ valores de umbral para obtener un panorama de cómo cambian las distintas medidas de gráficas, en función del valor de la conectividad, es decir, se tratan de observar la dinámica propia de los parámetros de la red y a su vez la dinámica de la conectividad cerebral en función de las diversas medidas de redes. 


\section{Capítulo 4}

\section{Metodología}

Para obtener los parámetros de red que caractericen el comportamiento de la conectividad funcional cerebral, se diseñó una metodología que consiste en seis etapas (figura 4.1), que se detallan en las secciones siguientes.

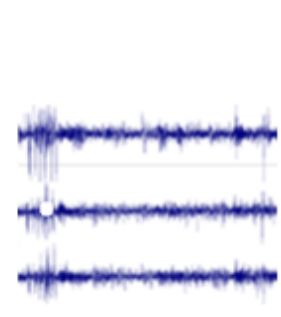

Registros de EEG

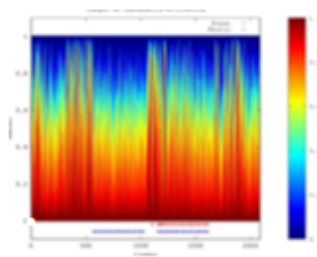

Visualización de parámetros de redes
Medidas de conectividad

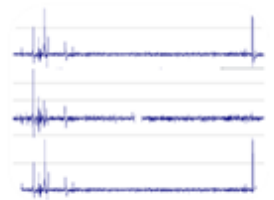

Procesamiento de señales
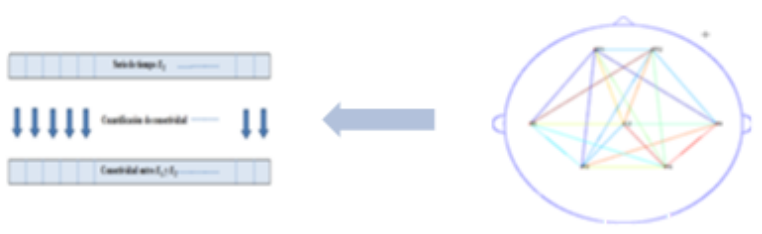

Parámetros de redes de gráficas de conectividad

FigurA 4.1: Etapas de la metodología propuesta. 


\subsection{Registros Electroencefalográficos}

Los registros utilizados para realizar pruebas de la herramienta computacional, se obtuvieron con la colaboración del Dr. H. Brust del Laboratorio de Electroencefalografía de la Dirección de Investigación del Instituto Nacional de Rehabilitación (INR). Son de tipo monopolar cumpliendo el Sistema Internacional 10-20 para la colocación de los electrodos en arreglo lateral. Se utilizó filtrado analógico, al momento de la adquisición, en banda de $0.5-40 \mathrm{~Hz}$ y un filtro notch a $60 \mathrm{~Hz}$ para eliminar artefactos provocados por la línea de alimentación, adicionalmente la frecuencia de muestro en todos los casos fue de $256 \mathrm{mps} /$ canal, el electrodo de referencia fue colocado en el hueso mastoide.

Los sujetos se colocaron en posición supina, con ojos abiertos u ojos cerrados durante todo el tiempo de adquisición de las señales de EEG. El protocolo está orientado a observar la respuesta del Sistema Nervioso Central (SNC) y del Sistema Nervioso Autónomo (SNA) en sujetos de diversas patologías, en particular, para este trabajo, sujetos con Evento Vascular Cerebral (EVC) y en sujetos sanos (grupo control) (ver figura 4.2). Para evaluar la respuesta del SNC y SNA se tienen cuatro etapas de estudio [96]:

- Estado basal, con ojos abiertos y cerrados durante un periodo de 2 minutos.

- Fotoestimulación (5Hz, 2 segundos), mediante emisión de un haz de luz blanca sobre el sujeto con los ojos cerrados, esta fotoestimulación se realiza con 20 repeticiones.

- Asociación, se pide al sujeto que al percibir una fotoestimulación apriete un botón, realizándose con 20 repeticiones.

- Hiperventilación (3 minutos) manteniendo la respiración profunda controlada.

Para referir los eventos de estimulación y respuesta en las gráficas de este trabajo, cada fotoestimulación se indica con marcas circulares azules y la etapa de asociación se indica con cruces rojas, cuando se presiona el botón, como se puede observar en la parte inferior de la figura 4.2 .

\subsection{Procesamiento de señales}

Esta etapa incluye el acondicionamiento de las señales cerebrales, la remoción de artefactos así como técnicas de re-referenciación, sumamente importante ya que la cuantificación de las medidas de conectividad sin este procesamiento resultaría en valores artificiales de conectividad como se discutió en la sección 2.2. Después es necesario realizar filtrado en bandas de frecuencias para hacer mediciones diferenciadas en banda. 


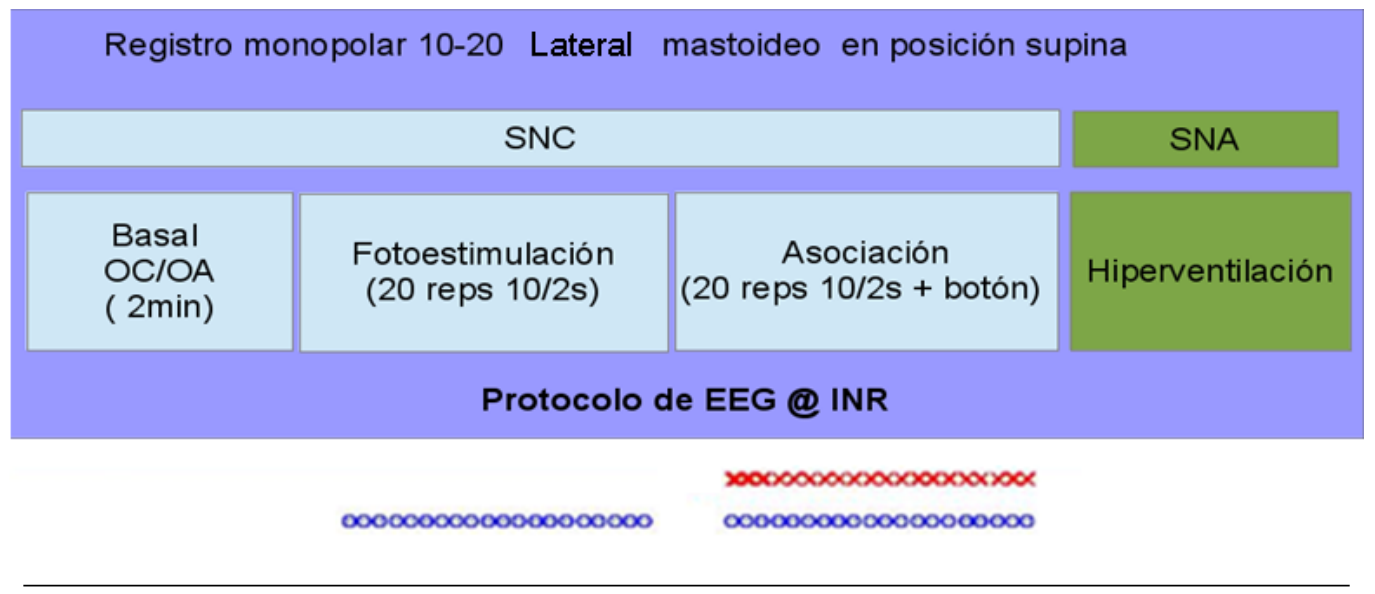

Figura 4.2: Protocolo de adquisición de registros de EEG del INR.

\subsubsection{Remoción de Artefactos}

El objetivo del Análisis de Componentes Independientes (ICA) es encontrar una representación lineal de datos no gaussianos tales que sus componentes sean estadísticamente independientes. En la sección 2.2 se expuso el modelo ICA, que describe cómo los datos medidos son generados por un proceso desconocido de mezclado lineal de componentes no observados $s_{j}$. Se pueden estimar $A$ (pesos de contribución de cada componente) y $s$ (componentes). Una vez estimada $A$, se calcula su inversa $W$ obteniendo los componentes mediante:

$$
S=W x
$$

Para realizar ICA se utiliza el algoritmo FastICA que tiene considerables ventajas:

- No está basado en gradientes, por lo que no se elige un parámetro de paso.

- La convergencia es cúbica o al menos cuadrática. Esto diferencia a FastICA de otros algoritmos basados en descenso por gradiente estocástico.

- Encuentra directamente los componentes independientes de cualquier distribución no gaussiana.

- Los componentes independientes pueden ser estimados uno a uno, siendo útil para la exploración de datos y disminuir la carga computacional, para estimar solo algunos componentes independientes.

Junto con FastICA se utiliza la prueba estadística de Shapiro-Wilk [97] para valorar la gaussianidad de los componentes estimados, de tal manera que se parte el registro de 
EEG en segmentos de longitud $m$ y se calcula la prueba estadística para cada uno de estos segmentos, a continuación se compara el valor de la prueba de Shapiro-Wilk de cada segmento con un umbral seleccionado, aquellos segmentos con valores mayores al umbral se eliminan mediante ventanas con cambios suaves en los extremos para evitar discontinuidades, de esta manera se reconstruye el EEG sin segmentos que contengan artefactos. De esta manera se están removiendo artefactos musculares y oculares sin recortar segmentos de tiempo del registro, es decir, se reconstruyen los segmentos (que presentaron artefactos) en segmentos sin artefactos, por lo tanto no se afecta la longitud del registro de EEG, pudiendo analizar el registro en toda su duración. En la figura 4.3 se pueden observar dos señales: con artefactos (azul) y después de remover los artefactos (verde), donde se puede apreciar la eliminación de artefacto ocular y muscular manteniendo la información del EEG. Cabe aclarar que esta técnica de remoción de artefactos no desarrolló como parte de este trabajo, sino que fue adaptada del programa INR-UAMI de análisis cuantitativo de EEG.

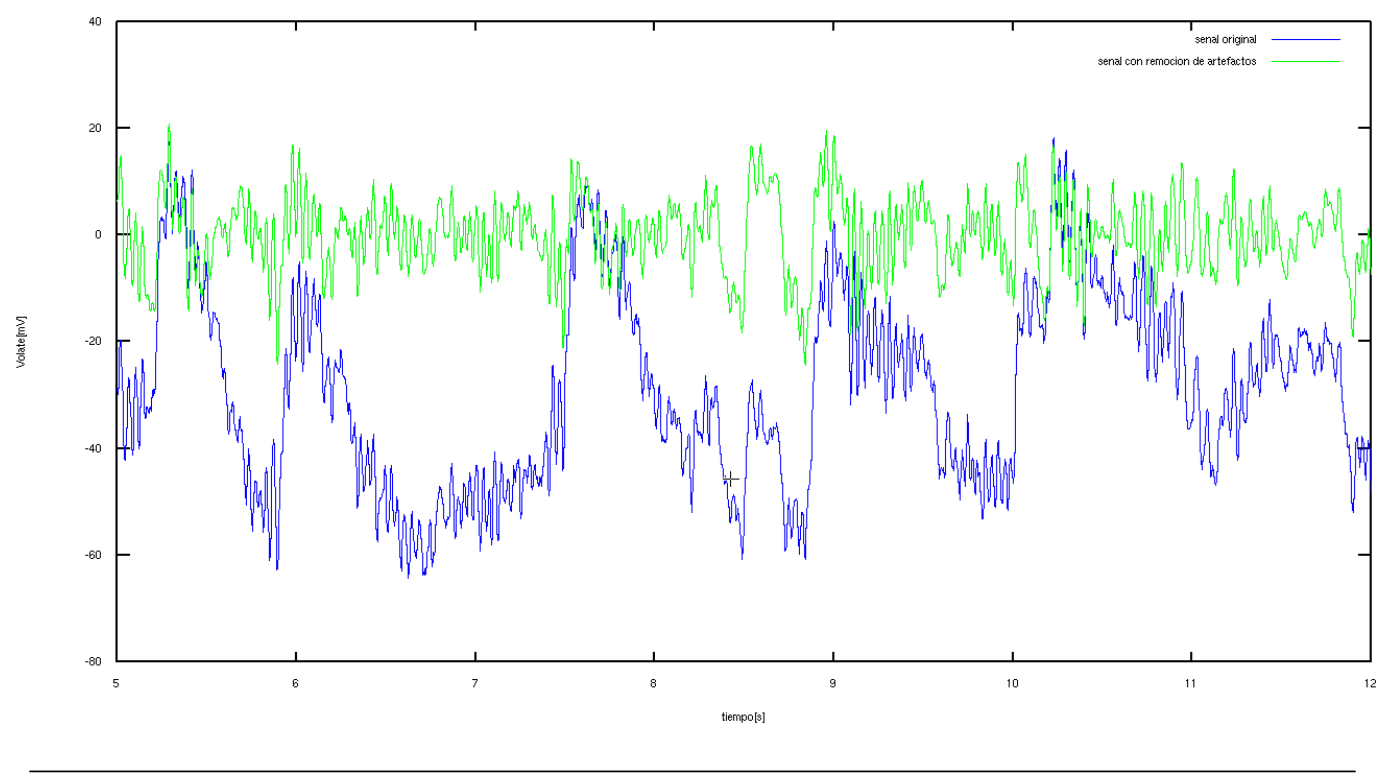

FigurA 4.3: Ejemplo de remoción de artefactos en el canal F3.

\subsubsection{Re-referenciación}

Utilizar un electrodo como referencia común al registrar la actividad EEG puede dar valores inflados de conectividad como se mencionó en la sección 2.3. Debido a lo anterior, en este trabajo se implementan tres técnicas de re-referencia: CAR, promediado de electrodos A1 y A2 y por último un arreglo bipolar lateral los cuales se describen a continuación. 


\subsubsection{CAR}

La implementación de CAR corresponde a restar el promedio de todas las señales de los electrodos en cada instante de tiempo (ecuación 4.2). Este promedio es un estimado de la actividad del electrodo de referencia que afecta a todos los electrodos del registro. Así al eliminar dicha estimación de la actividad de la referencia, se consiguen medidas de conectividad sin valores artificiales.

$$
\begin{aligned}
C A R & =\left(E_{k}-\operatorname{Ref}\right)-\left(\frac{\left(E_{1}-\operatorname{Ref}\right)+\left(E_{2}-\operatorname{Ref}\right)+\ldots+\left(E_{n}-\operatorname{Ref}\right)}{n}\right) \\
& =\left(E_{k}-\operatorname{Ref}\right)-\left(\operatorname{Ref}-\frac{\left.\left[E_{1}+E_{2}+\ldots+E_{n}\right]\right)}{n}\right) \\
& =E_{k}-\left(\frac{\left.\left[E_{1}+E_{2}+\ldots+E_{n}\right]\right)}{n}\right)
\end{aligned}
$$

donde $E_{k}$ es el k-ésimo electrodo al que se aplica CAR, $n$ el número de electrodos del registro y Ref la actividad del electrodo de referencia. Hay que tener en cuenta que mientras más cantidad de electrodos estén presentes en los registros el resultado de CAR mejora, por lo cual es dependiente del número de electrodos del EEG.

\subsubsection{Promedio de A1 y A2}

Otra técnica implementada es restar el promedio de los electrodos ubicados en los lóbulos de las orejas (A1 y A2) con el objetivo de que la lateralización de la actividad entre los hemisferios no afecte la cuantificación de la conectividad entre pares de electrodos. Para implementar dicha técnica se realizó lo siguiente:

- Sumar las señales A1 y A2:

$$
\left(A_{1}-R e f\right)+\left(A_{2}-R e f\right)=A_{1}+A 2-2 R e f
$$

- Dividir entre dos dicha suma:

$$
\frac{A_{1}+A_{2}}{2}-\frac{2 \operatorname{Ref}}{2}=\frac{A_{1}+A_{2}}{2}-\operatorname{Ref}
$$

- Restar el resultado anterior a cada serie de tiempo, p.e:

$$
\left(F_{p 1}-R e f\right)-\left(\frac{A_{1}+A_{2}}{2}-R e f\right)=F_{p 1}-\frac{A_{1}+A_{2}}{2}
$$


- Generalizando el paso anterior:

$$
\left(E_{k}-R e f\right)-\left(\frac{A_{1}+A_{2}}{2}-R e f\right)=E_{k}-\frac{A_{1}+A_{2}}{2}
$$

\subsubsection{Arreglo bipolar}

El arreglo bipolar involucra la diferencia de potencial entre dos canales activos del EEG, al utilizar un registro monopolar se debe realizar una transformación para poder obtener un arreglo bipolar, para este trabajo se utilizó un arreglo lateral.

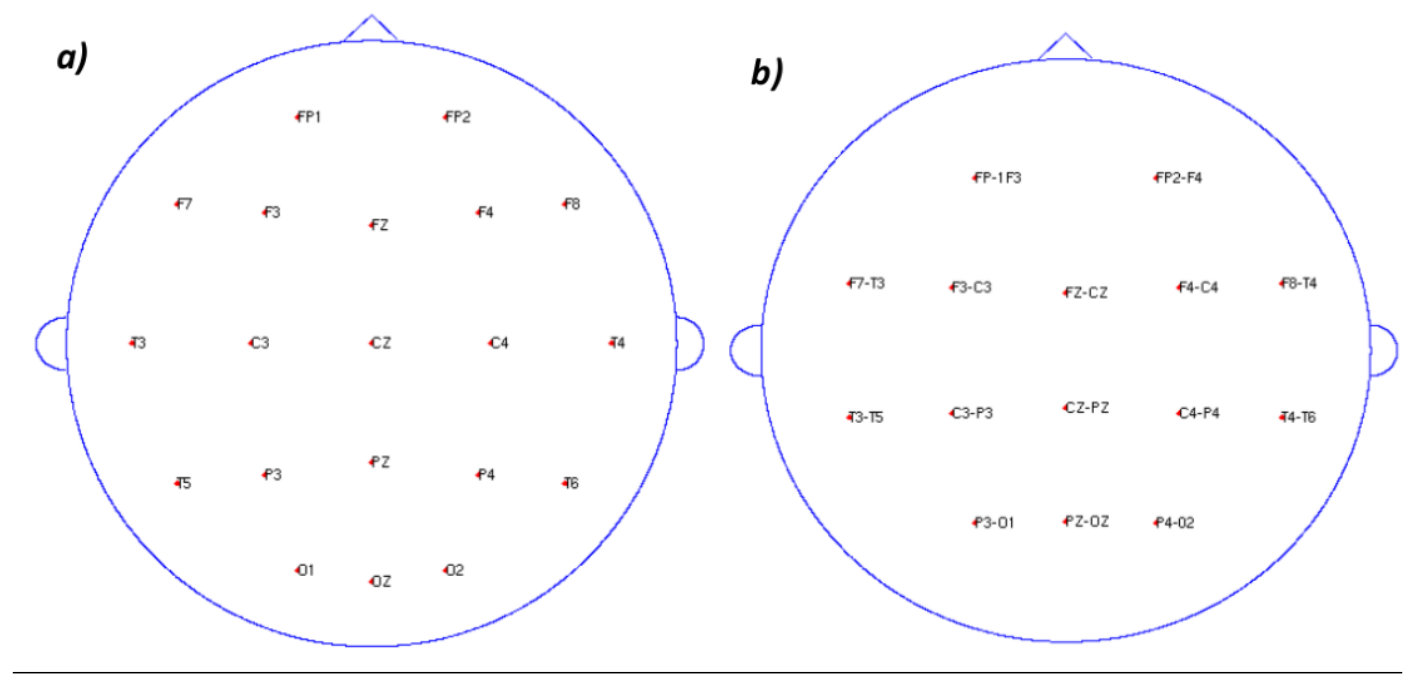

Figura 4.4: Diagramas de distribución de los electrodos: a) arreglo monopolar, b)arreglo bipolar.

El procedimiento para realizar la transformación bipolar se describe a continuación:

- Se eligen pares de canales en línea lateral, p.e. $F_{p 1}-F_{3}, P_{3}-O_{1}, F_{p 2}-F_{4}$.

- Se realiza la resta algebraica entre cada par de canales:

$$
\left(F_{p 1}-R e f\right)-\left(F_{3}-R e f\right)=F_{p 1}-F_{3}-R e f+R e f=F_{p 1}-F_{3}
$$

- Generalizando el paso anterior:

$$
\left(E_{k_{1}}-R e f\right)-\left(E_{k_{2}}-\operatorname{Ref}\right)=E_{k_{1}}-E_{k_{2}}-\operatorname{Ref}+\operatorname{Ref}=E_{k_{1}}-E_{k_{2}}
$$

Un ejemplo de arreglo bipolar resultante se puede apreciar en la figura 4.4, donde a partir de una arreglo monopolar de 20 canales se obtienen 15 canales bipolares. De esta manera se puede observar la conectividad funcional sin usar un electrodo como referencia común 
y poder comparar las tres técnicas de referencia en los resultados de la conectividad funcional.

\subsubsection{Filtrado digital}

Para poder analizar el comportamiento de los parámetros de redes complejas en diferentes bandas de frecuencia, se debe realizar filtrado en banda. En este trabajo se utilizan filtros de respuesta finita (FIR) ya que su respuesta es de fase lineal y no modifica la estructura de la fase, resultan ser siempre estables, no están basados en aproximaciones de los filtros analógicos, sin embargo requieren un grado considerablemente alto (número de coeficientes). La ecuación característica de un filtro FIR se muestra en la ecuación 4.9 , donde $N$ es el orden del filtro y $b_{k}$ son los coeficientes del filtro:

$$
y(n)=\sum_{k=0}^{N-1} b_{k} x(n-k)
$$

Para diseñar un filtro FIR de fase lineal se deben tener coeficientes simétricos $h(n)=$ $h(-n)$ con una longitud impar. Los filtros FIR con ventanas rectangulares provocan una respuesta en frecuencia inadecuada, por lo que se hace uso de ventanas que permiten mejorar las características del filtro en su respuesta en frecuencia. Existen una gran cantidad de ventanas como: Barlett, Von Hann, Hamming, Blackman y Káiser [98]. En este trabajo se utiliza la ventana Hamming (por omisión), también se puede elegir la ventana de Káiser.

El banco de filtros que se utilizan en este trabajo se diseñaron en base a las frecuencias a las cuales diversas regiones del cerebro se activan o inhiben ante diferentes actividades o tareas específicas (sección 2.1): delta $(0.5-4 H z)$, theta $(4-8 H z)$, alfa $(8-12 H z)$ y beta $(12-30 H z)$.

\subsection{Medidas de conectividad}

Después de acondicionar las señales de EEG se obtienen las medidas de conectividad, para establecer una relación funcional entre dos electrodos colocados en diferentes posiciones, dicho valor de relación funcional puede variar de acuerdo a la actividad mental que se realiza durante la obtención del registro de EEG (sección 2.4).

Las mediciones de interdependencia son obtenidas, mediante parejas de electrodos del registro de EEG a analizar. Estas mediciones son almacenadas en una matriz llamada de 
asociación o matriz de conexión, por lo tanto una matriz de asociación estará formada por $N(N-1)$ valores (siendo $N$ el número de nodos o electrodos), donde las conexiones entre el mismo nodo no son tomadas en cuenta, ya que tienen un valor máximo de interdependencia. Cabe destacar que las matrices de asociación obtenidas mediante las medidas de sincronización como coherencia y coherencia wavelet (medidas no direccionales), son idénticas por encima y debajo de la diagonal de la matriz, ante esto se utilizan solo los datos por encima de la diagonal, por lo tanto el máximo número de conexiones posibles se obtiene mediante la relación $\frac{N(N-1)}{2}$. Caso contrario, la entropía cruzada es una medida de conectividad direccional, es decir, no necesariamente son iguales los valores de conectividad en ambos sentidos, por lo cual las conexiones máximas posibles están dadas por $N(N-1)$.

Para obtener el valor de conectividad entre dos señales de EEG ( $E_{1}$ y $\left.E_{2}\right)$, se divide cada serie de tiempo en segmentos de un segundo (la duración de la ventana de tiempo es elección del usuario), para cada par de segmentos en el tiempo correspondiente se calcula el valor de la conectividad, se obtiene el valor de la conectividad en cada ventana de tiempo (figura 4.5). Este procedimiento se realiza para todos los pares de canales generando, por cada ventana de tiempo, una matriz de asociación. Por ejemplo, si se tienen 20 electrodos y un registro de 1000 segundos, se obtienen 1000 matrices de asociación de dimensiones $20 x 20$.

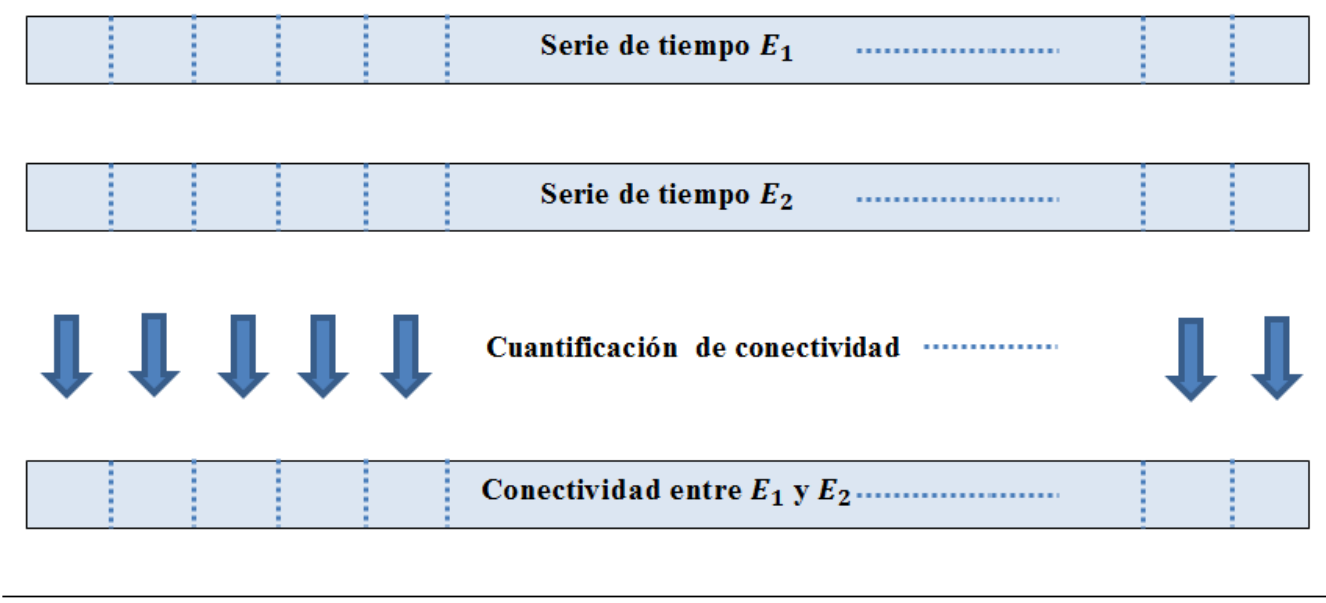

Figura 4.5: Esquema de cuantificación de conectividad entre dos series de tiempo.

\subsubsection{Coherencia}

La definición de coherencia de la ecuación 2.2 propone un valor de coherencia que sólo puede obtenerse para señales de duración infinita, en aplicaciones reales dos series de tiempo $x$ y $y$ son divididas en $N$ segmentos traslapados de longitud $L$ (método de Welch 
[36]). Cada segmento (j-ésimo) es multiplicado por una función ventana y para cada segmento ventaneado se obtiene la densidad del espectro de potencia $X_{j}(w)$ y $Y_{j}(w)$ :

$$
X_{j}(w)=\frac{1}{L U}\left|\sum_{j=1}^{L} x_{j}(n) w(n) e^{-\frac{j 2 \pi w n}{L}}\right|^{2}
$$

donde $U$ es el factor de normalización para la función de ventaneo utilizada $w(n)$

$$
U=\frac{1}{N} \sum_{n=0}^{L-1}|w(n)|^{2}
$$

El espectro de potencia obtenido por Welch es el promedio de los periodogramas obtenidos por la segmentación de la serie de tiempo original:

$$
\bar{S}(w)=\frac{1}{N} \sum_{j=0}^{N-1} X_{j}(w)
$$

ya obtenidos los espectros de potencia de las dos series de tiempo mediante la ecuación 4.12, se procede a obtener el coeficiente de espectro cruzado para cada uno de los segmentos (ecuación 4.13):

$$
c_{j}(w)=X_{j}(w) Y_{j}^{*}(w)
$$

con el promedio de estos coeficientes $c_{j}(w)$ se define la estimación de la densidad del espectro cruzado de los $N$ segmentos:

$$
S_{X Y}(w) \approx \bar{S}_{X Y}(w)=\frac{1}{N} \sum_{j=1}^{N} c_{j}(w)=\frac{1}{N} \sum_{j=1}^{N} X_{j}(w) Y_{j}^{*}(w)
$$

Mediante la ecuación 4.14 también es posible obtener los autoespectros de cada serie de tiempo (ecuaciones 4.15 y 4.16 ):

$$
\begin{aligned}
& \bar{S}_{X X}(w)=\frac{1}{N} \sum_{j=1}^{N} X_{j}(w) X_{j}^{*}(w) \\
& \bar{S}_{X X}(w)=\frac{1}{N} \sum_{j=1}^{N} Y_{j}(w) Y_{j}^{*}(w)
\end{aligned}
$$


Por último se estima el valor de la coherencia, a partir de las estimaciones de la densidad de espectro cruzado y autoespectros:

$$
\bar{\gamma}=\frac{\left\|\bar{S}_{X Y}(w)\right\|}{\left[\bar{S}_{X X}(w) \bar{S}_{Y Y}(w)\right]^{\frac{1}{2}}}
$$

dicha ecuación 4.17 se aplica en cada cada segmento de tiempo. La función de coherencia se calcula para todos los pares de canales posibles de los $N$ electrodos del registro, mediante la función pwelch.m incluida en Octave, que requiere de parámetros específicos como el tamaño de la ventana $w(n)$, dicha longitud se define como la potencia siguiente entera del logaritmo de base 2 de la longitud de la serie de tiempo, el traslape indica el porcentaje de traslape entre los segmentos para calcular la densidad del espectro de potencia, de manera predeterminada se usa un $50 \%$.

Para obtener la coherencia espectral como medida de conectividad entre dos series de tiempo, se usa el esquema general mostrado en la figura 4.5, a continuación se describe cómo se calcula la coherencia espectral. Dado un segmento de tiempo de dos señales, previamente acondicionadas (sección 4.2) se calcula la coherencia en todo el rango de frecuencias $\left[0, \frac{f s}{2}\right]$, por lo tanto se tiene un vector de valores de coherencia (un valor por cada valor en frecuencia), se procede a reducir a un sólo valor de coherencia, que represente la intensidad de la relación funcional en dicho segmento entre ambas series de tiempo. Para reducir un valor se implementan dos opciones: mediante la obtención del área bajo la curva normalizada y la mediana. De manera predeterminada se usa el área bajo la curva en la reducción, dando como resultado un sólo valor de coherencia para cada segmento de tiempo. Lo anterior se repite para todos los pares de electrodos, y como resultado se guardan dichos valores de conectividad entre los canales en una matriz de asociación.

\subsubsection{Coherencia Wavelet}

La transformada discreta wavelet es una representación compacta de los datos y particularmente usada para la reducción de ruido y compresión de información, mientras que la transformada continua es mejor para la extracción de características de la señal es por ello que es la principal herramienta para obtener la coherencia wavelet en este trabajo. Como se comentó en la sección 2.5.2, se requiere de una función wavelet madre, la cual producirá versiones escaladas y trasladadas necesarias para el análisis wavelet. La función wavelet más usada para medir la coherencia wavelet, es la llamada Morlet compleja:

$$
\psi_{o}(n)=\pi^{-\frac{1}{4}} e^{i w_{o} \eta} e^{-\frac{\eta^{2}}{2}}
$$


donde $w_{o}$ es la frecuencia no dimensional, con un valor de 6 se satisface la condición de tener media cero. El motivo de utilizar una función wavelet compleja es debido a que éstas logran capturar mayor información en ambientes oscilatorios. Ondas no ortogonales pueden ser usadas con la transformada wavelet continua, la cual se define, de una serie discreta $x_{n}$, como la convolución de $x_{n}$ con la wavelet escalada y trasladada:

$$
W_{n}(s)=\sqrt{\frac{\delta t}{s}} \sum_{m=0}^{N-1} x_{m} \psi^{*}\left[\frac{(m-n) \delta t}{s}\right]
$$

Al variar los parámetros de escala $(s)$ y traslación $(n)$, es posible obtener una representación que refleje información en tiempo y frecuencia a la vez, la ecuación 4.19 indica que se debe realizar $N$ convoluciones (para cada valor de escala $s$ ), necesitando una gran capacidad de cómputo y tiempo, ante ello existe una forma rápida de obtener la transformada wavelet continua, es decir, en la práctica se obtiene una versión eficiente por medio de la transformada de Fourier, en su versión discreta:

$$
\hat{X}_{k}=\frac{1}{N} \sum_{n=0}^{N-1} x_{n} e^{-\frac{2 \pi i k n}{N}}
$$

haciendo uso de una de las propiedades de Fourier, que permite realizar $N$ convoluciones simultáneamente en el espacio de Fourier, se realiza la transformada de Fourier de la wavelet $\psi(t / s) \rightarrow \psi(s w)$ para poder obtener $W_{n}(s)$ mediante la ecuación 4.21.

$$
W_{n}(s)=\sum_{k=0}^{N-1} \hat{X}_{k} \hat{\psi}^{*}\left(s w_{k}\right) e^{i w_{k} n \delta t}
$$

donde la frecuencia angular $w$ se define de la siguiente forma:

$$
w= \begin{cases}\frac{2 \pi k}{N \delta t} & k \leq \frac{N}{2} \\ \frac{2 \pi k}{-N \delta t} & k>\frac{N}{2}\end{cases}
$$

donde $k$ es el índice de frecuencia, de este modo al usar la ecuación 4.21 se reduce la necesidad de cómputo y tiempo de procesamiento.

Al utilizar una función wavelet compleja, la CWT es también compleja y puede dividirse en parte real $\Re\left\{W_{n}(s)\right\}$ y parte imaginaria $\Im\left\{W_{n}(s)\right\}$, en amplitud $\left|W_{n}(s)\right|$ y fase $\tan ^{-1}\left[\frac{\Re\left\{W_{n}(s)\right\}}{\Im\left\{W_{n}(s)\right\}}\right]$. Con estas características es posible definir el espectro de potencia wavelet como $\left|W_{n}(s)\right|^{2}$. Un paso muy importante para obtener la CWT es la elección de las escalas, para funciones no ortogonales se puede elegir de manera arbitraria, sin 
embargo, el algoritmo utilizado [99] sugiere un criterio: que sea una potencia entera de dos:

$$
\begin{gathered}
s_{j}=s_{o} 2^{j \delta_{j}}, j=0,1, \ldots, J \\
J=\delta_{j}^{-1} \log _{2}\left(\frac{N \delta_{t}}{s_{o}}\right)
\end{gathered}
$$

donde $s_{o}$ es la escala más pequeña y $s_{J}$ es la escala mayor. Los autores del algoritmo utilizado en este trabajo, Torrence [99] sugieren que la elección del parámetro $\delta$ depende de la resolución que se desea obtener de la función wavelet, el valor predeterminado es 0.5 ya que es adecuado para el muestreo del espectro con la wavelet Morlet. Para este trabajo se tienen valores predeterminados en base a las sugerencias mencionadas: $\delta_{j}$ tiene un valor de $0.5, \delta_{t}=\frac{1}{f s}, s_{o}=\frac{2}{f s}$. Para obtener la relación tiempo-frecuencia a partir de tiempo-escala se utiliza la relación de la escala wavelet y el periodo de Fourier $(\lambda)$, para la función Morlet, es $\lambda=1.0333 s$.

Para calcular el espectro de potencia cruzado wavelet (entre dos espectros wavelet) $W_{n}^{X}(s)$ y $W_{n}^{Y}(s)$ se utiliza:

$$
W_{n}^{X Y}(s)=W_{n}^{X}(s) W_{n}^{Y *}(s)
$$

donde $^{*}$ es el complejo conjugado, dando como resultado que $W_{n}^{X Y}(s)$ sea complejo. Para calcular la coherencia wavelet se usa la ecuación 4.26:

$$
\gamma(t, s)=\frac{\left|W_{n}^{X Y}(t, s)\right|^{2}}{W_{n}^{X}(s) W_{n}^{Y}(s)}
$$

La coherencia wavelet se obtiene mediante el procedimiento general mostrado en la figura 4.5 , por cada ventana de tiempo se calcula la coherencia wavelet, sin embargo, se obtiene una matriz de coherencia en representación tiempo-frecuencia, ante ello se decidió reducir la matriz de coherencia wavelet a un solo valor ¿Cómo realizar la reducción? Si bien en la literatura no existe una técnica comprobada, decidimos utilizar la siguiente forma:

- Por cada columna de la matriz de coherencia wavelet se obtuvo el área bajo la curva normalizada.

- Se obtuvo un vector de áreas para cada tiempo y se procedió a obtener de nuevo el área bajo la curva normalizada, el resultado fue un valor de coherencia wavelet por cada segmento de tiempo. 
Los pasos anteriores sugieren un problema, la pérdida de las características tiempofrecuencia de la técnica, ya que comprimir la información de la representación tiempofrecuencia a un sólo valor puede afectar la información de conectividad obtenida.

\subsubsection{Entropía Cruzada}

La entropía cruzada definida en la ecuación 2.9 puede tener dos variantes: una entropía cruzada temporal, es decir, actúa sobre las series de tiempo o su variante espectral, que actúa sobre los espectros de potencia de las series de tiempo, ambas variantes se implementan en este trabajo.

El procedimiento para cuantificar la conectividad entre los canales de EEG con la entropía cruzada temporal se observa en la figura 4.6 y la entropía cruzada espectral en la figura 4.7. Dados los segmentos de las series de tiempo (temporal) o de los espectros de potencia (espectral) se divide cada segmento en subsegmentos traslapados, con un $50 \%$ porcentaje de traslape, lo anterior se realiza debido a que las primeras pruebas (con ambas variantes) utilizando toda la longitud de cada segmento de tiempo, daban como resultado una alta conectividad en todos los casos, es decir, la variabilidad de la conectividad funcional en todas las bandas era prácticamente nula, ante esto se modificó la implementación de la entropía cruzada y se basó en la técnica de la estimación del espectro de potencia de Welch, es decir, usar segmentos traslapados, así para cada subsegmento se estimó la función de densidad y posteriormente se cuantificó la entropía de Kullback-Leibler para cada par de subsegmentos. Para reducir a un sólo valor la entropía cruzada (temporal y espectral) se obtuvo el promedio de todos los subsegmentos para obtener la estimación de la entropía cruzada para cada segmento. Esta implementación dió como resultado mayor información de la variabilidad de la conectividad funcional.

La estimación de la función de densidad se realiza mediante estimación por histograma (caso especial de kernel) y con kernel gaussiano. La estimación mediante histograma se obtiene por medio de la función hist.m (incluida en Octave) normalizando dicho histograma para obtener valores de frecuencia relativa y no absoluta, en otras palabras, la integral de la pdf sea igual a uno. La estimación por kernel gaussiano se implementa con el algoritmo kde.m [100], requiere principalmente de dos parámetros: la serie de tiempo y el ancho de banda de kernel, con un ancho de banda mayor se obtiene una mejor aproximación de la función de densidad, sin embargo puede producir valores de probabilidad muy cercanos a cero que pueden producir valores complejos al realizar la entropía de Kullback-Leibler, es por ello que se limitó dicho ancho de banda para la estimación por kernel gaussiano. 


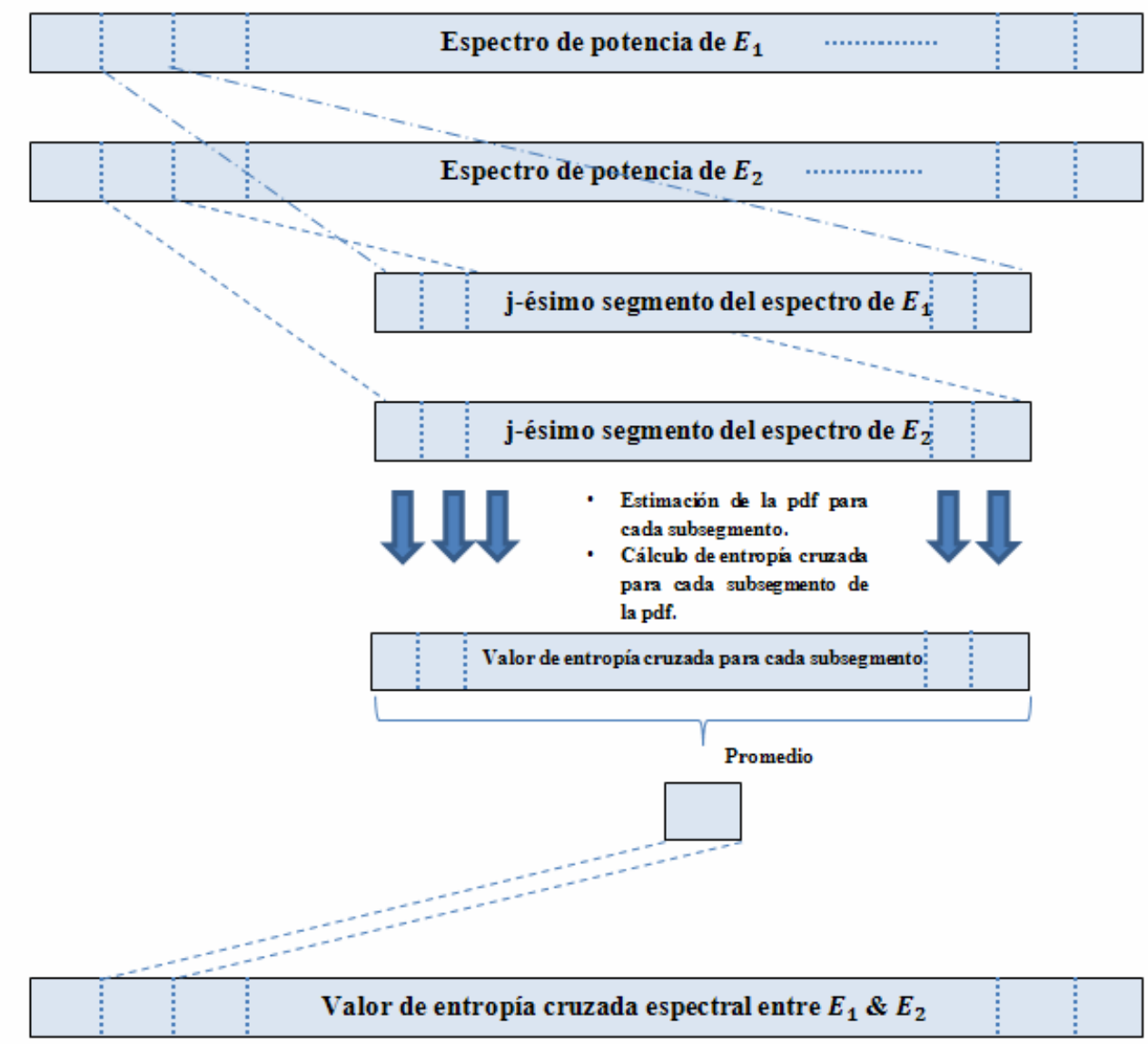

Figura 4.6: Esquema de cuantificación de la entropía cruzada espectral.

Dado que el valor mínimo de la entropía cruzada es 0 sí y solo sí ambas funciones de densidad son iguales, no existe un límite superior que indique el grado de diferencia, por lo cual es necesario normalizar todos los valores de entropía cruzada en todos los segmentos de tiempo, así se obtiene el valor máximo de las matrices de asociación y se dividen las matrices entre dicho valor máximo, con el paso anterior se limita a un rango de valores entre $[0,1]$. Sin embargo, el valor 1 indica la diferencia máxima posible entre las funciones de densidad de un par de electrodos y 0 indica la máxima similitud. Ante esto se modificó la ecuación 2.9 resultando la ecuación 4.27 .

$$
K(p, q)=1-\left(\sum_{x} p(x) \log \left(\frac{p(x)}{q(x)}\right)\right)
$$

\subsection{Visualización de gráficas de conectividad}

Obtenidas las matrices de asociación, es importante visualizar el comportamiento de la conectividad entre todos los electrodos, ya que nos da información de las áreas que están 


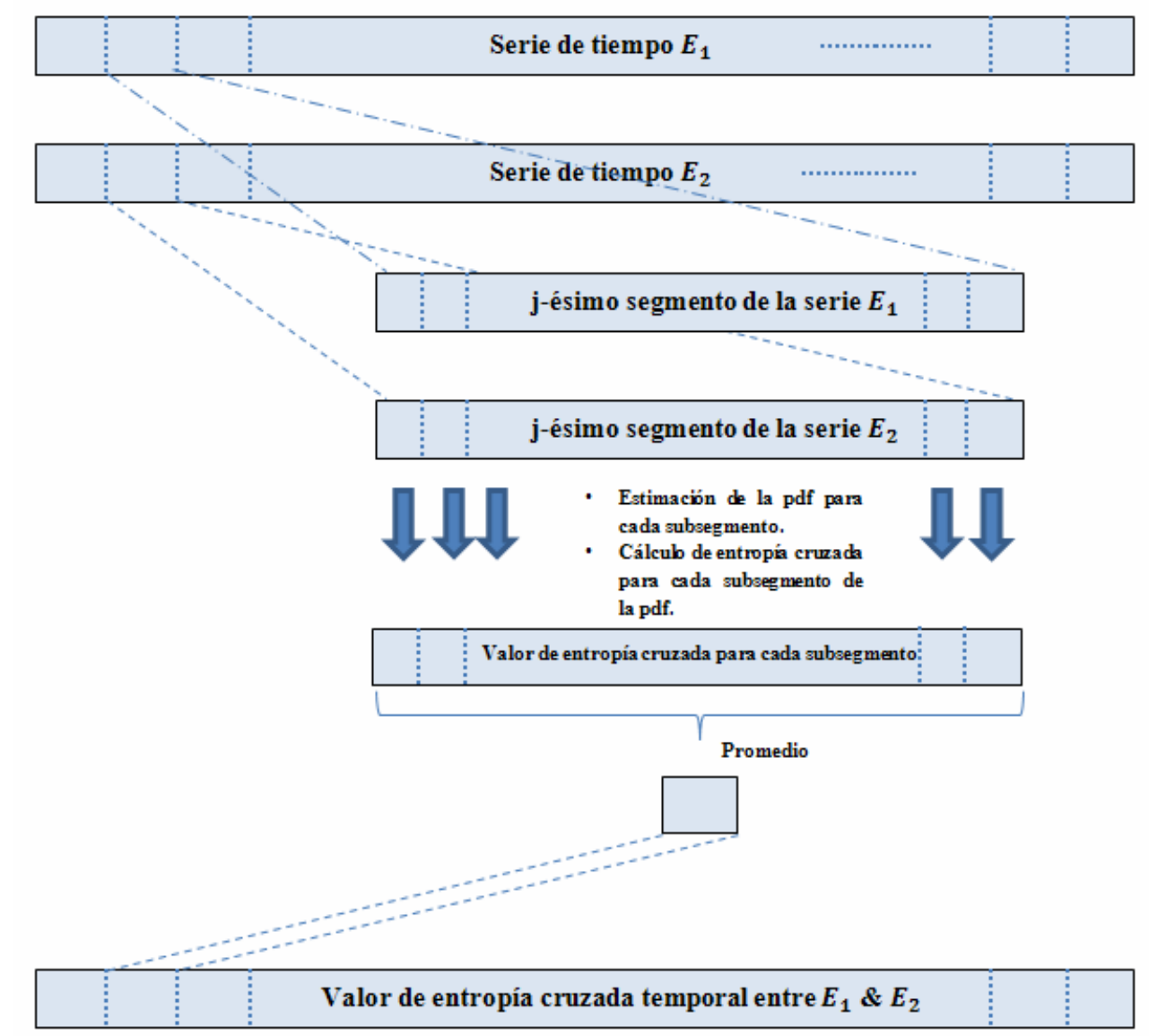

Figura 4.7: Esquema de cuantificación de la entropía cruzada temporal.

interactuando y cómo es el patrón de conectividad, es decir, reflejan relación funcional; por lo tanto, podemos observar la evolución de las relaciones funcionales en el tiempo. Para ello se decidió trabajar sobre dos representaciones que ayudan a visualizar dicho comportamiento.

La manera de representar gráficamente una matriz de asociación se conoce como gráfica de conectividad funcional (FCG) [92], donde cada electrodo corresponde a un nodo de la gráfica y una arista corresponde a un vínculo entre los electrodos, representados de forma binaria (conectados o no conectados) o por un peso, indicando la intensidad de su relación. En este trabajo, las medidas de conectividad tienen un intervalo de valores entre 0 y 1 , al graficar dichos valores se obtienen gráficas pesadas utilizando como peso de conexión alguna de las medidas de conectividad propuestas.

Se desarrollaron dos representaciones de las FCG. La primera muestra la conectividad entre dos electrodos mediante una línea coloreada, donde el color corresponde a un valor de intensidad de la conexión, es decir, se asocia un valor conectividad a un color de una paleta de colores. Se concibió para desplegar FCG no direccionales (coherencia y 
coherencia wavelet), es por ello que solo se indica la conexión con su valor mas no la dirección. En la figura 4.8 pueden observar los patrones de conectividad en tres FCG a diferentes tiempos.

La segunda representación está inspirada en la representación mostrada en [101] y se orientó para visualizar la conectividad mostrada en medidas direccionales como entropía cruzada temporal y espectral. Dentro del j-ésimo electrodo se grafican a escala los $N$ electrodos, con círculos coloreados para indicar la intensidad de la conectividad, entre el j-ésimo nodo y todos los démas (includo el auto-valor). Esta representación es útil debido a que las líneas de la primera representación serían confusas o insuficientes, ya que la medida de entropia cruzada presenta una dirección en la conectividad, por lo tanto existirían dos líneas de conexiones entre cada par de electrodos (no necesariamente con el mismo valor de conectividad), a su vez no sería posible interpretar la dirección de la conexión, además de presentar una gran cantidad de líneas $N(N-1)$ que evitaría que la imagen fuera comprendida de manera adecuada. En la figura 4.9 se puede observar el comportamiento de la conectividad funcional con gráficas direccionales para diferentes segmentos de tiempo.

\subsection{Parámetros de red}

Con las matrices de asociación para las medidas conectividad y pudiendo obtener las FCG que reflejen el comportamiento de la conectividad cerebral en el tiempo, se procedió a obtener los parámetros de redes para poder observar el comportamiento dinámico de los mismos. Para convertir cada matriz de asociación (pesada) a una matriz de adyacencia (binaria) de iguales dimensiones $(N x N)$, se utiliza un valor de umbral $u$ tal que $\epsilon[0,1]$. Al ser una matriz binaria (adyacencia) el valor 0 indica un ausencia de conexión y 1 indica un enlace entre dos nodos $i$ y $j$, al aplicar el valor de umbral $u$ a una matriz de asociación se obtiene una matriz de adyacencia, mediante la siguiente ecuación:

$$
A(i, j))= \begin{cases}1 & \text { si } w(i, j)>u \\ 0 & \text { en otro caso }\end{cases}
$$

donde $w(i, j)$ es el peso de conexión entre ambos nodos y $u$ el valor de umbral. Sin embargo, los parámetros obtenidos a partir de esta matriz de adyacencia, dependen del valor de umbralización utilizado, es decir, al utilizar otro valor diferente $u$ se puede obtener una matriz de adyacencia y por ende una gráfica de conectividad totalmente diferente, es decir, una distribución de conexiones diferentes. Por ejemplo, en la figura 4.10 se observan cuatro gráficas de conectividad resultantes al aplicar 4 distintos valores 
Grafica de conectividad en el segmento de tiempo: $1.000000-2.000000$ segundos

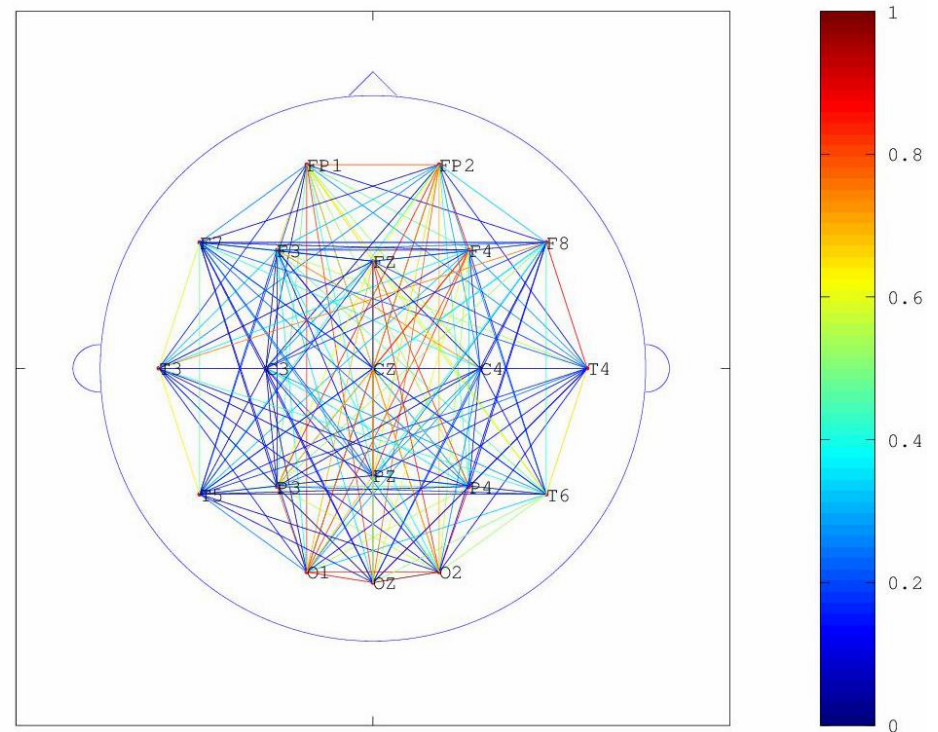

Grafica de conectividad en el segmento de tiempo: $3.000000-4.000000$ segundos

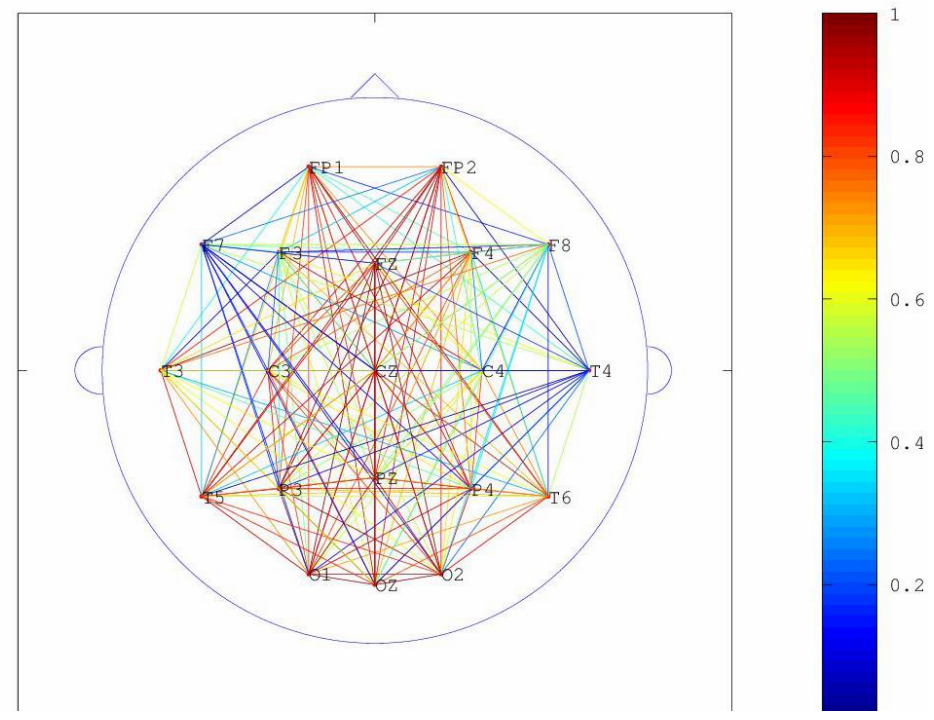

Grafica de conectividad en el segmento de tiempo: $28.000000-29.000000$ segundos

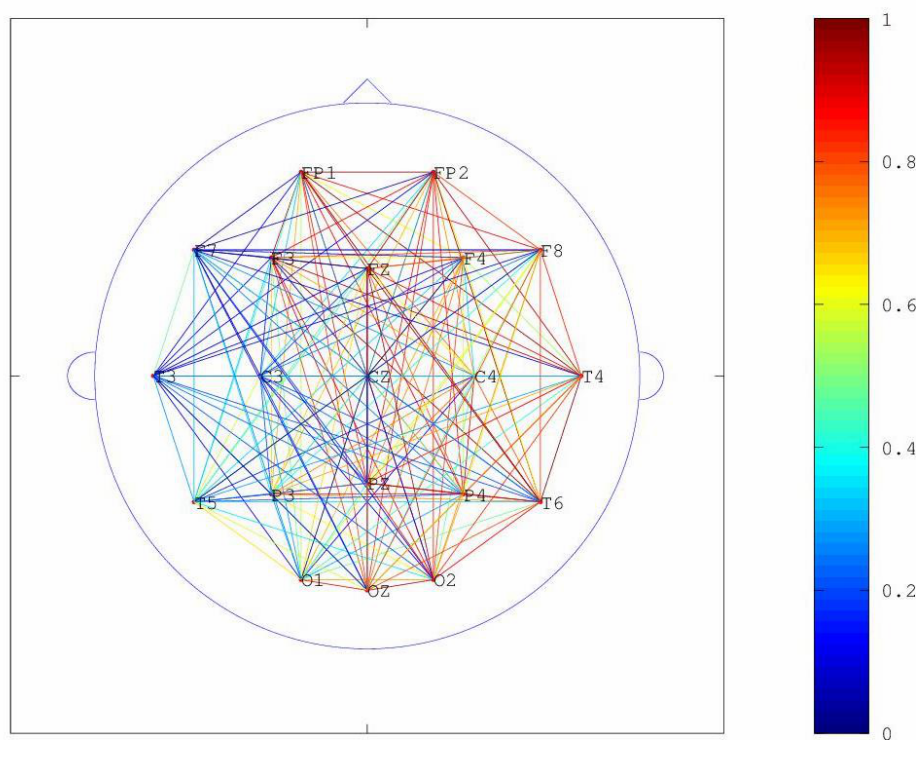

Figura 4.8: Ejemplos de gráficas de conectividad funcional cerebral no direccionales. 
Grafica de conectividad en el segmento de tiempo: $1.000000-2.000000$ segundos

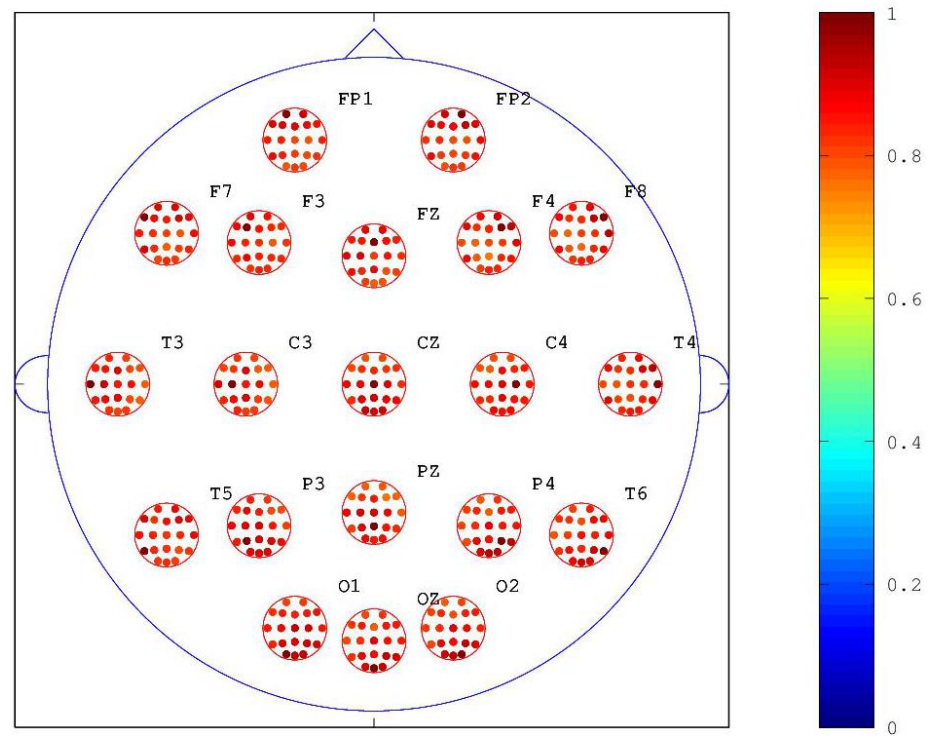

Grafica de conectividad en el segmento de tiempo: $3.000000-4.000000$ segundos

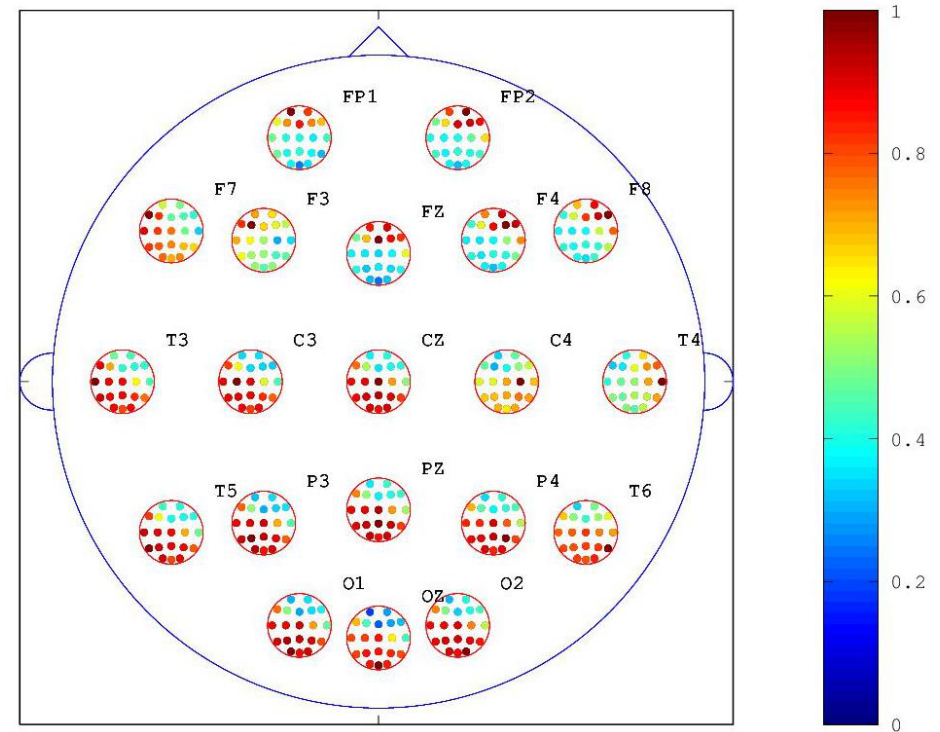

Grafica de conectividad en el segmento de tiempo: $28.000000-29.000000$ segundos

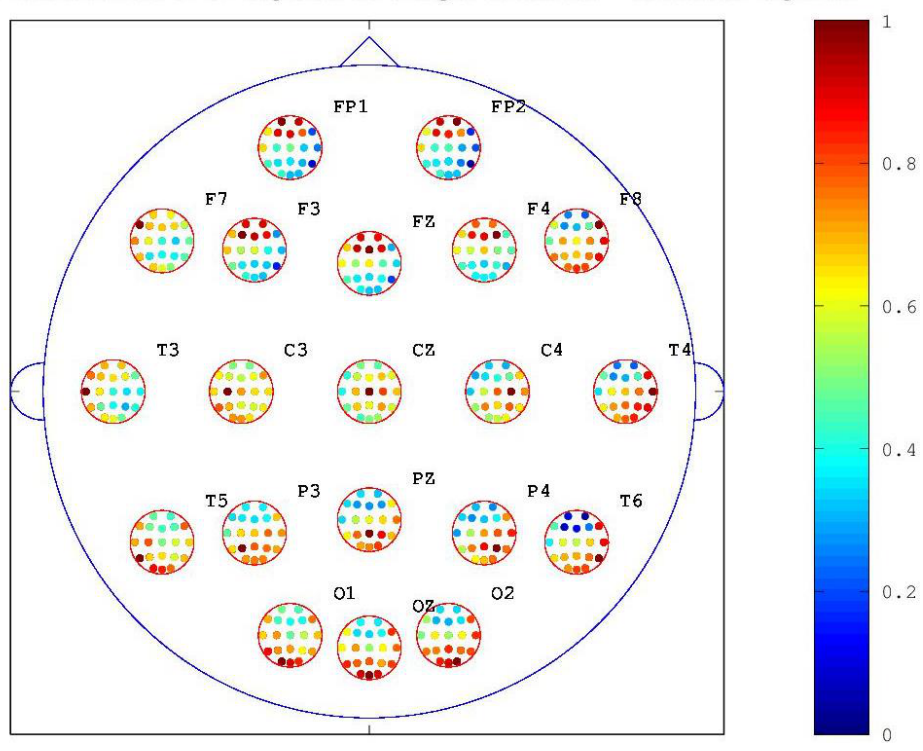

Figura 4.9: Gráficas de conectividad direccionales. Dentro de cada electrodo se grafican a escala los $N$ electrodos, asociando un color para indicar la intensidad de la conectividad, entre el electrodo y los démas (includo el auto-valor). 
de umbral a la gráfica superior de la figura 4.8; las gráficas de conectividad muestran diferentes patrones de conectividad: entre mayor sea el umbral menor cantidad de conexiones, por lo tanto el comportamiento de sus parámetros varía en función del umbral. Es por ello que se decidió obtener una matriz de adyacencia por cada valor de umbral entre 0 y 1 con incrementos de 0.01 .

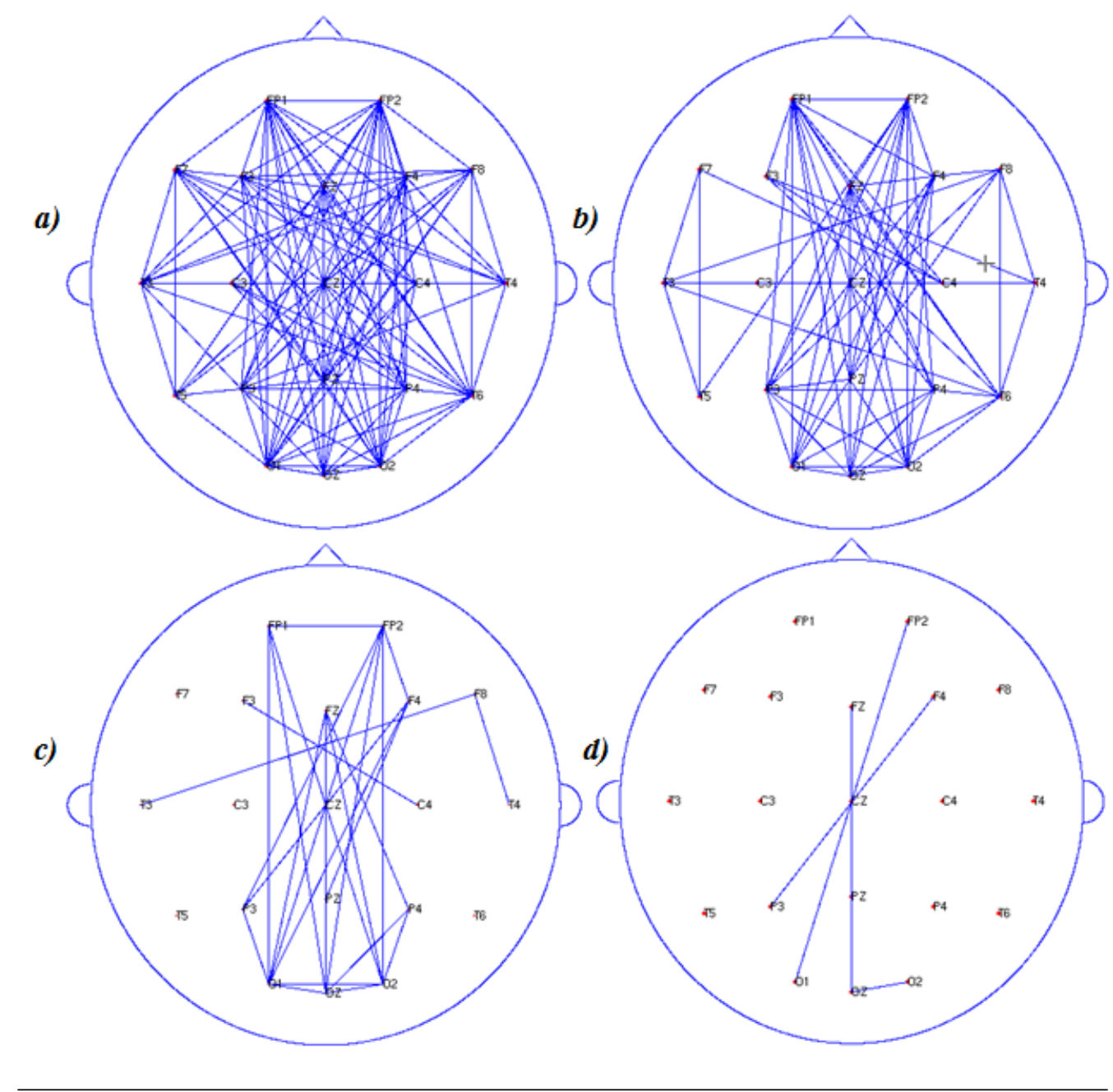

FIGURA 4.10: Gráficas de conectividad generadas a partir de cuatro valores de umbral diferentes, aplicados a la gráfica de la figura 4.8: a)0.2, b)0.4, c) 0.7 y d)0.9.

\subsubsection{Grado de nodo}

El grado de un nodo se define en la ecuación 2.15, es el número de conexiones que tiene dicho nodo con los demás presentes en la gráfica. El procedimiento para cuantificar el grado de nodo se muestra en la figura 4.11 y se describe a continuación: 
- Se umbraliza la matriz de asociación al tiempo $t$ para crear la matriz de adyacencia manteniendo las conexiones que están por encima de dicho umbral, las conexiones por debajo del umbral son eliminadas. Se obtiene el grado de cada nodo

- Se suman las conexiones para cada nodo presente en la matriz de adyacencia.

- Este procedimiento se repite para todos los valores $U$ de umbralización (101 valores).

- Se promedian los grados de los nodos generados por cada umbralización.

- Se aplica lo anterior a todas las matrices de asociación ( $T$ matrices), como resultado se obtiene una matriz grado de nodo que contiene para cada segmento de tiempo el promedio de los grados de todos los nodos.

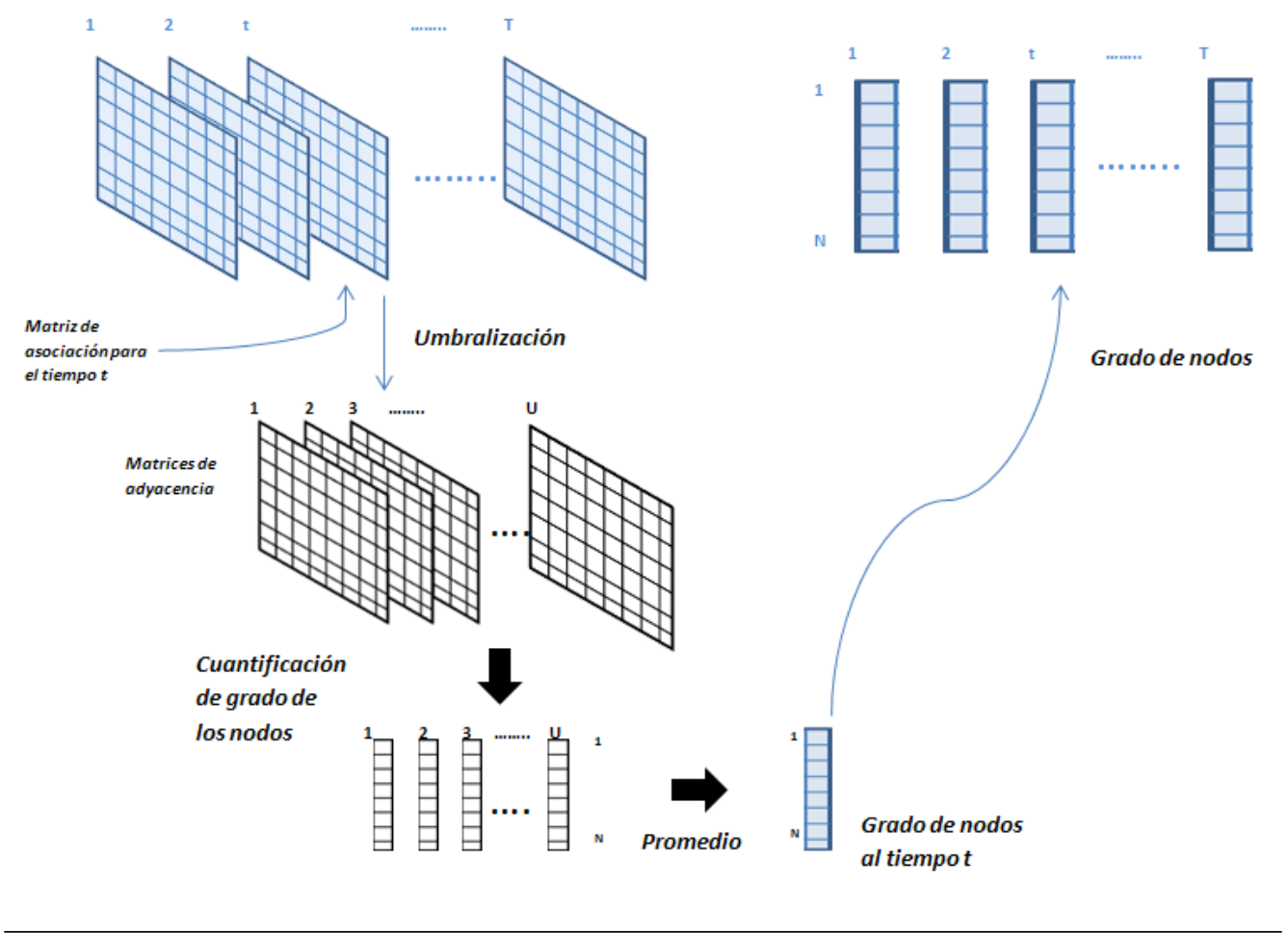

FigurA 4.11: Procedimiento para obtener el grado de cada nodo para toda la duración de un registro de EEG.

La visualización de la matriz grado de nodo tiene importancia ya que podemos observar el comportamiento de cada nodo (que tan conectado o no está) en cada segmento de tiempo. Asociando el valor del grado de nodo a un color, se observa en la figura 4.12 un ejemplo del comportamiento de todos los nodos en el tiempo. Más adelante se profundizará el procedimiento para la visualización de los parámetros de las redes, por el momento sólo se muestra la imagen obtenida a partir de los la cuantificación del parámetro grado de nodo. 


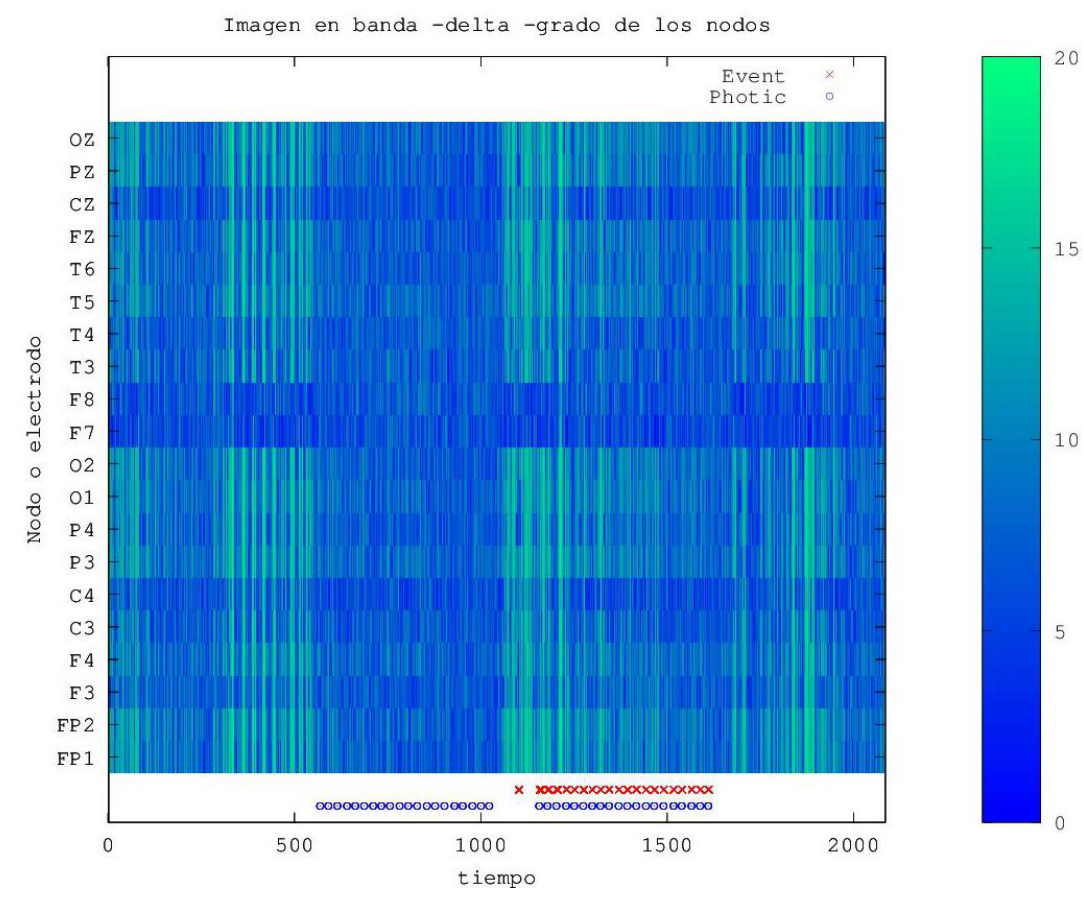

Figura 4.12: Visualización de la matriz grado nodo en toda la duración de un registro de EEG.

\subsubsection{Densidad}

Para obtener la densidad de una matriz de asociación, se debe obtener el número de conexiones presentes en la gráfica de conectividad y dividir entre el máximo de conexiones posibles de dicha red (ecuación 2.18). A continuación se describe el procedimiento y puede observarse en la figura 4.13:

- Se umbraliza la matriz de asociación al tiempo $t$ para crear la matriz de adyacencia manteniendo las conexiones que están por encima de dicho umbral, las conexiones por debajo del umbral son eliminadas. Se obtiene el valor de densidad

- Se suman las conexiones presentes de la matriz de adyacencia.

- Se obtiene el número el máximo número de conexiones posibles.

- Gráficas no direccionales: $\frac{N(N-1)}{2}$.

○ Gráficas direccionales: $N(N-1)$

- Se divide el número de conexiones presentes en la matriz de adyacencia entre el número máximo de conexiones posibles.

- Este procedimiento se repite para todos los valores $U$ de umbralización (101 valores). 
- Se aplica lo anterior a todas las matrices de asociación ( $T$ matrices), como resultado se obtiene una matriz que contiene para cada segmento de tiempo la densidad.

En la figura 4.14 se puede observar la información que se obtiene de la densidad a través de una imagen, tiempo vs umbral vs el valor de la densidad [0-1] asociada a un color.

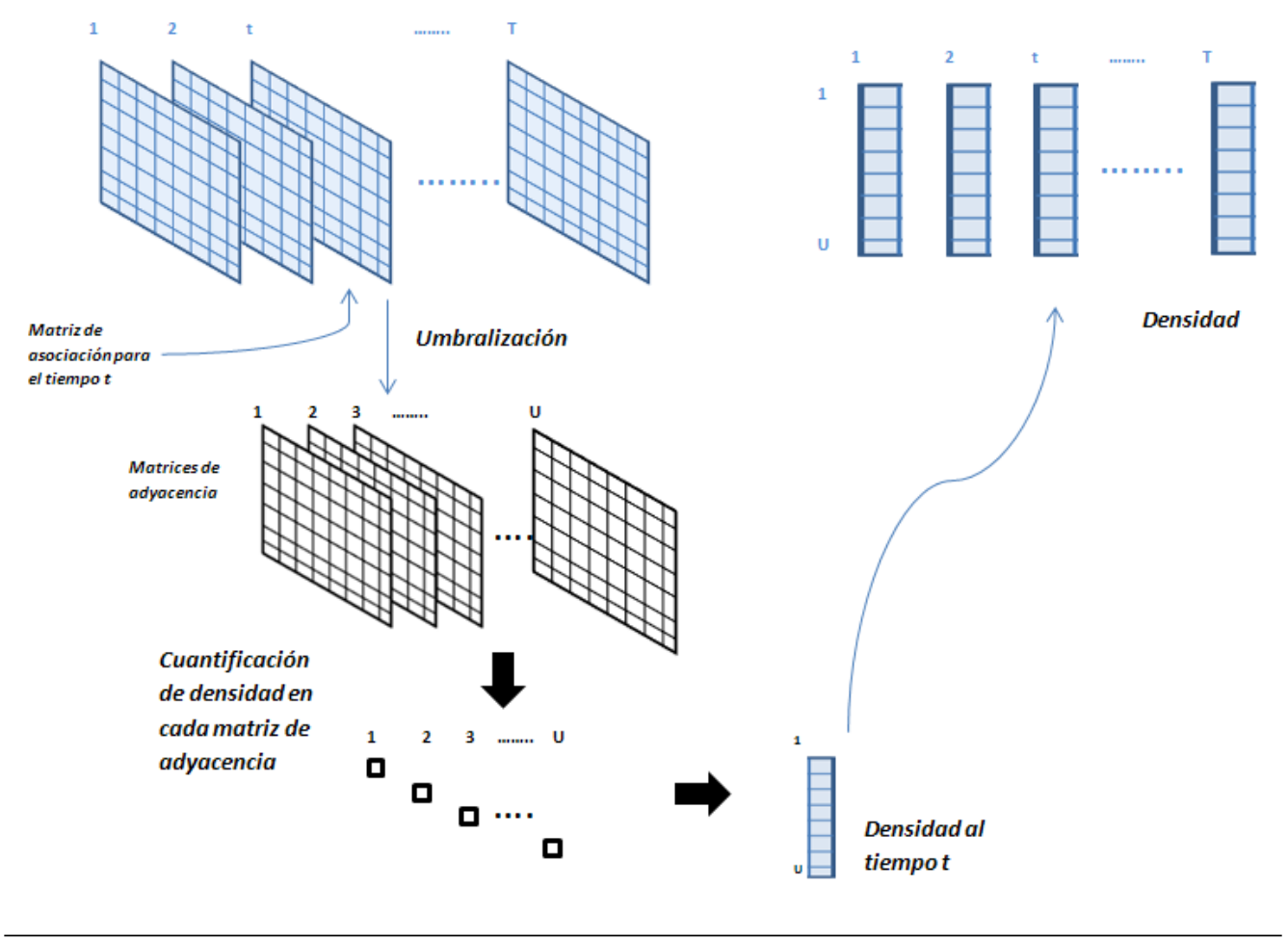

Figura 4.13: Procedimiento para obtener la densidad para toda la duración de un registro de EEG.

\subsubsection{Coeficiente de agrupamiento característico}

El coeficiente de agrupamiento característico definido en la ecuación 2.20 se obtiene mediante el siguiente procedimiento (figura 4.15):

- Se umbraliza la matriz de asociación al tiempo $t$ para crear la matriz de adyacencia manteniendo las conexiones que están por encima de dicho umbral, las conexiones por debajo del umbral son eliminadas. Se obtiene el coeficiente de agrupamiento característico

- Se obtiene el valor del coeficiente de agrupamiento para cada nodo.

- Se obtiene el número de vecinos del i-ésimo nodo $\left(N_{v}\right)$.

- Se obtiene el número máximo de conexiones posibles entre vecinos del i-ésimo nodo: 


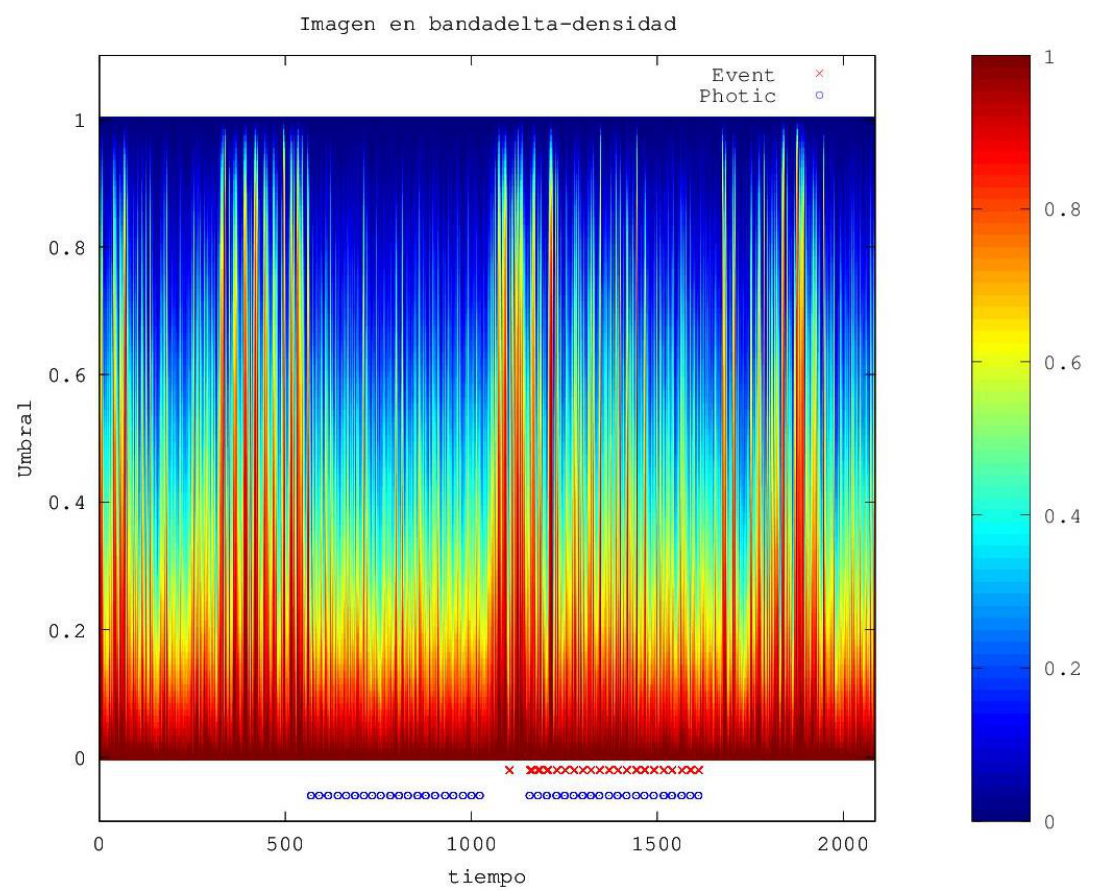

FigurA 4.14: Visualización de la matriz densidad en toda la duración de un registro de EEG.

- Gráfica no direccional: $\frac{N_{v}\left(N_{v}-1\right)}{2}$.

○ Gráfica no direccional: $N_{v}\left(N_{v}-1\right)$.

- Se encuentran los vecinos del nodo central:

- Si el nodo central tiene un vecino o ninguno su coeficiente de agrupamiento es 0 .

- De lo contrario se suman las conexiones que tienen entre sí los vecinos del i-ésimo nodo y se divide entre el número máximo de conexiones posibles entre los vecinos.

- Este procedimiento se repite para todos los valores $U$ de umbralización (101 valores).

- Se promedian todos los valores de los coeficientes de todos los nodos obtenido en cada valor de umbral.

- Se aplica lo anterior a todas las matrices de asociación ( $T$ matrices), como resultado se obtiene una matriz que contiene para cada segmento de tiempo el coeficiente de agrupamiento característico en función de los valores de umbral.

En la figura 4.16 se puede observar la información que se obtiene del coeficiente de agrupamiento a través de una imagen, tiempo vs umbral vs el valor del coeficiente asociado a un color. 


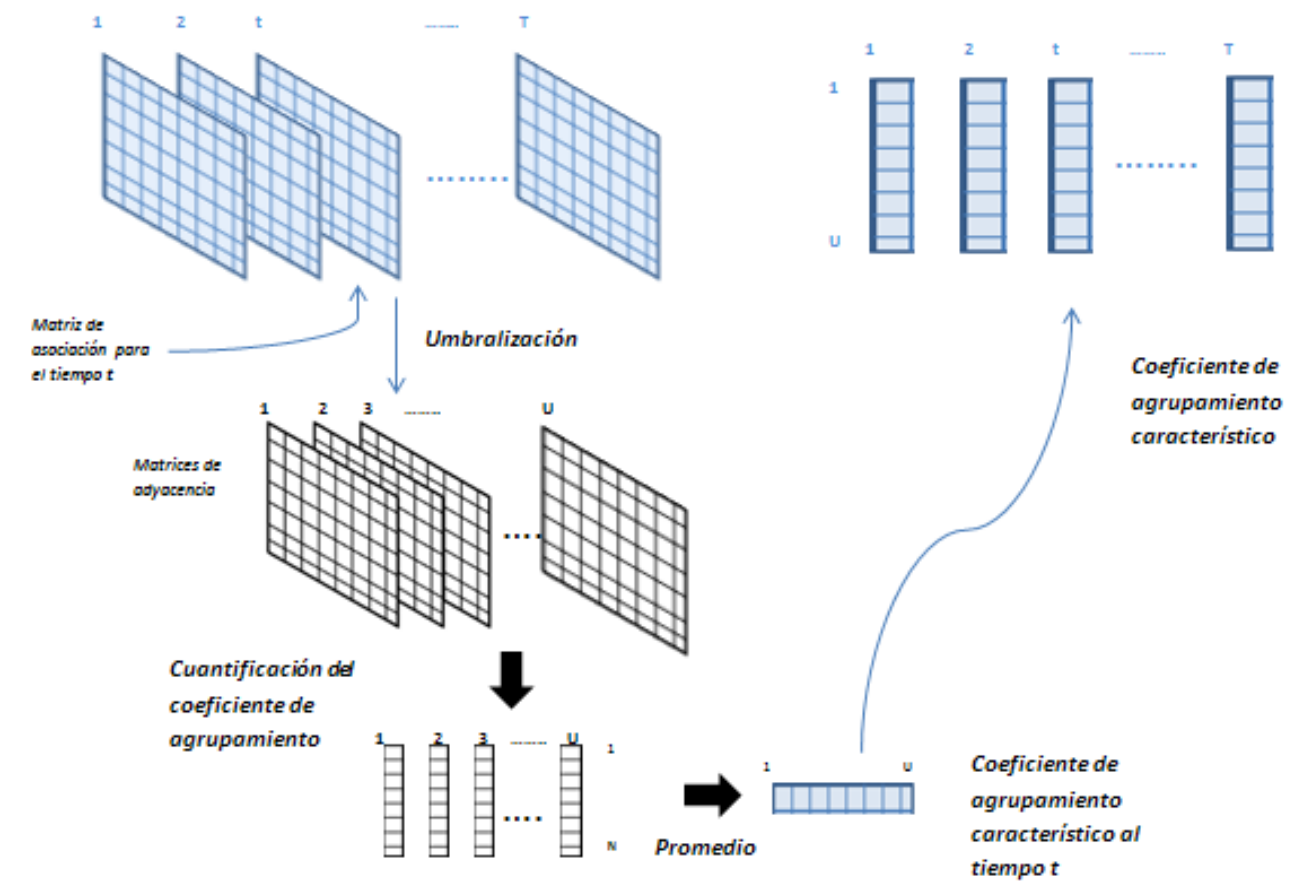

FiguRA 4.15: Procedimiento para obtener el coeficiente de agrupamiento característico para toda la duración de un registro de EEG.

\subsubsection{Distancia mínima característica y Eficiencia}

La distancia característica definida en la ecuación 2.22 se obtiene mediante al siguiente procedimiento (figura 4.17):

- Se umbraliza la matriz de asociación al tiempo $t$ para crear la matriz de adyacencia manteniendo las conexiones que están por encima de dicho umbral, las conexiones por debajo del umbral son eliminadas. Se obtiene la distancia mínima característica

- Se obtiene la matriz de distancia mínima entre todos los nodos, es decir, se cuantifica el camino más corto que comunica a dos nodos, si entre los nodos no existe conexión alguna el valor correspondiente de la matriz de distancias se llena con un valor de infinito (Inf), la distancia entre los mismos nodos es igual a cero.

- Se promedian todas las distancias mínimas de la matriz anterior, sin involucrar los valores Inf y 0 .

- Este procedimiento se repite para todos los valores $U$ de umbralización (101 valores).

- Se obtiene el valor de la eficiencia para la matriz de distancias mínimas: 


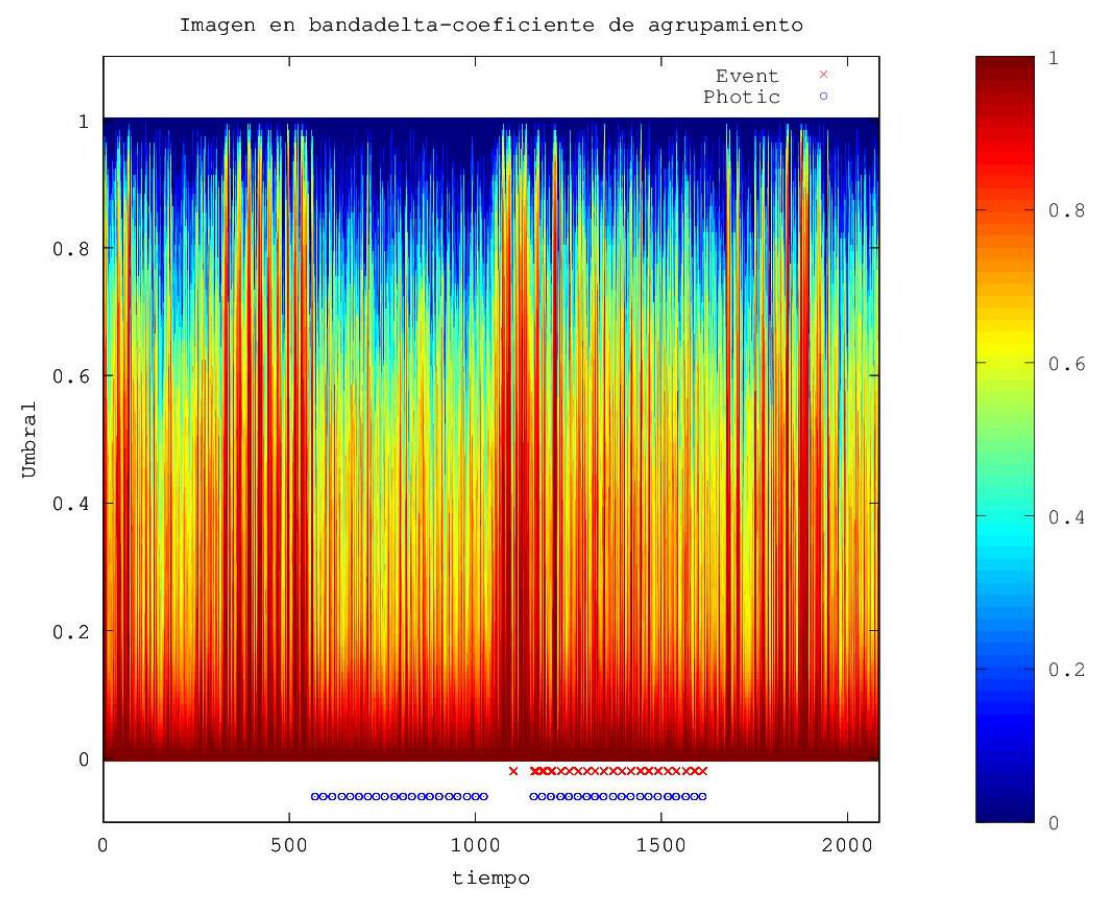

Figura 4.16: Visualización del coeficiente agrupamiento característico en toda la duración de un registro de EEG.

- Se invierte la matriz de distancias mínimas, por lo tanto los valores Inf se convierten a 0 y los valores de la diagonal se mantienen en ceros.

- Se suman los valores de la matriz inversa y se divide entre el número máximo de conexiones posibles de la matriz de adyacencia (sin contar los ceros):

- Gráficas no direccionales: $\frac{N(N-1)}{2}$.

- Gráficas direccionales: $N(N-1)$

- Este procedimiento se repite para todos los valores $U$ de umbralización (101 valores).

- Se aplica lo anterior a todas las matrices de asociación ( $T$ matrices), como resultado se obtienen dos matrices: una que contiene para cada segmento de tiempo la distancia mínima característica y la segunda la eficiencia.

En la figura 4.18 se pueden observar la representación que se obtiene de la distancia característica y la eficiencia respectivamente.

\subsubsection{Grado promedio}

El grado promedio se implementa de acuerdo a la ecuación 4.29, debido a que se puede simplificar la obtención del grado promedio al combinar las ecuaciones 2.15 y 2.17: 


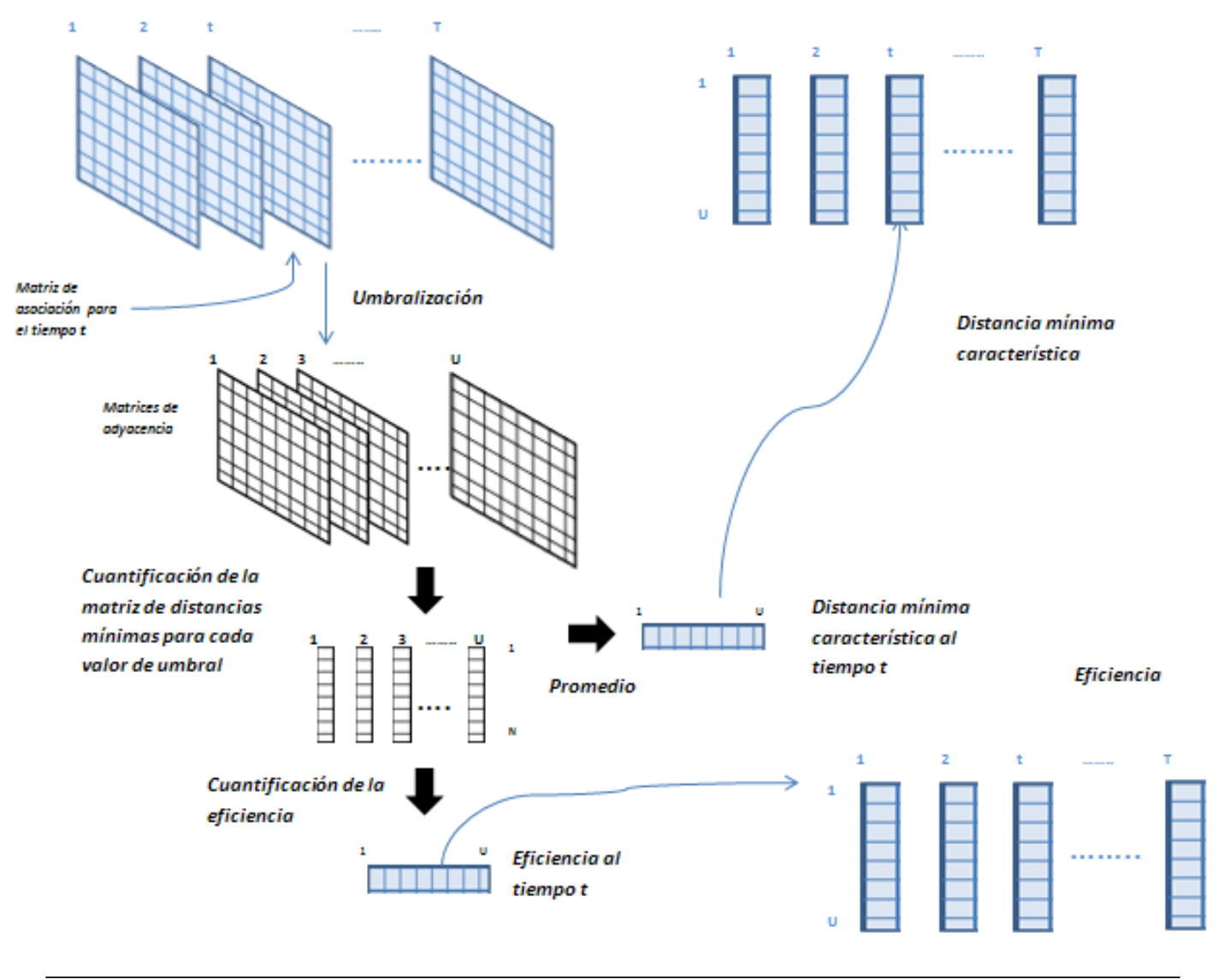

FigurA 4.17: Procedimiento para obtener la distancia mínima característica y eficiencia para toda la duración de un registro de EEG.

$$
d(G)=\frac{1}{|V|} \sum_{v \in V} \sum_{j} a_{v j}
$$

Por lo tanto se puede resumir en sumar todas las conexiones de la gráfica o matriz de adyacencia y dividir entre el número de nodos presentes en la figura 4.19 se puede observar el procedimiento que se describe a continuación:

- Se umbraliza la matriz de asociación al tiempo $t$ para crear la matriz de adyacencia manteniendo las conexiones que están por encima de dicho umbral, las conexiones por debajo del umbral son eliminadas. Se obtiene el valor del grado promedio:

- Se obtiene el total de conexiones presentes en la matriz de adyacencia.

- Se divide el total de conexiones entre el número de nodos:

- Gráficas no direccionales: $\frac{N}{2}$

- Gráficas direccionales: $N$

Nota: Debido a que en una gráfica no direccional se pueden obtener $\frac{N(N-1)}{2}$ conexiones máximas posibles, la división debe hacerse entre $\frac{N}{2}$, por ejemplo, si 

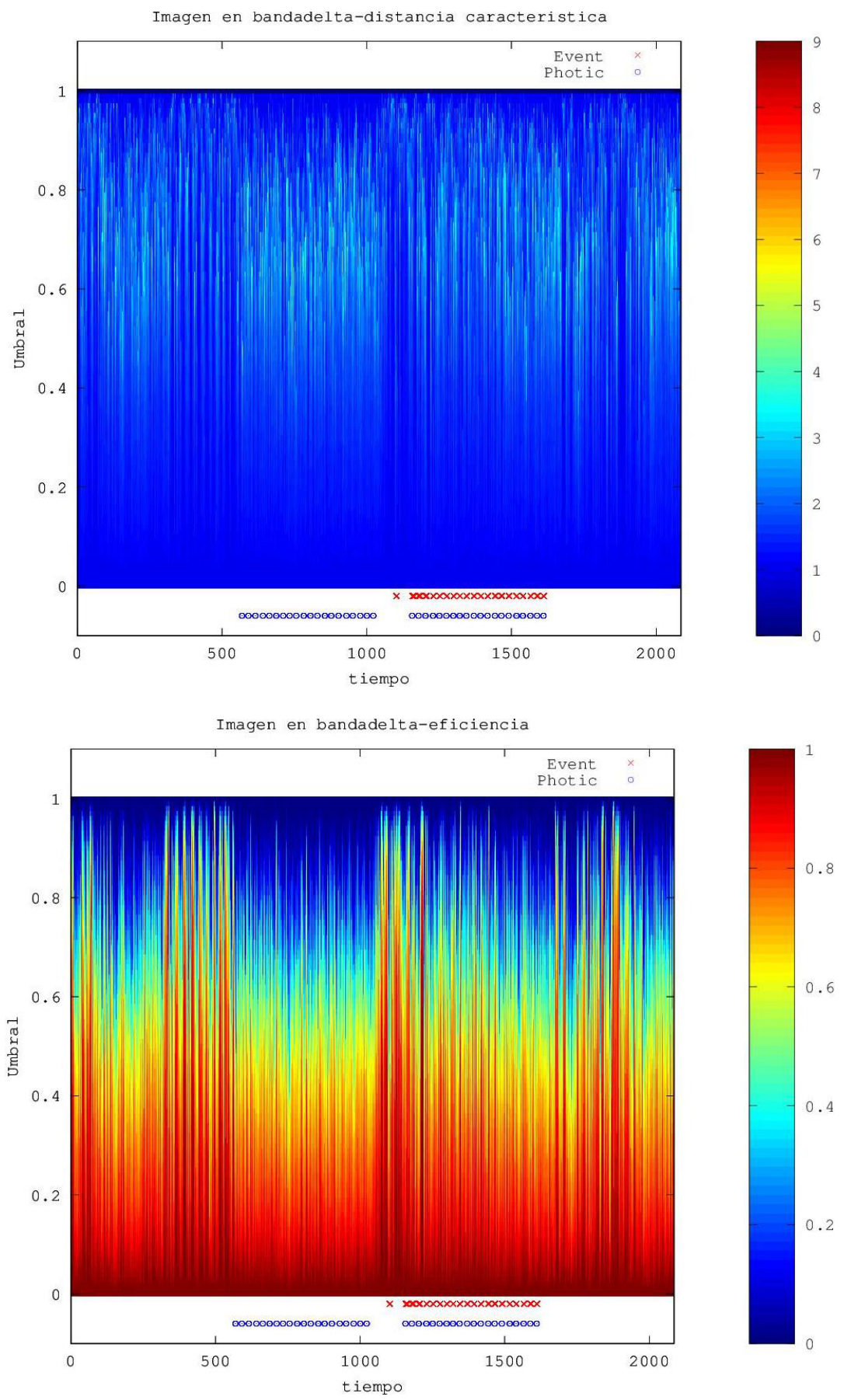

FiguRA 4.18: Visualización de la distancia mínima característica y eficiencia en toda la duración de un registro de EEG.

se tienen las conexiones máximas en la matriz de adyacencia entonces: $d(G)=$ $\frac{2}{N}\left(\frac{N(N-1)}{2}\right)=N-1$ de lo contrario se obtendría: $d(G)=\frac{2}{N}\left(\frac{N(N-1)}{2}\right)=$ $\frac{N-1}{2}$ siendo este último resultado erróneo ya que si todos los nodos están interconectados entre sí el grado máximo, para todos los nodos, sería $N-1$ y su promedio sería $N-1$. 
- Este procedimiento se repite para todos los valores $U$ de umbralización (101 valores).

- Se aplica lo anterior a todas las matrices de asociación ( $T$ matrices), como resultado se obtiene el grado promedio en toda la duración del registro.

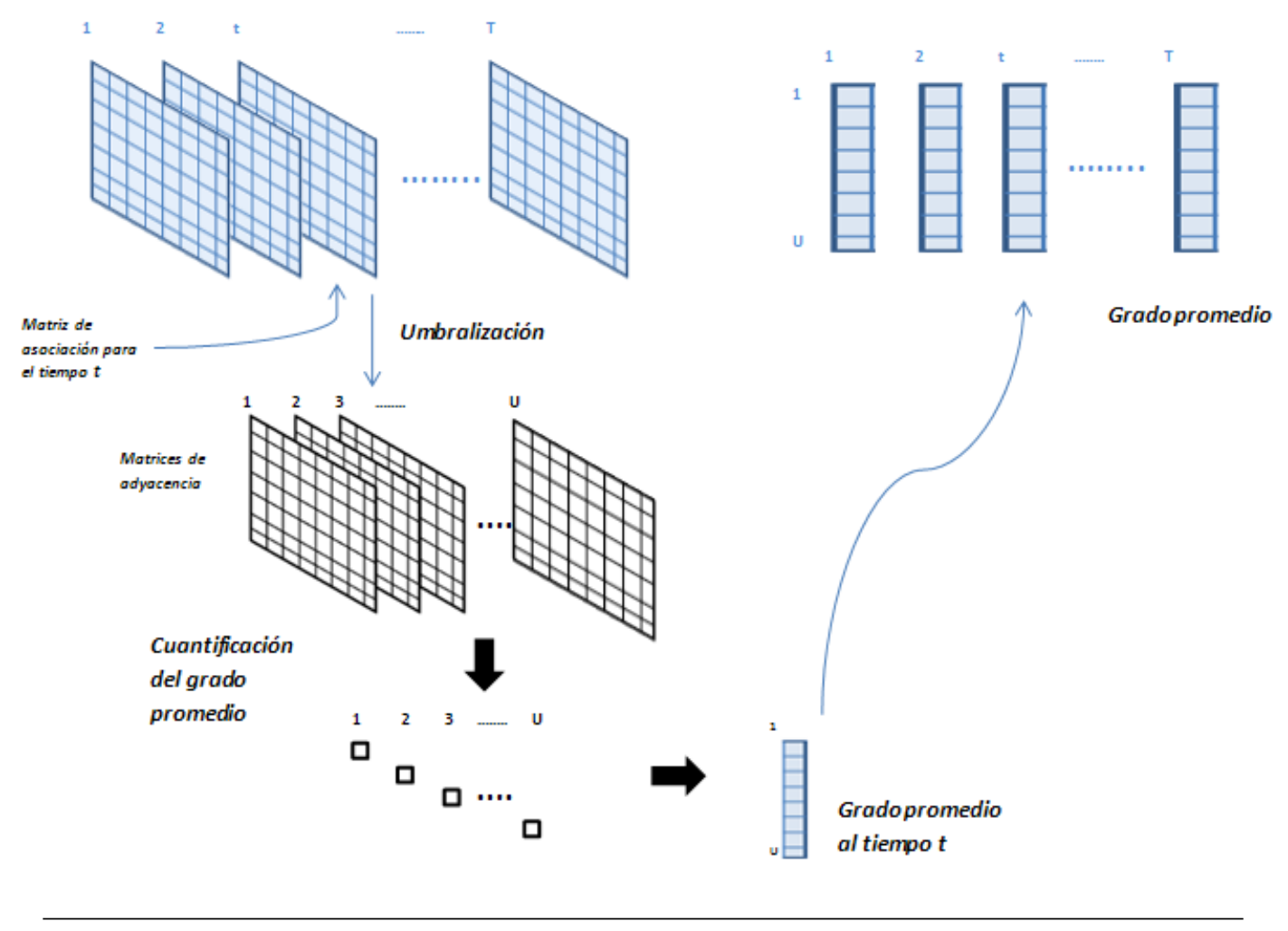

FigurA 4.19: Procedimiento para obtener el grado promedio para toda la duración de un registro de EEG.

En la figura 4.20 se puede observar la información que se obtiene del grado promedio a través de una imagen, tiempo vs umbral vs el valor del grado promedio asociado a un color.

\subsection{Visualización de los parámetros de redes complejas}

La visualización de la dinámica de los parámetros de redes complejas es de suma importancia para poder explorar la información acerca del comportamiento de los parámetros, adicionalmente es necesario observar dicho comportamiento en función de las estimulaciones inducidas durante el registro de EEG. En este trabajo al utilizar registros con el protocolo utilizado (sección 4.1) se pueden visualizar las marcas de las fotoestimulaciones y de asociación, con ello se pueden diferenciar en el tiempo las cuatros etapas que comprenden el protocolo de adquisición de registros. Con esta idea se decidió adicionar 


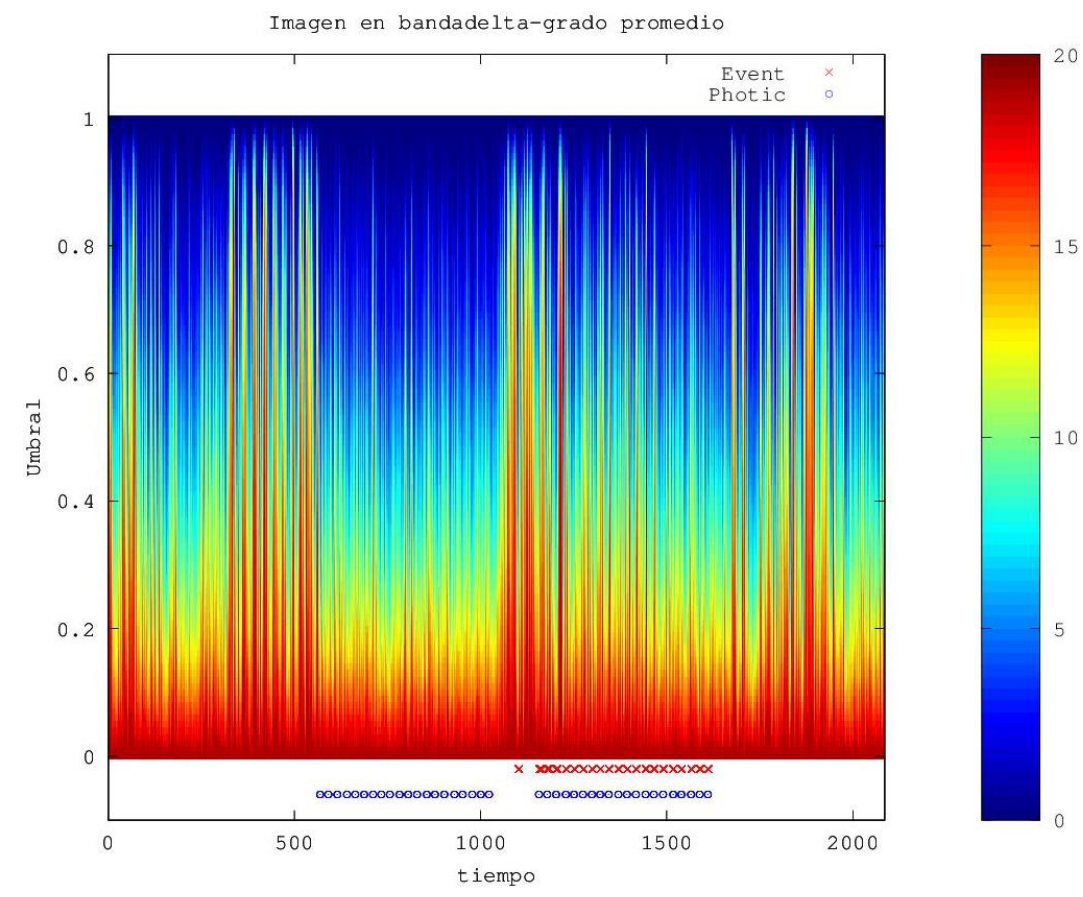

FiguRA 4.20: Visualización del grado promedio en toda la duración de un registro de EEG.

a las gráficas las marcas a las cuales ocurrieron las fotoestimulaciones y asociaciones, con lo que se puede observar la dinámica de los parámetros durante las cuatro etapas y así, en base a las imágenes, reconocer posiblemente un comportamiento o dinámica característica. En la figura 4.21 se muestra el procedimiento 


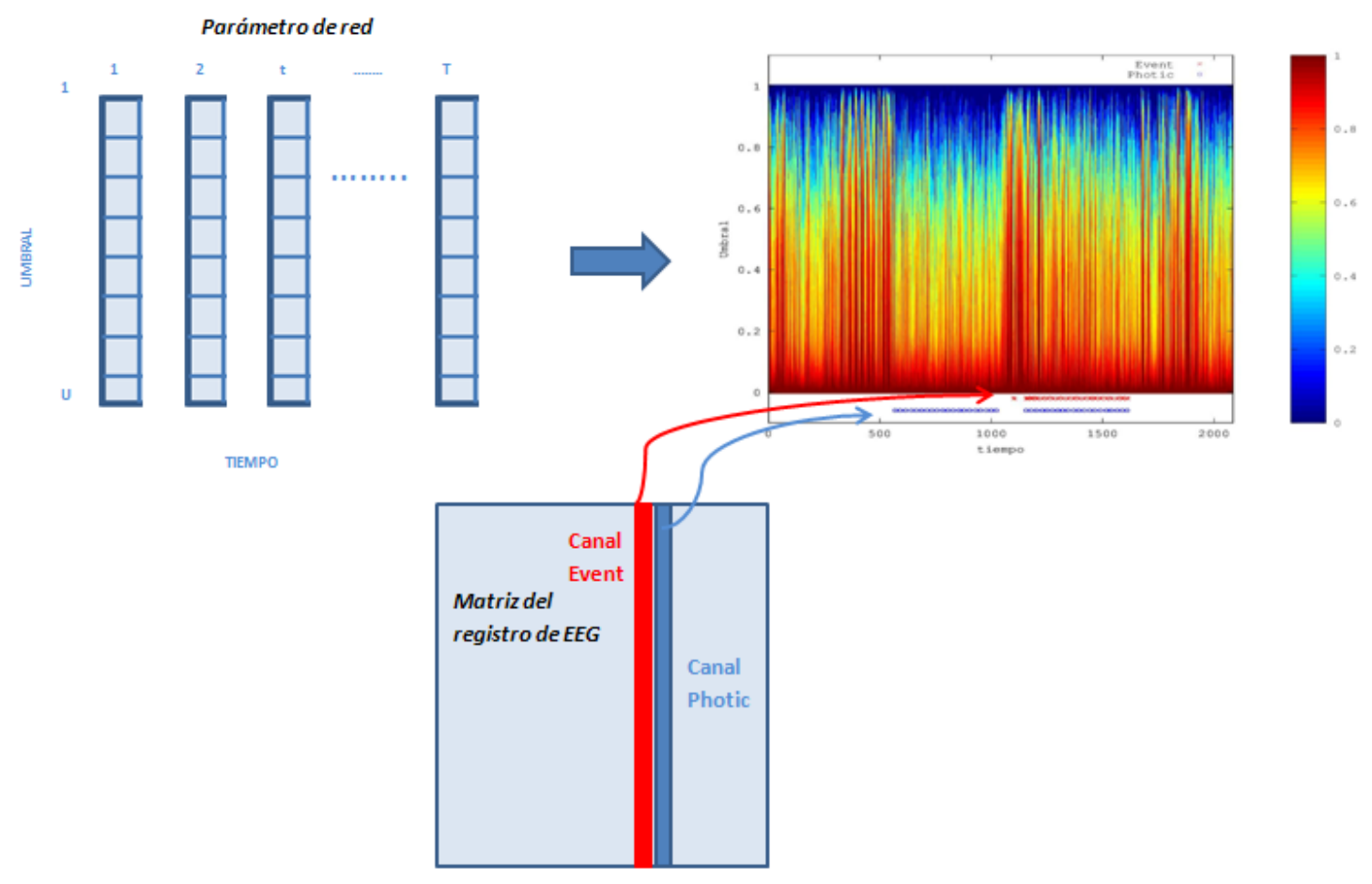

FigurA 4.21: Diagrama del procedimiento de visualización de las medidas de redes adicionando las marcas de las fotoestimulaciones y de asociaciones del protocolo de EEG. 


\section{Capítulo 5}

\section{Resultados}

\subsection{Preprocesamiento}

La obtención de los parámetros sin aplicar una etapa de remoción de artefactos puede visualizarse en la figura 5.1 (arriba) y contrastarse con la figura 5.1 (abajo) que sí se preprocesó. Se puede observar que no reducir los artefactos provoca incrementos en los valores de parámetros de red y estos resultados difieren de aquellos obtenidos al remover los artefactos.

La técnica del promedio de los electrodos $A 1$ y $A 2$ no muestra variabilidad en los patrones de las gráficas de conectividad (con las diferentes medidas de conectividad), además produce una dinámica que muestra siempre el valor máximo de los parámetros de redes (figura 5.2).

Al usar CAR y el arreglo bipolar se obtienen dinámicas que pueden indicar algunos patrones de los parámetros de redes. Los resultados que se mostrarán a continuación son en base a estas dos técnicas.

\subsection{Pacientes de EVC}

La dinámica de los parámetros de redes en el grupo de pacientes de EVC en banda delta y theta muestra dos comportamientos utilizando la coherencia y la entropía cruzada temporal y ambas técnicas de re-referencia. 

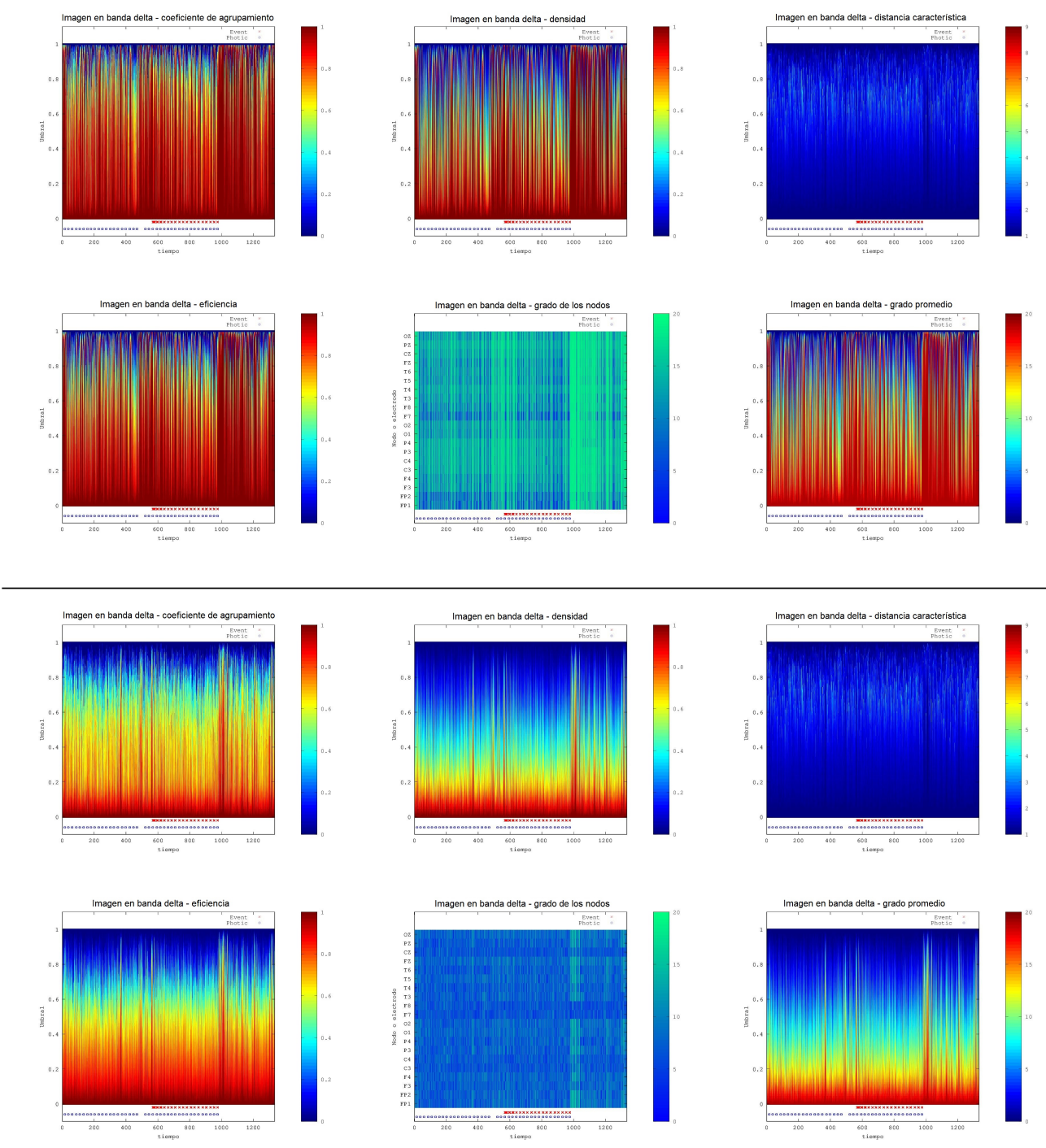

Figura 5.1: Imágenes de C, densidad, L, eficiencia y G y G promedio sin etapa de remoción de artefactos (arriba) y con etapa de remocion de artefactos (abajo).

\section{Coherencia y Entropía cruzada temporal}

El primer comportamiento usando la coherencia espectral se presenta en dos pacientes de seis, donde los seis parámetros de redes obtenidos diferencias durante las cuatro etapas del protocolo de adquisición de EEG. C muestra valores por encima de 0.8 en casi todo el rango de los valores de umbral durante las etapas basal e hiperventilación. Durante la etapa de fotoestimulación sufre una disminución notable alrededor de un valor de $\mathrm{C}$ de 0.6 en casi todo el rango de umbral. La etapa de asociación presenta un incremento en su inicio pero baja conforme transcurre dicha etapa.

La densidad indica que durante la etapa de fotoestimulación las FCG están altamente conectadas por debajo de un umbral de 0.1, y disminuye conforme el umbral aumenta, 


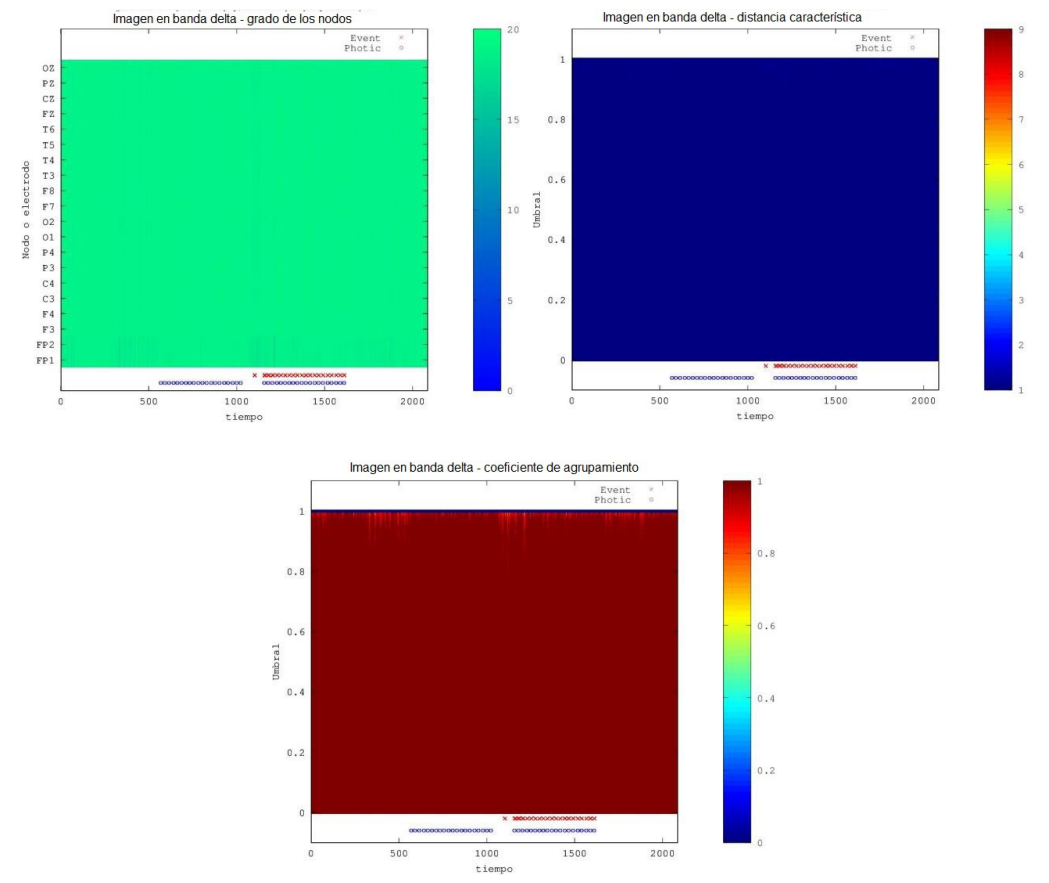

Figura 5.2: Imágenes de C, L y G usando el promedio de A1 y A2 como técnica de re-referencia

por encima de un umbral de 0.2 el valor de densidad es menor a 0.4. En las tres etapas restantes se observa que existen picos de alta densidad que corresponden con los incrementos de C. El parámetro L muestra un decremento de la distancia mínima promedio al finalizar las cuatro etapas, en la etapa de fotoestimulación L oscila de 2 a 4.5 nodos de distancia entre el rango de umbral de $0.5-0.85$.

La eficiencia muestra que las FCG tienen picos con un valor mayor de eficiencia durante las tres etapas: basal, asociación e hiperventilación; en la etapa de fotoestimulación la eficiencia disminuye teniendo por debajo de un umbral 0.2 un valor por encima $0.8 \mathrm{y}$ disminuye en 0.5. El grado de los nodos muestra la tendencia que las otras medidas presentadas, durante las etapas basal e hiperventilación se observa un incremento en la conexiones de todos los nodos (un grado mayor a 15), mientras que en la etapa de fotoestimulación se observa una disminución notable en todos los grados de los nodos (grado entre 10 y 12). En la etapa de asociación inicia con un grado por encima de 15 pero disminuye a media etapa. También puede observarse que los electrodos $\mathrm{Cz}, \mathrm{F} 8, \mathrm{~F} 7$, C4, C3, F3, F4 mantienen un grado menor durante todo el tiempo. Las imágenes de la descripción anterior se pueden observar en la figura 5.3

En la figura 5.4 se puede observar el comportamiento en la banda alfa donde se observa que previo a la etapa de asociación los parámetros de redes decrecen considerablemente, mientras que durante las etapas de fotoestimulación, asociación e hiperventilación 

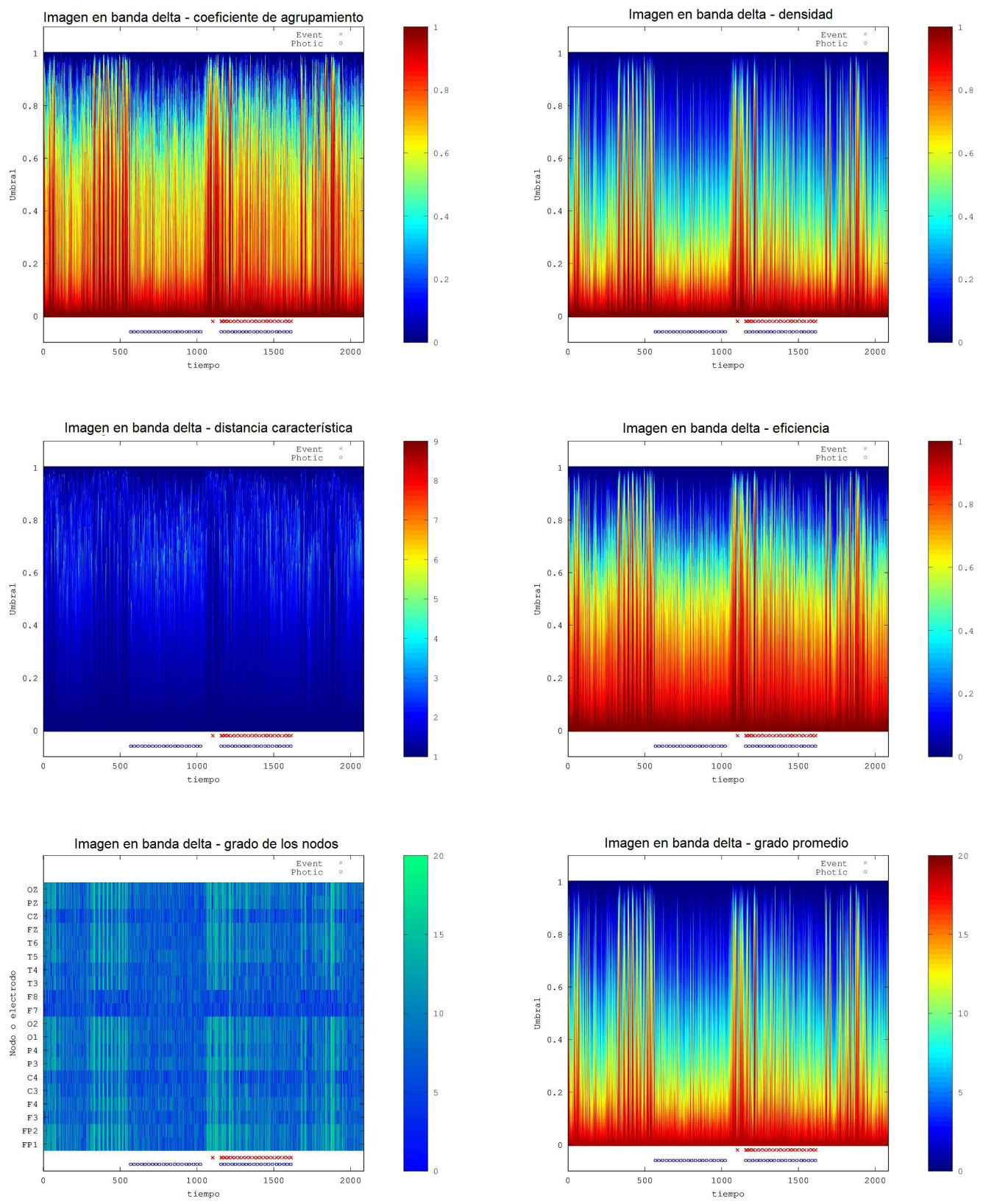

Figura 5.3: Imágenes representativas del primer comportamiento de los seis parámetros de redes en banda delta y theta, usando coherencia y CAR de dos pacientes de EVC

se tienen mas conexiones occipitales y frontales, disminuyendo principalmente en los electrodos $\mathrm{Pz}, \mathrm{Cz}, \mathrm{C} 3$ y C4. La red de conectividad mantiene un nivel de eficiencia por arriba del $50 \%$ por debajo de un umbral de 0.5 . El grado promedio y la densidad tienen comportamiento similar; por debajo de 0.3 de umbral se tienen altos valores para ambas medidas y disminuyen coonforme el umbral aumenta.

En los mismos pacientes, las bandas delta y theta presentan una dinámica similar a las 

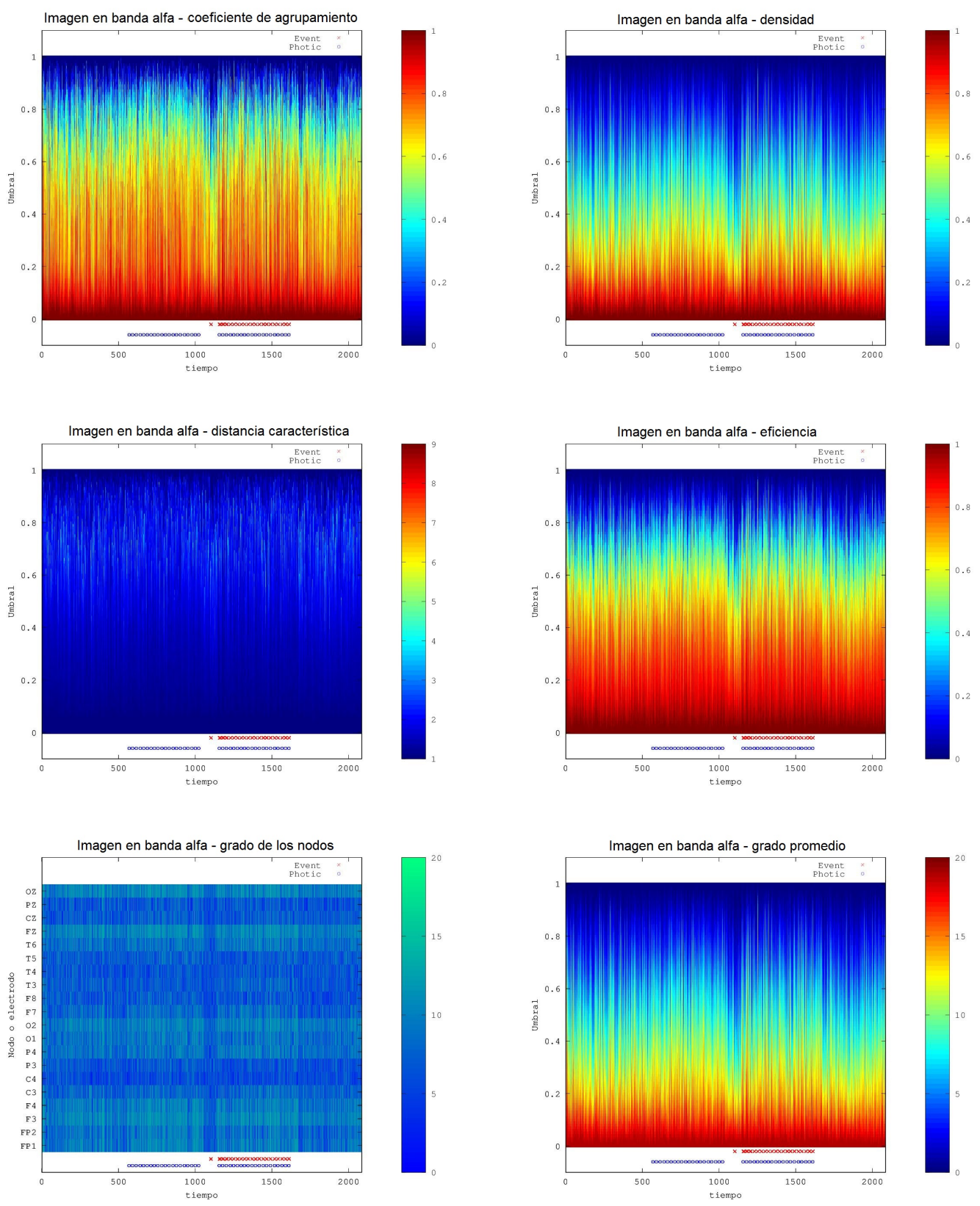

Figura 5.4: Imágenes representativas del primer comportamiento de los seis parámetros de redes en banda alfa, usando coherencia y CAR de dos pacientes de EVC

mostradas en la figura 5.3 pero usando el arreglo bipolar (figura 5.5). La diferencia propia de la técnica de re-referencia es que ahora los pares de electrodos $P 4-O 2, F p 2-F 4$, $P z-O z, P 3-O 1, F P 1-F 3$ y $F 7-T 3$ mantienen un grado de nodo menor en todo el tiempo del registro a diferencia de los pares bipolares restantes. L varía entre el rango de umbrales de $0.4-0.8$. Los demás parámetros comparten muchas similitudes en su dinámica con los reflejados al usar CAR.

Con la entropía cruzada temporal también se aprecian en los seis parámetros de redes 

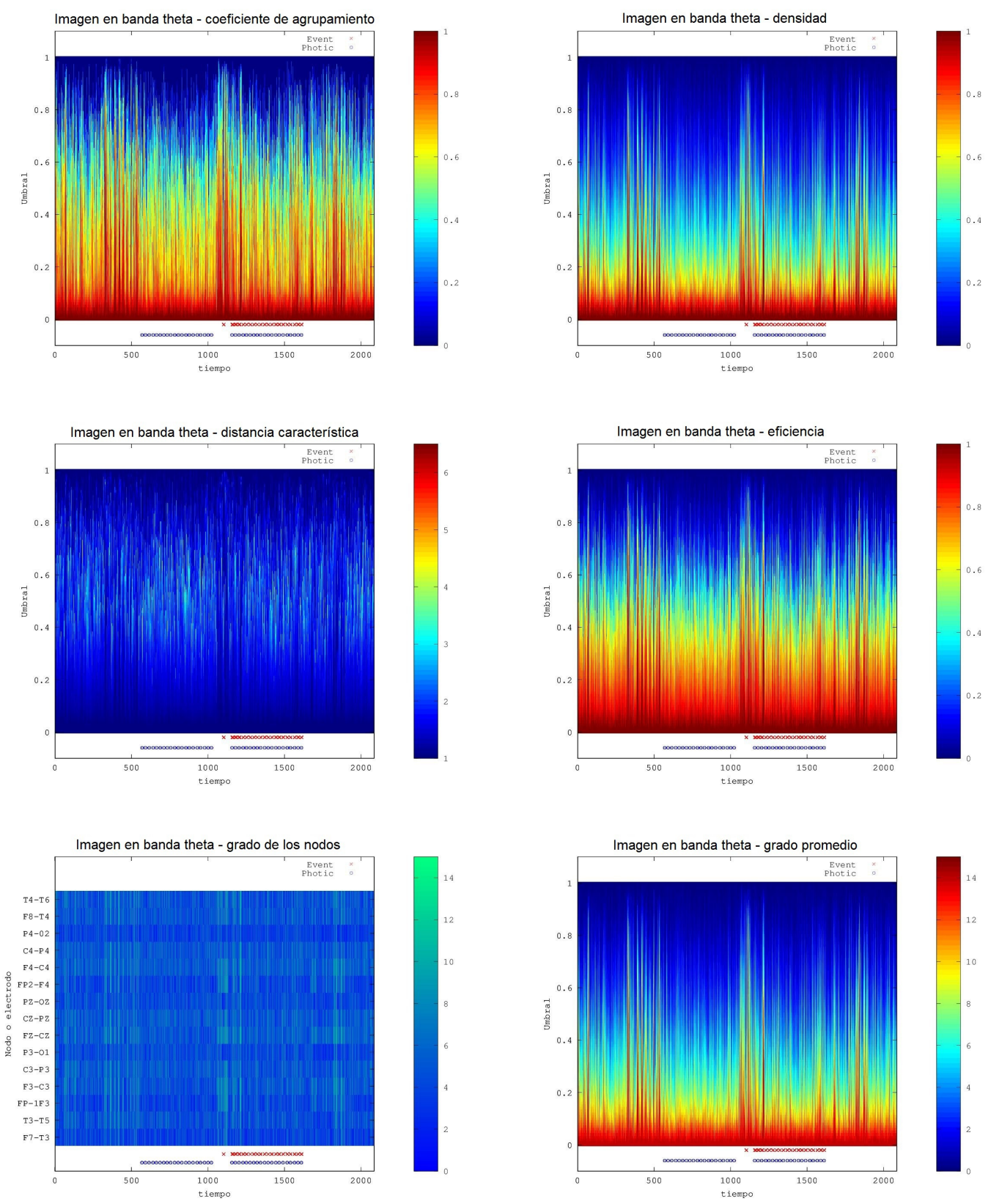

FIGURA 5.5: Imágenes representativas del primer comportamiento de los seis parámetros de redes en banda delta y theta, usando coherencia y arreglo bipolar de dos pacientes de EVC.

obtenidos diferencias durante las cuatro etapas del protocolo de adquisición de EEG. Sin embargo, existen diferencias con respecto a la coherencia espectral, por ejemplo en $\mathrm{C}$ muestra valores por encima de 0.9 por debajo de un umbral de 0.4 para todo el registro. La densidad indica que durante la etapa de fotoestimulación las FCG están altamente conectadas por debajo de un umbral de 0.4, y disminuye conforme el umbral aumenta, teniendo en un umbral de 0.6 alrededor de 0.5 de densidad. El parámetro L muestra un decremento de la distancia mínima promedio al finalizar las cuatro etapas, en la etapa 
de fotoestimulación L oscila de 2 a 4.5 nodos de distancia entre el rango de umbral de $0.7-0.85$. La eficiencia muestra diferencias entre las transiciones. G también muestra las etapas diferenciadas pero con valores de grado alrededor de 12. Puede observarse que los electrodos Fz, F8, F7, F3, F4, FP2 y FP1 disminuyen sus conexiones a lo largo de todo el registro de EEG (figura 5.6).
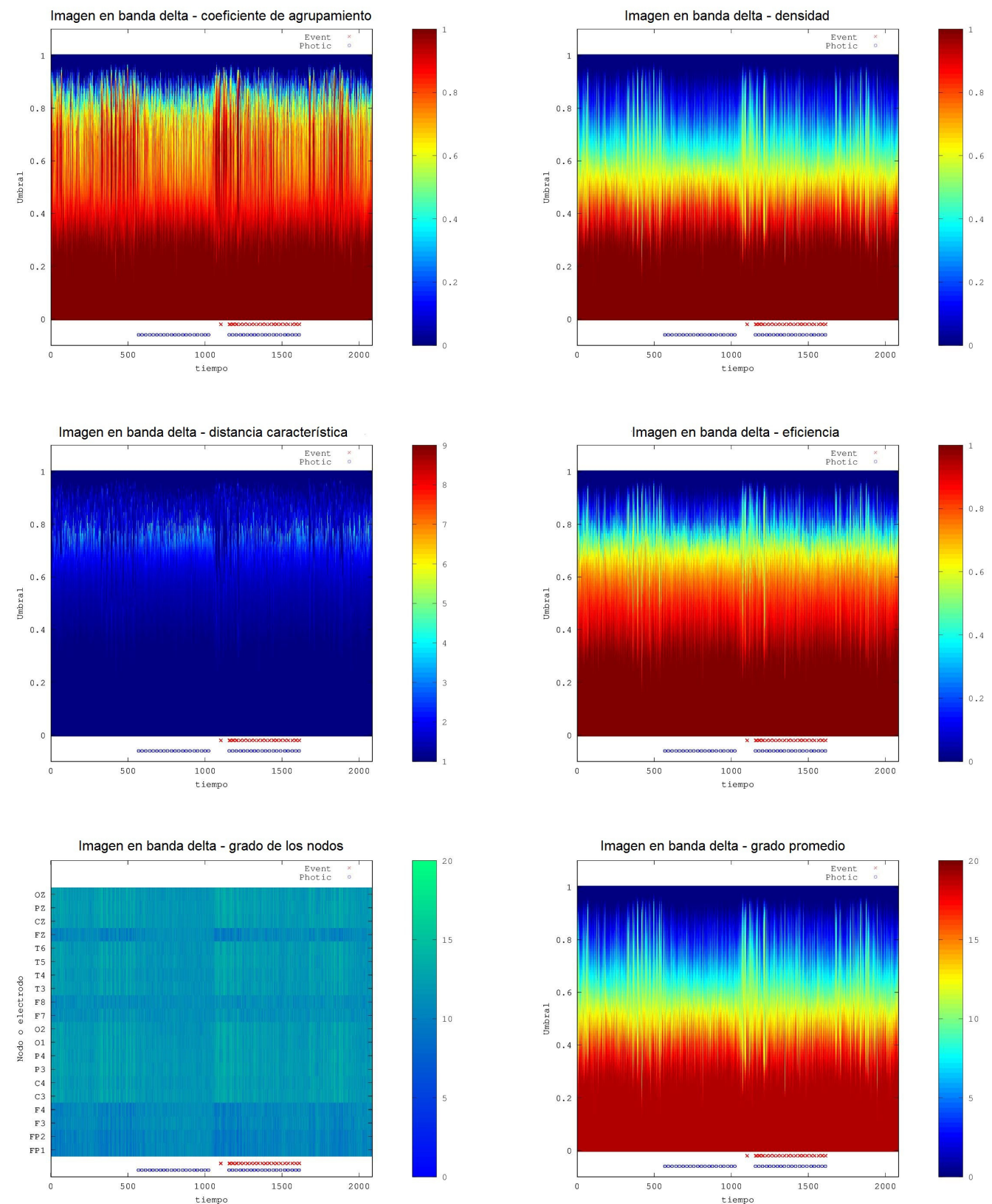

FiguRA 5.6: Imágenes representativas del primer comportamiento de los seis parámetros de redes en banda delta y theta, usando entropía cruzada temporal y CAR en pacientes de EVC

El segundo comportamiento se presenta en los cuatro pacientes restantes de EVC. La coherencia obtiene dinámicas similares de los parámetros de gráficas en ambas bandas 
(figura 5.7). No se pueden distinguir diferencias de los parámetros de redes durante las diferentes etapas del protocolo, sin embargo, los cuatro pacientes coinciden en una disminución del número de conexiones en los electrodos Cz, Pz, C3, C4, F7 y F8 durante toda la duración del registro (grado de nodo en la figura 5.7).
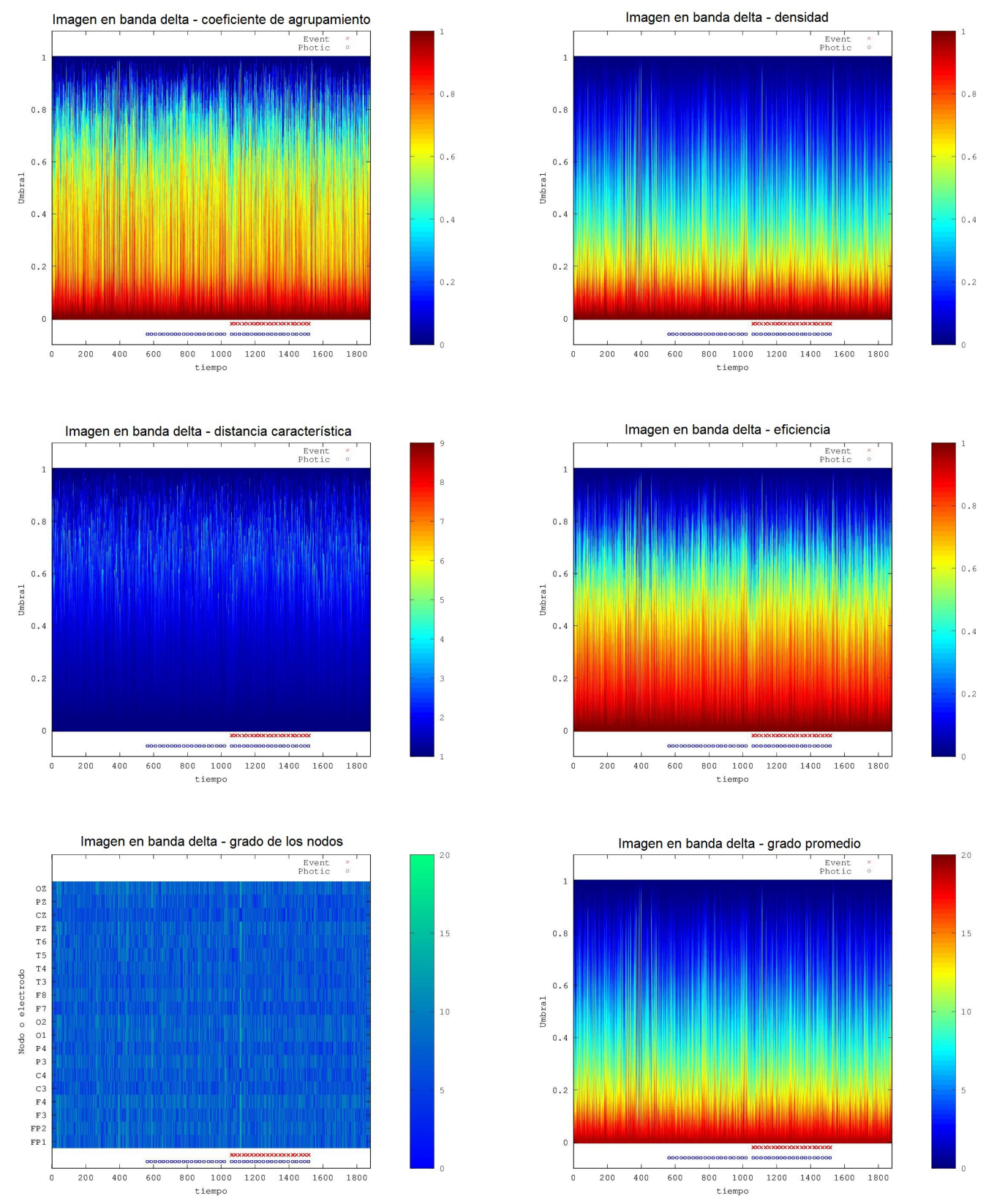

FigurA 5.7: Imágenes representativas del segundo comportamiento de los seis parámetros de redes en banda delta, usando coherencia y CAR en pacientes de EVC

En banda theta la dinámica de los parámetros es similar a la presentada en banda delta, sin embargo, en el grado de los nodos se pierden conexiones en los electrodos F7, P4, C3, C4 y T3. La densidad es máxima por debajo de un valor de 0.1 y disminuye rápidamente conforme los valores de umbral se incrementan teniendo que por encima de un umbral 
de 0.4 las gráficas pierden conexiones con respecto a las máximas posibles. La eficiencia muestra que las gráficas de conectividad son altamente eficientes por abajo de un umbral de 0.5, disminuyendo gradualmente conforme el valor de umbral se aumenta (figura 5.8). El coeficiente de agrupamiento característico muestra que por debajo de 0.1 se tiene un alto coeficiente, que disminuye conforme el umbral se incrementa, teniendo un coeficiente de 0.5 alrededor de un umbral de 0.6 . L varía entre 0.55 y 0.8 de umbral, por debajo y encima de ese intervalo se tiene una distancia mínima promedio menor a 2.
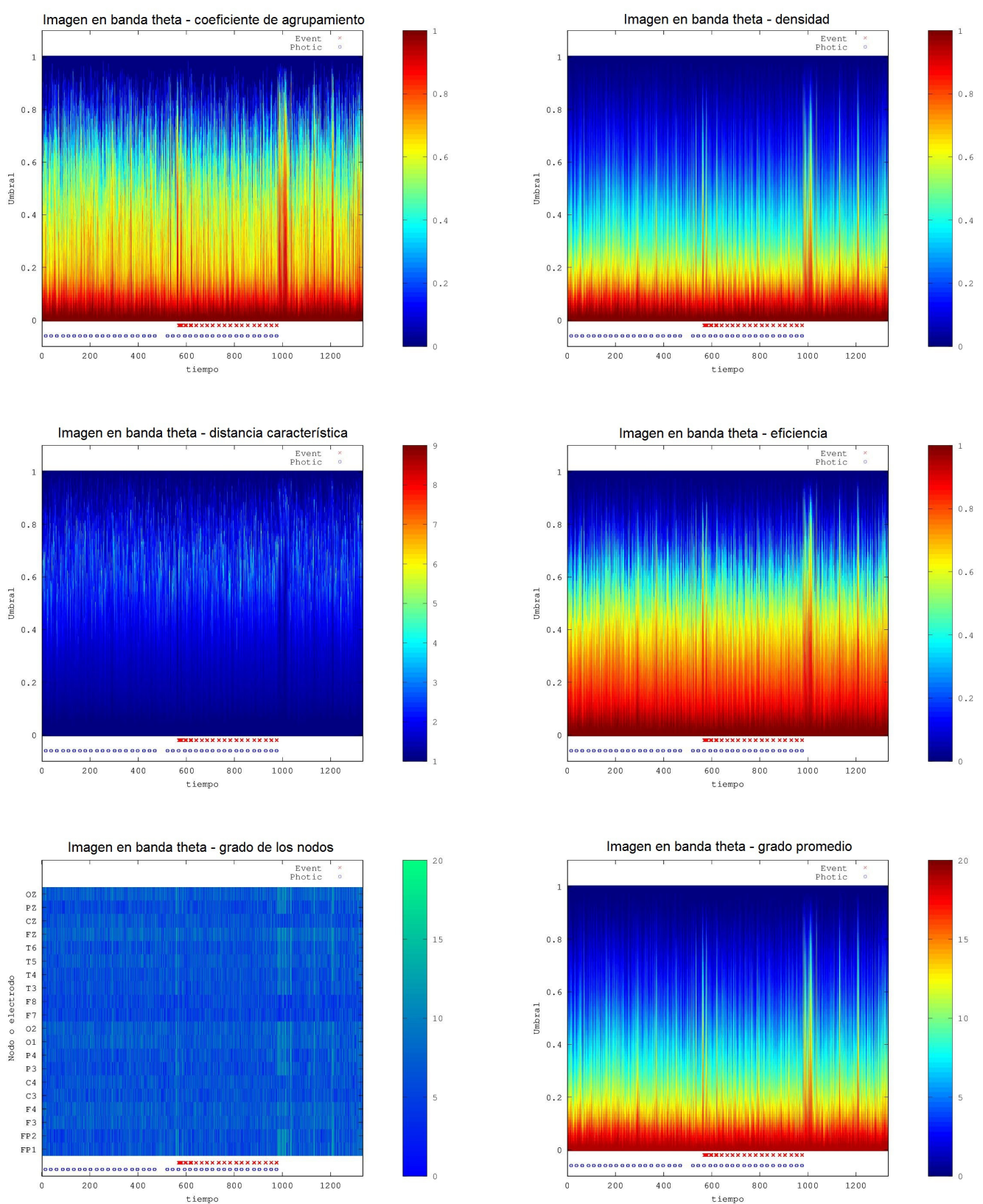

FIGURA 5.8: Imágenes representativas del segundo comportamiento de los seis parámetros de redes en banda theta, usando coherencia y CAR en pacientes de EVC 
La entropía cruzada en bandas delta y theta también muestra un comportamiento similar en $\mathrm{C}$, L, densidad y eficiencia. El grado de los nodos refleja una pérdida de conexiones durante todo el registro en los electrodos Fz, T3, F8, F7, Fp2 y Fp1 como se puede observar en las figuras 5.9 y 5.10
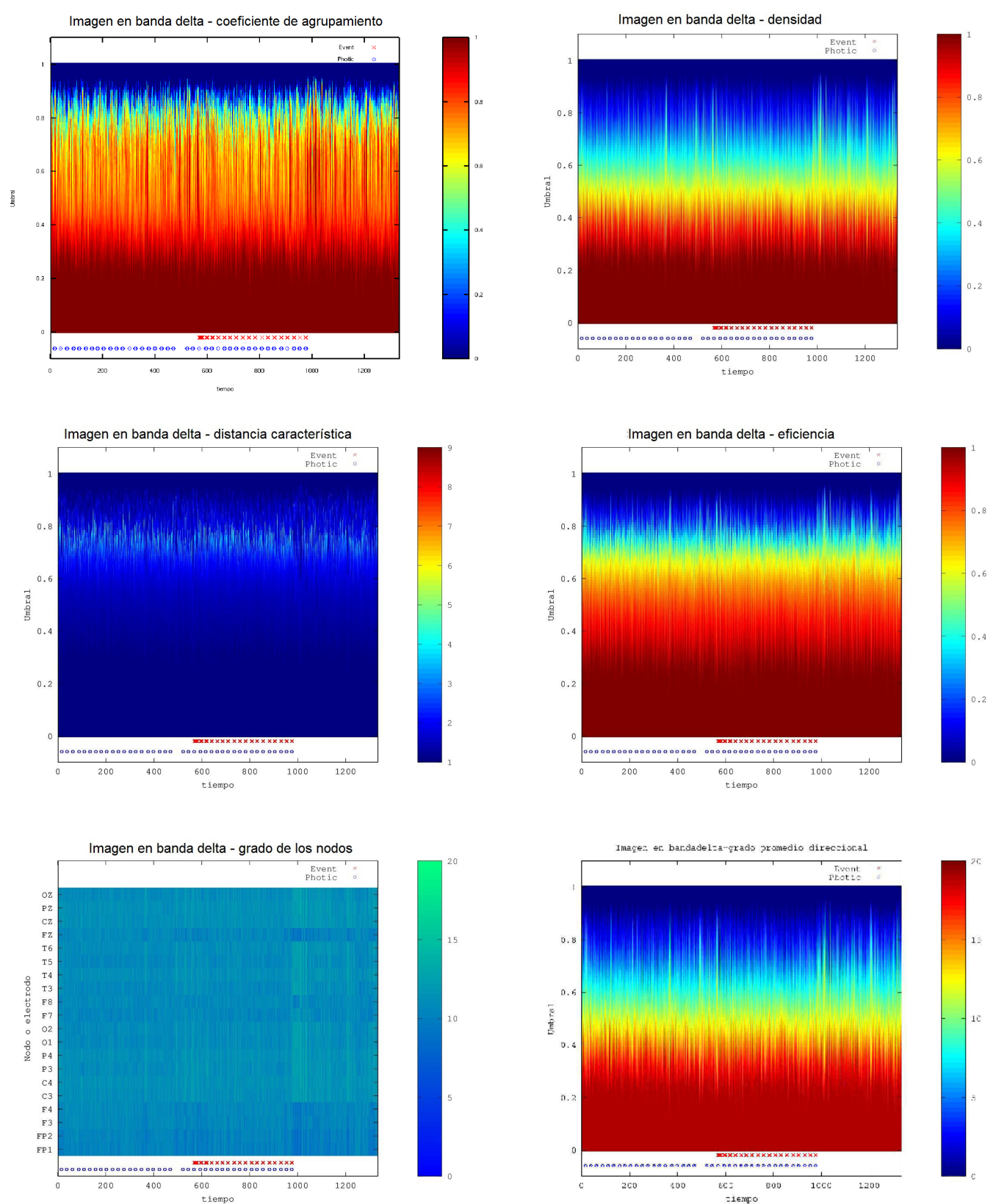

FIGURA 5.9: Imágenes representativas del segundo comportamiento de los seis parámetros de redes en banda delta, usando entropía cruzada temporal y CAR en pacientes de EVC 

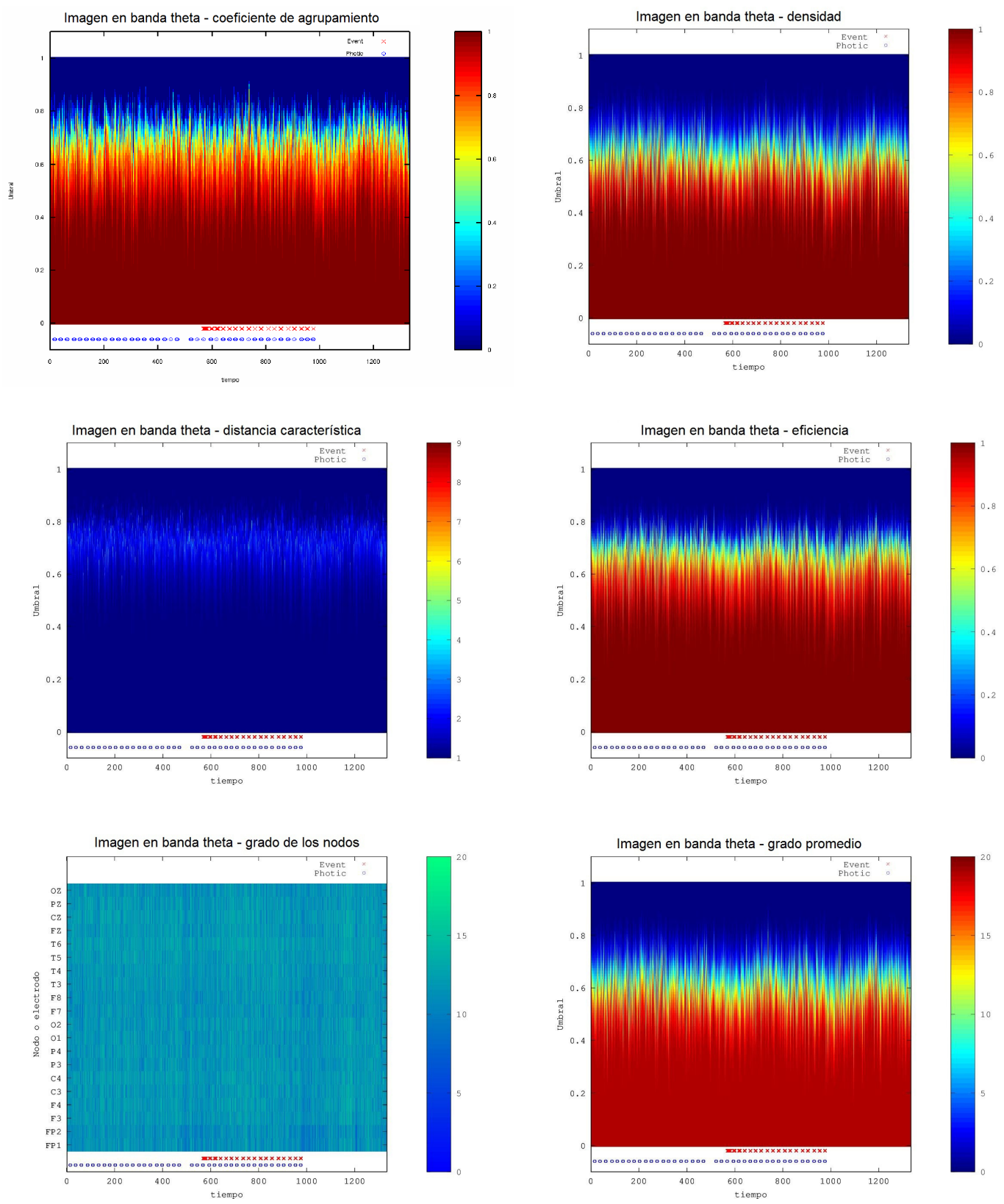

FIGURA 5.10: Imágenes representativas del segundo comportamiento de los seis parámetros de redes en banda theta, usando entropía cruzada temporal y CAR en pacientes de EVC

\section{Coherencia wavelet}

Los parámetros de redes presentan similar comportamiento, al usar la coherencia wavelet con CAR, en las bandas theta, alfa y beta como se muestra en la figura 5.11. Por debajo de un umbral de 0.4 se tiene un coeficiente de 0.4, con ciertos incrementos llegando hasta un umbral de 0.8. La densidad presenta la misma dinámica pero difiere en el valor del parámetro siendo cercano al $20 \%$ de las conexiones máximas posibles. L muestra 
que el intervalo de variación se encuentra entre 0.6 y 0.85 de umbral tomando valores entre 3 y 5 nodos de distancia. La eficiencia muestra un $50 \%$ de eficiencia por debajo de un umbral de 0.4 disminuyendo gradualmente hasta llegar a un $20 \%$ alrededor de un umbral de 0.8 .
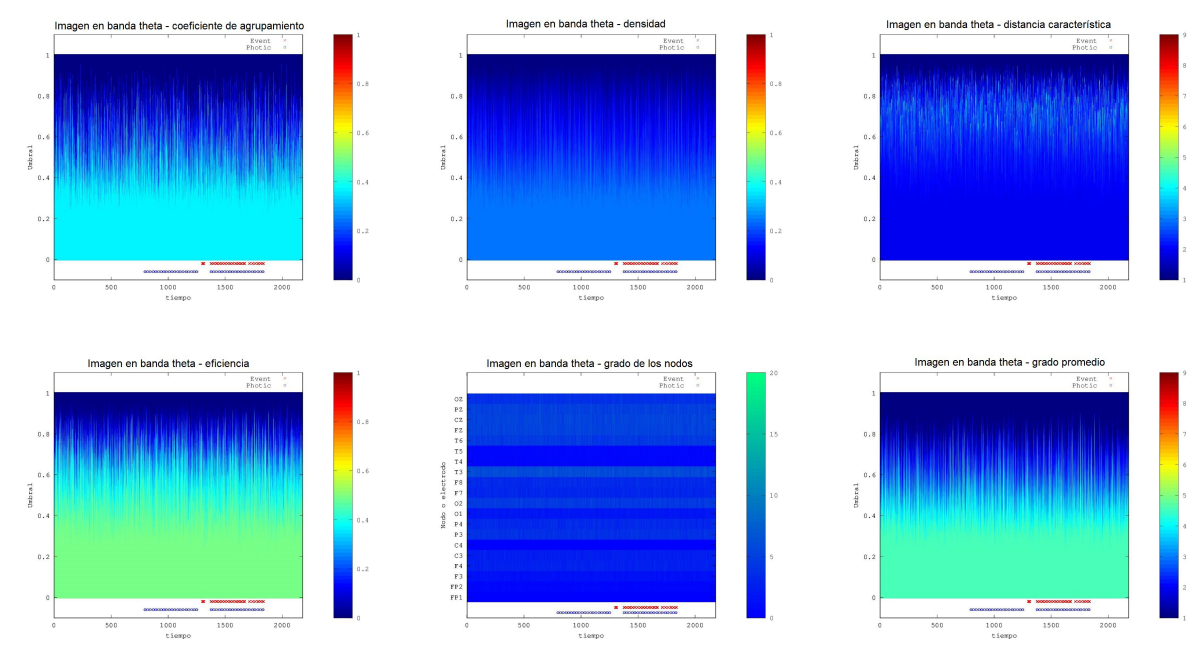

FiguRA 5.11: Imágenes representativas comportamiento de los seis parámetros de redes en banda theta, usando coherencia wavelet y CAR en pacientes de EVC

Para el caso de la banda delta (figura 5.12) existen diferencias con respecto al patrón de las otras bandas. Por debajo de un umbral de 0.6 se tiene un coeficiente de 0.4 , con ciertos incrementos llegando hasta un umbral de 0.8. La densidad presenta la misma dinámica pero difiere en el valor del parámetro siendo cercano al $20 \%$ de las conexiones máximas posibles. L muestra que el intervalo de variación se encuentra entre 0.7 y 0.9 de umbral tomando valores entre 3 y 5 nodos de distancia. La eficiencia muestra un $50 \%$ de eficiencia por debajo de un umbral de 0.6 disminuyendo gradualmente hasta llegar a un $20 \%$ alrededor de un umbral de 0.7 .

Con respecto al grado de los nodos en las cuatro bandas, si se observa dicho parámetro en las figuras 5.11, y 5.12 se tiene el mismo comportamiento, es decir, los nodos T5, T4, F8, F7, O1, C4, F3, Fp2 y Fp1 pierden conexiones manteniéndose por debajo de 8, a pesar que las dinámicas de los otros parámetros tienen algunas diferencias entre las bandas.

Los resultados usando el arreglo bipolar modifican los valores de los parámetros pero la forma de onda es similar en las bandas theta, alfa y beta; por otro lado en la banda delta, se puede observar la comparación mediante las figuras 5.12 y la figura 5.13. 

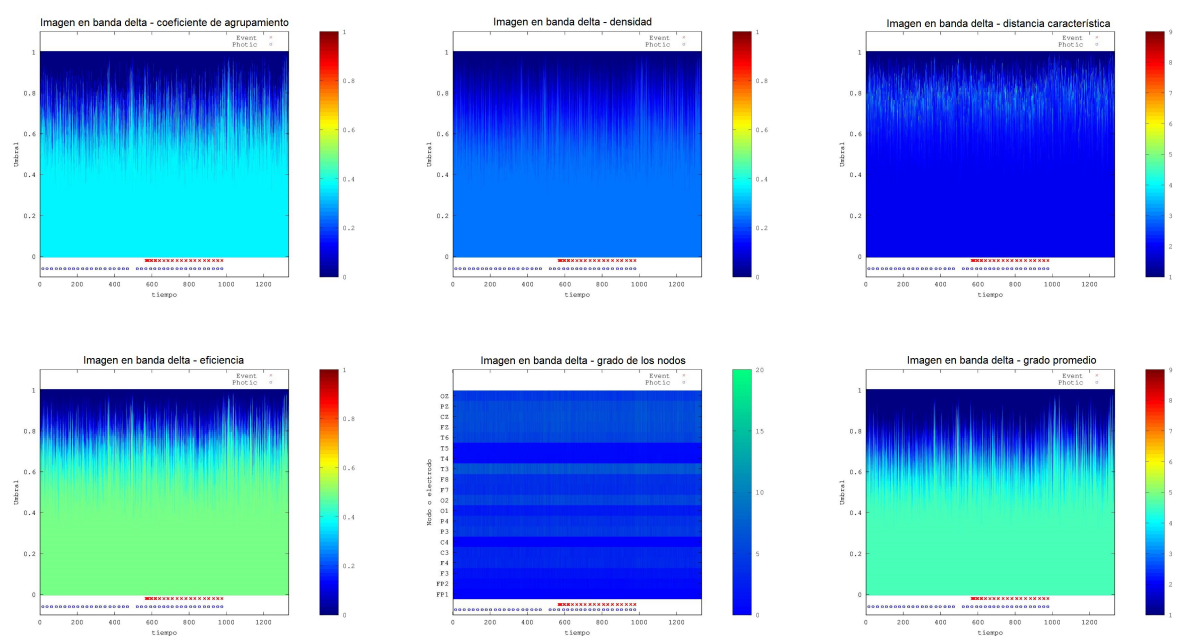

FIGURA 5.12: Imágenes representativas comportamiento de los seis parámetros de redes en banda delta, usando coherencia wavelet y CAR en pacientes de EVC
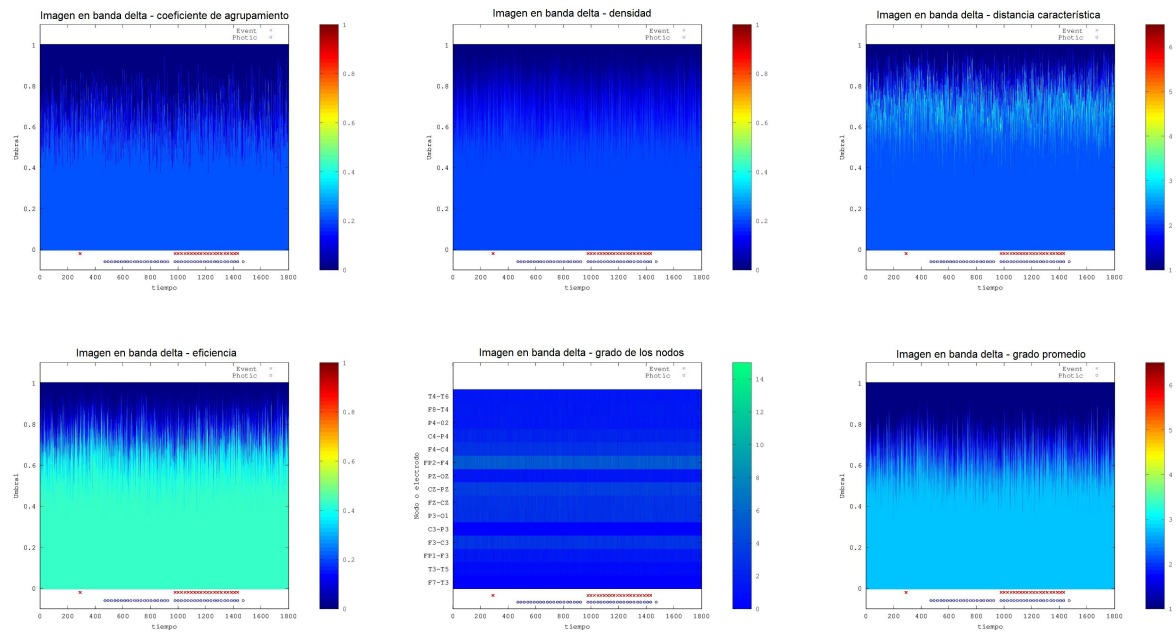

FiguRA 5.13: Imágenes representativas comportamiento de los seis parámetros de redes en banda delta, usando coherencia wavelet y arreglo bipolar en pacientes de EVC

\section{Entropía cruzada espectral}

Los resultados obtenidos a partir de usar la entropía cruzada espectral como medida de conectividad se dividen en dos grupos: el primero comparten caracteristicas las bandas theta, alfa y beta con ambas técnicas de re-referencia y el segundo grupo es en base a la banda delta tambien en ambas técnicas de re-referencia. En la figura 5.14 puede observarse el primer grupo y en la figura 5.15 el segundo grupo. 

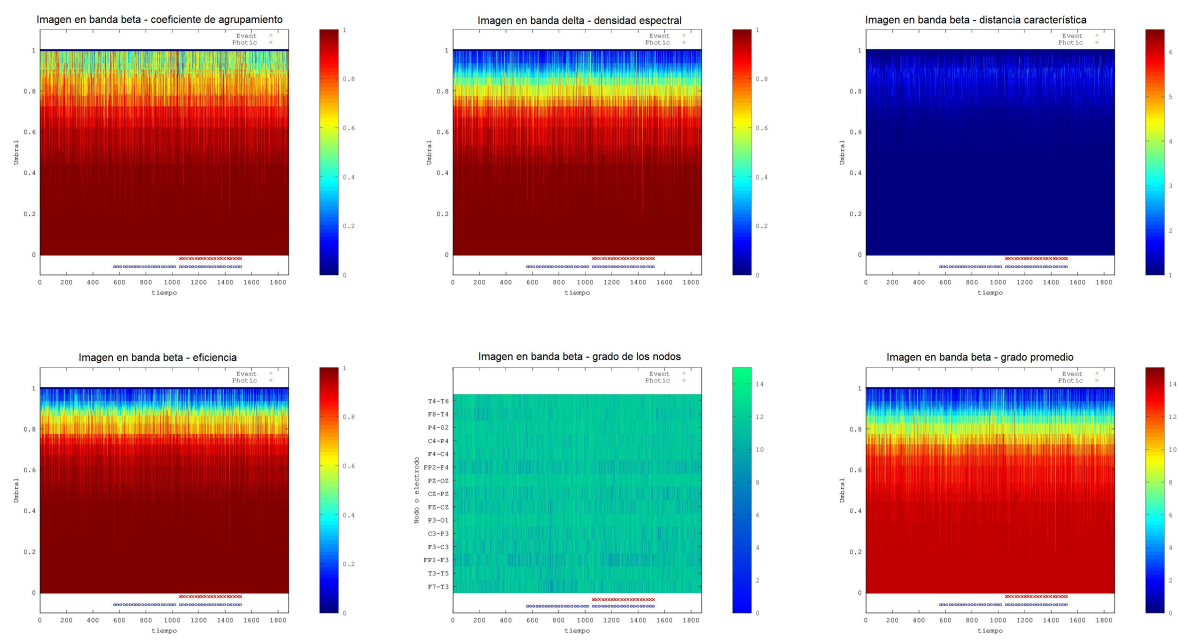

FiguRA 5.14: Imágenes representativas comportamiento de los seis parámetros de redes en las bandas theta, alfa y beta usando entropía cruzada espectral y arreglo bipolar en pacientes de EVC.
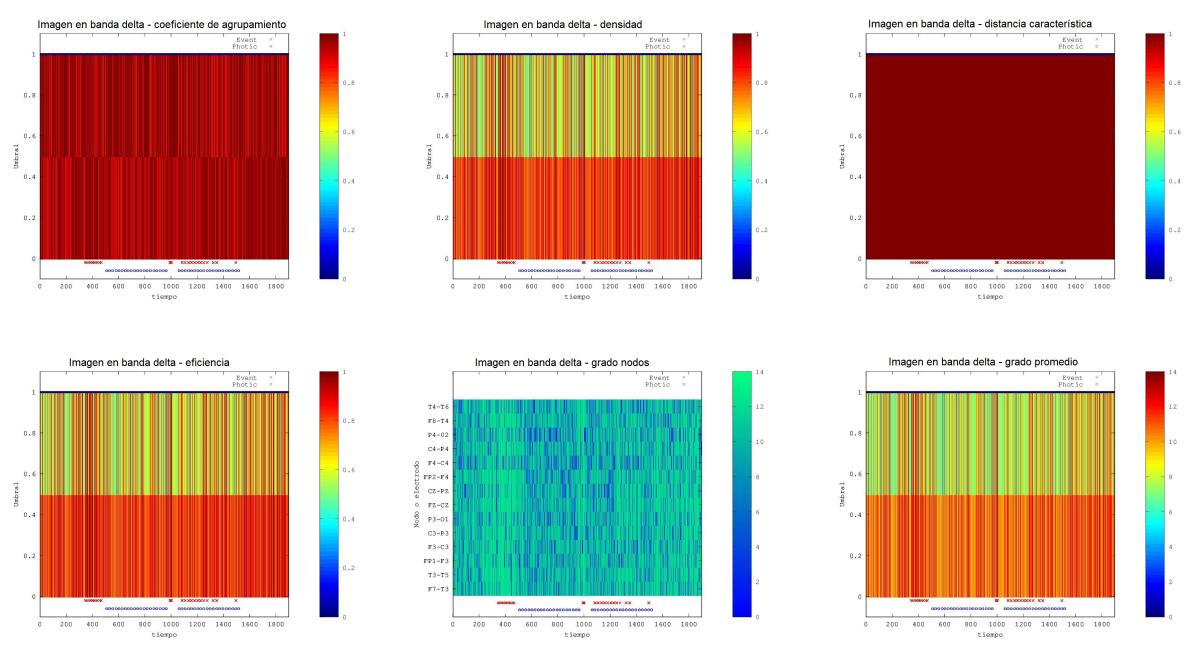

FiguRA 5.15: Imágenes representativas comportamiento de los seis parámetros de redes en banda delta, usando entropía cruzada espectral y arreglo bipolar en pacientes de EVC.

\subsection{Grupo Control}

El grupo control presenta dinámicas de los parámetros de redes donde no pueden hallarse diferencias entre los valores de los parámetros entre las etapas del protocolo como algunos de los pacientes de EVC. Sin embargo, entre los sujetos control se observan dos grupos: uno que muestra mayores valores de todos los parámetros y otro que presenta menores valores, dependiente de la banda de frecuencia analizada. 


\section{Coherencia}

En banda delta utilizando CAR y coherencia espectral; tres sujetos presentan la dinámica mostrada en la figura 5.16, con un comportamiento estable en todos los parámetros, por ejemplo para $\mathrm{C}$ se tiene que por debajo de un umbral de 0.1 se tiene un coeficiente cercano a 1 , por debajo de un umbral de 0.4 se tiene $\mathrm{C}$ alrededor de 0.5 . La densidad refuerza la idea anterior debido a que por debajo de 0.1 se tiene un gran número de conexiones pero baja rápidamente, por arriba de un umbral de 0.3 se tiene una densidad menor a 0.4 , es decir, se pierden conexiones. L varía entre 0.4 y 0.7 de umbral. En este mismo intervalo la eficiencia se encuentra por debajo del $30 \%$, por último G muestra un grado casi uniforme, sin que existan diferencias visibles en el número de conexiones por electrodo.
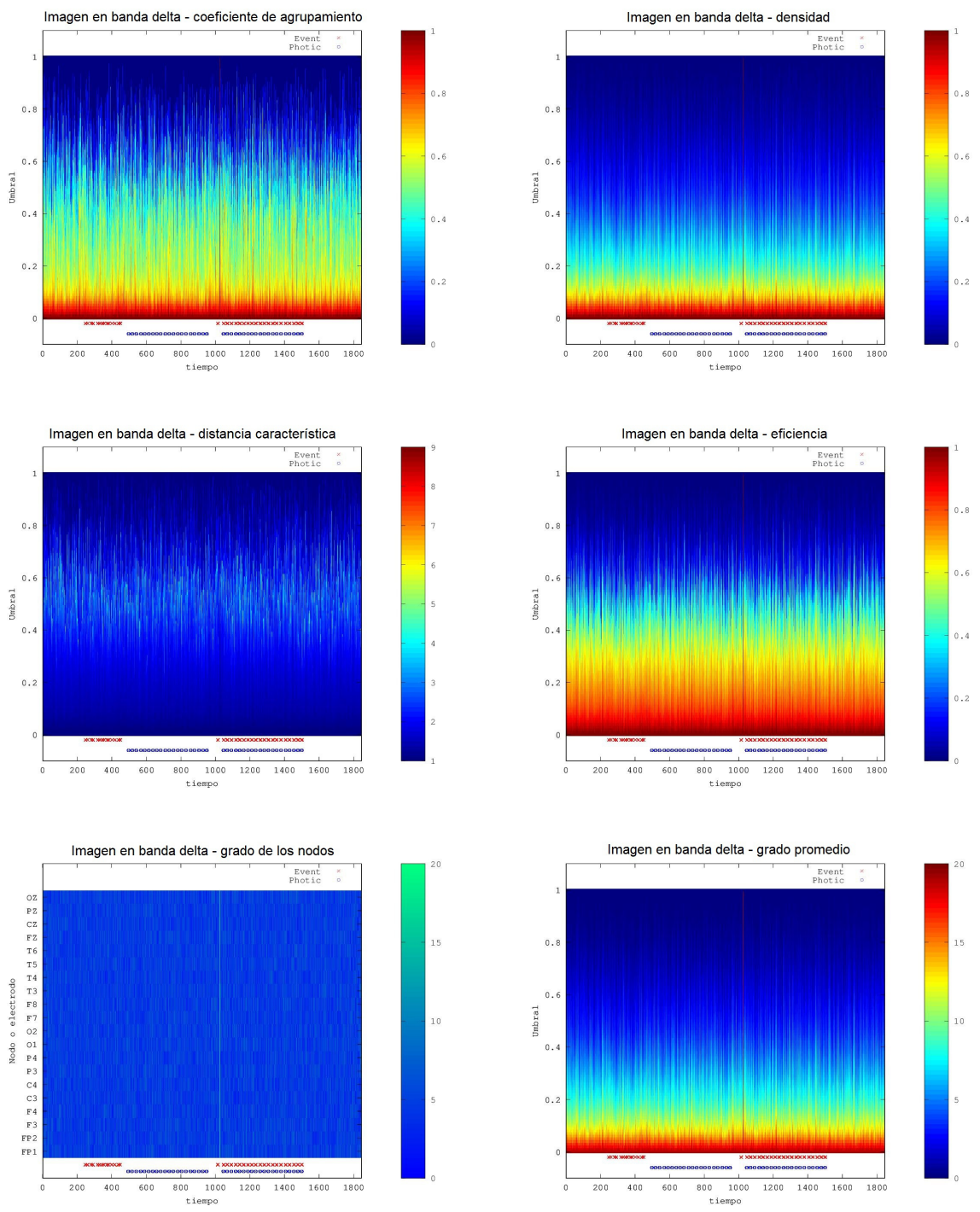

FiguRA 5.16: Imágenes representativas del comportamiento de los seis parámetros de redes en banda delta, usando coherencia y CAR en 3 sujetos del grupo control. 
Los otros tres sujetos presentan una disminución en las conexiones en los electrodos CZ, T4, F7, C3 para todo el tiempo del registro, C presenta tambien valores mayores que el primer grupo, primordialmente entre los umbrales 0.2 a 0.8 se tiene un coeficiente por encima de 0.6 .

En la banda theta cuatro sujetos de seis coinciden en el comportamiento de los parámetros calculados (figura 5.17). C muestra picos de incremento al inicio de la etapa de asociación, manteniendo un valor alto por debajo de 0.05. La densidad muestra que las redes tienen alta densidad de conexiones por debajo de 0.1 de umbral y disminuye gradualmente teniendo alrededor de un umbral de 0.4 el $40 \%$ de las conexiones máximas posibles. L muestra un intervalo de variación entre 0.5 y 0.8 con distancias entre 3 y 5 . El grado de los nodos disminuye en los electrodos Pz, T6, T4, F8, F7, P4 y C3.
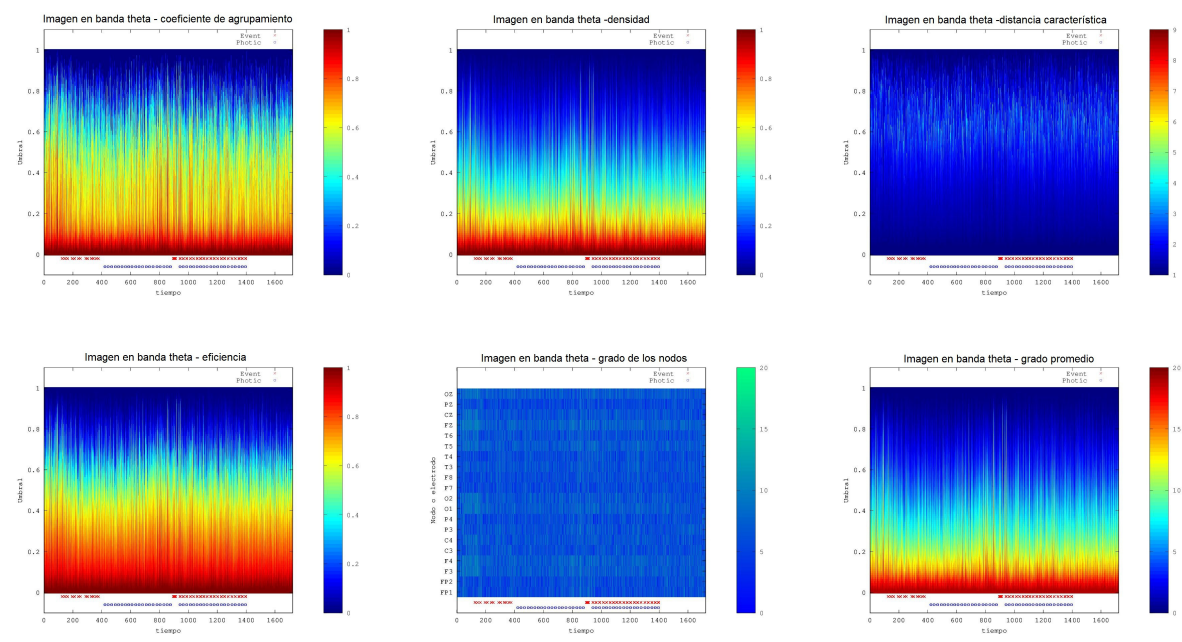

FigurA 5.17: Imágenes representativas del comportamiento de los seis parámetros de redes en banda theta, usando coherencia y CAR en 4 sujetos del grupo control.

C, L y eficiencia incrementan sus valores en la banda alfa para los seis sujetos. Además los electrodos T4, T3, C4, C3 mantienen un menor número de conexiones durante el registro de EEG. En la banda beta 5 sujetos muestran un dinámica muy similar a la presentada en la banda delta (figura 5.16), tan sólo en el grado de los nodos difiere en que los electrodos Pz, T6, T4, T3, F7, P4 y P3 mantienen un menor número de conexiones que los electrodos restantes.

El arreglo bipolar en banda delta muestra dinámicas semejantes a las obtenidas con CAR para C, L, grado promedio, densidad y eficiencia. Para el grado de los nodos los pares bipolares también presentan uniformidad en el valor del grado como se puede apreciar en la figura 5.18 con respecto a la figura 5.16. En banda theta el grado de los nodos muestra un decremento en el número de conexiones en los pares $F p 2-F 4, F p 1-C 3$, 
$F z-C z, F 8-T 4$, en la banda alfa y beta se presentan comportamientos similares en las misma bandas usando CAR.
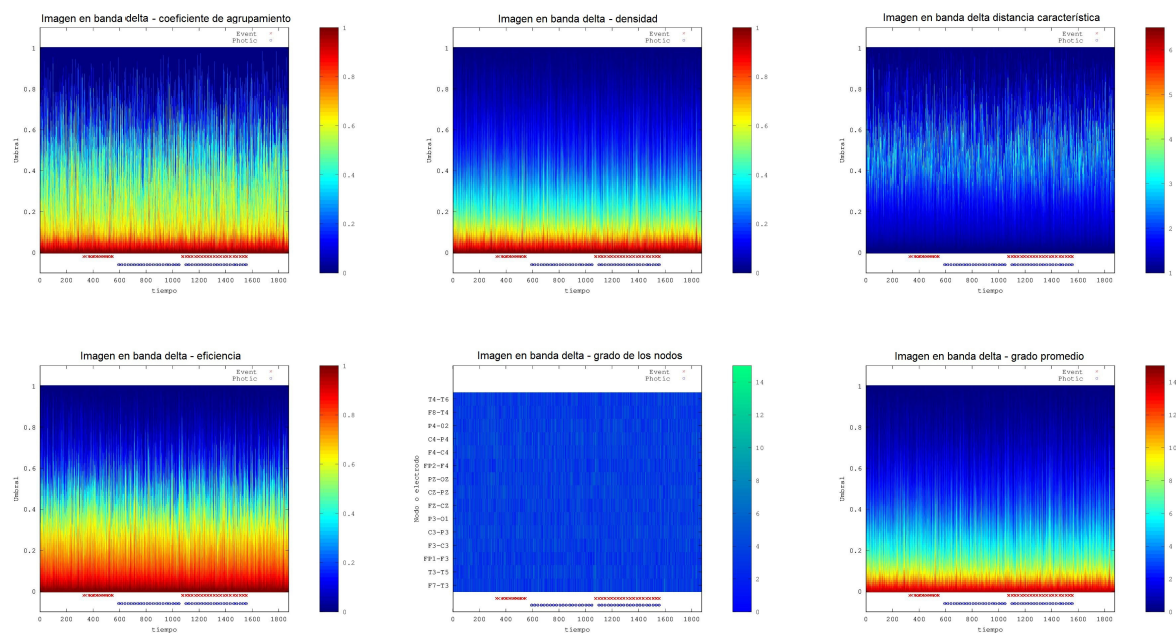

FigurA 5.18: Imágenes representativas del comportamiento de los seis parámetros de redes en banda delta, usando coherencia y arreglo bipolar en 3 sujetos del grupo control.

\section{Entropía cruzada temporal}

En banda delta, theta y alfa usando CAR cinco sujetos comparten características que se pueden observar en la figura 5.19, no presentan picos de incrementos o decrementos, sino se observa un tendencia definida, por arriba de un umbral de 0.6 se tiene el valor menor de cada parámetro, mientras que por debajo de de 0.4 se tiene su mayor valor. El grado de cada nodo se mantiene "estable" durante todo el tiempo de los registros para las bandas delta y theta. En la banda alfa el grado de los nodos muestra que los electrodos T6, T5, P3, y P4 pierden aproximadamente 4 conexiones durante todo el registro.

En la figura 5.20 se puede observar el comportamiento de los parámetros de redes en banda beta usando entropía cruzada y CAR. Se mantiene la tendencia mostrada en las otras bandas, una dinámica que se puede considerar estable.

Al usar el arreglo bipolar en tres sujetos se observa, en bandas delta, theta y alfa, la misma tendencia que con CAR para todos los parámetros menos G, sin embargo los tres sujetos restantes incrementan sus valores de C, entre 0.4 y 0.9 de umbral aún se tienen valores por arriba de 0.7 de coeficiente (ver figura 5.21), la densidad muestra que por debajo de 0.5 las redes contienen un gran número de conexiones a diferencia de los primeros 3 sujetos. L varía entre los umbrales de 0.5 y 0.95 con distancias que van desde 2 a 4 nodos y el grado de los nodos muestra que los pares $F p 2-F 4, P 4-O 2$ y $F p 1-F 3$ disminuyen en número de conexiones durante toda la duración del registro. En banda 

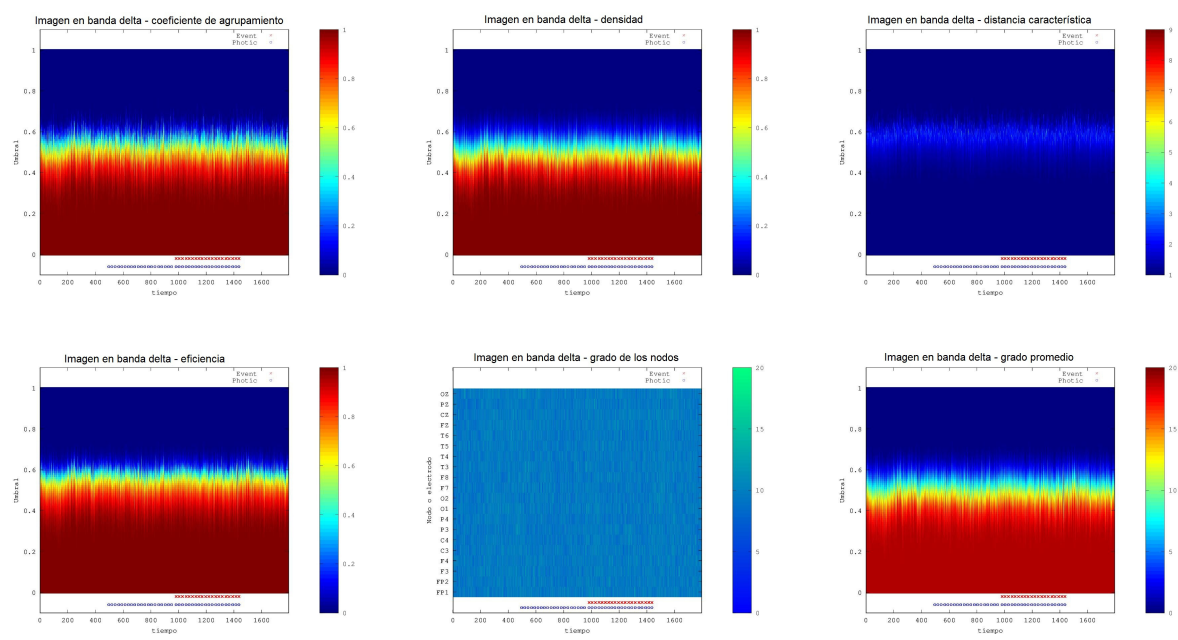

FigurA 5.19: Imágenes representativas del comportamiento de los parámetros de redes de cinco sujetos control en banda delta, theta y alfa, usando entropía cruzada temporal y CAR.
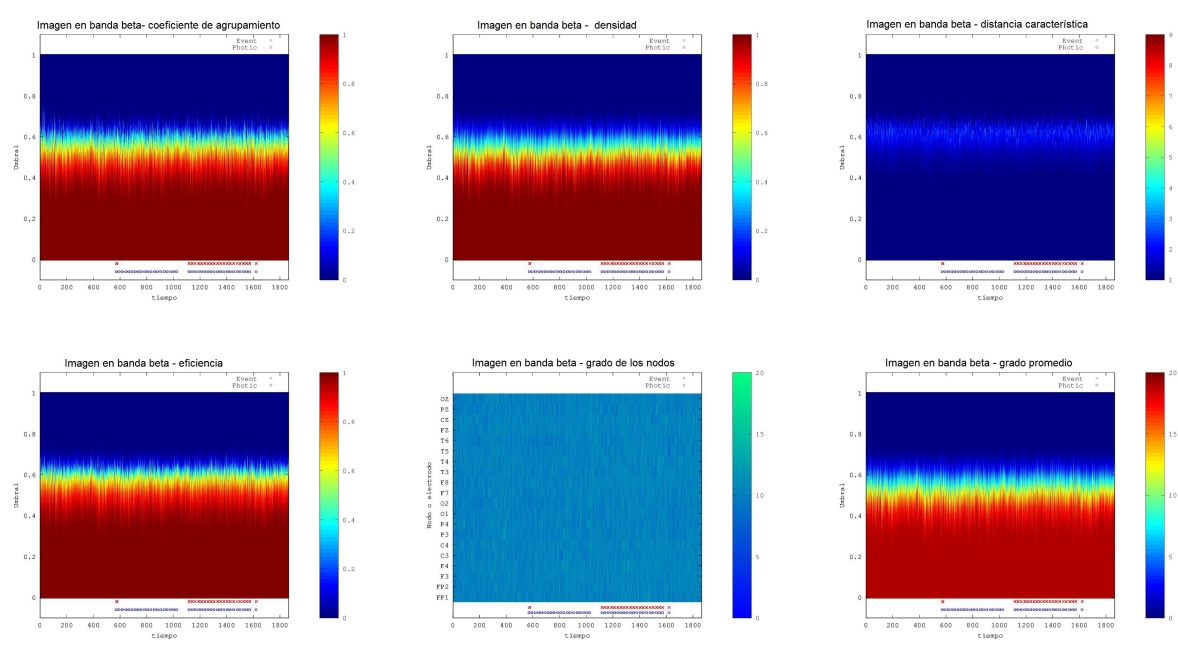

FiguRA 5.20: Imágenes representativas del comportamiento de los parámetros de redes de cinco sujetos control en banda beta, usando entropía cruzada temporal y CAR.

beta se obtiene una disminución en los valores de los diferentes parámetros obtenidos con respecto a las tres bandas restantes.

\section{Coherencia wavelet}

Los resultados muestran que al utilizar la coherencia wavelet con arreglo bipolar y CAR, en banda delta son muy similares a los obtenidos para el grupo de pacientes de EVC en los seis parámetros; a su vez la dinámica de las bandas theta, alfa y beta de los pacientes 

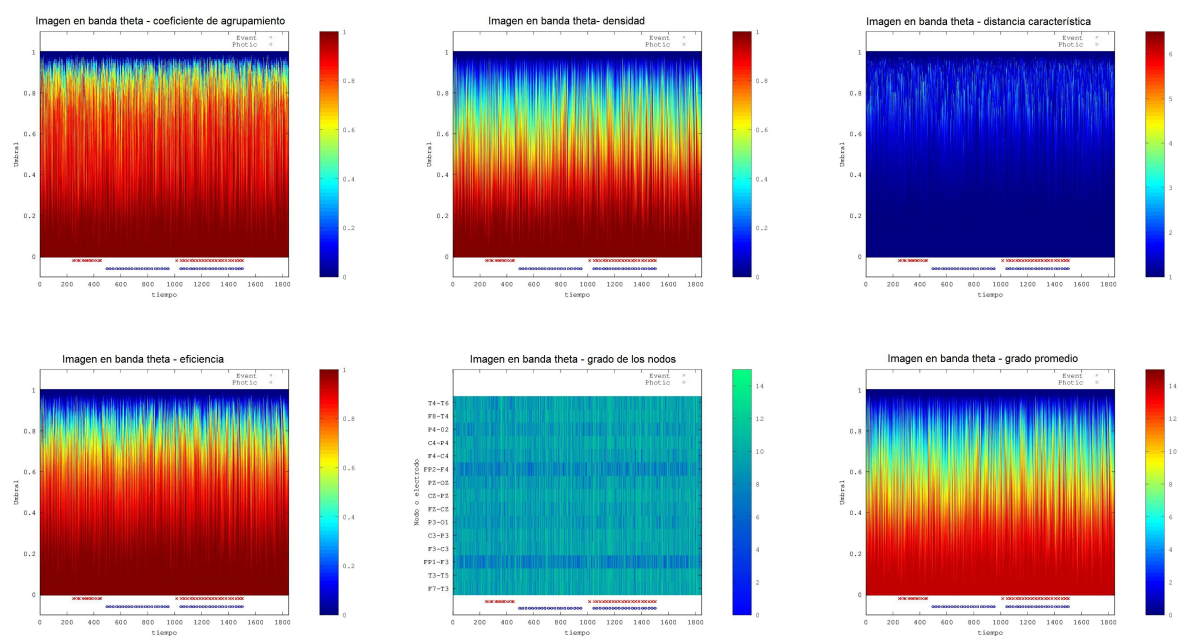

FigurA 5.21: Imágenes representativas del comportamiento de los parámetros de redes de cuatro sujetos control en bandas delta, theta y alfa usando entropía cruzada temporal y arreglo bipolar.

de EVC también son muy similares a los obtenidos en dichas bandas en el grupo control (ver figuras 5.11, 5.12, 5.13 y 5.22).
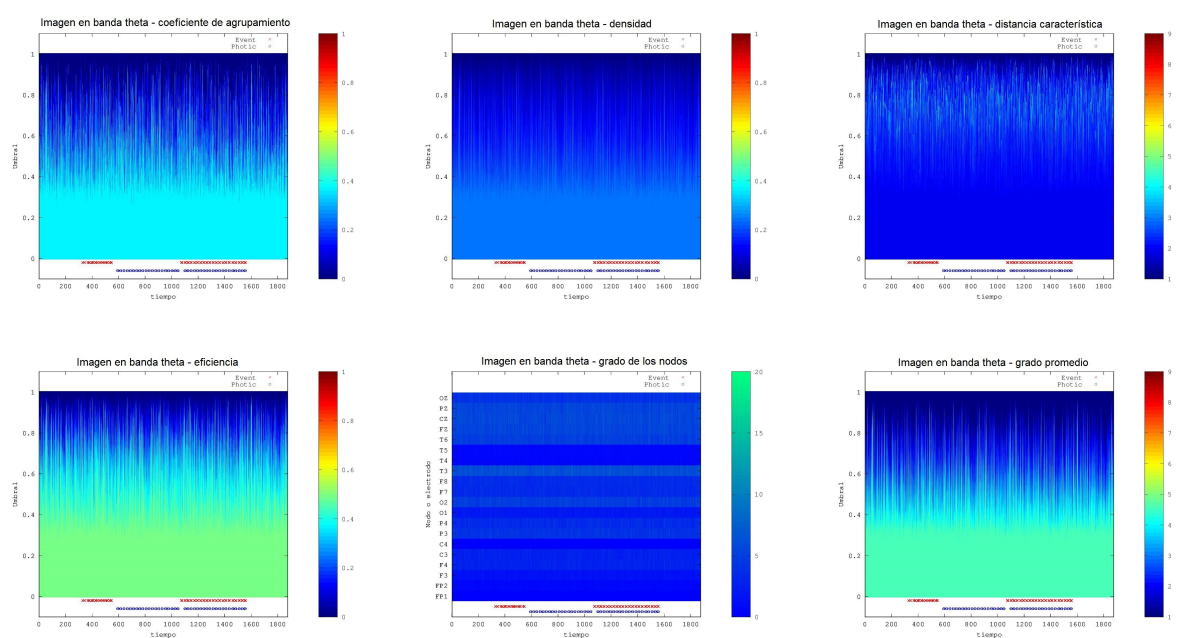

FigurA 5.22: Imágenes representativas del comportamiento de los seis parámetros de redes en banda theta, usando coherencia wavelet y CAR en el grupo control.

\section{Entropía cruzada espectral}

Los resultados utilizando la entropía cruzada espectral se muestran en las figuras 5.23 y 5.24. La primera figura corresponde al comportamiento de los 6 sujetos en las bandas theta y beta, y la segunda figura representa el comportamiento de los 6 sujetos en la banda delta; la banda alfa presenta siempre los valores máximos de cada parámetro. 

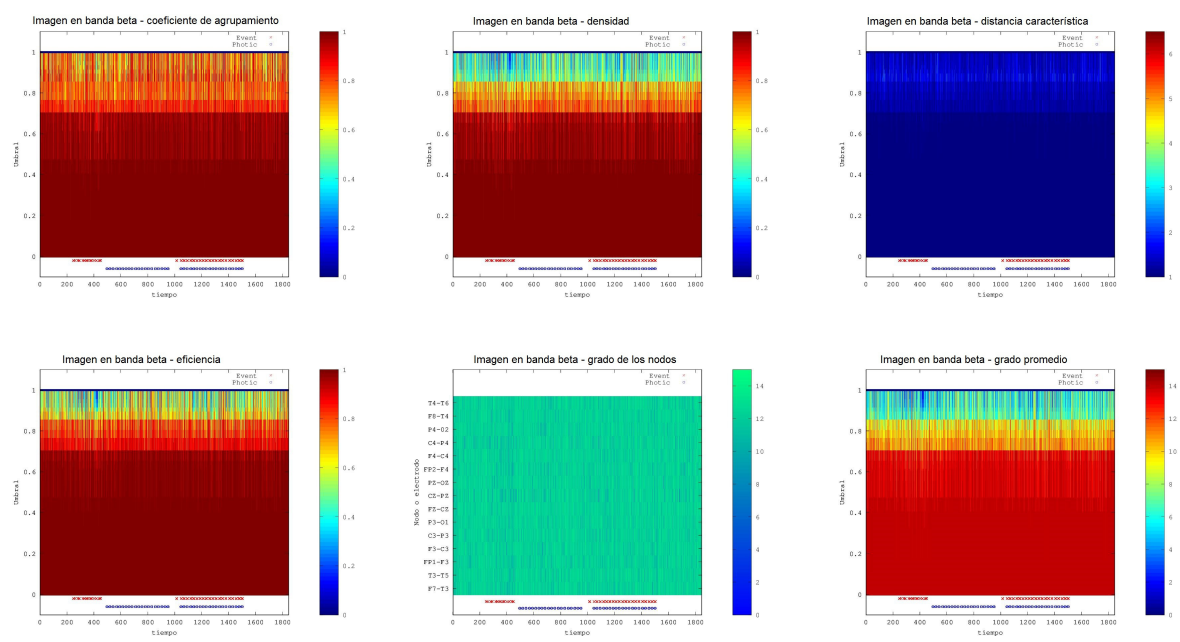

FiguRA 5.23: Imágenes representativas del comportamiento de los seis parámetros de redes en bandas theta, alfa y beta, usando entropía cruzada espectral y arreglo bipolar en el grupo control.
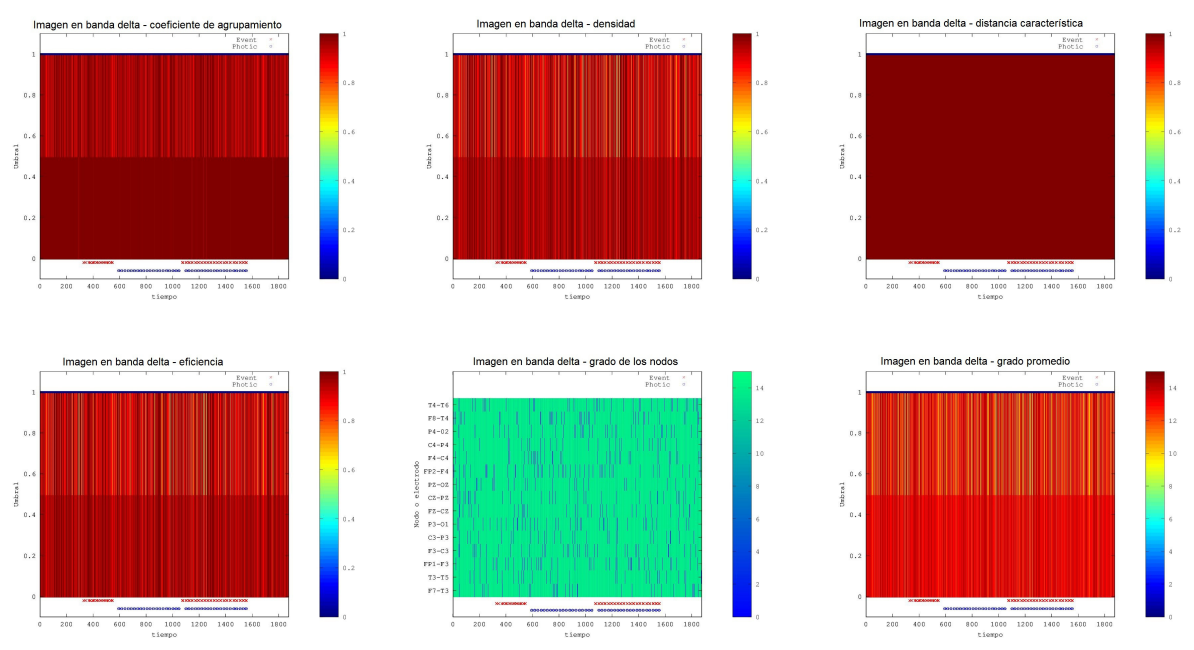

FiguRA 5.24: Imágenes representativas del comportamiento de los seis parámetros de redes en banda delta usando entropía cruzada espectral y arreglo bipolar en el grupo control.

\subsection{Curvas poblacionales}

Para complementar los resultados presentados anteriormente se obtuvieron curvas promedio del grupo control y grupo de pacientes de EVC. Dichas curvas concentran el comportamiento de cada uno de los parámetros de redes obtenidos para cada uno de los 101 valores de umbral y muestran el promedio y desviación estándar de cada grupo. Así esta representación, en base al valor del parámetro y el umbral de conectividad, muestra si ambas curvas promedio se diferencian o no. 


\section{Bandas delta y theta}

Las curvas promedio en banda delta y theta usando CAR se muestran en la figura 5.25. Se puede observar que la curva correspondiente al grupo control tiene una desviación mayor que la del grupo de pacientes de EVC, abarcando una región de la curva del grupo de pacientes. Ésta desviación es provocada por la dinámica de los parámetros de redes de tres sujetos del grupo control. Si no se toman en cuanta para la obtención de la curva promedio, la desviación disminuye notablemente, mostrando curvas diferenciadas (figura 5.26). La banda delta muestra que los parámetros de redes de los sujetos control disminuyen más rápido que los pacientes de EVC y en banda theta este comportamiento es inverso.

En las figuras 5.27 y 5.28 se muestran también las curvas con todos los sujetos control y quitando a los sujetos que presentan una mayor desviación del grupo en bandas delta y theta.

En la figura 5.29 se puede presentan diagramas de caja para el parámetro de densidad en banda delta donde se puede observar que el grupo control presenta valores atípicos, mismos que provocan una desviación y que la curva del grupo control se superponga a la curva de los pacientes de EVC, principalmente en banda delta y theta.

\section{Banda alfa y beta}

A diferencia de las bandas delta y theta, las bandas alfa y beta no presentan curvas diferenciadas en ambos casos (grupo control completo y quitando los datos de los sujetos con mayor desviación) como se muestra en las figuras 5.30 y 5.31, es decir, las curvas se superponen durante casi todos los valores de umbral de conectividad.

Con estas curvas, se puede observar un resumen de los resultados mostrados en las representaciones de cada uno de los parámetros de redes, se encuentran principales diferencias en el comportamiento de dichos parámetros en banda delta y theta (sin incluir a los sujetos control que crean una desviación alta). 

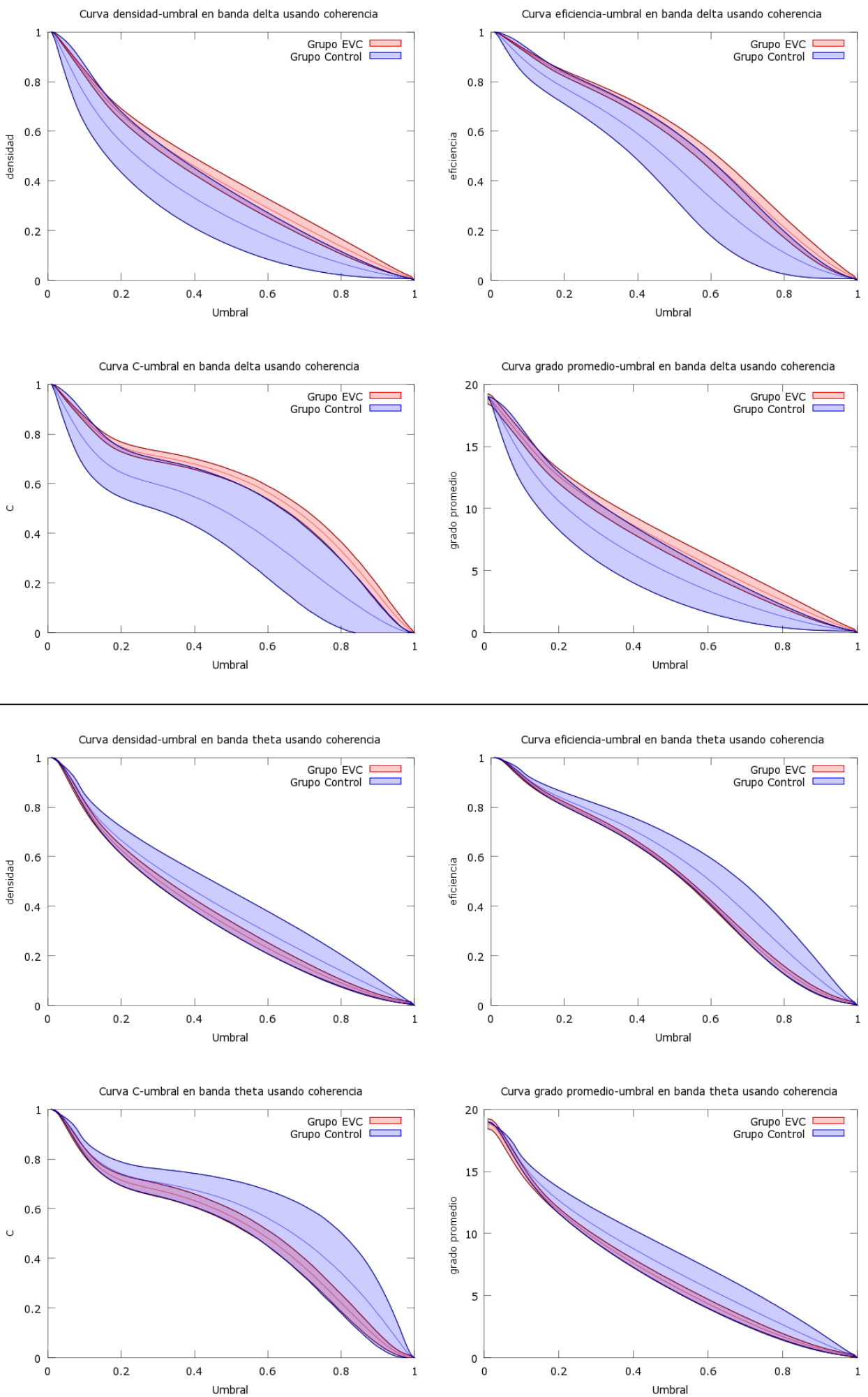

FIGURA 5.25: Curvas promedio del grupo control (todos los sujetos) y EVC en banda delta y theta usando coherencia y CAR. 

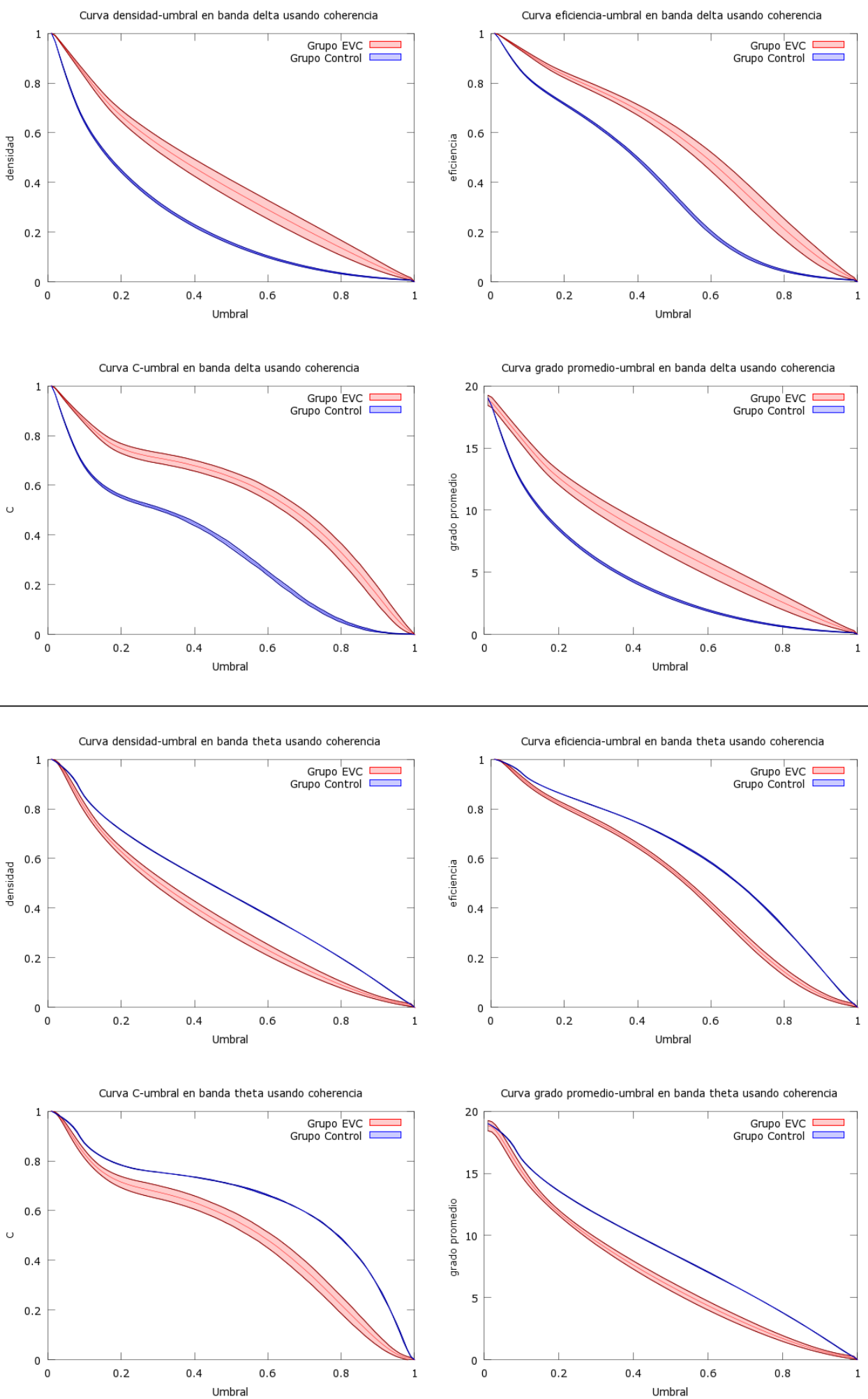

Figura 5.26: Curvas promedio del grupo control (sin tres sujetos) y EVC en banda delta y theta usando coherencia y CAR. 

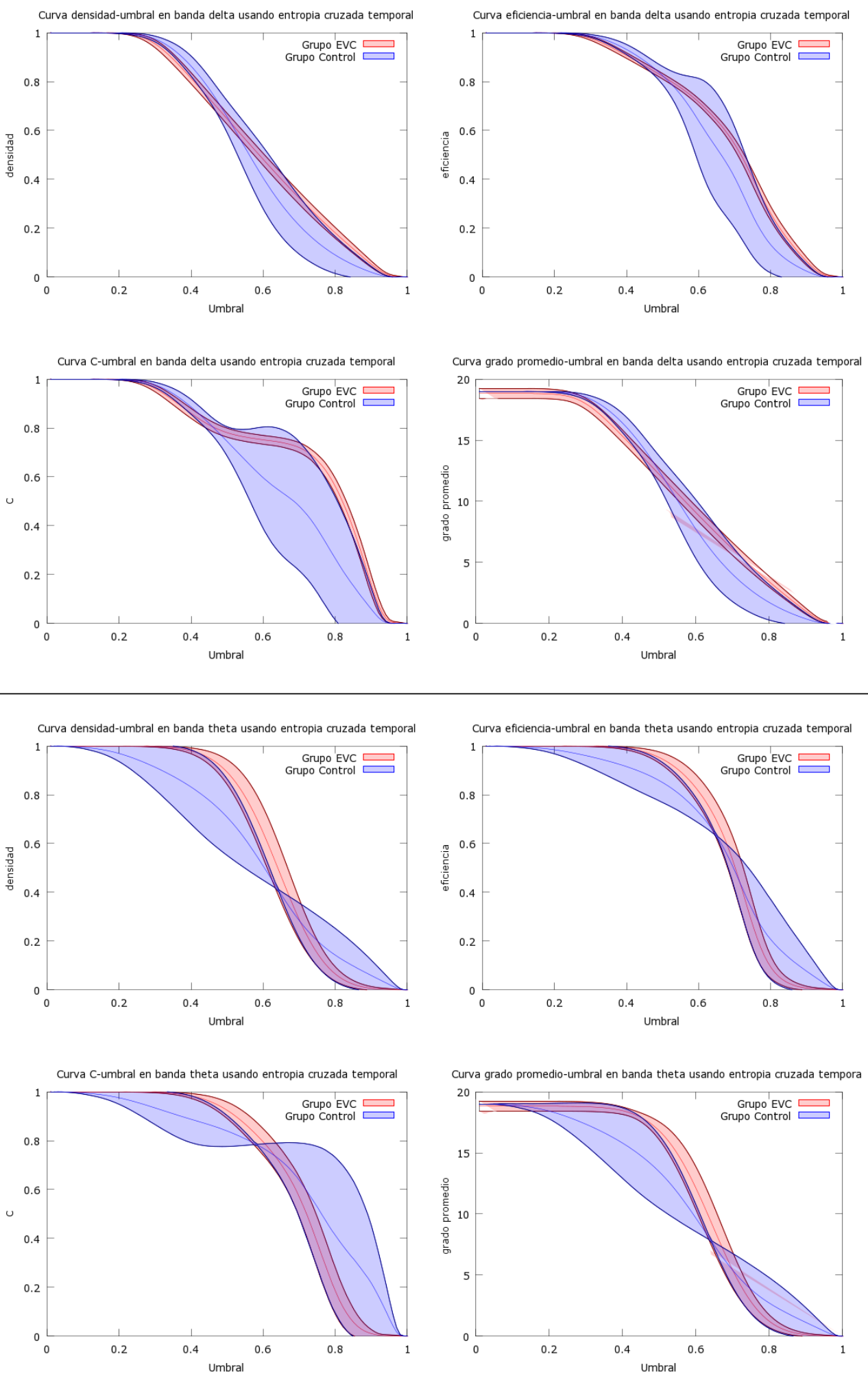

FIGURA 5.27: Curvas promedio del grupo control y EVC en banda delta y theta usando entropía cruzada temporal y CAR. 

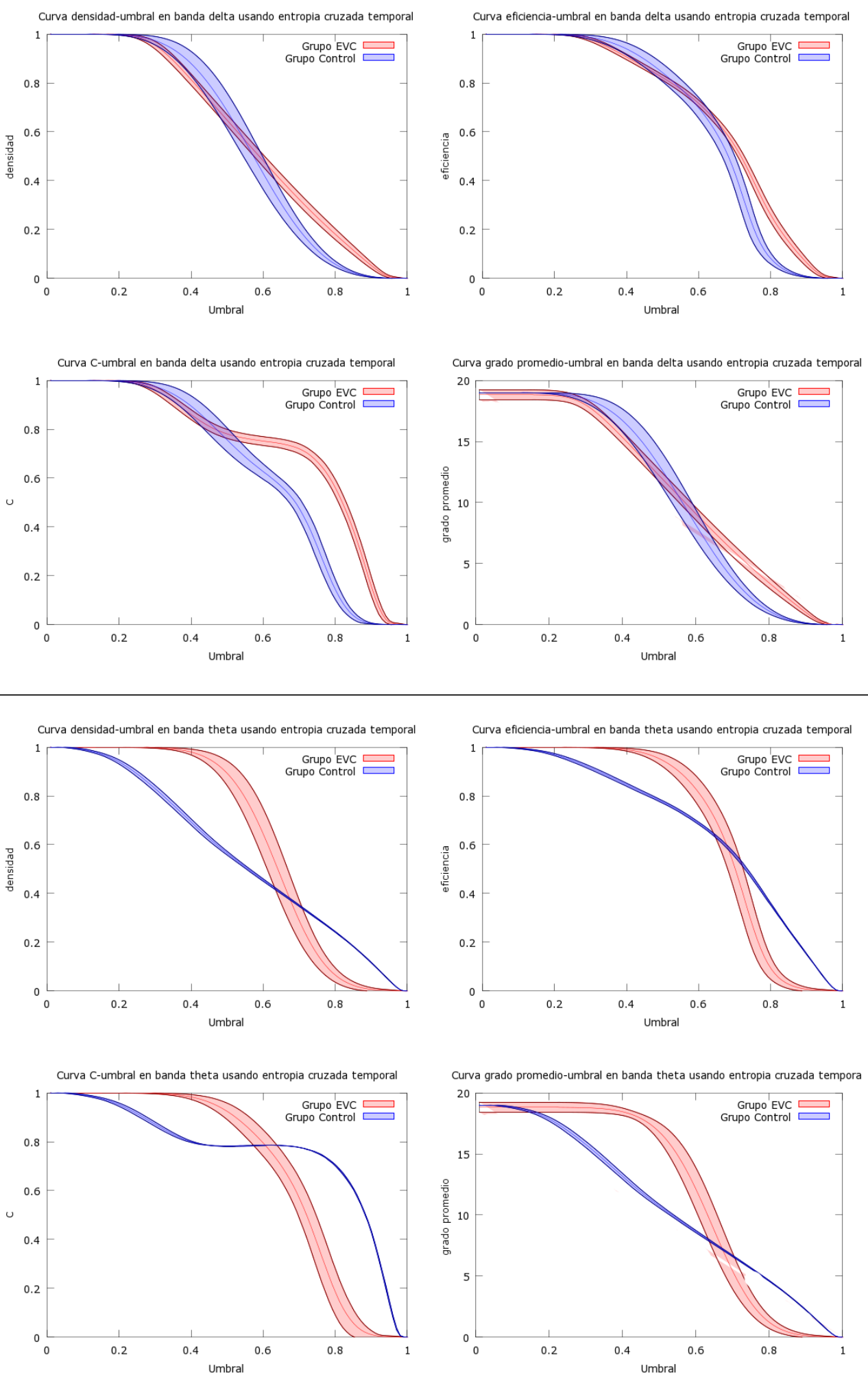

FigurA 5.28: Curvas promedio del grupo control (sin tres sujetos) y EVC en banda delta y theta usando entropía cruzada temporal y CAR. 


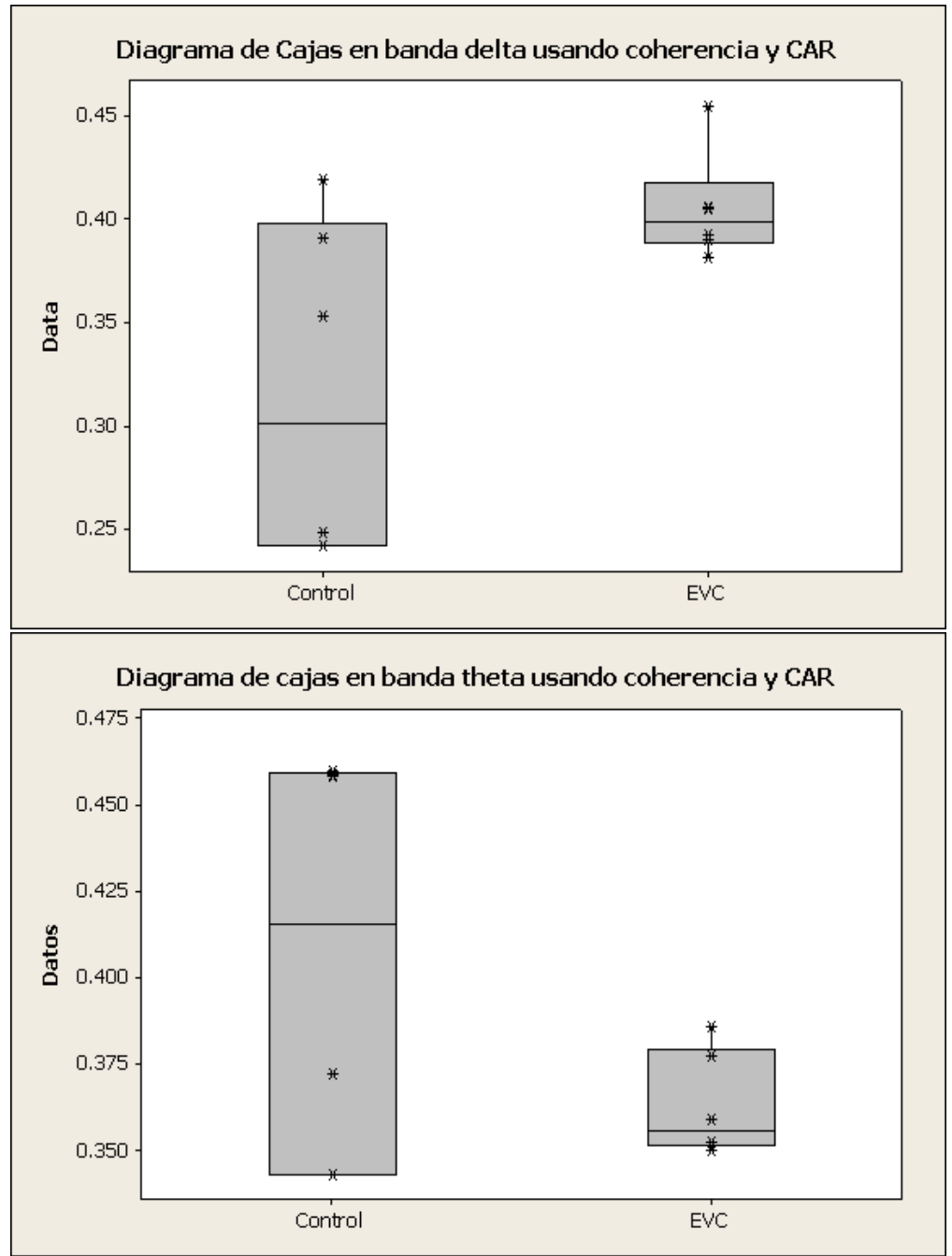

Figura 5.29: Diagrama de cajas en banda delta y theta usando coherencia y CAR con el parámetro densidad. 

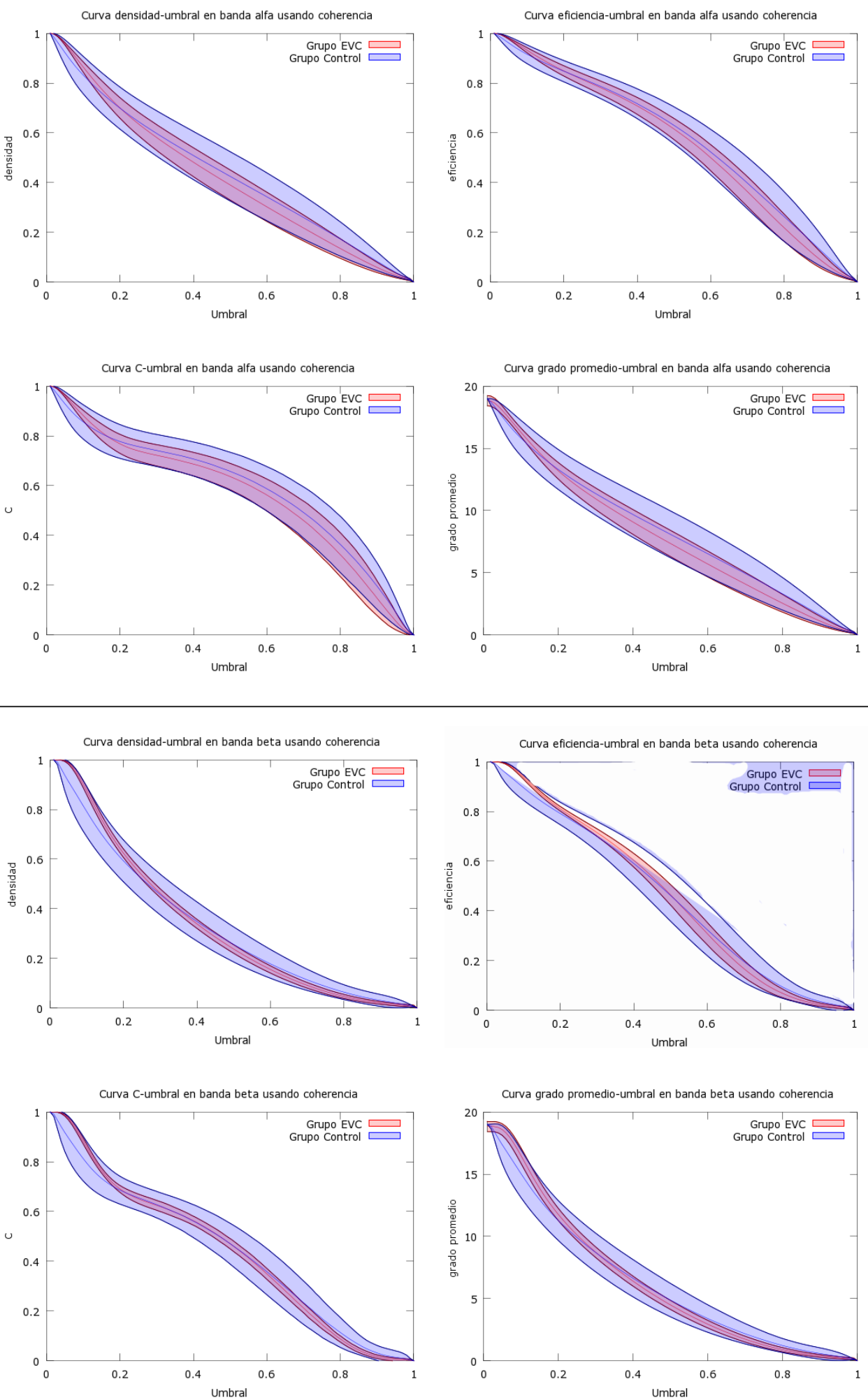

FIGURA 5.30: Curvas promedio del grupo control y EVC en banda alfa y beta usando coherencia y CAR. 

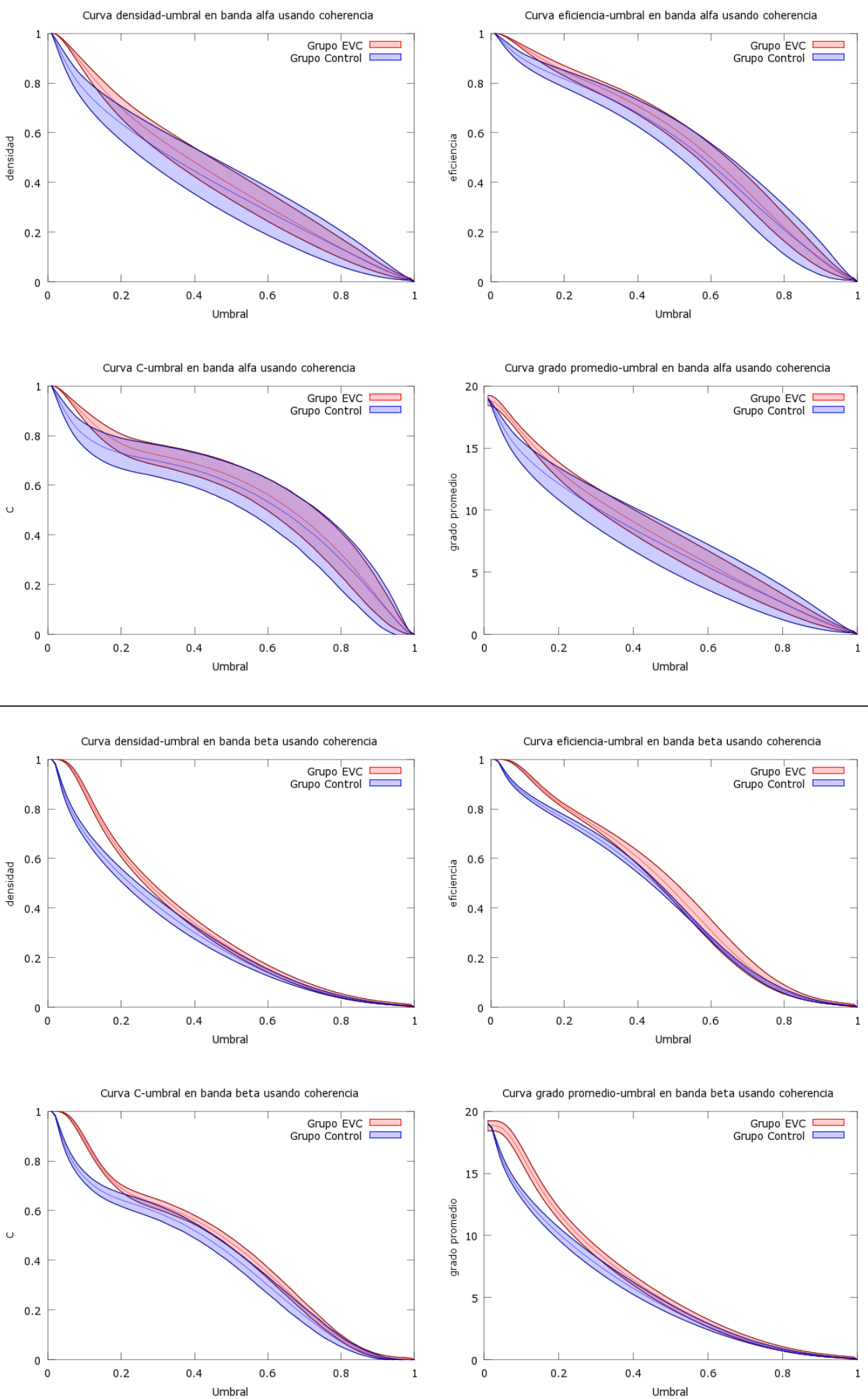

FIGURA 5.31: Curvas promedio del grupo control (sin tres sujetos) y EVC en banda alfa y beta usando coherencia y CAR. 


\section{Capítulo 6}

\section{Conclusiones}

Este trabajo se centra en el desarrollo de una metodología y una herramienta computacional para el análisis de gráficas de conectividad funcional cerebral a partir del EEG. Dicha metodología y herramienta permiten el análisis de las FCG, obtenidas mediante cuatro medidas de conectividad, de manera sistemática. Permite obtener información de los registro de EEG a utilizar, procesar de manera adecuada las señales para la remoción de artefactos así como el filtrado en banda para obtener resultados de aplicación diferenciados.

A partir de la estimación del nivel de conectividad entre la actividad cerebral generada en diferentes regiones, es posible que exista una relación funcional en dichas áreas, por lo tanto se estimaron las distribuciones de las conexiones, éstas distribuciones se visualizaron para medidas no direccionales y medidas direccionales. Esta visualización de las FCG para cada instante de tiempo permite conocer el desarrollo y la dinámica de los patrones funcionales cerebrales en base al valor de conectividad entre todos los pares de electrodos; lo anterior da un soporte para la interpretación de la cuantificación de los parámetros de cada FCG obtenida. Esta cuantificación se despliega en una imagen tiempo-umbral-valor del parámetro que brinda información acerca de la dinámica de cada parámetro en la duración del registro. Una de las aportaciones de este trabajo fue no elegir un sólo valor de umbral de conectividad, sino analizar una variación continua de éste para observar la dinámica de los parámetros en base a dichos umbrales.

Dos de los seis parámetros elegidos en este trabajo son los que modelan las redes de pequeño-mundo $(C$ y $L)$. La eficiencia es una medida que surge a partir del cálculo de L, sin embargo, el grado de los nodos, el grado promedio, la densidad y grado promedio son medidas básicas de descripción de la teoría de gráficas, estas se añadieron como complemento a las medidas $\mathrm{C}$ y L. 
Para este trabajo la técnica de re-referencia del promedio de los electrodos $A 1$ y $A 2$ no brinda información relevante del comportamiento de los parámetros de las gráficas de conectividad funcional, ya que a partir de dicha técnica las diferentes medidas de conectividad muestran una alta conectividad entre todos los electrodos para ambos grupos (pacientes de EVC y control). Las dos técnicas restantes se utilizaron para obtener los parámetros de las redes encontrando información relevante como se mencionó en el capítulo 5 .

Existen diferencias cualitativas entre la dinámica de los diversos parámetros calculados para el grupo control y pacientes de EVC dependientes de la medida conectividad utilizada, así como de la banda de frecuencia de interés. Dichas diferencias se observan principalmente en las bandas delta y theta utilizando la medida de coherencia espectral y entropía cruzada temporal. Dos de los seis pacientes de EVC presentaron etapas diferenciadas del protocolo de EEG, es decir, durante la etapa de fotoestimulación se obtiene que la eficiencia de las redes de conectividad disminuye considerablemente ya que se pierden conexiones entre todos los electrodos, provocando que grupos locales de conectividad disminuyan su interacción a nivel global. Esto implica que en intervalos de umbral entre 0.2 y 0.8 la distancia mínima oscile entre 2 y 5 nodos, por lo que es necesario que la información tenga que pasar por más nodos intermedios para llegar a su destino final, a diferencia de las etapas de asociación y basal donde se tiene la distancia mínima promedio de 1 a 2 . Lo anterior indica que en éstas últimas etapas la información fluye de manera casi directa entre el nodo fuente y nodo destino.

El segundo grupo de pacientes de EVC no presenta alguna dinámica característica en base a la diferencia de las etapas del protocolo de EEG, sin embargo, sus valores de parámetros son mayores que los presentados por el grupo control en todas las bandas; adicionalmente la entropía cruzada temporal muestra que los electrodos colocados en los lóbulos frontales (principalmente) pierden conexiones con respecto al resto de electrodos, lo que da indicios de que la conectividad en dichos lóbulos en pacientes de EVC disminuye. Esto contrasta con un grupo de sujetos control ya que presentan comportamientos con una tendencia definida en todos los parámetros, donde no se pueden apreciar pérdidas de conexiones en electrodos o etapas diferenciadas.

El segundo grupo de sujetos control presenta pérdida de conexiones en los electrodos en Pz, T6, T4, P4, C3, F8 y F7 en banda theta usando coherencia y CAR, mientras que la entropía cruzada temporal indica que pierden conexiones temporales (T6 y T5) y parietales (P3 y $\mathrm{P} 4$ ) en banda alfa.

La implementación de la coherencia wavelet no refleja diferencias entre los pacientes de EVC y el grupo control, en las distintas bandas. Se piensa que debido a la implementación de la reducción de cada matriz de conectividad tiempo-frecuencia a un sólo valor se afecta 
el valor de conectividad obtenido y resulta en una dinámica similar para pacientes de EVC y grupo control.

La medida de entropía cruzada espectral no otorga información que refleje alguna característica o patrón entre el grupo control y el grupo de pacientes de EVC. Se piensa que las funciones de densidad para cada segmento de tiempo son muy similares, dando como resultado un valor alto de conectividad. Una alternativa sería utilizar un patrón de referencia de la entropía cruzada espectral, es decir, en la etapa basal obtener un espectro de potencia que represente el estado basal del sujeto (para cada electrodo) y utilizarlo para comparar las señales de generadas en las diversas etapas del protocolo.

Las curvas promedio de las dinámicas de los parámetros de redes presentadas muestran que dichos parámetros del grupo control en banda delta disminuyen más rápido que los del grupo de pacientes, en banda theta se tiene el escenario inverso, lo anterior sólo aplica cuando se eliminan los datos de tres sujetos control que presentan una desviación mayor a la que presentan los sujetos restantes. En banda alfa y beta las curvas promedio no se diferencian ya que ambas curvas se superponen. Lo anterior refuerza los resultados, se puede observar una diferencia entre las dinámicas de ambos grupos en bandas delta y theta principalmente, en los parámetros obtenidos.

A partir de los resultados de las cuatro medidas para la estimación de la conectividad cerebral, se descartarían la coherencia wavelet y entropía cruzada espectral (con la implementación descrita). La coherencia y entropía cruzada temporal brindan información interesante pero al ser medidas no comparables (una lineal y otra no lineal) no se puede elegir alguna medida principal ya que ambas observan relaciones diferentes a pesar que arrojen coincidencias en la dinámica de los parámetros de redes.

Como trabajo futuro se propone ampliar ésta herramienta con parámetros de otro modelo de red como sería el de redes libres de escala [102]. Este modelo podría dar una perspectiva diferente al uso del grado de los nodos debido a que el planteamiento del modelo depende de dicho parámetro caracterizado por una ley de potencia, así se podría tratar de estimar el grado de distribución característico para cada grupo. También podría añadirse un análisis estructural mediante tractografía.

El trabajo presentado no sólo propone la inclusión de parámetros de red para el análisis de la conectividad funcional cerebral, también establece una metodología para el procesamiento de las señales de EEG para la estimación de los niveles de conectividad entre todos los electrodos y brinda la presentación de manera gráfica de la información para un mejor entendimiento de la información obtenida: patrones de conectividad y dinámica de los parámetros de redes. Los resultados de la aplicación de la herramienta computacional propuesta en pacientes de EVC se deben estudiar en colaboración de 
neurofisiólogos para tratar de interpretar de una mejor manera los resultados expuestos. Este sería un siguiente paso para complementar un futuro trabajo con miras a la utilización de la técnica explorada en el campo clínico. Se piensa que con la mejora y adición de otros modelos de redes o técnicas como la tractografía, esta perspectiva del estudio de conectividad cerebral puede brindar datos relevantes que puedan ayudar a entender un poco más acerca del cómo y del por qué de la interacción entre diversas regiones del cerebro. 


\section{Apéndice A}

\section{Teoría de Gráficas}

En 1736, la ciudad de Königsberg se preguntaba si sería posible cruzar los siete puentes de la ciudad y regresar al punto inicial sin pasar por un puente dos veces. Durante años en la opinión pública, dominaba la idea que era imposible, sin embargo, nadie lo había comprobado de manera concluyente. Leonard Euler abordó el problema mediante una gráfica (figura A.1), una abstracción de una red a partir de nodos (vértices) conectados mediante aristas (enlaces), Euler afirmó que no era posible sentando las bases de la teoría de gráficas. Años después, Kirchoff desarrolló una representación gráfica con la cual modelaba sus leyes de voltajes y corrientes de un circuito eléctrico, esta representación es usada aún en la actualidad. La teoría de gráficas, iniciada por Euler, es una herramienta para analizar las características de una red, como abstracción de un problema o modelo.

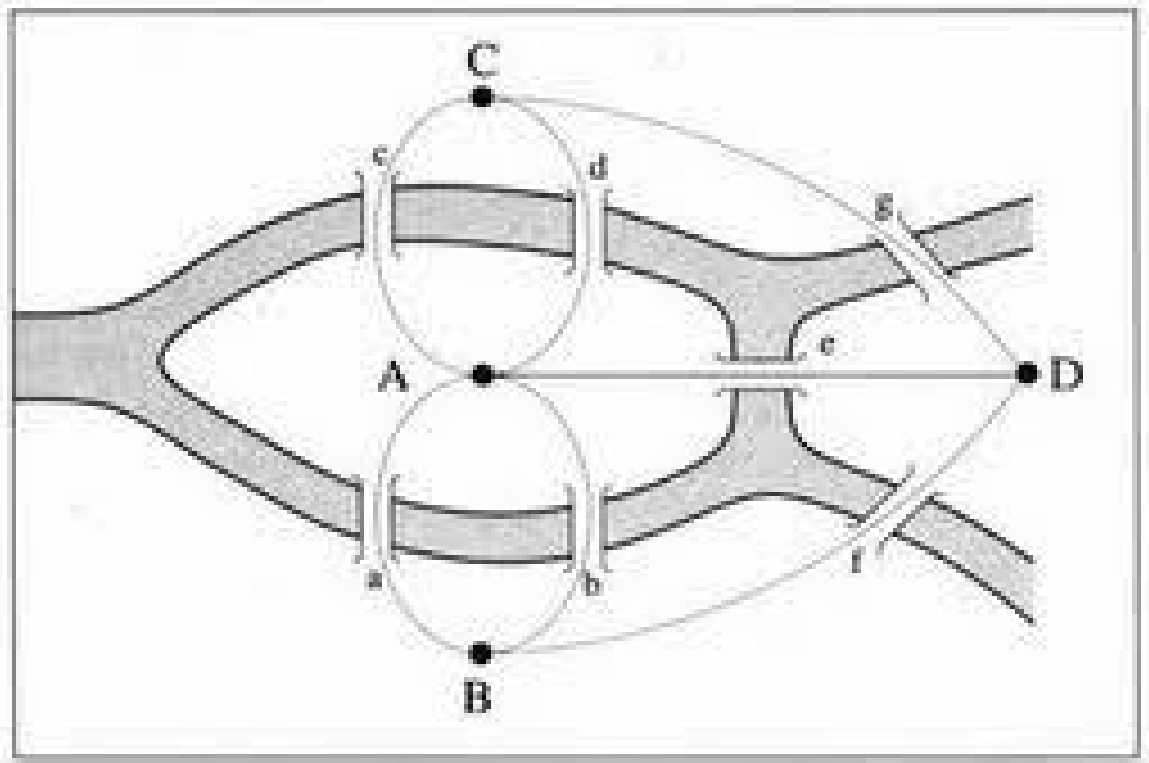

Figura A.1: Los siete puentes de Königsberg y la gráfica desarrollada por Euler mediante nodos y aristas. 
en 1959 Erdos y Renyi [103] desarrollaron el concepto de redes aleatorias, caracterizadas por que los nodos están conectados de acuerdo a una probabilidad de conexió $p$, pero en ausencia de estudios sobre redes de gran tamaño (con este modelo) fueron utilizadas rara vez en el mundo real [102], además que no se han encontrado fenómenos que sean descritos por la red aleatoria.

En 1967 Stanley Milgram [104], realizó un experimento social que consistía en enviar un gran número de cartas a personas escogidas aleatoriamente dentro de los Estados Unidos. El objetivo era que estas personas trataran de enviar la carta correspondiente a una persona específica en Boston, y para realizar lo anterior había una regla a seguir: que se conociera el nombre de la persona (intermediario) a utilizar para enviar la carta a su destinatario final. Los resultados fueron interesantes, en promedio se requirieron 6 pasos (personas) para que la carta llegara a su destinatario en Boston. A partir de ahí se propuso que en una red muy grande, un elemento de la red (persona) puede comunicarse con cualquier otro elemento (en cualquier región) a través de un número reducido de pasos, este fenómeno conocido como conectividad de mundo pequeño (small world) no pudo ser explicado por la teoría clásica de gráficas. Hasta ese momento, en la teoría clásica se tienen dos tipos de redes: aleatoria (random) y otra con conexiones regulares (lattice), con un coeficiente de agrupamiento alto y una longitud característica alta), ambos son extremos ya que muchas redes encontradas en la biología, tecnología y relaciones sociales se describen con modelos que se ubican entre ambas redes extremas. Años después, a finales de los noventa, Watts y Strogatz [105] exploraron un modelo de red que puede caminar en medio de dichos extremos: redes con conexiones regulares pero con una dosis de desorden, por medio del parámetro $p$, el cual es la probabilidad de reconexión entre los nodos. Para dicho modelo, se parte de una red de conexiones regulares, donde cada nodo está conectado a $k$ vecinos más cercanos y conforme la probabilidad $p$ crece se crean conexiones aleatorias entre dos nodos, en la figura A.2 se observa el procedimiento de reconexión partiendo de una red regular hasta llegar a un red aleatoria, formulado por Watts y Strogatz. Esta nueva red puede tener un alto grado de agrupamiento (propiedad de redes regulares) y mantener una longitud de camino característica menor (propiedad de redes aleatorias). La llamaron red smallworld o pequeño-mundo, como analogía con el fenómeno observado por Milgram. En ese trabajo, concluyen que la red neuronal del gusano Caenorhabditis elegans, la red de energía del oeste de Estados Unidos así como la gráfica de colaboración de actores de cine son redes de pequeño-mundo.

También dichos autores, muestran que las redes de pequeño-mundo son altamente efectivas para la transmisión de la información, redes escasamente conectadas con una configuración de pequeño-mundo se sincronizan mucho mejor que una red regular. En el contexto de conectividad funcional cerebral (analizado con fMRI y MEG), el modelo 


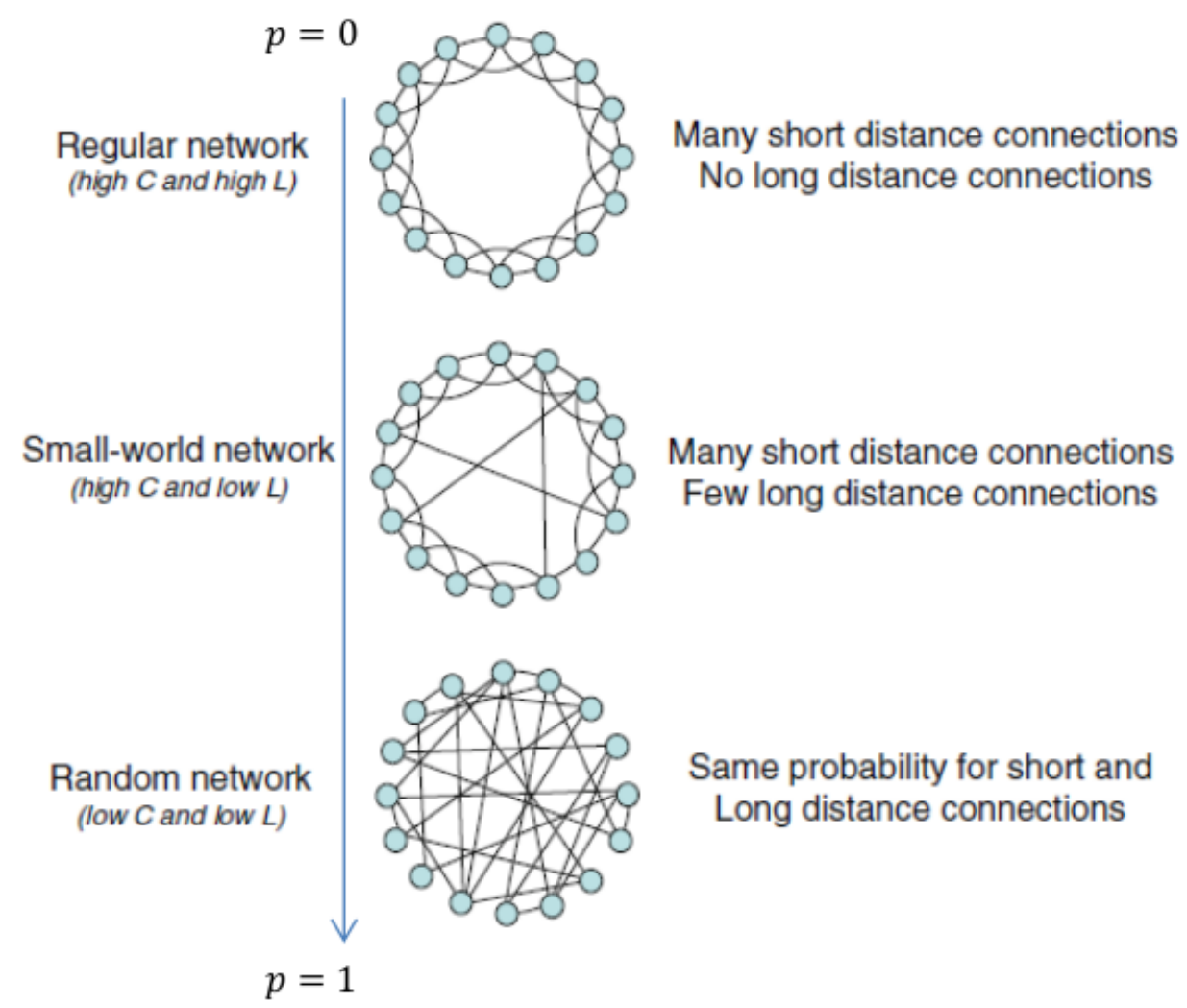

FigurA A.2: Procedimiento de reconexión partiendo del extremo de red regular, con una probabilidad igual a 0 , es decir, no hay ningún enlace aleatorio entre los nodos. Conforme se incrementa el valor de p, se pasa por una red intermedia (pequeño-mundo) y por último el caso extremo cuando $\mathrm{p}=1$, se obtiene una redaleatoria. Imagen tomada y modificada de [106].

de pequeño-mundo ha demostrado ser una arquitectura óptima para el procesamiento y propagación de la información entre diferentes regiones cerebrales, además la modificación de las propiedades de la red de pequeño-mundo tiene una relación con la presencia de enfermedades o síndromes del cerebro humano.

Un año después, Barabasi y Albert [102] proponen un modelo en base al crecimiento de una red, donde existe una probabilidad de que una nueva conexión se añada a un nodo dependiendo del grado de dicho nodo, lo que da como resultado que los vértices con un grado mayor (mayor número de conexiones) tienen más probabilidades de conseguir más conexiones . En su estudio examinaron la red WWW (World Wide Web) así como los patrones de referencias, dando como observación que la probabilidad $P(k)$ de que un nodo de la red interactúe con $k$ nodos se describe como una ley de potencia $P(k) \sim k^{-\gamma}$, es decir, la red generada bajo este modelo es caracterizada por el grado de distribución descrita con dicha ley de potencia; a estas redes descritas se les llama redes scale-free o de libres de escala. Una de las propiedades más interesantes de dichas redes es que mantienen una longitud característica extremadamente baja. A partir de estas dos últimas redes, 
se despierta el interés por describir distintas funciones del cuerpo humano mediante las redes complejas, por ejemplo en el cerebro humano se empieza a estudiar la conectividad entre diferentes regiones del cerebro, es decir, la conectividad funcional, usando la teoría de gráficas. 


\section{Apéndice B}

\section{Código}

A continuación se describen las funciones . $m$ desarrolladas en este trabajo.

\section{B.1. Registros Electroencefalográficos}

Para acceder a la información de los registros se creó una función leereeg.m que permite obtener una matriz $X$ con las series de tiempo de todos los canales utilizados; cada serie de tiempo es un vector columna de dicha matriz, las etiquetas de los canales de EEG colocados se almacenan en la variable listacanales, la frecuencia de muestreo $f s$ así como información del paciente (si se ingresó al momento de la adquisición), información eléctrica, filtrado analógico, todo lo anterior contenido en la estructura de datos head. La función identcanales. $m$ obtiene las coordenadas de los electrodos $X Y$ y necesarias para graficar las posiciones de los electrodos, dicha función requiere los siguientes parámetros: 
- X. Matriz que contiene las series de tiempo de todos los canales del registro de EEG.

- Label. Estructura que contiene toda la información relacionada al registro de EEG (head).

- Canales. (Opcional) Vector que contiene las etiquetas de los electrodos que se desean eliminar, de manera predeterminada se eliminan A1, A2, ECG, EOG, es decir se eliminan electrodos que no fueron colocados en el cuero cabelludo, pero es posible eliminar uno o varios electrodos colocados en el área cerebral por ejemplo ['fp1';' fp2';'c4'].

- Canales_enc. (Opcional) Vector que contiene etiquetas de canales específicos dados por el usuario, esto con el fin de obtener un identificador de la serie de tiempo correspondiente a uno o varios electrodos, para su posterior uso. Puede aplicarse a electrodos del cuero cabelludo o no.

y regresa los siguientes parámetros: 
- $Y$. Canales utilizados en la adquisición bajo el Sistema Internacional 10-20, es decir, es capaz de adaptarse al número de electrodos utilizados siendo capaz de reconocer más de 100 canales de EEG.

- Canales. Etiquetas de los canales identificados, necesario para obtener la gráfica de conectividad.

- Numcanales. Indica el número de canales identificados y con los cuales se realizará el análisis de conectividad.

- Codigo. Corresponde a un vector que contiene los códigos de los electrodos identificados, dichos códigos corresponden a la codificación de BioSig.

- XY. Obtiene las coordenadas de los electrodos para obtener posteriormente la gráfica de conectividad.

- Etiqueta. Vector que contiene todas la etiquetas posibles de los canales de EEG.

- $C$. Vector que contiene todos los pares de electrodos posibles de acuerdo a los canales identificados.

- Canales_encontrados. Vector que regresa el número de columna de la matriz $X$ que corresponde a un o varios electrodos específicos, es decir, contiene un identificador de la serie de tiempo de canales que se requieren utilizar, esto facilita su acceso posterior.

Como se observa se dota de una función que simplifica la identificación de los canales requeridos para el análisis de conectividad, sus coordenadas, código de identificación, etiquetas (nombres de electrodos) pero también de supresión y localización de otros electrodos.

\section{B.2. Procesamiento de señales}

\section{Remoción de Artefactos}

La función elim_eog_f.m realiza la remoción de artefactos requiriendo cuatro parámetros de entrada: 
- Aux1. Matriz de registro de EEG, cada canal en vector columna (corresponde al parámetro $Y)$.

- Tam_vent. Es el tamaño en muestras de la ventana a analizar, p.e. 256 muestras.

- Umbral. Valor de umbral a comparar con la prueba de Shapiro-Wilk en cada segmento.

- Fs. Valor de la frecuencia de muestro del registro.

\section{CAR}

La función que realiza CAR es car.m y como parámetro de entrada solo requiere la matriz de las señales de los electrodos $Y$, previamente obtenida con identcanales.m y regresa la matriz re-referenciada.

\section{Promedio de A1 y A2}

Se realiza con la función ref_prom_a.m y requiere los siguientes parámetros de entrada:

- $Y$. Matriz que contiene las series de tiempo del registro en vectores columna de los electrodos a analizar (se obtiene mediante identcanales.m).

- X. Matriz que contiene las series de tiempo de todos los canales del registro de EEG.

- Canales_encontrados. Vector que contiene los identificadores de los canales A1 y A2 (se obtiene mediante identcanales.m con el parámetro canales_enc= ['a1';'a2']).

El único parámetro que regresa la función es $Y$, que contiene la matriz re-referenciada.

\section{Arreglo bipolar}

La función que obtiene el arreglo bipolar es bipolar.m, esta función requiere siguientes parámetros de entrada que se describen a continuación: 
- $Y$. Matriz que contiene las series de tiempo del registro en vectores columna de los electrodos a analizar (se obtiene mediante identcanales.m).

- XY. Coordenadas de los electrodos en arreglo monopolar.

Los parámetros de salida son:

- $Y$. Matriz que contiene los datos del arreglo bipolar.

- Canales. Etiquetas de los canales identificados para el arreglo bipolar.

- Numcanales. Indica el número de canales identificados del arreglo bipolar.

- XY. Obtiene las coordenadas de los nodos del arreglo bipolar.

- C. Vector que contiene todos los pares de electrodos posibles de acuerdo a los canales identificados del arreglo bipolar.

Por último se realizó una función re_referencia.m, y su objetivo es realizar alguna de las técnicas de re-referencia, está pensada para facilitar la elección de las técnicas que en un futuro se puedan adicionar a este trabajo. Los parámetros de entrada son:

- $Y$. Matriz que contiene las series de tiempo del registro en vectores columna de los electrodos a analizar (se obtiene mediante identcanales.m).

- Tecnica. Se elige para utilizar 'CAR', 'promedio' de A1y A2 y 'bipolar'.

- X. Matriz que contiene las series de tiempo de todos los canales del registro de EEG (en el caso de usar 'promedio', en el caso de elegir para 'bipolar'debe ser la matriz de coordenadas monopolares.

- Canales_encontrados. Vector que contiene los identificadores de los canales A1 y A2 (se obtiene mediante identcanales.m con el parámetro canales_enc= ['a1';'a2']).

La técnica de re-referencia por omisión es CAR, bastando con introducir el parámetro $Y$, para el promedio de $A 1$ y $A 2$ y arreglo bipolar es necesario introducir los demás parámetros. 


\section{Filtrado Digital}

La función desarrollada para este trabajo es pasabandas.m, donde se utilizan funciones del paquete de procesamiento de señales digitales (signal) incluido en Octave, dicha función puede utilizar ventana Hamming o Káiser y requiere los siguientes parámetros:

- X. Matriz de las series de tiempo a filtrar en banda, (cada canal debe ser un vector columna).

- wc1. Frecuencia de corte baja en $\mathrm{Hz}$.

- wc2. Frecuencia de corte alta en HZ.

- $f s$. Frecuencia de muestreo del registro de EEG.

- $N$. Orden del filtro deseado.

- ventana. 'vhamming' o 'vkaiser', de manera predeterminada se usa la ventana de Hamming.

El procedimiento que realiza la función pasabandas.m se describe a continuación:

- De acuerdo a la ventana a utilizar se lee o calcula el orden del filtro:

- Ventana Hamming. Se usa una longitud $N+1$, donde $N$ es el orden proporcionado por el usuario.

- Ventana Káiser. Se utiliza la función kaiserord.m (paquete signal de Octave) para calcula el orden del filtro necesario al usar esta ventana y también obtiene el valor de $\beta$.

- Se calculan los coeficientes del filtro FIR mediante la función fir1.m (paquete signal de Octave), necesarios para obtener la respuesta en frecuencia requerida por el usuario.

- Se convolucionan los coeficientes del filtro con las señales a filtrar. 


\section{B.3. Medidas de conectividad}

\section{Coherencia}

La función coherencia.m usa pwelch.m para calcular dicho valor de coherencia, pero también implementa la reducción a un sólo valor y requiere los siguientes parámetros:

- $Y$. Matriz de las series de tiempo, con artefactos removidos, con técnica de rereferencia y filtrada en banda previamente.

- $f s$. Frecuencia de muestreo del registro.

- C. Vector que contiene todos los pares de electrodos posibles de acuerdo a los canales identificados.

- window. (Opcional) Longitud de la ventana para el cálculo del espectro de potencia mediante el método de Welch.

Los parámetros de salida son:

- Zintegral. Matriz de conectividad o asociación, obtenida mediante el área bajo la curva normalizada de los valores de coherencia.

- Zmedian. Matriz de conectividad o asociación, obtenida mediante la mediana de los valores de coherencia.

- espcru. Matriz que contiene los valores de coherencia, en todo el rango de frecuencias, entre cada par de electrodos posibles.

- freq. Vector de semillas de frecuencia a los cuales se obtuvo los valores de coherencia.

\section{Coherencia Wavelet}

La función que realiza la coherencia wavelet es coherencia_w.m y requiere los siguientes parámetros: 
- $Y$. Matriz de las series de tiempo, con artefactos removidos, con técnica de rereferencia y filtrada en banda previamente.

- $f s$. Frecuencia de muestreo del registro.

- C. Vector que contiene todos los pares de electrodos posibles de acuerdo a los canales identificados.

- nescalas. (Opcional) Número de escalas deseadas, el valor predeterminado es el criterio de bajo las ecuaciones 4.23 y 4.24 .

Los parámetros de salida de dicha función son:

- cohe_w. Matriz de conectividad o asociación wavelet.

- scale. Vector de escalas utilizadas para la CWT.

Cabe destacar que la implementación de coherencia_w.m incluye funciones tomadas del toolbox waveletcoherence [107] y de wave_matlab [99].

\section{Entropía cruzada}

La función que realiza la entropía de Kullback-Leibler es kullback_leibler_distance.m, para poder utilizarla se debe instalar el paquete informationtheory de Octave, y requiere tan solo las funciones de densidad estimadas para el par de señales de los electrodos a analizar.

\section{Entropía Cruzada Temporal}

$\mathrm{Al}$ partir en segmentos de cierta duración los registros de EEG, se estima la función de densidad de probabilidad para cada segmento (pdf) y dada dicha función de densidad se calcula la entropía cruzada de Kullback-Leibler comparando dos funciones de densidad de dos series de tiempo, el valor obtenido (para cada segmento) se almacena en una matriz de manera provisional (Z), lo anterior se realiza para todos los electrodos del registro. La función implementada es entropía_cruzada.m y requiere de los siguientes parámetros: 
- X. Matriz de las series de tiempo, con artefactos removidos, con técnica de rereferencia y filtrada en banda previamente.

- $f s$. Frecuencia de muestreo del registro.

- C. Vector que contiene todos los pares de electrodos posibles de acuerdo a los canales identificados.

- tipo. 'histograma' o 'kernel' para el método de estimación de la función de densidad, de manera predeterminada se usa 'histograma'.

\section{Entropía Cruzada Espectral}

Para cada segmento, se calcula el espectro de potencia de ambas series de tiempo mediante la función pwelch.m, se estima la pdf por histograma o kernel (elección del usuario) y se obtiene la distancia de Kullback-Leibler, dicho valor se almacena en una matriz temporal Z. La función para obtener la entropía cruzada espectral es entropía_cruzada_espectral.m y sus parámetros de entrada son:

- X. Matriz de las series de tiempo, con artefactos removidos, con técnica de rereferencia y filtrada en banda previamente.

- $f s$. Frecuencia de muestreo del registro.

- $C$. Vector que contiene todos los pares de electrodos posibles de acuerdo a los canales identificados.

- window. (Opcional). Longitud de la ventana para el cálculo del espectro de potencia mediante el método de Welch.

- tipo. 'histograma' o 'kernel' para el método de estimación de la función de densidad, de manera predeterminada se usa 'histograma'.

Para ambas funciones, el único parámetro de salida es la matriz $Z$ (matriz de asociación).

\section{Matriz de conectividad}

Las funciones mencionadas coherencia.m, coherencia_w.m, entropia_cruzada_temporal.m y entropia_cruzada_espectral.m generan una matriz de asociación, dado un segmento de tiempo de entrada. Se agruparon de las matrices de asociación en una matriz de 
conectividad para facilitar la implementación. La función que obtiene la matriz de conectividad para una medida indicada, es medidasconectividad.m. La función medidasconectividad2.m, obtiene las cuatro medidas de conectividad, por lo tanto al tener que calcular las 4 medidas para toda la duración del registro de EEG conlleva una carga computacional así como tiempo necesario muy grande, hay factores que afectan la duración del proceso, por ejemplo la cantidad de escalas a utilizar en la coherencia wavelet, la longitud del registro, el número de segmentos $(T)$ en los que se parte el registro de EEG, el número de canales o electrodos del registro $(N)$. Es por ello que también se incluye medidasconectividad.m, al obtiene una sola medida de conectividad para todo el registro requiere menor poder de procesamiento y de tiempo. Ambas funciones requieren los mismos parámetros a diferencia de uno, la elección de la medida de conectividad:

- $Y$. Matriz de las series de tiempo, con artefactos removidos, con técnica de rereferencia y filtrada en banda previamente.

- C. Vector que contiene todos los pares de electrodos posibles de acuerdo a los canalesidentificados.

- $f s$. Frecuencia de muestreo del registro.

- pasos. (Opcional, escalar). Resolución deseada del vector de umbralización (entre más cercano a 0 , el costo computacional se incrementa) el valor predeterminado es 0.01 .

- segmento. (Opcional, escalar). Indica la duración de los segmentos de tiempo en los que se partirá el registro de EEG (en segundos). El valor predeterminado es 1 segundo.

- medida. (Sólo para medidasconectividad.m).Elección de la medida de conectividad a calcular: 'coherencia', 'coherencia_w', 'entropia_cruzada' o 'entropia_cruzada_espectral'.

Ambas funciones (medidasconectividad.m y medidasconectividad2.m) guardan las matrices resultantes de conectividad, así como una matriz de tiempo $(1 x T)$, la cual contiene el tiempo al que se calculó cada matriz de conectividad y un vector de umbral $(1 x U)$, dicho vector de umbral se utilizará para cuantificar los parámetros de las redes complejas y así estudiar la dinámica en base al valor de conectividad. Las matrices de asociación se almacenan en vectores columna, por ejemplo si se tiene un registro con 20 electrodos y una duración de 1000s, con un tiempo de duración de los segmentos de 1s se obtendrán 1000 matrices de asociación y a su vez, la matriz de conectividad se conformará de 1000 vectores columna (matrices de asociación) y 400 filas $\left(20^{2}\right)$, es decir, la dimensión de 
la matriz de conectividad es de 400 x1000. Por lo tanto las funciones que trabajen con las matrices de conectividad (para calcular los parámetros de redes) incluyen código de reordenación para convertir un vector columna en una matriz cuadrada de asociación.

\section{B.4. Visualización de gráficas de conectividad}

La función desarrollada que despliega las gráficas de conectividad con la primera representación propuesta, es grafconectividad\%.m y requiere de los siguientes parámetros:

- H_list. Vector de handles de líneas de conectividad, se obtiene a través de la función graficarlineas.m.

- Z. Matriz de asociación entre los canales de EEG.

- C. Vector que contiene todos los pares de electrodos posibles de acuerdo a los canales identificados.

Para que la función grafconectividad\%.m funcione correctamente requiere del parámetro H_list, el cual se obtiene a través de la función graficarlineas.m y su objetivo es graficar una sola vez las líneas de conectividad entre todos los electrodos. Por lo tanto al usar la función graficarlineas.m se crean un identificador por cada línea, posteriormente en grafconectividad.m se asigna un color dependiente del valor de conectividad, lo anterior se realiza para cada gráfica de conectividad. Los parámetros necesarios de la función graficarlineas.m se indican a continuación:

- C. Vector que contiene todos los pares de electrodos posibles de acuerdo a los canales identificados.

- XY. Coordenadas de los electrodos para obtener posteriormente la gráfica de conectividad.

- Canales. Etiquetas de los canales identificados, necesario para obtener la gráfica de conectividad posteriormente.

- ancho. (Opcional, escalar). Ancho deseado de las líneas de conectividad, el valor predeterminado es 1 .

La función desarrollada que despliega las gráficas de conectividad, con la segunda representación propuesta, es grafconectividad3.m y requiere de los siguientes parámetros: 
- Z. Matriz de asociación entre los canales de EEG.

- C. Vector que contiene todos los pares de electrodos posibles de acuerdo a los canales identificados.

- $X Y$. Coordenadas de los electrodos.

- Canales. Etiquetas de los canales identificados, necesario para obtener la gráfica de conectividad posteriormente.

Las funciones Grafconectividad\%.m y grafconectividad3.m solo pueden desplegar una gráfica de conectividad a la vez, sin embargo, se desarrolló otra función videoconectividad.m que puede obtener una gráfica para cada segmento de tiempo, durante toda la duración del registro y a su vez genera un vídeo con dichas imágenes, con este vídeo es posible observar la dinámica de la conectividad funcional del durante todo el registro. Los parámetros necesarios para esta función son:

- matrizconectividad. Matriz de conectividad entre los canales de EEG para todo elregistro (se obtiene mediante medidasconectividad.m o medidasconectividad2.m).

- $X Y$. Coordenadas de los electrodos.

- C. Vector que contiene todos los pares de electrodos posibles de acuerdo a los canales identificados.

- Canales. Etiquetas de los canales identificados, necesario para obtener la gráfica de conectividad posteriormente.

- intervalo. Vector $1 \mathrm{x} 2$ que indica el tiempo de inicio y final del video requerido, si no se indica se obtiene el video para toda la duración del registro.

- Tsegmento. Tiempo en segundos de la duración de cada segmento de tiempo, usar tiempo $(1,1)$ (la matriz tiempo se obtiene con medidasconectividad.m o medidasconectividad2.m).

- tipograf. 'lineas' o 'nodos' para elegir la representación para medida no direccional o direccional.

Para que pueda funcionar adecuadamente dicha función, es necesario que se cuente con el programa mencoder ${ }^{1}$ que es un codificador de vídeo necesario para utilizar el formato

\footnotetext{
${ }^{1}$ Página oficial http://www.mplayerhq.hu/design7/news.html.
} 
.avi para almacenar el vídeo producido; adicionalmente se almacenan todas las gráficas de conectividad obtenidas (fotogramas del vídeo).

\section{B.5. Parámetros de Red}

\section{Grado de nodo}

La función que obtiene el grado de nodo es grado_nodo.m para medidas no direccionales y grado_nodo_d.m para medidas direccionales. Ambas funciones siguen el mismo procedimiento (sección 4.5.1), sólo cambia la sección de la matriz de asociación utilizados, es decir, se utilizan los datos por encima de la diagonal superior (no direccional) y toda la matriz (direccional). Para ambas funciones se requieren los siguientes parámetros:

- Matriz. Matriz de conectividad.

- umbral. Vector de umbralización.

- tiempo. Vector de tiempo o segmentos de tiempo.

- intervalo. (Opcional). Vector 1x2 que contiene el intervalo de tiempo a analizar, el valor predeterminado es analizar toda la matriz de conectividad.

Ambas funciones regresan los siguientes parámetros:

- ejey. Indica las etiquetas en orden para visualizar la matriz Grado de nodo. Este parámetro debe introducirse en graficarmedidas.m en el parámetro Umbral para poder graficar de manera adecuada el grado de cada nodo.

- grado_nodo_matriz: Matriz que contiene los promedios de los grados de cada nodo.

- grado_nodo_arreglo: Arreglo de matrices que contiene las matrices Grado nodoumbral.

\section{Densidad}

Las funciones densidadgraf.m y densidad_graf_d.m requieren los siguientes parámetros: 
- Matriz. Matriz de conectividad.

- Umbral. Vector de umbralización.

- tiempo. Vector de tiempo o segmentos de tiempo.

- intervalo. (Opcional). Vector 1x2 que contiene el intervalo de tiempo a analizar, el valor predeterminado es analizar toda la matriz de conectividad.

Ambas funciones regresan la matriz densidad_matriz que contiene las densidades para cada valor de umbral y cada segmento de tiempo.

\section{Coeficiente de agrupamiento}

Las funciones coef_agrupamiento.m y coef_agrupamiento_d.m requieren los siguientes parámetros:

- Matriz. Matriz de conectividad.

- Umbral. Vector de umbralización.

- tiempo. Vector de tiempo o segmentos de tiempo.

- intervalo. (Opcional). Vector 1x2 que contiene el intervalo de tiempo a analizar, el valor predeterminado es analizar toda la matriz de conectividad.

Ambas funciones regresan la matriz que contiene los coeficientes de agrupamiento para cada valor de umbral y cada segmento de tiempo (promedio_coeficiente_matriz).

\section{Distancia mínima característica y eficiencia}

Las funciones distancia_graf.m y distancia_graf_d.m requieren los siguientes parámetros:

- Matriz. Matriz de conectividad.

- umbral. Vector de umbralización.

- tiempo. Vector de tiempo o segmentos de tiempo.

- intervalo. (Opcional). Vector 1x2 que contiene el intervalo de tiempo a analizar, el valor predeterminado es analizar toda la matriz de conectividad. 
Ambas funciones regresan los siguientes parámetros:

- distancia_promedio _matriz: Matriz que contiene las distancias mínimas características para cada valor de umbral y cada segmento de tiempo.

- eficiencia_matriz: Matriz que contiene los valores de eficiencia para cada valor de umbral y cada segmento de tiempo.

\section{Grado promedio}

Las funciones grado_promedio.m y grado_promedio_d.m requieren los siguientes parámetros:

- Matriz. Matriz de conectividad.

- umbral. Vector de umbralización.

- tiempo. Vector de tiempo o segmentos de tiempo.

- intervalo. (Opcional). Vector 1x2 que contiene el intervalo de tiempo a analizar, el valor predeterminado es analizar toda la matriz de conectividad.

Ambas funciones regresan únicamente la matriz que contiene los grados promedio para cada valor de umbral y cada segmento de tiempo en el parámetro grado_promedio_matriz.m.

\section{B.6. Visualización de los parámetros de red}

La función que implementa la visualización de las matrices de los parámetros es graficarmedidas.m y puede utilizarse para visualizar parámetros de gráficas direccionales y no direccionales: 
- tiempo. Vector de tiempo o segmentos de tiempo.

- umbral. Vector de umbralización.

- medida. Matriz de parámetros de redes complejas.

- X. Matriz que contiene las series de tiempo de todos los canales del registro de EEG.

- cevent. Escalar que indica el número al que corresponde el canal EVENT, el cual registra las marcas en el botón durante la etapa de asociación. Se obtiene mediante la función identevph.m.

- cphotic. Escalar que indica el número al que corresponde el canal PHOTIC, el cual registra las marcas durante las fotoestimulaciones. Se obtiene mediante la función identevph.m.

- banda. Cadena de texto el cual se utilizará en el título de cada imagen obtenida, elegir la banda analizada.

- $f s$. Frecuencia de muestreo del registro de EEG.

- canales. Etiquetas de los canales identificados, necesario para obtener la gráfica de conectividad posteriormente.

- título. Cadena de texto a utilizar como título de las gráficas obtenidas p.e. poner el nombre del parámetro a obtener.

- intervalo. (Opcional) Escalar. Intervalo de tiempo hacia atrás y hacia adelante para mostrar de un intervalo de tiempo definido.

- tiempos. (Opcional) Vector 1x2 y contiene el tiempo de inicio y final para visualizar un segmento especifico de la medida de redes complejas, el valor predeterminado analiza toda la duración de la matriz de parámetros. 


\section{Bibliografía}

[1] M. Catani et al., "The rises and falls of disconnection syndromes," Brain, vol. 128, no. 10, pp. 2224-2239, 2005.

[2] G. L. Gerstein, P. Bedenbaugh, and A. M. Aertsen, "Neuronal assemblies," IEEE Transactions on Biomedical Engineering, vol. 36, no. 1, pp. 4-14, 1989.

[3] R. D. Frostig, Y. Gottlieb, E. Vaadia, and M. Abeles, "The effects of stimuli on the activity and functional connectivity of local neuronal groups in the cat auditory cortex," Brain research, vol. 272, no. 2, pp. 211-221, 1983.

[4] C. J. Stam, "From synchronisation to networks: assessment of functional connectivity in the brain," in Coordinated Activity in the Brain, pp. 91-115, Springer, 2009 .

[5] K. J. Friston, "Functional and effective connectivity in neuroimaging: a synthesis," Human brain mapping, vol. 2, no. 1-2, pp. 56-78, 1994.

[6] S. H. Strogatz, "Exploring complex networks," Nature, vol. 410, no. 6825, pp. 268$276,2001$.

[7] O. Sporns, "Graph theory methods for the analysis of neural connectivity patterns," in Neuroscience Databases, pp. 171-185, Springer, 2003.

[8] C. Stam, B. Jones, I. Manshanden, A. Van Cappellen Van Walsum, T. Montez, J. Verbunt, J. De Munck, B. Van Dijk, H. Berendse, and P. Scheltens, "Magnetoencephalographic evaluation of resting-state functional connectivity in alzheimer's disease," Neuroimage, vol. 32, no. 3, pp. 1335-1344, 2006.

[9] K. Caeyenberghs, A. Leemans, M. H. Heitger, I. Leunissen, T. Dhollander, S. Sunaert, P. Dupont, and S. P. Swinnen, "Graph analysis of functional brain networks for cognitive control of action in traumatic brain injury," Brain, vol. 135, no. 4, pp. 1293-1307, 2012.

[10] C. J. Stam and J. C. Reijneveld, "Graph theoretical analysis of complex networks in the brain," Nonlinear biomedical physics, vol. 1, no. 1, p. 3, 2007. 
[11] M. Guye, G. Bettus, F. Bartolomei, and P. J. Cozzone, "Graph theoretical analysis of structural and functional connectivity mri in normal and pathological brain networks," Magnetic Resonance Materials in Physics, Biology and Medicine, vol. 23, no. 5-6, pp. 409-421, 2010.

[12] H. H. Jasper, "The ten twenty electrode system of the international federation," Electroencephalography and Clinical Neurophysiology, vol. 10, pp. 371-375, 1958.

[13] R. W. Homan, J. Herman, and P. Purdy, "Cerebral location of international 10-20 system electrode placement," Electroencephalography and Clinical Neurophysiology, vol. 66, no. 4, pp. $376-382,1987$.

[14] S. Sanei and J. A. Chambers, EEG signal processing. Wiley. com, 2008.

[15] P. Érdi, Complexity explained. Springer London, Limited, 2008.

[16] S. Gudmundsson, T. P. Runarsson, S. Sigurdsson, G. Eiriksdottir, and K. Johnsen, "Reliability of quantitative EEG features," Clinical Neurophysiology, vol. 118, no. 10, pp. 2162-2171, 2007.

[17] A. Schlögl, C. Keinrath, D. Zimmermann, R. Scherer, R. Leeb, and G. Pfurtscheller, "A fully automated correction method of EOG artifacts in EEG recordings," Clinical Neurophysiology, vol. 118, no. 1, pp. 98-104, 2007.

[18] S. Romero, M. Mañanas, and M. J. Barbanoj, "Ocular reduction in EEG signals based on adaptive filtering, regression and blind source separation," Annals of biomedical engineering, vol. 37, no. 1, pp. 176-191, 2009.

[19] P. He, G. Wilson, and C. Russell, "Removal of ocular artifacts from electroencephalogram by adaptive filtering," Medical and biological engineering and computing, vol. 42, no. 3, pp. 407-412, 2004.

[20] M. Rohál'ová, P. Sykacek, M. Koskaand, and G. Dorffner, "Detection of the EEG artifacts by the means of the (extended) kalman filter," Meas. Sci. Rev, vol. 1, no. 1, pp. 59-62, 2001.

[21] T.-P. Jung, S. Makeig, T.-W. Lee, M. J. McKeown, G. Brown, A. J. Bell, and T. J. Sejnowski, "Independent component analysis of biomedical signals," in Proc. Int. Workshop on Independent Component Analysis and Signal Separation, pp. 633644, Citeseer, 2000.

[22] T.-P. Jung, S. Makeig, M. Westerfield, J. Townsend, E. Courchesne, and T. J. Sejnowski, "Removal of eye activity artifacts from visual event-related potentials in normal and clinical subjects," Clinical Neurophysiology, vol. 111, no. 10, pp. 17451758, 2000. 
[23] T.-P. Jung, S. Makeig, C. Humphries, T.-W. Lee, M. J. Mckeown, V. Iragui, and T. J. Sejnowski, "Removing electroencephalographic artifacts by blind source separation," Psychophysiology, vol. 37, no. 2, pp. 163-178, 2000.

[24] L. Astolfi, F. Cincotti, D. Mattia, F. Babiloni, M. Marciani, F. De Vico Fallani, M. Mattiocco, F. Miwakeichi, Y. Yamaguchi, P. Martinez, et al., "Removal of ocular artifacts for high resolution EEG studies: a simulation study," in Engineering in Medicine and Biology Society, 2006. EMBS'06. 28th Annual International Conference of the IEEE, pp. 976-979, IEEE, 2006.

[25] J. Dien, "Issues in the application of the average reference: Review, critiques, and recommendations," Behavior Research Methods, Instruments, $\&$ Computers, vol. 30, no. 1, pp. 34-43, 1998.

[26] M. M. Essl and P. Rappelsberger, "EEG coherence and reference signals: experimental results and mathematical explanations," Medical and Biological Engineering and Computing, vol. 36, no. 4, pp. 399-406, 1998.

[27] M. J. Alhaddad, "Common average reference (car) improves p300 speller," International Journal of Engineering and Technology, vol. 2, no. 3, 2012.

[28] D. A. Samson-Dollfus and H. Bendoukha, "Choice of the reference for EEG mapping in the newborn: An initial comparison of common nose reference, average and source derivation," Brain Topography, vol. 2, no. 1-2, pp. 165-169, 1989.

[29] G. Fein, J. Raz, F. F. Brown, and E. L. Merrin, "Common reference coherence data are confounded by power and phase effects," Electroencephalography and clinical neurophysiology, vol. 69, no. 6, pp. 581-584, 1988.

[30] F. Perrin, O. Bertrand, and J. Pernier, "Scalp current density mapping: value and estimation from potential data," IEEE Transactions on Biomedical Engineering, vol. BME-34, no. 4, pp. 283-288, 1987.

[31] T. Solis-Escalante, G. Müller-Putz, and G. Pfurtscheller, "Overt foot movement detection in one single laplacian EEG derivation," Journal of neuroscience methods, vol. 175, no. 1, pp. 148-153, 2008.

[32] P. L. Nunez, R. B. Silberstein, Z. Shi, M. R. Carpenter, R. Srinivasan, D. M. Tucker, S. M. Doran, P. J. Cadusch, and R. S. Wijesinghe, "EEG coherency ii: experimental comparisons of multiple measures," Clinical Neurophysiology, vol. 110, no. 3, pp. 469-486, 1999.

[33] H. Ramoser, J. Muller-Gerking, and G. Pfurtscheller, "Optimal spatial filtering of single trial EEG during imagined hand movement," IEEE Transactions on Rehabilitation Engineering, vol. 8, no. 4, pp. 441-446, 2000. 
[34] G. Fein, J. Raz, F. F. Brown, and E. L. Merrin, "Common reference coherence data are confounded by power and phase effects," Electroencephalography and clinical neurophysiology, vol. 69, no. 6, pp. 581-584, 1988.

[35] N. Geschwind, "Disconnexion syndromes in animals and man: Part i," Neuropsychology Review, vol. 20, no. 2, pp. 128-157, 2010.

[36] P. Welch, "The use of fast fourier fransform for the estimation of power spectra: a method based on time averaging over short, modified periodograms," IEEE Transactions on Audio and Electroacoustics, vol. 15, no. 2, pp. 70-73, 1967.

[37] D. B. Chorlian, M. Rangaswamy, and B. Porjesz, "EEG coherence: topography and frequency structure," Experimental brain research, vol. 198, no. 1, pp. 59-83, 2009 .

[38] R. W. Thatcher, D. M. North, and C. J. Biver, "Development of cortical connections as measured by EEG coherence and phase delays," Human brain mapping, vol. 29 , no. 12 , pp. 1400-1415, 2008.

[39] P. L. Nunez, R. Srinivasan, A. F. Westdorp, R. S. Wijesinghe, D. M. Tucker, R. B. Silberstein, and P. J. Cadusch, "EEG coherency: I: statistics, reference electrode, volume conduction, laplacians, cortical imaging, and interpretation at multiple scales," Electroencephalography and clinical Neurophysiology, vol. 103, no. 5, pp. 499-515, 1997.

[40] K. Akrofi, M. C. Baker, M. W. O'Boyle, and R. B. Schiffer, "A model of alzheimer's disease and mild cognitive impairment based on EEG coherence," in ICME International Conference on Complex Medical Engineering, 2009., pp. 1-6, IEEE, 2009

[41] J. Dauwels, F. Vialatte, T. Musha, and A. Cichocki, "A comparative study of synchrony measures for the early diagnosis of alzheimer's disease based on EEG," NeuroImage, vol. 49, no. 1, pp. 668-693, 2010.

[42] A. Pressman, A. Peled, and A. Geva, "Synchronization analysis of multi-channel EEG of schizophrenic during working-memory tasks," in The 21st IEEE Convention of the Electrical and Electronic Engineers in Israel, 2000., pp. 337-341, IEEE, 2000 .

[43] E. Pachou, M. Vourkas, P. Simos, D. Smit, C. J. Stam, V. Tsirka, and S. Micheloyannis, "Working memory in schizophrenia: an EEG study using power spectrum and coherence analysis to estimate cortical activation and network behavior," Brain topography, vol. 21, no. 2, pp. 128-137, 2008. 
[44] E. M. Holz, M. Doppelmayr, W. Klimesch, and P. Sauseng, "EEG correlates of action observation in humans," Brain topography, vol. 21, no. 2, pp. 93-99, 2008.

[45] S. Aksahin, Mehmetand Aydin, H. Firat, and O. Erogul, "Artificial apnea classification with quantitative sleep EEG synchronization," Journal of medical systems, vol. 36, no. 1, pp. 139-144, 2012.

[46] R. Guevara, J. L. P. Velazquez, V. Nenadovic, R. Wennberg, G. Senjanovic, and L. G. Dominguez, "Phase synchronization measurements using electroencephalographic recordings," Neuroinformatics, vol. 3, no. 4, pp. 301-313, 2005.

[47] D. A. Silage, "Spectral and coherence analysis applied to sleep apnea," Engineering in Medicine and Biology Magazine, IEEE, vol. 9, no. 1, pp. 76-78, 1990.

[48] N. Saiwaki, H. Tsujimoto, S. Nishida, and S. Inokuchi, "Directed coherence analysis of EEG recorded during music listening," in Engineering in Medicine and Biology Society, 1996. Bridging Disciplines for Biomedicine. Proceedings of the 18th Annual International Conference of the IEEE, vol. 2, pp. 827-828, IEEE, 1996.

[49] D. Gmehlin, C. Thomas, M. Weisbrod, S. Walther, F. Resch, and R. Oelkers-Ax, "Development of brain synchronisation within school-age-individual analysis of resting (alpha) coherence in a longitudinal data set," Clinical Neurophysiology, vol. 122, no. 10, pp. 1973-1983, 2011.

[50] R. Srinivasan, P. L. Nunez, and R. B. Silberstein, "Spatial filtering and neocortical dynamics: estimates of EEG coherence," IEEE Transactions on Biomedical Engineering, vol. 45, no. 7, pp. 814-826, 1998.

[51] A. de Sa, D. Simpson, and A. Infantosi, "An investigation of the statistics of coherence estimates in EEG signals," in 14th Annual International Conference of the IEEE Engineering in Medicine and Biology Society, 1992, vol. 6, pp. 26472648, IEEE, 1992.

[52] G. Carter and A. Nuttall, "Statistics of the estimate of coherence," Proceedings of the IEEE, vol. 60, no. 4, pp. 465-466, 1972.

[53] H.-L. Chan, L.-F. Meng, P.-K. Chao, and M.-A. Lin, "Coherence analyses of eventrelated potentials using fourier and wavelet transforms," in Neural Engineering, 200\%. CNE'07. 3rd International IEEE/EMBS Conference on, pp. 627-629, IEEE, 2007.

[54] A. Klein, T. Sauer, A. Jedynak, and W. Skrandies, "Conventional and wavelet coherence applied to sensory-evoked electrical brain activity," IEEE Transactions on Biomedical Engineering, vol. 53, no. 2, pp. 266-272, 2006. 
[55] M. Shen, X. Li, and X. Zhang, "The time-varying coherent analysis of medical signals," in 6th International Conference on Signal Processing, 2002, vol. 2, pp. 15281531, IEEE, 2002.

[56] L. Sun, M. Shen, K. Ting, and F. Chan, "Analysis of time-varying synchronization of multi-channel EEG signals using wavelet coherence," in Proceedings of the 2003 International Conference on Neural Networks and Signal Processing, 2003., vol. 1, pp. 216-219, IEEE, 2003.

[57] M. Shen, L. Sun, K. Ting, and F. Chan, "The investigation of time-varying synchrony of EEG during sentence learning using wavelet analysis," in Proceedings of the 9th International Conference on Neural Information Processing, 2002., vol. 1, pp. 92-95, IEEE, 2002.

[58] W. Xu, M. Shen, S. Wang, and F. H. Chan, "Analysis of time-varying coherence of EEG during face recognition based on harmonic transform," in 27th Annual International Conference of the Engineering in Medicine and Biology Society, 2005. IEEE-EMBS 2005., pp. 5927-5930, IEEE, 2006.

[59] M. Cotic, O. Zalay, T. Valiante, P. L. Carlen, and B. L. Bardakjian, "Frequency interactions in human epileptic brain," in Annual International Conference of the IEEE Engineering in Medicine and Biology Society, EMBC, 2011, pp. 2057-2060, IEEE, 2011.

[60] S. A. Markazi, S. A. Qazi, and L. Stergioulas, "Study of change blindness EEG synchronisation using wavelet coherence analysis," in 27th Annual International Conference of the Engineering in Medicine and Biology Society, 2005. IEEE-EMBS 2005., pp. 5995-5998, IEEE, 2006.

[61] A. Catarino, A. Andrade, O. Churches, A. P. Wagner, S. Baron-Cohen, H. Ring, et al., "Task-related functional connectivity in autism spectrum conditions: an EEG study using wavelet transform coherence," Molecular autism, vol. 4, no. 1, p. $1,2013$.

[62] J. W. Sleigh, E. Olofsen, A. Dahan, J. de Goede, and D. A. Steyn-Ross, "Entropies of the EEG: The effects of general anaesthesia," in 5th International Conference on Memory, Awareness and Consciousness, 2001.

[63] R. Q. Quiroga, J. Arnhold, K. Lehnertz, and P. Grassberger, "Kulback-leibler and renormalized entropies: applications to electroencephalograms of epilepsy patients," Physical Review E, vol. 62, no. 6, p. 8380, 2000.

[64] D. Obradovic, An information-theoretic approach to neural computing. Springer, 1996. 
[65] J. Gao, J. Hu, and W.-w. Tung, "Entropy measures for biological signal analyses," Nonlinear Dynamics, vol. 68, no. 3, pp. 431-444, 2012.

[66] M. Kreuzer, H. Hentschke, B. Antkowiak, C. Schwarz, E. Kochs, and G. Schneider, "Cross-approximate entropy of cortical local field potentials quantifies effects of anesthesia-a pilot study in rats," BMC neuroscience, vol. 11, no. 1, p. 122, 2010.

[67] H.-B. Xie, J.-Y. Guo, and Y.-P. Zheng, "A comparative study of pattern synchronization detection between neural signals using different cross-entropy measures," Biological cybernetics, vol. 102, no. 2, pp. 123-135, 2010.

[68] A. Bianchi, F. Panzica, F. Tinello, S. Franceschetti, S. Cerutti, and G. Baselli, "Analysis of multichannel EEG synchronization before and during generalized epileptic seizures," in First International IEEE EMBS Conference in Neural Engineering, 2003., pp. 39-42, IEEE, 2003.

[69] J. Alonso, M. Mañanas, S. Romero, M. Rojas-Martínez, and J. Riba, "Crossconditional entropy and coherence analysis of pharmaco-EEG changes induced by alprazolam," Psychopharmacology, vol. 221, no. 3, pp. 397-406, 2012.

[70] A. N. Bermúdez, E. M. Spinelli, and C. M. Muravchik, "Detección de eventos en señales de EEG mediante entropía espectral," in Memorias del XVIII Congreso Argentino de Bioingeniería - SABI, 2011.

[71] P. Peebles, Probability, random variables, and random signal principles, vol. 3. McGraw-Hill New York, 1987.

[72] C. Therrien, Discrete Random Signals and Statistical Signal Processing. No. v. 1 in Prentice-Hall signal processing series, Prentice-Hall International, 1992.

[73] M. J. Silfverhuth, H. Hintsala, J. Kortelainen, and T. Seppanen, "Experimental comparison of connectivity measures with simulated EEG signals," Medical $\mathscr{E}$ biological engineering \& computing, vol. 50, no. 7, pp. 683-688, 2012.

[74] E. Pereda, R. Q. Quiroga, and J. Bhattacharya, "Nonlinear multivariate analysis of neurophysiological signals," Progress in neurobiology, vol. 77, no. 1, pp. 1-37, 2005 .

[75] N. F. Rulkov, M. M. Sushchik, L. S. Tsimring, and H. D. Abarbanel, "Generalized synchronization of chaos in directionally coupled chaotic systems," Physical Review E, vol. 51, no. 2, p. 980, 1995.

[76] C. Stam and B. Van Dijk, "Synchronization likelihood: an unbiased measure of generalized synchronization in multivariate data sets," Physica D: Nonlinear Phenomena, vol. 163, no. 3, pp. 236-251, 2002. 
[77] M. D. Humphries, K. Gurney, and T. J. Prescott, "The brainstem reticular formation is a small-world, not scale-free, network," Proceedings of the Royal Society B: Biological Sciences, vol. 273, no. 1585, pp. 503-511, 2006.

[78] O. A. Prokopyev, V. L. Boginski, W. Chaovalitwongse, P. M. Pardalos, J. C. Sackellares, and P. R. Carney, "Network-based techniques in EEG data analysis and epileptic brain modeling," in Data Mining in Biomedicine, pp. 559-573, Springer, 2007.

[79] E. Bullmore and O. Sporns, "Complex brain networks: graph theoretical analysis of structural and functional systems," Nature Reviews Neuroscience, vol. 10, no. 3, pp. 186-198, 2009.

[80] F. De Vico Fallani, L. Astolfi, F. Cincotti, D. Mattia, A. Tocci, S. Salinari, M. Marciani, H. Witte, A. Colosimo, and F. Babiloni, "Brain network analysis from highresolution EEG recordings by the application of theoretical graph indexes," IEEE Transactions on Neural Systems and Rehabilitation Engineering, vol. 16, no. 5, pp. 442-452, 2008.

[81] F. De Vico Fallani, L. Astolfi, F. Cincotti, D. Mattia, M. G. Marciani, A. Tocci, S. Salinari, H. Witte, W. Hesse, S. Gao, et al., "Cortical network dynamics during foot movements," Neuroinformatics, vol. 6, no. 1, pp. 23-34, 2008.

[82] C. Stam, W. De Haan, A. Daffertshofer, B. Jones, I. Manshanden, A. v. C. van Walsum, T. Montez, J. Verbunt, J. De Munck, B. Van Dijk, et al., "Graph theoretical analysis of magnetoencephalographic functional connectivity in alzheimer's disease," Brain, vol. 132, no. 1, pp. 213-224, 2009.

[83] J. McBride, X. Zhao, N. Munro, C. Smith, G. Jicha, and Y. Jiang, "Resting EEG discrimination of early stage alzheimer's disease from normal aging using interchannel coherence network graphs," Annals of biomedical engineering, pp. 1-10, 2013.

[84] N. P. Castellanos, N. Paúl, V. E. Ordóñez, O. Demuynck, R. Bajo, P. Campo, A. Bilbao, T. Ortiz, F. del Pozo, and F. Maestú, "Reorganization of functional connectivity as a correlate of cognitive recovery in acquired brain injury," Brain, vol. 133, no. 8, pp. 2365-2381, 2010.

[85] F. D. V. Fallani, F. A. Rodrigues, L. da Fontoura Costa, L. Astolfi, F. Cincotti, D. Mattia, S. Salinari, and F. Babiloni, "Multiple pathways analysis of brain functional networks from EEG signals: an application to real data," Brain topography, vol. 23, no. 4, pp. 344-354, 2011. 
[86] P. Barttfeld, B. Wicker, S. Cukier, S. Navarta, S. Lew, and M. Sigman, "A bigworld network in asd: dynamical connectivity analysis reflects a deficit in longrange connections and an excess of short-range connections," Neuropsychologia, vol. 49, no. 2, pp. 254-263, 2011.

[87] Z. J. Wang, P. W.-H. Lee, M. J. McKeown, et al., "A novel segmentation, mutual information network framework for EEG analysis of motor tasks," Biomedical engineering online, vol. 8, no. 9, pp. 1-19, 2009.

[88] H. Wu, X. Li, and X. Guan, "Networking property during epileptic seizure with multi-channel EEG recordings," in Advances in Neural Networks-ISNN 2006, pp. 573-578, Springer, 2006.

[89] P. Lang, D.-B. Liu, S.-M. Cai, L. Hong, and P.-L. Zhou, "Recurrence network analysis of the synchronous EEG time series in normal and epileptic brains," Cell biochemistry and biophysics, pp. 1-6, 2012.

[90] F. D. V. Fallani, A. Maglione, F. Babiloni, D. Mattia, L. Astolfi, G. Vecchiato, A. De Rinaldis, S. Salinari, E. Pachou, and S. Micheloyannis, "Cortical network analysis in patients affected by schizophrenia," Brain topography, vol. 23, no. 2, pp. 214-220, 2010.

[91] V. Sakkalis, T. Oikonomou, E. Pachou, I. Tollis, S. Micheloyannis, and M. Zervakis, "Time-significant wavelet coherence for the evaluation of schizophrenic brain activity using a graph theory approach," in 28th Annual International Conference of the IEEE Engineering in Medicine and Biology Society, 2006. EMBS'06., pp. 4265-4268, IEEE, 2006.

[92] S. I. Dimitriadis, N. A. Laskaris, Y. Del Rio-Portilla, and G. C. Koudounis, "Characterizing dynamic functional connectivity across sleep stages from EEG," Brain topography, vol. 22, no. 2, pp. 119-133, 2009.

[93] K. Supekar, M. Musen, and V. Menon, "Development of large-scale functional brain networks in children," PLoS biology, vol. 7, no. 7, p. e1000157, 2009.

[94] V. Sakkalis, V. Tsiaras, M. Zervakis, and I. Tollis, "Optimal brain network synchrony visualization: application in an alcoholism paradigm," in 29th Annual International Conference of the IEEE Engineering in Medicine and Biology Society, 200\%. EMBS 200\%., pp. 4285-4288, IEEE, 2007.

[95] L. Senhadji, K. Ansari-Asl, and F. Wendling, "From EEG signals to brain connectivity: methods and applications in epilepsy," in Advanced Biosignal Processing, pp. 145-164, Springer, 2009. 
[96] H. Brust, M. Galicia, B. Flores, F. Borunda, and O. Yáñez, "Las neurociencias en el diagnóstico y en la evaluación de la rehabilitación integral de secuelas de lesiones cerebrales en el inr," Investigación en Discapacidad, vol. 2, no. 1, pp. 28-37, 2013.

[97] S. S. Shapiro and M. B. Wilk, "An analysis of variance test for normality (complete samples)," Biometrika, vol. 52, no. 3/4, pp. 591-611, 1965.

[98] A. V. Oppenheim, R. W. Schafer, J. R. Buck, et al., Discrete-time signal processing, vol. 5. Prentice Hall Upper Saddle River, 1999.

[99] C. Torrence and G. P. Compo, "A practical guide to wavelet analysis," Bulletin of the American Meteorological society, vol. 79, no. 1, pp. 61-78, 1998.

[100] Z. Botev, J. Grotowski, and D. Kroese, "Kernel density estimation via diffusion," The Annals of Statistics, vol. 38, no. 5, pp. 2916-2957, 2010.

[101] A. Alba, J. L. Marroquin, J. Peña, T. Harmony, and B. Gonzalez-Frankenberger, "Exploration of event-induced EEG phase synchronization patterns in cognitive tasks using a time-frequency-topography visualization system," Journal of neuroscience methods, vol. 161, no. 1, pp. 166-182, 2007.

[102] A.-L. Barabasi and R. Albert, "Emergence of scaling in random networks," science, vol. 286, no. 5439, pp. 509-512, 1999.

[103] P. ERDdS and A. R\&WI, "On random graphs i.," Publ. Math. Debrecen, vol. 6, pp. 290-297, 1959.

[104] S. Milgram, "The small world problem," Psychology today, vol. 2, no. 1, pp. 60-67, 1967.

[105] D. J. Watts and S. H. Strogatz, "Collective dynamics of 'small-world'networks," nature, vol. 393, no. 6684, pp. 440-442, 1998.

[106] M. Guye, G. Bettus, F. Bartolomei, and P. J. Cozzone, "Graph theoretical analysis of structural and functional connectivity mri in normal and pathological brain networks," Magnetic Resonance Materials in Physics, Biology and Medicine, vol. 23, no. 5-6, pp. 409-421, 2010.

[107] A. Grinsted, J. C. Moore, and S. Jevrejeva, "Application of the cross wavelet transform and wavelet coherence to geophysical time series," Nonlinear processes in geophysics, vol. 11, no. 5/6, pp. 561-566, 2004. 